\section{2}

U.S. Department of Transportation

\section{HOV Lane Violation Study}

\title{
A TECHNOLOGY SHARING REPRINT
}

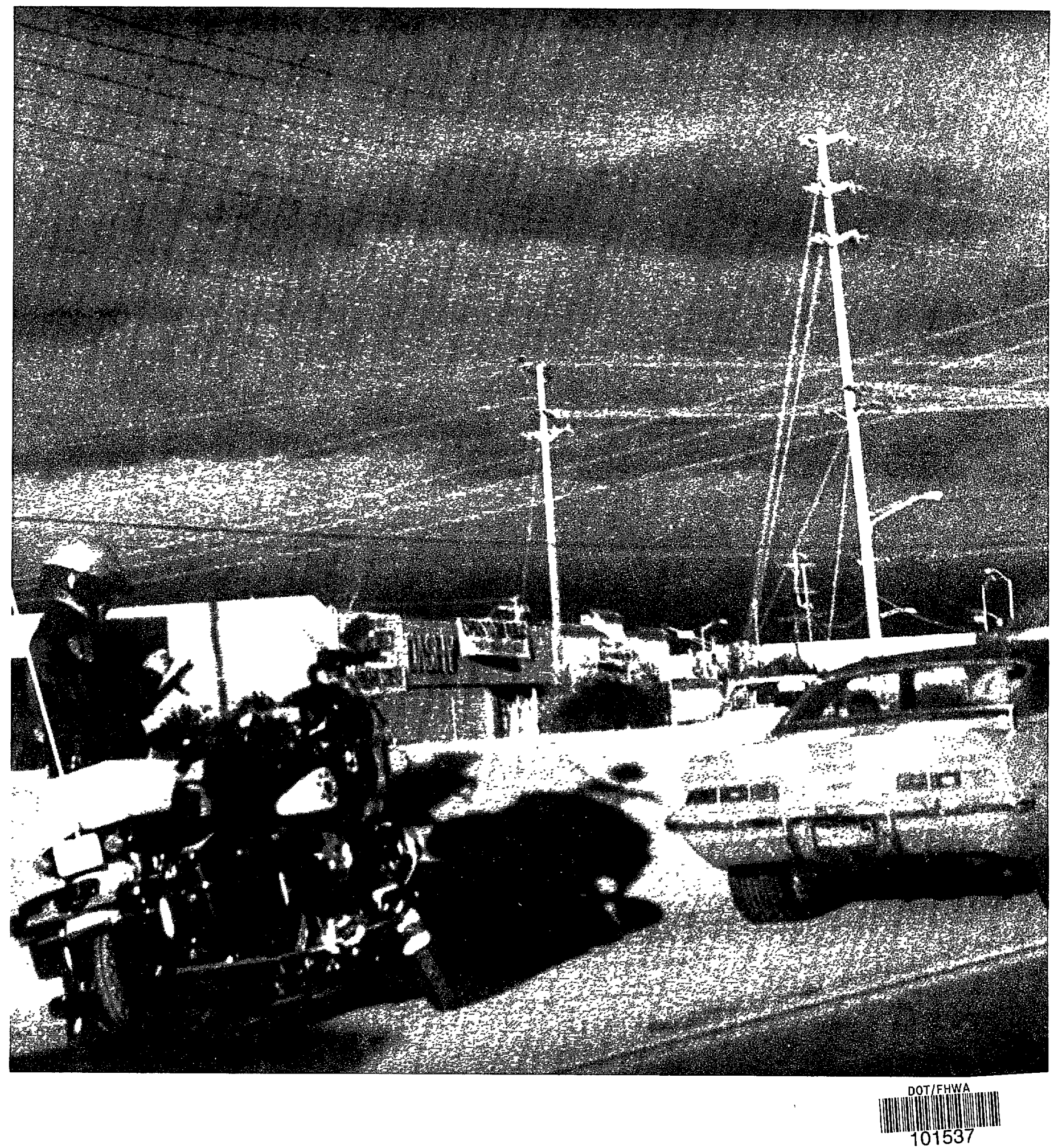




\section{HOV Lane Violation Study}

Final Report

January 1990

Prepared by

John W. Billheimer

Systan, Inc.

343 Second Street (P.O. Box U)

Los Altos, California 94023

Prepared for

California Department fo Transportation

P.O. Box 942874

Sacramento, California 94274-0001

Distributed and Reprinted by

Technology Sharing Program

Research and Special Programs Administration

U.S. Department of Transportation

Washington, D.C. 20590

\section{DOT-T-90-22}




\section{PREFACE AND ACKNOWLEDGEMENTS}

This report covers a year-long study designed to evaluate the effects of different enforcement strategies and engineering designs on violation rates on California's mainline HOV lanes.

The report has been prepared in the Los Altos, California offices of SYSTAN, Inc. under Contract No. 55 G710 with the California Department of Transportation (CALTRANS). The project was jointly sponsored by the California Highway Patrol (CHP). Mr. Philip Jang, Chief of the HOV Systems Branch of CALTRANS Division of Traffic Operations served as project administrator, while Scott McGowen of CALTRANS acted as the project's technical monitor.

A steering committee comprised of representatives from CALTRANS, the CHP and the Federal Highway Administration (FHWA) was responsible for overall project guidance and for approving the products of major project tasks. In addition to Mr. Jang and Mr. McGowen, other members of the steering committee included: Assistant Chief N.K. Newman of the CHP's Border Division; Mr. Robert Anderson and Mr. Bill Shoemaker of CALTRANS District 4 (San Francisco); Mr. Glen Clinton of the FHWA; Mr. Joe El Harake of CALTRANS District 12 (Orange County); Mr. Ron Klusza of CALTRANS District 7 (Los Angeles); and Lieutenants Ron Phulps and Shawn Watts of the CHP's Long Range Planning Section.

SYSTAN's project manager and principal investigator was Dr. John W. Billheimer. Other SYSTAN staff members assigned to the study included: Ms. Juliet McNally and Mr. Eric Lin, who were responsible for data coordination, survey analyses, and data processing; and Ms. Darci Anderson, who helped to organize the final report. Mr. Jesse Glazer of Crain and Associates coordinated data collection efforts in Southern California, while Mr. Kevin Fehon of DKS Associates did the same in Northern California. Professor Adolf D. May of the University of California's Institute of Transportation Studies and Mr. Len Newman provided consulting assistance on freeway design issues. Ms. Fran Vella of Phrasemaker Word Processing prepared all project reports, including the Study Plan and this Final Report.

The study has relied on data and interviews provided by CALTRANS and CHP personnel throughout the state. Representatives of these agencies who were most generous with their time and insights included:

Mr. John W. Amaral, CALTRANS (District 4)

Lt. Val Daniels, CHP (Marin)

Officer B.R. Eckerfield, CHP (San Jose)

Mr. Joel Haven, CALTRANS (District 11)

Lt. Mike Howard, CHP (Santa Ana)
Sgt. Don Hulen, CHP (Westminster)

Mr. Andrew M. Miceli, CALTRANS (District 7)

Captain Kevin Mince, CHP (Marin)

Mr. Hanibal D. Seriani, CALTRANS (District 4)

Sgt. John Steel, CHP (Santa Ana)

SYSTAN wishes to thank all those who provided information and insights on the enforcement and operation of California's mainline HOV lanes, and acknowledges full responsibility for the analysis, interpretation, and presentation of the data they provided. 


\section{TABLE OF CONTENTS}

PAGE

1.0 EXECUTIVE SUMMARY

$1-1$

1.1 Introduction $1-1$

1.2 Study Overview 1-2

1.3 Historical Enforcement Levels and Violation Rates 1-3

1.4 Violation Patterns $1-7$

1.5 Enforcement Options 1-10

1.6 Design Options $1-19$

1.7 Public Awareness 1-23

1.8 Proposed Enforcement Program 1-27

1.9 Additional Concerns 1 1-30

2.0 INTRODUCTION 2-1

$2.1 \quad$ Background 2-1

2.2 Objectives $2-2$

2.3 Key Issues $2-2$

2.4 Study Overview 2-3

2.5 Management Structure 2-5

3.0 MAINLINE HOV LANES 3-1

3.1 Overview 3-1

3.2 Existing Mainline Lanes 3-5

3.3 Start-Up Projects 3-13

3.4 Past Projects $3-15$

3.5 Violation Patterns 3-17

4.0 ENFORCEMENT OPTIONS 4-1

4.1 Overview 4-1

4.2 Test Strategies 4-5

4.3 Enforcement Levels $4-10$

4.4 Enforcement Impacts 4-13

4.5 Enforcement Observations 4-24

5.0 ENGINEERING OPTIONS 5-1

5.1 Overview 5-1

5.2 Lane Separation 5-4

5.3 Access/Egress Limitations 5-7

5.4 Enforcement Areas 5-9

5.5 Median Shoulders 5-16

5.6 Operating Hours $5-19$

5.7 Carpool Definitions 5-21

5.8 Signing and Marking 5-22

5.9 Time Savings 5-24

5.10 Project Length 5-25

5.11 Summary of Engineering Design Issues 5-27

6.0 PUBLIC AWARENESS 6-1

6.1 Focus Group Discussions 6-1

6.2 Survey Plan 6-14

6.3 Survey Findings 6-18

6.4 Summary of Key Public Awareness Findings 6-28 


\section{TABLE OF CONTENTS}

(Continued)

\section{PAGE}

7.0 PROPOSED ENFORCEMENT PROGRAM

7.1 Tolerable Violation Rates

$7-1$

7.2 General Planning Guidance

$7-4$

7.3 Proposed Program

7.4 Enforcement Costs

7-8

$7-14$

\section{APPENDICES}
A. FOCUS GROUP PROTOCOL
B. MAIL-OUT SURVEY
C. GLOSSARY
D. BIBLIOGRAPHICAL REFERENCES
E. DESIGN AND ENFORCEMENT NOTES 


\section{LIST OF EXHIBITS}

1.1 Pattern of Field Observations

1.2 Characteristics Of Mainline HOV Lanes in California

Peak Period Violations - Mainline HOV Lanes

$1-4$

Routine vs. Special Enforcement - Average Citations Per Day (1988)

$1-5$

Violation Rate By Time of Day - Marin 101

1.6 Citations and Violations - OR 55

1.7 Citations and Violations - LA 91

1.8 Citations and Violations - Marin 101

1.9 Citations and Violations - Santa Clara 101

1.10 Conceptual Plan for an Enforcement Area

1.11 Perceived and Actual Time Savings - Evening Commute

$1-6$

$1-8$

$1-10$

$1-11$

$1-12$

$1-14$

$1-21$

$1-24$

1.12 Drivers Reporting That They Had Never Seen Highway Patrol

$1-26$

$2.1 \quad$ Task Interrelationships

2.4 Management Organization

3.1 Operating Characteristics of Mainline HOV Lanes in California

3.2 Design Characteristics and Citation Rates of Mainline HOV Lanes in California

3.3 Peak Period Violations

3-4

3-6

3-8

3.5 Santa Clara 101 Summary Sheet

3.6 LA 91 Summary Sheet

3.7 OR 55 Summary Sheet

3.8 Violation Rate vs. Time - Marin 101 AM/SB

3.9 Violation Rates vs. Time of Day During Periods of Low Visibility (Marin 101 PM NB)

3.10 Unadjusted and Adjusted Violation Rates - Santa Clara 101

3-12

3-14

3-18

3-19

3-20

3-21

3.11 Unadjusted and Adjusted Violation Rates - Marin 101

3-23

3.12 Violation Rate vs. Speed Differential

Violations vs. Speed Differential

Buffer Violations By Time of Day - OR 55 Meats and Walnut

3.16 Summary of Speed Run Data

4.1 Routine vs. Special Enforcement - Average Citations Per Day (1988)

4.2 Special Enforcement Strategies Special Enforcement Levels

4.4 Violations Cited by Special Enforcement

4.5 Violation Rate Vs. Time: OR 55

4.6 Violation Rate Vs. Time - Peak and Off-Peak Directions: OR 55

4.7 Violation Rate Vs. Time - LA 91 PM Wilmington

4.8 Violation Rate Vs. Time - Marin 101

4.9 Violation Rate Vs. Time - Santa Clara $101 \quad 4-22$

4.10 San Diego I-15 Violation Rates

5.1 Interrelationships of Key Study Elements

5.3 Enforcement Area Mouths

5:4 Typical CHP Enforcement Area

5.5 Enforcement Area Test Photos 


\section{LIST OF EXHIBITS}

(Continued)

EXHIBIT NO.

PAGE

6.1 Driver Profile Focus Group Participants 6-3

6.2 Perceived Purposes of California HOV Lanes 6-5

6.3 Adjectives Used to Describe California HOV Lanes 6-6

6.4 Survey Response Rates 6-17

6.5 Drivers Reporting They Have Never Seen Highway Patrol
Ticketing an HOV Lane Violator

$\begin{array}{ll}\text { 6.6 Perceived Enforcement Changes Reported by Owners } & \text { 6-20 }\end{array}$

6.7 Drivers Reactions to the Statement "HOV Lanes Should Be
Enforced More Heavily" (post-enforcement survey)

6.8 Awareness of First-Offense Fine 6-22

6.9 HOV Time Savings $\quad 6-25$

6.10 Estimated and Actual Violation Rates 6-26

6.11 Perceived Seriousness of HOV Violations $6-27$

6.12 Does HOV Lane Increase Accidents? 6-29

6.13 Do HOV Lanes Improve Freeway Flow? 6-29

7.1 Violation Rate vs. Legitimate Vehicles 7-3

7.2 Nomograph for Planning Special Enforcement for Barrier-Free
Mainline HOV Lanes

$\begin{array}{ll}\text { 7.3 Proposed Enforcement Program } & 7-9\end{array}$ 


\subsection{EXECUTIVE SUMMARY}

\section{$1.1 \quad$ INTRODUCTION}

\subsubsection{Background}

In an attempt to cope with the traffic congestion caused by the rapid growth of suburban populations and the relative decline in funds and space for additional freeway construction, the California Department of Transportation (CALTRANS) has introduced a number of High Occupancy Vehicle (HOV) Lanes designed to help the freeway network operate more efficiently. Several factors have arisen to frustrate efforts to enforce the traffic laws associated with HOV lanes. These factors include personnel constraints, enforcement priorities, public hostility toward certain preferential treatment projects, confusion over new traffic concepts, and physical limitations imposed by the geometric and engineering features of specific projects.

Since the early 1980's, the number of mainline HOV projects in California has doubled, as has the freeway mileage devoted to these projects. Illegal use of certain projects has also increased. As more and more HOV projects are introduced in an attempt to improve freeway operations, the available enforcement personnel will be stretched thinner and thinner, and the violation problem is likely to become more acute. This report measures violation patterns and addresses the impact of different engineering designs and enforcement strategies on HOV violation rates.

\subsubsection{Objective}

Adequate control of violation rates on HOV facilities requires an effective mixture of enforcement, engineering design changes, and public education. The general objective of this study has been to investigate the engineering features. enforcement procedures. and public attitudes associated with mainline HOV lanes with the aim of identifying those factors which contribute to violation rates and developing countermeasures to reduce these rates. 


\subsection{STUDY OVERVIEW}

The current study has lasted one year, consisting of a three-month review period, two four-month enforcement waves, and a one-month reporting period. The study has been composed of five distinct tasks:

Task 1. Review of Existing Data, in which historical violation rates were documented, mainline HOV lanes were observed, traffic engineers and enforcement personnel were interviewed, background studies were reviewed, and a Study Plan (SYSTAN, 1988) documenting detailed data collection and analysis procedures was produced.

Task 2. Observation of Enforcement and Violations, during which two fourweek waves of special enforcement were conducted on four mainline HOV lanes (Orange County Route 55, Los Angeles Route 91, Marin 101, and Santa Clara 101). In addition, start-up strategies were monitored on two HOV lanes opened during the study (San Diego I-15 and I-405 in Orange County).

Different levels and combinations of routine and special enforcement were tested to ascertain their effectiveness in controlling violations on the study freeways. Each of the two four-week waves of special enforcement was preceded by one month of "before" data collection and followed by two months of post-enforcement measurements. A typical pattern of field observations for a specific enforcement wave is shown in Exhibit 1.1 .

EXHIBIT 1.1

PATTERN OF FIELD OBSERVATIONS

AM PEAK

ENFORCEMENT

ROADSIDE

OBSERVATIONS

Location 1

Location 2

\section{PM PEAK}

ENFORCEMENT

ROADSIDE OBSERVATIONS

Location 1

Location 2

\begin{tabular}{|c|c|c|c|}
\hline \multicolumn{4}{|c|}{ FIRST ENFORCEMENT WAVE } \\
\hline $\begin{array}{l}\text { BEFORE } \\
\text { September }\end{array}$ & $\begin{array}{l}\text { DURING } \\
\text { October }\end{array}$ & $\begin{array}{c}\text { AFTER } \\
\text { November }\end{array}$ & $\begin{array}{c}\text { AFTER } \\
\text { December }\end{array}$ \\
\hline Routine & $\begin{array}{l}\text { Special } \\
\text { Specia }\end{array}$ & Routine & Routine \\
\hline & & 1 & $\sqrt{1}$ \\
\hline & & $\sqrt{1}$ & $\sqrt{ }$ \\
\hline Routine & $\begin{array}{l}\text { Special } \\
\text { Spation }\end{array}$ & Routine & Routine \\
\hline $1 \sqrt[*]{ }$ & & $\sqrt{ }$ & $\sqrt{ }$ \\
\hline$|\sqrt{ }|$ & & $\sqrt{ }$ & $\sqrt{ }$ \\
\hline
\end{tabular}

${ }^{*}$ As Needed 
Task 3. Measurement of Attltudes and Awareness, in which over 2,400 violators, carpoolers, and non-carpoolers were surveyed through two mailback questionnaires documenting drivers' attitudes toward HOV lanes, enforcement, and violations. The mail-back surveys were augmented with a series of six focus group discussions designed to provide firsthand, in-depth responses to key issues regarding the design and enforcement of HOV lanes.

Task 4. Analysis of Data. Data from roadside observations and license plate surveys were analyzed and combined with the results of focus group discussions and interviews with CALTRANS and CHP personnel to produce recommendations regarding the enforcement measures, personnel levels, and engineering design features needed to control violation rates on California's mainline HOV lanes. The analysis addressed such key issues as:

- The relationship between enforcement strategies, personnel levels, and violation rates;

- The impact of geometric and engineering design considerations (i.e., refuge areas, buffer lanes, access restrictions, signing, striping, operating hours, and Carpool definitions) on violation rates and enforcement efficiency;

- The relationship of such operational considerations as speed differentials and past violation history to current violation rates;

- The relationship between public information, public understanding, public attitudes, public acceptance, and violation rates; and

- The impact of violations and enforcement on freeway operations.

Task 5. Preparation of a Final Report This final report outlines data collection procedures, summarizes collected data, documents analytic findings, and recommends enforcement approaches, staffing requirements, and engineering design guidelines for mainline HOV lanes.

\subsection{HISTORICAL ENFORCEMENT LEVELS AND VIOLATION RATES}

As a first step in documenting the impact of design and enforcement options on HOV violation rates, California's mainline HOV projects were surveyed, plans for future lanes were documented, and statistics were assembled describing design features, historical violation rates, enforcement levels, and operating performance.

\subsubsection{Design and Operating Features}

Exhibit 1.2 summarizes the design and operating characteristics of California's existing mainline HOV lanes. In addition to such design data as project length, median and buffer characteristics, Carpool definitions, and operating hours, the exhibit also lists the average time savings and hourly volumes recorded on mainline HOV lanes January 1989. 
EXHIBIT 1.2

DESIGN CHARACTERISTICS

MAINLINE HOV LANES IN CALIFORNIA

(Lanes Operating January 1, 1990)

\begin{tabular}{|c|c|c|c|c|c|c|c|c|}
\hline Mainline HOV Lane & $\begin{array}{l}\text { Length } \\
\text { jmiles) }\end{array}$ & $\begin{array}{l}\text { Median } \\
\text { Shoulder } \\
\text { Jwidth-ft.) } \\
\end{array}$ & $\begin{array}{c}\text { Buffer } \\
\text { Separation }\end{array}$ & $\begin{array}{c}\text { Access } \\
\text { Unllmlted? }\end{array}$ & $\begin{array}{c}\text { Carpool } \\
\text { Deflnitlon }\end{array}$ & $\begin{array}{c}\text { Operating } \\
\text { Hours }\end{array}$ & $\begin{array}{l}\text { Avg. TIme } \\
\text { Savlngs } \\
\text { min./pk. period; }\end{array}$ & $\begin{array}{c}\text { Avg. HOV } \\
\text { Lane Volume } \\
\text { (veh./peak hr.) }\end{array}$ \\
\hline - Marin 101 (south) & 3.7 & $2 '$ to 5 & Stripe & Yes & $2+\cdots$ & $\begin{array}{l}0630-0830 \\
1630-1900\end{array}$ & 0.8 & 350 \\
\hline . Marin 101 (north) & 3.0 & $2^{\prime}$ to $5^{\prime}$ & Stripe & Yes & $2+\cdots$ & $\begin{array}{ll}0630-1 & 830 \\
1630-1 & 900\end{array}$ & 1.5 & 300 \\
\hline - Santa Clara 101 & $3.0+$ & $10^{\prime}$ & Stripe & Yes & 2+. M/C OK & $\begin{array}{l}0500-0900 \\
1500-1900\end{array}$ & 3.0 & 850 \\
\hline - Santa Clara 237 & 4.5 & -ー- & Stripe & Yes & $2+, \mathrm{M} / \mathrm{C} \mathrm{OK}$ & $\begin{array}{l}0500-0900 \\
1500-1900\end{array}$ & 3.0 & 1000 \\
\hline - San Francisco 280 & 1.9 & varies & Stripe & Yes & $3+$ & 24/day & 4 & 300 \\
\hline $\begin{array}{l}\text { IA } 10 \text { (El Monte } \\
\text { Busway/West }\end{array}$ & 4.5 & $10^{\prime}$ & $\begin{array}{l}\text { Concrete } \\
\text { Barrier }\end{array}$ & No & $3+$ & 24/day & 11.0 & 700 \\
\hline $\begin{array}{l}\text { LA } 10 \text { (El Monte } \\
\text { Busway/East) }\end{array}$ & 7.0 & $2^{\prime}$ & 13' Buffer & $\mathbf{N b}$ & $3+$ & 24/day & & 1200 \\
\hline - Los Angeles 91 & 8.0 & $2^{\prime}$ • & 2' Stripe & No & $2+$ & 24/day & 3.0 & 1500 \\
\hline - Orange 55 & 11.0 & - & 1' Stripe & No & $2+, \mathrm{M} / \mathrm{C} O \mathrm{~K}$ & 24/day & 10.0 & 1700 \\
\hline - I-405 (Orange Co.) & 14.0 & - & Stripe & No & $2+M / C O K$ & 24/day & NA & 1400 \\
\hline - I-15 (San Diego) & 9.8 & $10.5^{\prime}$ & $\begin{array}{l}\text { Concrete } \\
\text { Barrier }\end{array}$ & No & $2+M / C O K$ & $\begin{array}{l}0600-0900 \\
1500-1800 \\
\end{array}$ & 7.5 & 850 \\
\hline
\end{tabular}

*Median contains enforcement area(s).

${ }^{* *}$ Changed to 2t October 3, 1988.

**'HOV lane is outside lane.

+Extended to 12 miles in December 1988. Data reflect operation of original 3-mile segment. 


\subsubsection{Violation Rates}

Historical violation statistics for California's mainline HOV lanes are plotted in Exhibit 1.3. This exhibit plots the total number of violators during the morning and evening peaks, and expresses these violations as a percentage both of the total number of vehicles in the HOV lane (lane violation rate) and of the total number of vehicles using the freeway during the peak period (freeway violation rate). The rates plotted generally reflect conditions in early 1988 (except for freeways no longer operational at that time) and represent the most recent observations available at the start of the current study. Freeways in Exhibit 1.3 are arranged in order of increasing lane violation rates (AM and PM combined). The combined lane violation rate was lowest (4\%) on the physically separated right-of-way at the western end of the El Monte Busway. Combined lane violation rates were highest (31.5\%) along the lightly enforced section of I-280 south of San Francisco.

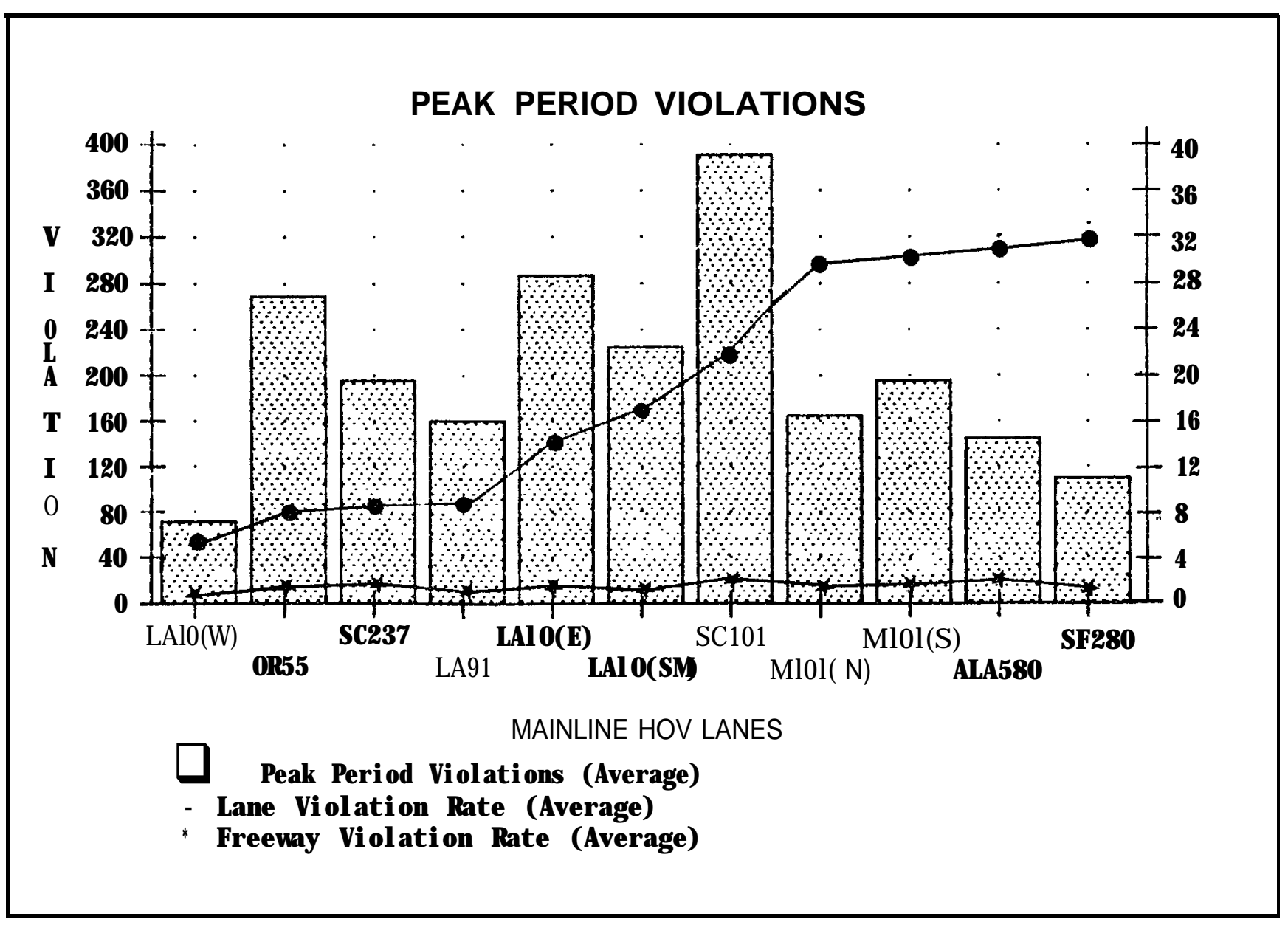


Because lane violation rates depend on the number of ridesharing vehicles using the lane, as well as on the number of violators, these rates vary considerably from project to project, and are highest where Carpool definitions require three or more people. There is less variation in overall freeway violation rates, which range from $1 \%$ of all vehicles using Los Angeles Route 91 to $2.4 \%$ of all the vehicles using State Route 237 in Santa Clara County.

\subsubsection{Enforcement Activities}

Citation Rates. Exhibit 1.4 tabulates the number of citations for violations of vehicle code 21655.5 issued to HOV lane occupancy violators by CHP officers during 1988. Citations have been divided into two categories: (1) Citations issued by beat officers in the course of their routine duties, and 2) Citations issued by officers assigned to special HOV overtime enforcement.

\section{EXHIBIT 1.4}

ROUTINE VS. SPECIAL ENFORCEMENT

AVERAGE CITATIONS PER DAY (1988)

\begin{tabular}{|c|c|c|c|c|}
\hline Lane & Routine & Special & Total & $\%$ Routine \\
\hline OR 55 & 11.8 & 3.9 & $15.7^{\star}$ & $75 \%$ \\
\hline LA 91 & 2.4 & 2.2 & $4.7^{\star \star}$ & $53 \%$ \\
\hline SC 101 & 11.3 & 6.8 & $18.1^{*}$ & $62 \%$ \\
\hline Marin 101 & 4.2 & 6.1 & 10.3 & $41 \%$ \\
\hline SC 237 & 7.5 & 0.0 & 7.5 & $100 \%$ \\
\hline SF I-280 & 1.2 & 0.1 & 1.3 & $92 \%$ \\
\hline LA 10 & 11.7 & 3.3 & 15.0 & $88 \%$ \\
\hline TOTAL & 50.1 & 22.4 & 72.6 & $69 \%$ \\
\hline
\end{tabular}

The exhibit shows that the routine beat otticer was the primary enforcer of California's mainline HOV lanes in 1988, writing $69 \%$ of all 21655.5 citations. On a project-by-project basis, the relative percentage of routine citations as a proportion of all citations ranged from $41 \%$ on Marin 101 to $100 \%$ on Santa Clara 237. Routine enforcement accounted for more than half of the occupancy citations issued on every one of California's mainline lanes except Marin 101. 
The predominance of routine enforcement on California mainline HOV lanes, with an average of over 7 citations per lane per day, stands in contrast to the historical situation on the state's ramp meter bypass lanes, where routine enforcement levels stood at roughly one citation per ramp per week prior to a previous SYSTAN study (Billheimer, et al., 1981).

Apprehension Rates. When citation rates are considered in the light of violations, it appears that the percentage of violators who are ticketed ranges from $0.7 \%$ (on the southern segment of Marin 101) to $2.7 \%$ (on Route 237 in Santa Clara County). On the average, officers seem to be citing approximately $2.5 \%$ of all drivers using California's mainline lanes illegally. This apprehension rate is roughly 10 times the rate experienced on ramp meter bypass lanes before the introduction of special enforcement activities during the earlier study. With an apprehension rate of $2.5 \%$, the typical violator could expect to use mainline lanes illegally 40 times before being caught, so that a daily commuter using mainline lanes illegally morning and evening would expect to be caught within a month.

\subsection{VIOLATION PATTERNS}

In an attempt to explore the pattern and underlying causes of HOV violations, roadside observers recorded violation rates and HOV speed differentials at 5-minute increments over the peak commute periods. Violations were also tabulated by observers riding in the mixed-flow lanes to provide a driver's eye view of violation rates.

\subsubsection{Occupancy Violations}

Eringe Effects In nothern California, where HOV lanes operate only at specified times during the peak commute periods, violation rates tended to be highest at the fringes of the operating period, just after the lanes are opened to HOV traffic and just before they revert to general use. Exhibit 5.1 plots this effect on Marin 101, where HOV lanes operate between 6:30 a.m. and 8:30 a.m.

In Southern California, where mainline HOV lanes operate 24 hours per day, there were no pronounced variations in violation patterns during the peak commuting period. 


\section{VIOLATION RATE BY TIME OF DAY}

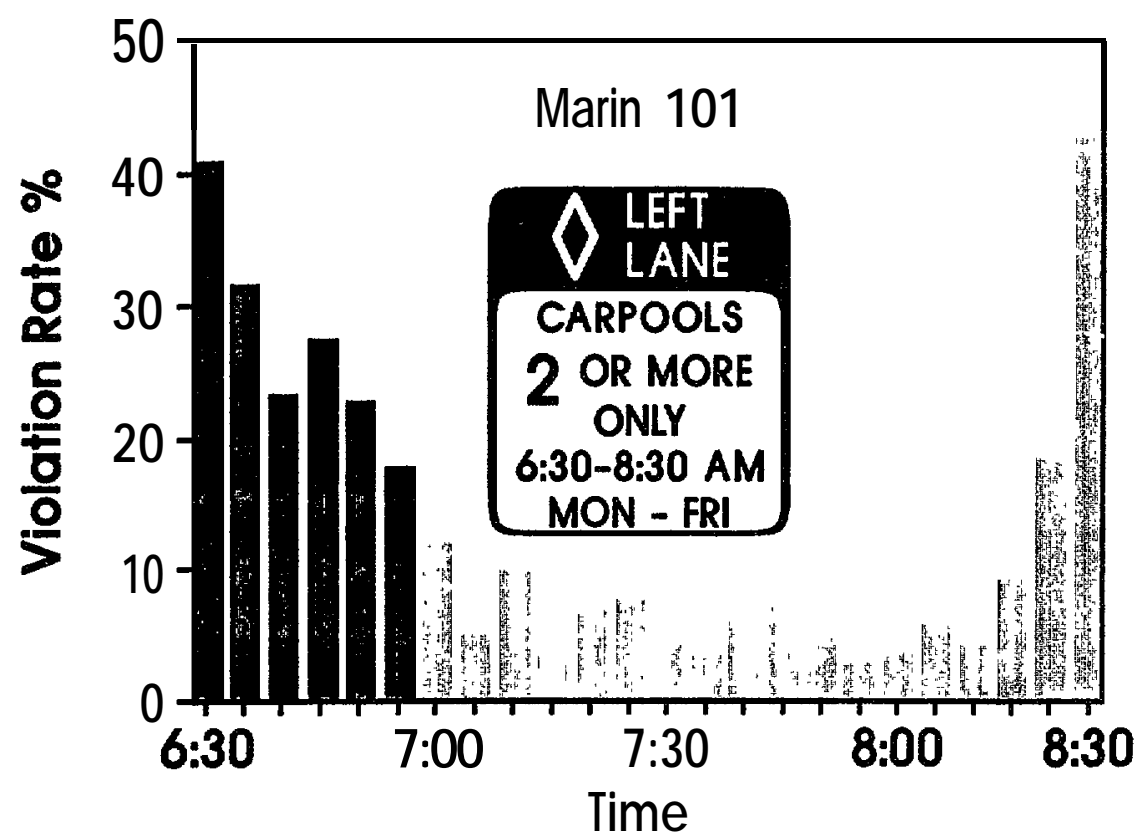

- Rate Affected by Darkness

Darkness Effects. Just as violation rates increased at the fringes of operating hours in Northern California, they also appeared to increase after dark and during other periods when visibility was limited. These aberrant effects were adjusted in comparing day-to-day violation rates. Since CHP officers do not actively enforce HOV lanes at the fringes of operating periods or when visibility is limited, the higher violation rates measured at these times provide a certain amount of insight into the impact of enforcement on violations.

\section{Impact Kime Savings N}

the speed differential between the HOV lanes and mixed flow lanes. Although it is somewhat surprising that violation rates do not appear to increase as HOV time savings increase, this finding undoubtedly reflects the tendency of drivers to overestimate any time savings in the HOV lanes, and is consistent both with earlier findings on ramp meter bypass lanes (Billheimer, et al., 1981) and with the observations of CHP officers. In noting that traffic conditions seem to have little effect on HOV lane violations, one officer reported that drivers use the lanes illegally "...to save time when the adjacent lanes are clogged and as a passing lane when adjacent lanes are freeflowing." 


\subsubsection{Buffer Violations}

In Southern California, access to mainline HOV lanes is restricted to certain locations along the mainline freeway. Since the mainline freeway is most often separated from the HOV lane by a narrow one- or two-foot stripe (or a 13-foot stripe in the case of the El Monte Busway) it is possible for drivers to enter and leave the HOV lanes illegally by crossing the buffer between designated access points. Buffer violations will vary widely from point to point on a specific freeway. Observers on OR 55 counted an average of 10 illegal crossings per hour during the evening commute while observers on LA 91 counted 20 illegal crossings per hour during the same period.

Impact of Enforcement Area. Observers placed upstream and downstream from the enforcement area on OR 55 detected no tendency for drivers to leave the HOV lane illegally before reaching the HOV enforcement area, or to enter cross the buffer into the HOV lane after the enforcement area had been passed.

Legal Carpoolers and Illegal Crossings. Legitimate carpoolers accounted for $72 \%$ of all buffer violations cited by officers during special enforcement periods. Since carpoolers account for well over $90 \%$ of the vehicles in the HOV lane, it can be inferred that occupancy violators are overrepresented among the population of buffer violators.

Drivers-Eye View. Because buffer violations occur in the few seconds it takes to change freeway lanes while occupancy violators remain in the HOV lane over longer time periods, the driver in the mixed-flow lane is much more likely to observe an occupancy violation than a buffer violation. Drivers traveling the length of OR 55 or LA 91 in the mixed flow lanes see approximately two buffer violations on each freeway. At the same time, they would see 15 occupancy violations on OR 55 and 9 on LA 91. Taking all four study freeways into consideration, drivers saw an average of 0.64 occupancy violators for every minute they spent driving next to the HOV lane. Even though they saw far more occupancy violators than buffer violators, drivers generally agreed that buffer violations were far more hazardous and serious. 


\subsection{ENFORCEMENT OPTIONS}

\subsubsection{Special Enforcement Activities}

Two four-week waves of special enforcement activities were scheduled on four study freeways. The first wave took place between October 17 and November 10, 1988, while the second wave was scheduled between March 6 and March 31, 1989. The results of the special enforcement activity on each freeway are summarized below.

Orange County Route 55. Citation rates and violation levels on OR 55 are graphed in Exhibit 1.6.

\section{EXHIBIT 1.6}

\section{CITATIONS AND VIOLATIONS}

OR 55

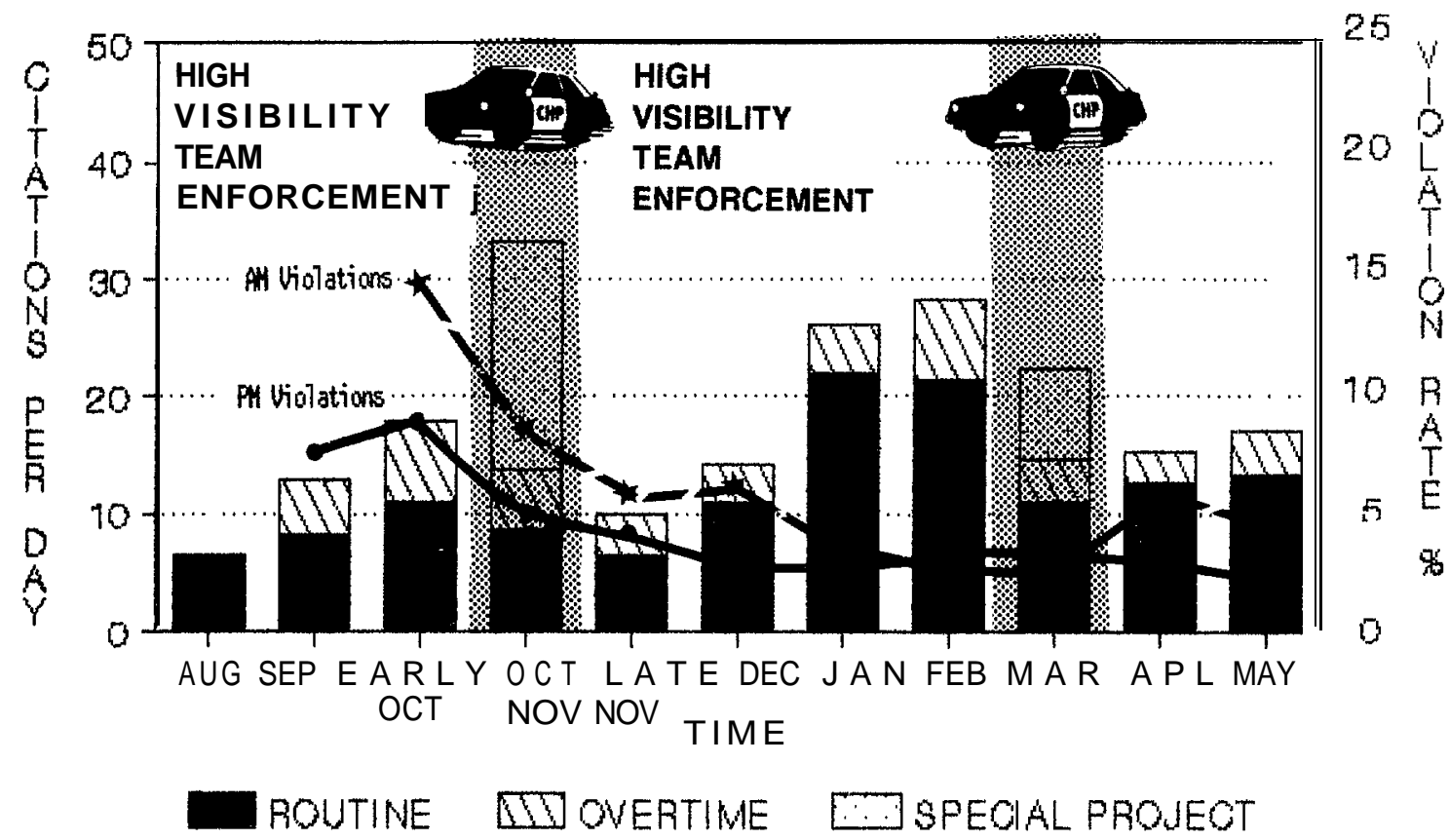

Violation rates dropped significantly during the first enforcement wave along OR 55, and remained low before, during, and after the second enforcement wave. During the first enforcement wave, officers worked in three-person teams, two days per week, with two officers pursuing violators spotted by the third officer, who was continuously visible in the enforcement area. Officers following this strategy issued an average of 2.5 citations per officer hours over the four-week period, more than doubling the average number of citations issued at other times during 1988. Although violation rates dropped significantly at two observation points in both the 
peak and off peak directions, the heavy enforcement activity severely disrupted traffic when all units were operating.

During the second enforcement wave, the high visibility enforcement program employed during the first wave was modified in an attempt to avoid disrupting traffic flow. As part of this program, a motor officer was continuously visible in the enforcement area two days per week (AM and PM). The officer relayed information on violators to a single chase vehicle. The violation rate recorded at observation points upstream and downstream from the enforcement area was below $5 \%$ during both the morning and evening peaks. The use of a single chase vehicle caused the number of citations issued to drop to 1.7 citations per officer hour, down from 2.5 citations per officer hour during the first enforcement wave, but violation rates remained low. The traffic disruption noted during the first enforcement wave did not recur during the second wave.

Los Angeles Route 91. Violation rates have historically been low along Los Angeles Route 91, which has a 14' wide, 1300' long enforcement area that has been accepted and used by the CHP since the project opened. Exhibit 1.7 plots citation and violation rates on LA 91 before, during, and after the two waves of special enforcement. The already low violation rates on LA 91 remained low before, during, and after each wave.

\section{EXHIBIT 1.7}

\section{CITATIONS AND VIOLATIONS LA 91}

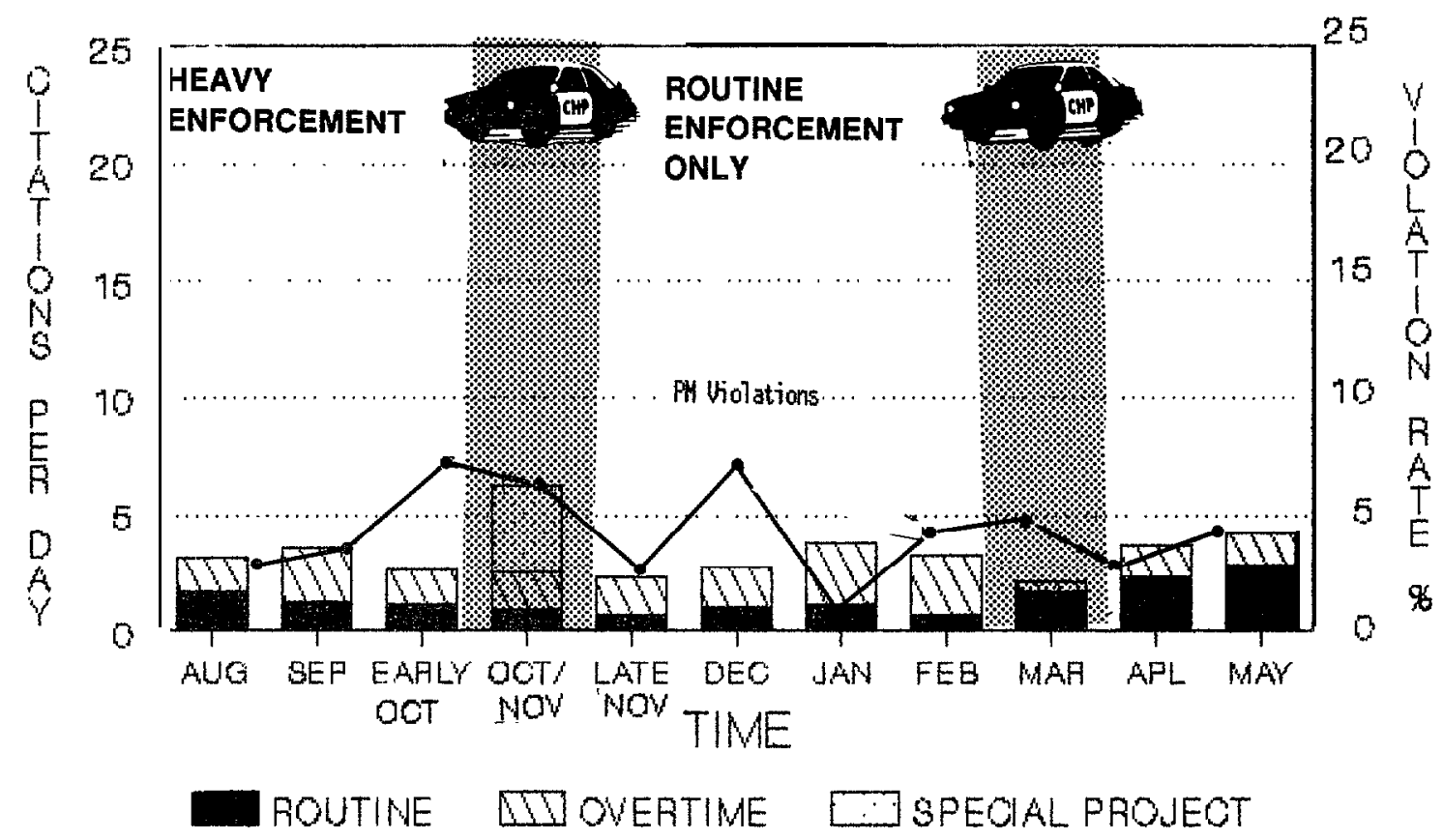


During the first enforcement wave, two officers were assigned to work out of the LA 91 enforcement area four days per week. The number of citations issued more than doubled historical levels, although there weren't enough violators to keep two officers busy during the last two weeks of the enforcement period, and citation rates dropped below one citation per officer hour. The heavy enforcement activity had no demonstrable impact on violation rates, which remained low during and after the enforcement period.

In view of the consistently low violation rates, LA 91 reverted to routine enforcement enly during the second enforcement wave in March 1989. The violation rate remained below $5 \%$, suggesting that acceptable violation rates may be achieved with lower levels of special enforcement, so long as consistent levels of routine enforcement are maintained and enforcement areas are provided.

Marin 101. Exhibit 1.8 plots violation rates on Marin 101 before, during, and after the two waves of special enforcement.

EXHIBIT 1.8

CITATIONS AND VIOLATIONS

MARIN 101

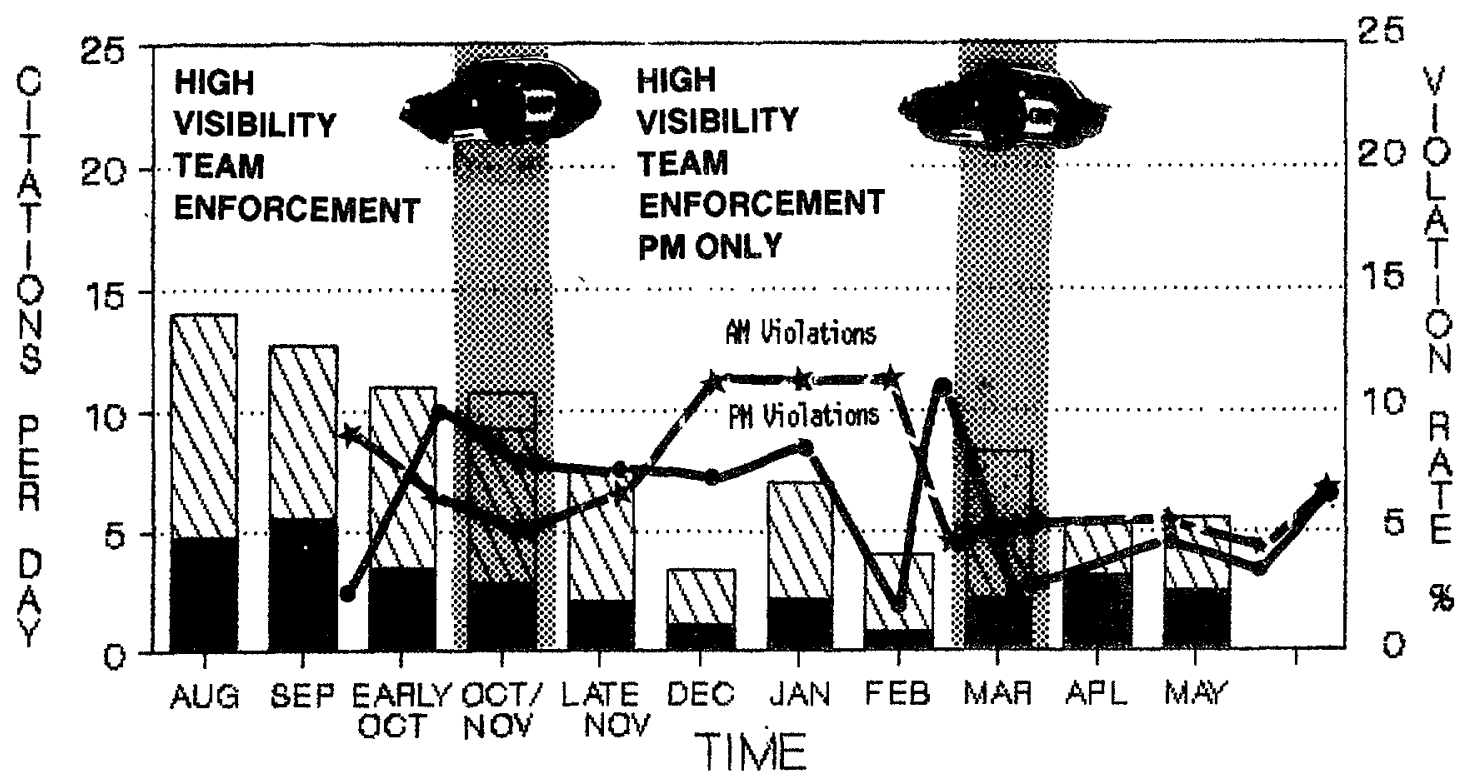

ROUTINE $\square$ ONERTIME $\because$ SPEOIAL PROJEOT 
On Marin 101, the Carpool definition had been changed from three persons to two persons just two weeks in advance of the first enforcement wave. During the years preceding this change, violation rates of $20 \%$ to $30 \%$ had been recorded. The change in cat-pool definition caused the violation rate to drop below $10 \%$. Special enforcement activities caused the violation rate to drop still further, to $5 \%$ during the evening peak and $7.5 \%$ during the morning peak. After the first period of special enforcement ended, violation rates rose slightly, before dropping during and after the second enforcement wave.

During the first four-week period of special enforcement, the Marin CHP added a spotter to their traditional HOV enforcement team during eight morning commute periods and six evening commute periods. The spotter took a visible position at one of the few locations where the center median was wide enough to accommodate a vehicle and broadcast the identity of violators as they passed. Chase teams of up to three vehicles pursued the violators, producing an average of three citations per peak period. The task of pursuing violators was time consuming, as officers had to thread their way through traffic to pursue a violator and thread their way back again once the violator was apprehended. The Marin commander and his staff felt that the exposed location of the spotter, particularly during the morning peak, made the spotter's job too difficult and hazardous. They felt, however, that if a protected enforcement area could be constructed for the spotter, the spotter/chaser arrangement might be made to work and other enforcement activities would be enhanced. Perhaps because of the visibility of the spotter, the special enforcement activity (following in the wake of the Carpool definition change), dropped the violation rate to the lowest level in the ten years of the lane's operation.

In view of the low violation rates observed following the first enforcement wave, a version of the visible enforcement program was repeated during the second wave. In an effort to improve overall safety, however, special enforcement activities were limited to daylight hours during the evening shift. Two motor officers were used as spotters on ten afternoons, while a patrol car served as a chase vehicle. One motor officer was constantly on view in a small, partially sheltered indentation in the northbound median barrier. Noting the need for better enforcement areas, Marin's lead motorcycle officer said of the partially sheltered observation point: "It's not a particularly dangerous place (to sit on a motorcycle)...it's just not particularly safe." Violation rates on Marin 101 ranged from $7 \%$ to $9 \%$ between enforcement waves, but dropped to $5 \%$ during and after the second enforcement wave. 
Santa Clara 101. Exhibit 1.9 plots violation rates on Santa Clara 101 before, during, and after the two waves of special enforcement. Violation rates on Santa Clara 101 ranged between $5 \%$ and $10 \%$ before, during, and after the first wave of enforcement, dropping slightly below $5 \%$ immediately after the second enforcement wave.

EXHIBIT 1.9

\section{CITATIONS AND VIOLATIONS}

SANTA CLARA 101

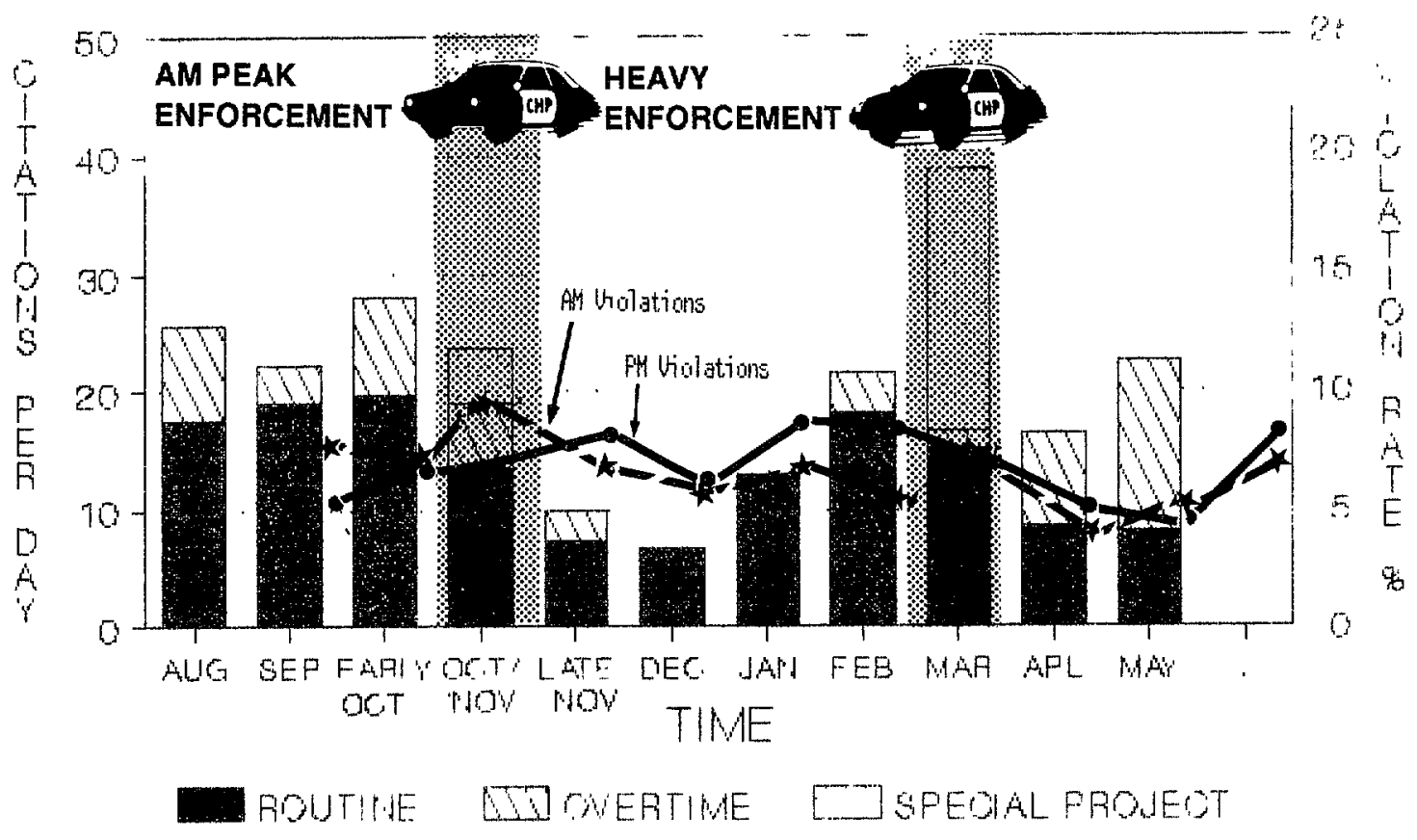

During the first enforcement wave, special enforcement activities concentrated on the morning commute period. Officers on HOV overtime issued an average of 5.2 citations during the morning commute. Many of these citations were issued from a highly visible position on the 11foot shoulder separating the HOV lane from the median barrier. This enforcement level was not significantly higher than the combined levels of routine and special enforcement recorded historically, and had no measurable impact on violation rates, which remained low (between $5 \%$ and $10 \%$ ) before, during, and after the first wave of enforcement.

During the second enforcement wave, special enforcement levels on Santa Clara 101 were increased to more than double the usual level of enforcement activity. Three officers were assigned to special enforcement activities five days per week. Violation rates averaged $7.3 \%$ 
during the enforcement period, dropped below $5 \%$ for the first time after special enforcement ceased, but subsequently returned to the $7.5 \%$ average.

Start-Up Strategy: San Diego 1-15. Barrier-separated HOV lanes on San Diego I15 opened in mid-October 1988. When the new lanes became operational, they received four weeks of daily special enforcement attention. In addition to the special enforcement activities, a single motor officer was assigned to patrol the separate facility during each peak period to assist stranded motorists, monitor traffic, and respond to accidents. As time progressed, special enforcement levels were cut back gradually, to two days per week after one month, and two days per month after six months. The single motorcycle officer continued to provide routine enforcement on a daily basis. Although violation rates of $6 \%$ and $7 \%$ were recorded during the first month of lane operations, violation rates well under $5 \%$ were common in subsequent months. The gradual reductions in special enforcement had no measurable impact on occupancy violation rates. By the time of the second enforcement wave, occupancy violations accounted for only $23 \%$ of the citations issued on I-15's HOV lanes. Forty-three percent of the drivers stopped by enforcement officers were cited for speeding on the separate right-of-way.

\subsubsection{Special_Enforcement Summary}

The four freeways selected for special enforcement observations presented different enforcement problems, as did the newly opened lanes on San Diego I-15. Two of the study freeways, OR 55 and Marin 101, had no median shoulder and minimal right-hand shoulders, so that violators had to be escorted across several lanes of traffic before they could be ticketed. $A$ single enforcement area on OR 55 proved to be too narrow for any practical use except as a visible observation post. A special enforcement area on LA 91 was wide enough to accommodate both ticketing and frequent use as an observation post, even though the freeway had a narrow median along the remainder of its length. Santa Clara 101 had an 11' median shoulder running the length of the HOV lane. This shoulder was frequently used by officers both to cite violators and to observe passing HOV traffic.

Enforcement Impact. During the first enforcement wave, visible enforcement strategies on OR 55 and Marin 101 effectively lowered violation rates on these two freeways. These rates remained low as enforcement levels returned to historical levels following the first wave and stayed between $5 \%$ and $10 \%$ during and after the second wave of special enforcement. The two remaining test freeways, Los Angeles 91 and Santa Clara 101, offered either an 
enforcement area or a wide median shoulder for the use of enforcing officers, and both had relatively low violation rates at the start of the current study. The levels of enforcement applied during the two enforcement waves did not have a significant impact on these low lane violation rates. On LA 91, in fact, violation rates did not change significantly when enforcement was cut back to routine levels during the second enforcement wave.

Residual Impacts. Special attention was directed to the violation levels measured after special enforcement strategies had been completed on the test freeways. Violations were observed for a period of three-and-a-half months following the first wave of enforcement, and twoand-a-half months following the second wave. On every freeway, the levels of routine enforcement applied after special enforcement ceased were sufficient to keep violation rates below $10 \%$. On LA $91, \mathrm{I}-15$ and OR 55, in fact, violation rates lower than 5\% were maintained during the subsequent periods of routine enforcement. Thus routine enforcement efforts were equal to the task of maintaining low violation rates in the periods between special enforcement activities. In fact, there is reason to believe that the driving public was unable to distinguish between applications of special enforcement and ongoing levels of routine enforcement. Over two-thirds of all drivers surveyed during the second wave of special enforcement felt that enforcement levels had ...stayed about the same" over the past three months.

\subsubsection{Enforcement Issues}

Enforcement Tactics. In the absence of an enforcement area or median shoulder, the most common method of HOV lane enforcement employed by CHP officers is to drive to the adjacent lane while watching for violators in their rear-view mirror. This mirror-watching takes a good deal of the driver's attention, and some officers said that they felt uncomfortable driving in congested traffic while devoting so much time to their rear-view mirror. Enforcement areas and wide medians provide observation posts which relieve the officer of this potentially hazardous diversion of driving attention.

In the absence of an enforcement area or median shoulder, officers must escort violators across mixed-flow traffic to get to the right-hand shoulder or all the way off the freeway. The escort process disrupts traffic, and the fact that tickets are issued away from the HOV lanes minimizes the possibility that the ticketing activity will deter potential violators. 
Duration of Special Enforcement. Previous research (Billheimer, et al., 1981) has shown that twelve-week periods of special enforcement are not significantly more effective than four-week periods either in reducing violations or generating longer residual impacts. This finding, along with the difficulty of driving lane violation rates below $5 \%$ and the observed decline in citation rates as special enforcement progressed in the current study, suggests that enforcement impacts are subject to a law of diminishing returns.

Freeway Impacts. Officers and drivers have observed that heavy HOV enforcement can cause freeway traffic to break down as gawkers slow to watch the ticketing process. Such slow-downs were documented during the first enforcement wave on OR 55, when teams of chase units were sent out under the direction of a single observer. Limiting the number of chase units to a single vehicle limited freeway disruption during the second wave. To minimize disruption during special enforcement activities, officers should work separately, avoid bunching together, limit stacking so that no more than one car is waiting to be ticketed at any time (in addition to the vehicle being cited), release motorists cited in the median back into the HOV lane rather than into the mainline lanes, and avoid pursuing violators across several lanes of traffic.

Number of Officers. Previous research also suggests that assigning two officers one day of special enforcement is almost--but not quite--as effective as assigning a single officer for two days. Since mainline enforcement by several officers can potentially disrupt freeway flow, single officer assignments are preferred over multiple officer assignments. An exception occurs when teams of officers are needed to provide high-visibility enforcement on freeways such as Marin 101 or OR 55 which have no convenient refuge areas. Even in this case, teams should be limited to an observer and a single chase unit.

AM/PM Spilts. Results of earlier studies suggested that special enforcement concentrated on the morning peak on a mainline HOV lane lowered violation rates during the evening peak as well, and vice versa. When single-period enforcement was tested during the current study the results were inconclusive. Although violation rates did not increase during the unenforced peak, they had been at relatively low levels before, during, and after the special enforcement activities. CHP areas should be cognizant of the potential for cross-peak impacts in assigning officers to special enforcement.

n Fines. In January 1989, the cost of a first conviction for an HOV occupancy violation in $\mathrm{i}$ California was raised to $\$ 100$. Levels had previously ranged from $\$ 35$ to $\$ 65$ at different locations throughout the state. The cost of second and third convictions ranged from minimums of $\$ 150$ to 
$\$ 250$. The impact of this change on measured violation rates is not known, although surveys suggest that the driving public was not generally aware of the increase.

Moving Violatlon Statue. HOV occupancy and buffer violations are not classified as moving violations in California and do not contribute to a driver's point count. There has been considerable confusion throughout the state regarding this issue, and focus group discussions suggest that most drivers are not aware that HOV violations are not 'moving violations.

\subsubsection{Enforcement Problems}

In discussing the enforcement of California's mainline HOV lanes, CHP officers identified several common enforcement problems:

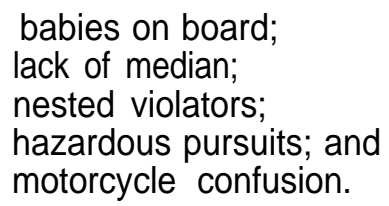

Babies on Board. Officers on all study projects cited the problem of pulling over a suspected violator only to find that a sleeping adult or a small child below window level made the vehicle a legitimate carpool.

Lack of Median Shoulder.Most of California's existing mainline HOV lanes have no median shoulder. This means that officers usually drive warily in the adjacent lane when watching for violators, have no escape hatch when pursuing violators in the HOV lane, and must escort violators across mixed flow lanes to the right-hand shoulder once they are apprehended. The escort process disrupts traffic, and the fact that tickets are issued away from the HOV lanes minimizes the possibility that the ticketing activity will deter passing violators.

"Nested Violators". Officers found it difficult to pursue violators who were "nested" in a group of cars, particularly if the violating vehicle was followed closely by a truck or bus. This was especially true when there was no median lane that the officers could use to accelerate. 
Hazardous Pursult. The lack of a median shoulder also makes it more hazardous to pursue violators in the HOV lane. Pursuing officers and violators alike are at risk if a carpooler noses into the HOV lane as the pursuit is occurring.

Motorcycle Confusion. Motorcyclists cannot legally use the HOV lanes on Marin 101, the El Monte Busway, or LA 91. However, they are allowed on Santa Clara County's HOV lanes, Orange County Route 55, and most ramp meter bypass lanes. This inconsistency causes some confusion and much ill will.

\subsection{DESIGN OPTIONS}

\subsubsection{Lane Separation}

Physical separation of HOV lanes is desirable from the standpoint of safety, operations, and enforcement. Physically separate lanes have lower violation rates. They also require a daily enforcement commitment, since officers in adjacent mixed-flow lanes do not have ready access to the barrier-separated HOV lanes.

When physical separation is not possible, buffer lanes or stripes will separate HOV lanes from mixed-flow traffic. Based on California's experience with Alameda 580 and the El Monte Busway, painted buffer lanes appear to be no more effective than simple stripes in discouraging occupancy violations. However, the wider buffer lanes do appear to discourage (but not eliminate) illegal buffer crossings. To keep cars from stopping on the buffer itself, it is recommended that buffer lanes be no more than four feet wide. Striped separations of one-foot and two-foot widths are no more difficult to enforce than wider buffer-separations.

\subsubsection{Access/Eqress Limitations}

Access/egress limitations on contiguous HOV lanes appear to impose a marginal additional load on enforcing officers. Less than $16 \%$ of the tickets issued by Southern California CHP officers during periods of special enforcement cited drivers for illegal buffer crossings. Accordingly, the decision to limit access and egress to HOV lanes (as is common in Southern California) or to allow unlimited access (as is common in Northern California) should be made on the basis of traffic engineering and safety concerns, with enforcement a minor consideration. 


\subsubsection{Refuge Areas}

Protected Enforcement Areas. Enforcement areas are protected refuge areas adjacent to mainline HOV lanes where officers can observe traffic conditions and issue citations. Exhibit 1.10 contains a conceptual plan for an enforcement area, along with a photograph of a CHP officer using the enforcement area on LA 91. Experience on LA 91 shows that a welldesigned enforcement area can be used effectively to control violations along a mainline lane. Two-way enforcement areas such as that depicted in the conceptual plan of Exhibit 1.10 can have a deterrent effect on potential violators traveling in both peak and off-peak directions.

A usable enforcement area constructed from a flared median barrier must have a mouth of at least 9'-8" and be set in a 14-median shoulder. To provide adequate acceleration/deceleration distances the 14-median shoulder should extend at least 1,300 feet beyond the mouth of the enforcement area. Study results suggest that properly designed enforcement areas can enhance the effectiveness of routine enforcement activities and reduce the need for special enforcement waves. Initial construction costs can be offset by reduced requirements for overtime enforcement over the life of the project.

Median Shoulders. Where space and funds are available, a continuous 14-foot median shoulder should be provided along the length of the HOV lane for both safety and enforcement purposes. This median shoulder may be enhanced through the addition of enforcement areas. However, a properly designed enforcement area should be the minimum acceptable refuge area accompanying future mainline HOV lane designs. The difficulties encountered in enforcing Mat-in 101 suggest that mainline HOV lanes lacking a substantial median shoulder should not be contemplated if space cannot be found for at least one well-designed enforcement area.

\subsubsection{Operating Hours}

HOV lanes that are restricted to peak period use are no more difficult or costly to enforce than lanes which are open around the clock. When HOV operations are restricted to the peak period, violations tend to cluster at the fringes of operating hours, and officers don't generally enforce HOV restrictions until the lanes have been operating for at least 10 minutes. Opening lanes to all-day operations does not appear to increase either violation levels or enforcement 


\section{EXHIBIT 1.10}

\section{CONCEPTUAL PLAN FOR AN ENFORCEMENT AREA}

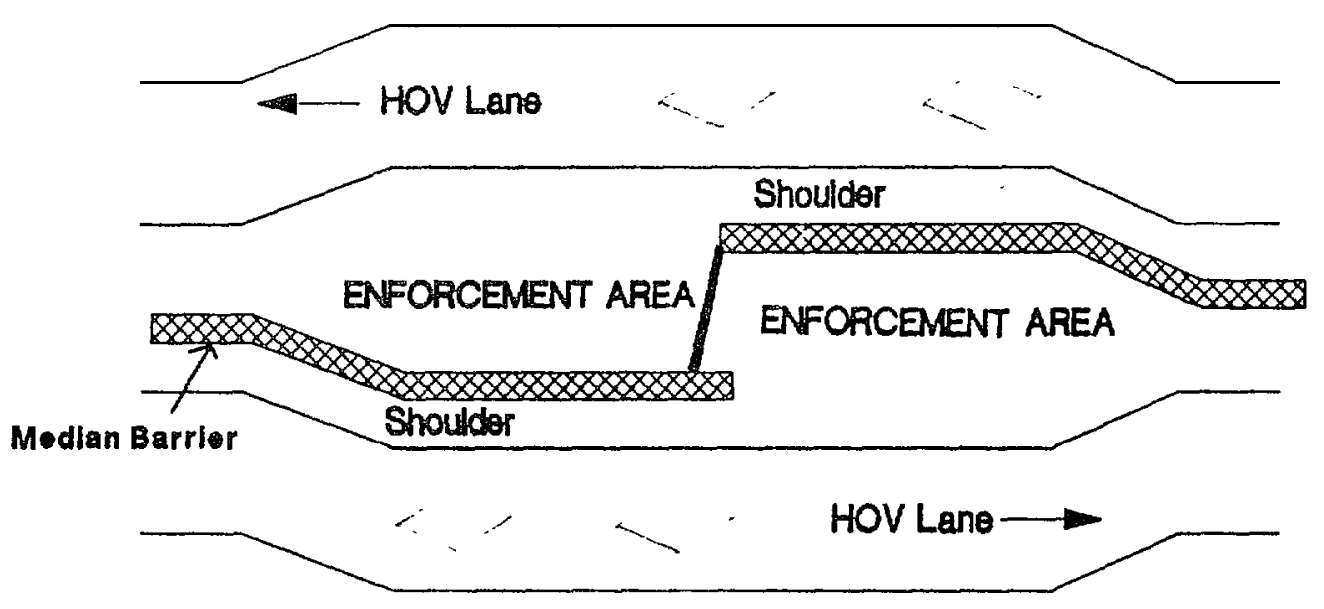

A. CONCEPTUAL DESIGN

BI-DIRECTIONAL ENFORCEMENT AREA

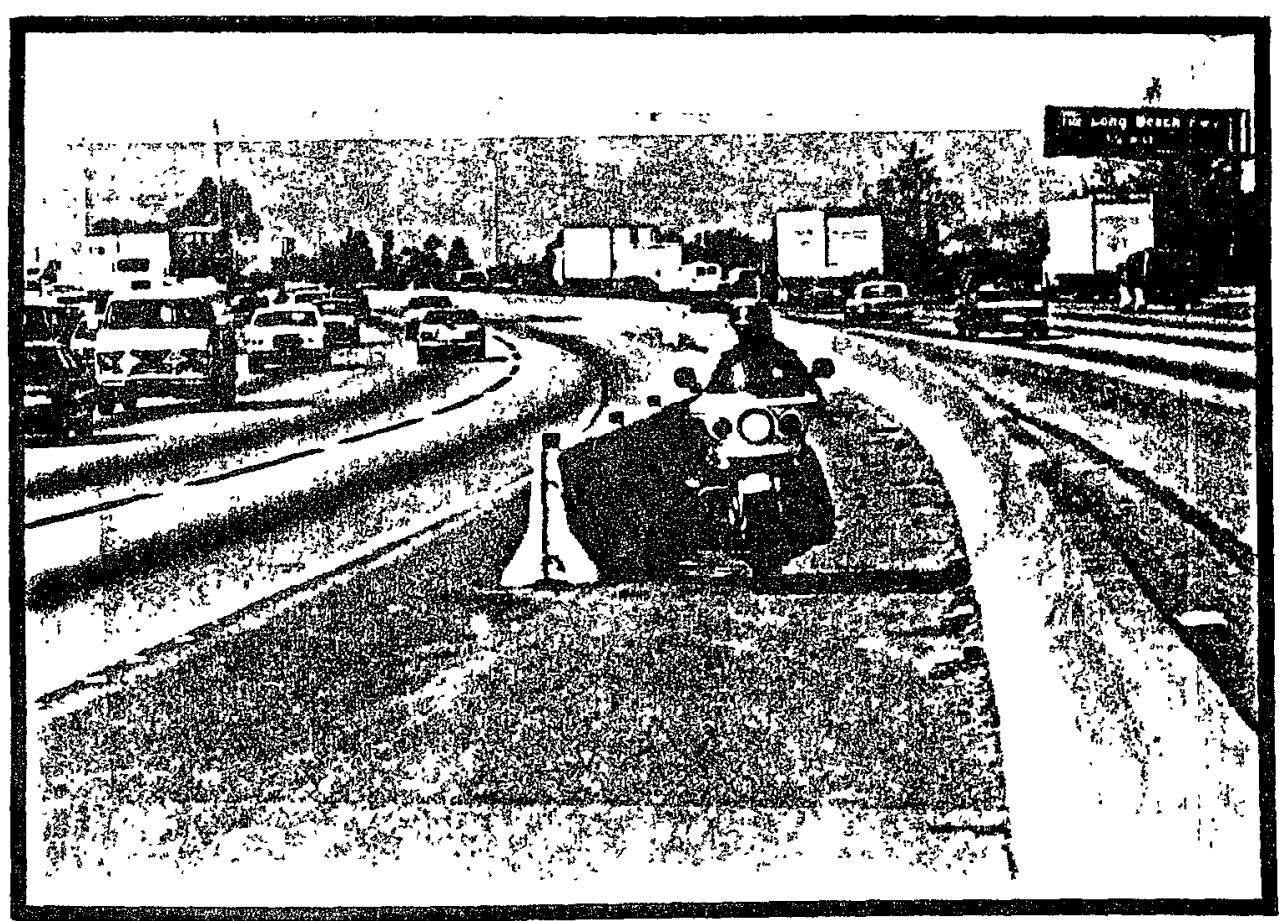

B. MOTOR OFFICER USING UNI-DIRECTIONAL

LA 91 ENFORCEMENT AREA 
requirements appreciably, and may simplify signing problems and reduce confusion (and violation rates) at the changeover times. At the same time, it is impossible to enforce occupancy restrictions after dark, off-peak accident rates are likely to be lower if more lanes are available to mixed-flow traffic, and the additional hours of operation at times when there is no speed differential in the HOV lanes are not likely to encourage many additional carpools.

\subsubsection{Carpool Definitions}

The task of enforcing mainline HOV lanes is much the same whether Carpools are defined as two persons or three persons. Violation rates tend to be much lower when carpooiers are defined as two-or-more persons, but this largely reflects the dramatic increase in the number of legitimate HOV lane users. The actual number of violators does not appear to drop appreciably when carpool restrictions are relaxed from $3+$ to $2+$ persons.

\subsubsection{Signing and Marking}

Most drivers appear to understand the use of HOV lanes and recognize the standard signs and painted diamonds which are used throughout the state to designate bus and Carpool lanes.

Part Time Shoulder Use. The creation of HOV lanes through the use of part-time shoulder conversion is not recommended, since confusion regarding shoulder use can create serious hazards for disabled vehicles. After considerable experimentation on LA 91, including the use of electronically operated message signs and traffic signals, CALTRANS concluded that no signing system was sufficiently unambiguous to permit the lanes to be returned to shoulder use during off-peak hours. As a result, the LA 91 HOV lane was opened to buses and Carpools 24 hours per day.

Continuous Medians. Where a continuous 14' median shoulder is available for enforcement activities, it should be designated by placing diagonal Botts Dots at intervals to warn drivers that the widened shoulder is not a traveled way and alert officers using the median to the presence of oncoming vehicles.

\subsubsection{Time Savings}

Larger time savings do not necessarily mean more violations. Any savings, even the smallest, looks much larger than it actually is and looms as a temptation to potential violators. 


\subsubsection{Project Length}

In general, the shorter a contiguous HOV lane is, the more likely that special enforcement will be required. At one extreme, the shortest HOV lanes in California, ramp meter bypass lanes, get relatively little routine enforcement and rely almost exclusively on special enforcement. At the other extreme, long mainline HOV lanes such as OR 55 and Santa Clara 101 expose violators to capture by routine patrol for longer periods, lessening the need for special enforcement. So long as the population of freeway drivers does not change dramatically over the length of a mainline HOV lane, special enforcement requirements appear to be nearly independent of lane length.

\subsection{PUBLIC AWARENESS}

in an attempt to probe and document public attitudes toward mainline HOV lanes, six focus group discussions were held with drivers on the four study freeways, and surveys were mailed to a sampling of over 14,000 carpoolers, violators and non-carpoolers who had been observed using these freeways during the peak commute periods. The group discussions were held prior to the start of the first enforcement wave, and surveys were mailed at two times during the study: (1) Just before the first enforcement wave began, and (2) Just before the second enforcement wave ended. Over 2,400 drivers responded to the survey (a response rate of 17.5\%). Those responses, coupled with the in-depth reactions of fifty-nine focus group participants, led to the following conclusions regarding driver attitudes toward mainline HOV lanes.

\subsubsection{HOV Lane Perceptions}

- Drivers understand the purpose of HOV lanes. The vast majority (over $75 \%$ ) of the drivers believe that the laws are effective in inducing Carpools and improving traffic conditions. Over $60 \%$ felt that the HOV lanes were fair

- Southern California drivers perceived the lanes on OR 55 and LA 91 to be "scary" and "dangergous." Reasons cited included the high speed differential, the close proximity of the median barrier, and weaving drivers. Northern California drivers did not express similar levels of concern regarding the safety of Marin 101 and Santa Clara 101. 
- Violators. carpoolers. and general drivers alike greatly Overestimate the average time savinas afforded by HOV lanes. Exhibit 1.11 compares perceived time savings reported by drivers with actual time savings reported on the four study projects during the evening commute. Perceived time savings were approximately double the savings recorded during the heaviest traffic period, and nearly four times the average savings realized by drivers throughout the evening commute. This tendency to perceive greater time savings in the Carpool lane undoubtedly makes the carpool lanes appear more attractive to drivers than to statisticians comparing raw numbers, and indicates that there may be a psychological advantage in providing a Carpool lane even when the available time savings appear minimal.

EXHIBIT 1.11

PERCEIVED AND ACTUAL TIME SAVINGS
EVENING COMMUTE

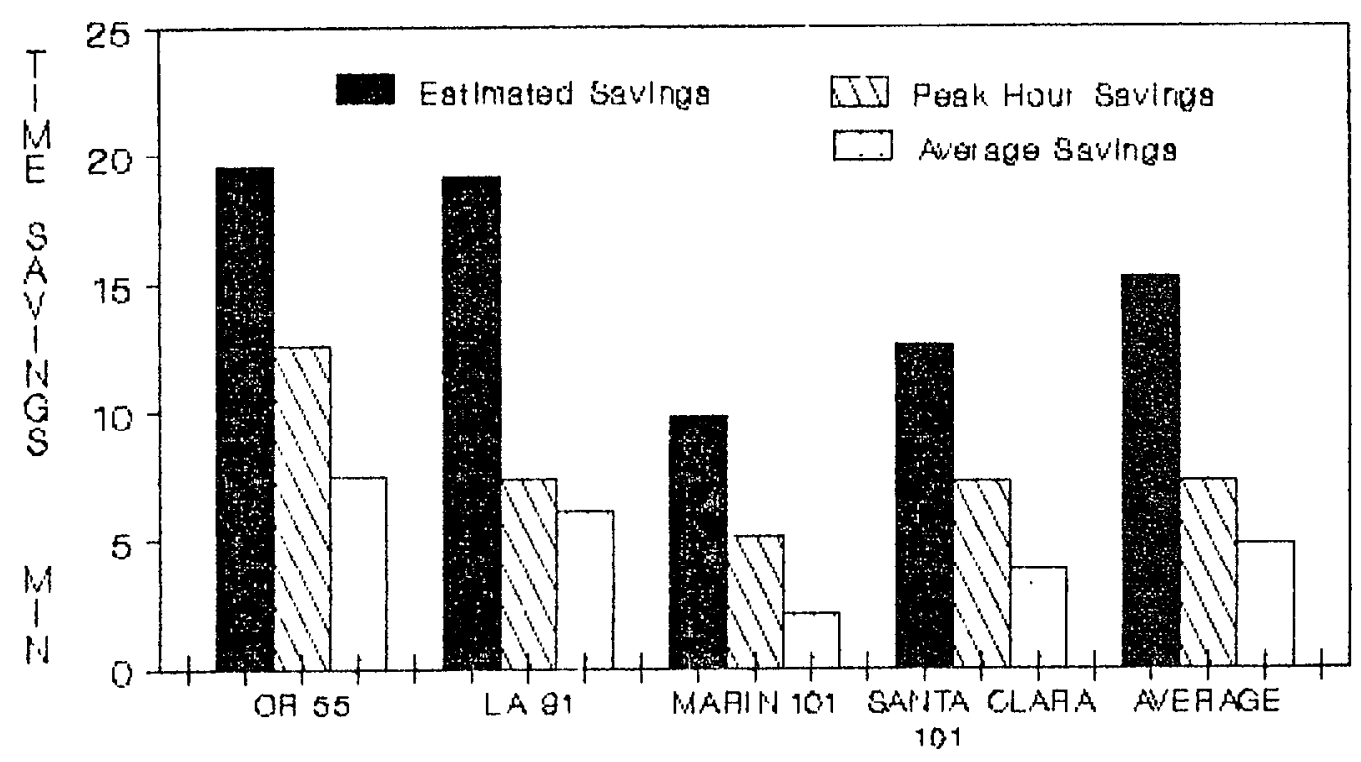

Drivers felt that existing HOV lanes should be extended. Other suggestions for improving HOV lane operations included lengthening the entry and exit points on OR 55 and LA 91, opening LA 91 in both directions, and reducing the Carpool definition on Marin 101 to two or more occupants. 


\subsubsection{Violation Perceptions}

- All drivers are aware of violations. and tend to overestimate the extent of low violation rates. Earlier work suggests that drivers are likely to be insensitive to violation changes in the $10 \%$ to $20 \%$ range.

- Drivers acknowledge that HOV occupancy violations are a problem, but most consider them a minor problem. Southern California drivers viewed buffer violations as far more serious than occupancy violations.

- Drivers felt that raising fines and posting the minimum level along the freeway would deter violations. Sixty-two percent of the drivers surveyed by mail were unaware of the minimum fine level, and Northern California drivers who professed to know the level greatly underestimated it.

\subsubsection{Enforcement Perceptions}

- Enforcement awareness Is greatest on freewavs with median lanes or enforcement areas adjacent to the HOV lane. Exhibit 1.12 plots the percentage of drivers who posted that they had never seen enforcement stops before and after the enforcement waves on the four study freeways. After two waves of special enforcement, this percentage had dropped on all four freeways. However, the relative ranking of the freeways in terms of enforcement awareness did not change. Drivers' awareness of enforcement was lowest on those freeways, OR 55 and Marin 101, where the median is too narrow for enforcement and there is no usable enforcement lanes. Over 25 percent of the drivers on these two freeways reported that they had "never seen the CHP ticketing an HOV violator." Awareness of enforcement was greatest on those freeways, Los Angeles 91 and Santa Clara 101, where enforcement can be carried out on the median. Fewer than $10 \%$ of the drivers surveyed on Santa Clara 101 said that they had never seen an enforcement stop. 
- Drivers themselves percelve a need for more enforcement. Over seventy percent of those surveyed thought that enforcement should be heavier. Most drivers perceived no change in enforcement rates during the period of special enforcement, possibly because of the relatively heavy year-round incidence of routine enforcement. Drivers generally felt that "...the police are doing a good job," but noted that "...stopping people on the freeway slows things down."

EXHIBIT 1.12

DRIVERS REPORTING THAT THEY HAD NEVER SEEN HIGHWAY PATROL TICKETING AN HOV LANE VIOLATOR

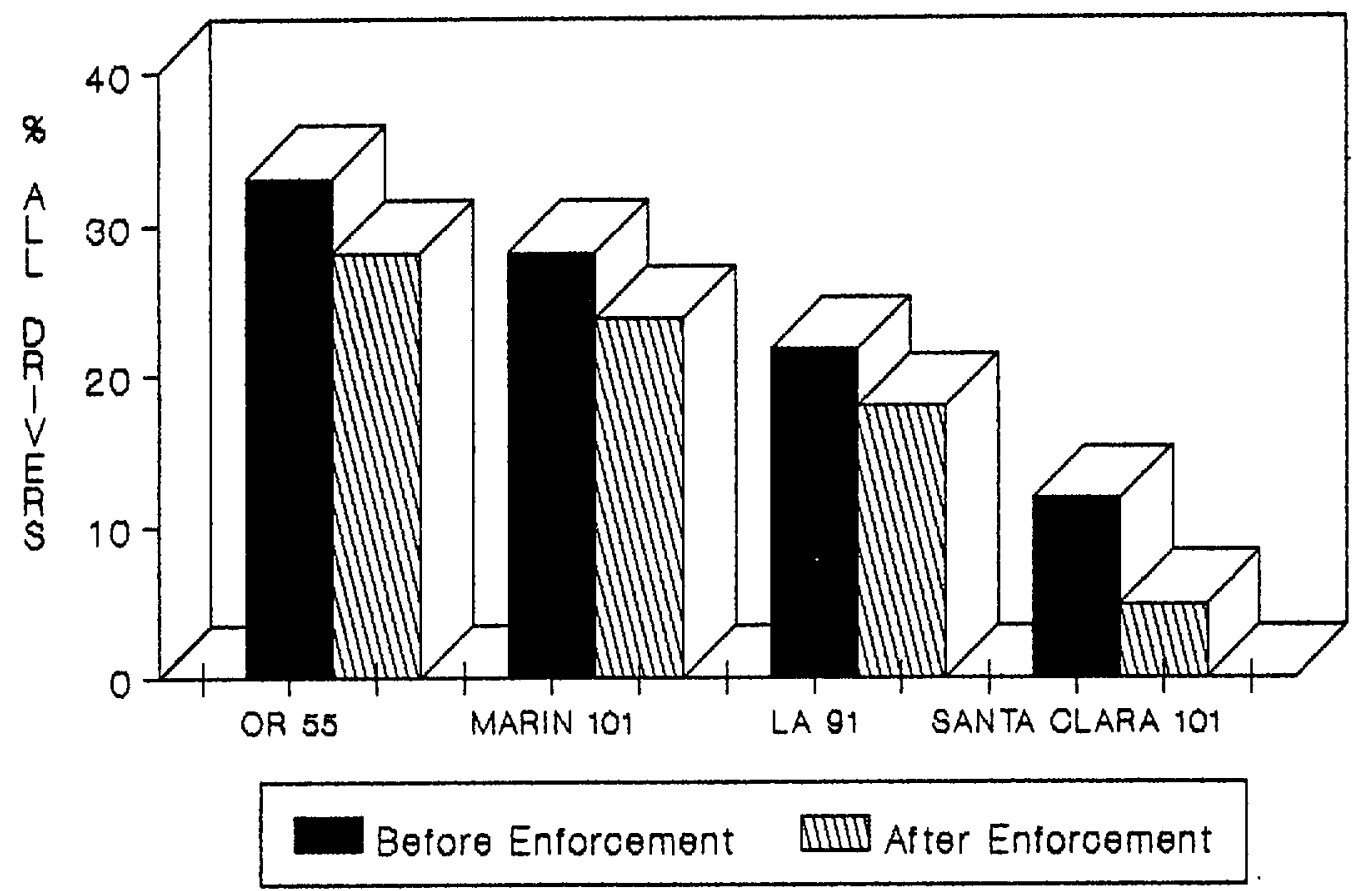

- Drivers tend to overestimate the risk of being caught using an HOV lane illegally. Risk levels estimated by focus group participants ranged from $1 \%$ to $18 \%$. The actual range on the study freeways appears to be between $1.5 \%$ and $2.8 \%$. Northern California drivers tended to feel that the likelihood of getting a ticket was higher than Southern California drivers.

- Driver opinion split dramatically on the deslrabllity of videotape survelllance and mail out citations. The possibility of using videotape surveillance to trigger mail-out citations generated heated focus group debates. Opponents cited "big-brotherism" while proponents argued that freeway ticketing 
caused significant traffic slowdowns. Most drivers agreed that the public would have to be educated regarding the need both for HOV lanes and mail-out citations if such a procedure were to succeed.

\subsection{PROPOSED ENFORCEMENT PROGRAM}

\subsubsection{Tolerable Violation Rates}

The task of keeping violation rates within reasonable bounds implies an ability to determine a "tolerable" or "acceptable" violation rate. Criteria for establishing tolerable violation rates include safety, freeway operations, public attitudes, and practicality. This study and previous research have provided insights into the impact of violations on several of these important criteria.

- $\quad$ Safety. Past studies suggest that it is impossible to correlate accident rates with violation rates on any of California's mainline projects (Billheimer, et al., 1981). Nonetheless, the practice of weaving illegally in and out of a mainline HOV lane creates a direct safety hazard. Unsafe weaving has been and should continue to be the primary focus of officers assigned to HOV lane enforcement.

- Freeway Operations. The practical capacity of a mainline HOV lane is estimated to range between 1500 and 1700 vehicles per hour (Cechini, 1988). On barrierseparated lanes, the limit is close to 1500 vehicles per hour, while some concurrent flow lanes with no physical separation can accommodate 1700 vehicles per hour before performance begins to deteriorate. Most of California's mainline HOV lanes are comfortably below these capacity limits.

- $\quad$ Public Attitudes. Over three-quarters of the drivers surveyed felt that illegal use of Carpool lanes is a problem, although most classify it as a minor problem. This is consistent with findings on earlier studies. Even in the case of unpopular projects such as the Santa Monica Diamond Lanes and Alameda 580, where public sentiment ran high against commuter lanes, drivers recognized violations as a problem. Drivers tend to overestimate violation rates on most mainline projects, and to be insensitive to changes in the $10 \%$ range.

- Practicality. Experience suggest that steady doses of routine enforcement combined with moderate applications of special enforcement can keep mainline HOV lane violation rates in the $5 \%$ to $10 \%$ range. Heavy consistent doses of special enforcement would be necessary to drive violation rates below $5 \%$ on barrier-free mainline lanes, and the difference between $10 \%$ and $5 \%$ would have little effect on freeway performance or driver perceptions.

These considerations have led to the development of a $10 \%$ target level for violation rates on California's mainline HOV rates. Enforcement efforts shall be sufficient to keep violation rates below $10 \%$, unless violation rates are large enough to cause HOV flow levels to exceed 1500 vehicles per hour on a separated lane or 1700 vehicles per hour on a concurrent-flow lane. 


\subsubsection{Program Components}

Proposed program components are summarized in Exhibit 1.13

EXHIBIT 1.13

\section{PROPOSED ENFORCEMENT PROGRAM MAINLINE HOV LANES}

\begin{tabular}{|c|c|c|c|c|c|}
\hline & Annual $\mathrm{Pe}$ & on Hours & & Annual Co & \\
\hline & $\begin{array}{l}\text { Overtime } \\
\text { Hours }\end{array}$ & $\begin{array}{l}\text { Routine } \\
\text { Howrs }\end{array}$ & $\begin{array}{l}\text { Overtime } \\
\text { Cost }\end{array}$ & $\begin{array}{l}\text { Routine } \\
\text { Cost }\end{array}$ & $\begin{array}{l}\text { Total } \\
\text { Cost }\end{array}$ \\
\hline $\begin{array}{l}\text { Marin } 101 \text { (San Rafael) } \\
\text { Marin } 101 \text { (Corte Madera) }\end{array}$ & $\begin{array}{l}1152 \\
1152\end{array}$ & $\begin{array}{r}210 \\
52.5\end{array}$ & $\begin{array}{r}\$ 58,137 \\
58,137\end{array}$ & $\begin{array}{r}\$ 5,074 \\
1,268\end{array}$ & $\begin{array}{r}\$ 63,210 \\
59,405\end{array}$ \\
\hline $\begin{array}{l}\text { Santa Clara } 101 \\
\text { Santa Clara } 237\end{array}$ & $\begin{array}{l}128 \\
256\end{array}$ & $\begin{array}{r}706 \\
662.5\end{array}$ & $\begin{array}{r}5,719 \\
11,439\end{array}$ & $\begin{array}{l}17,057 \\
16,006\end{array}$ & $\begin{array}{l}22,776 \\
27,445\end{array}$ \\
\hline Orange 55 & 192 & 737 & 9,884 & 17,806 & 27,690 \\
\hline Los Angeles 91 & 64 & 150 & 2,860 & 3,624 & 6,484 \\
\hline $\begin{array}{l}\text { San Diego I-15 (Daily) } \\
\text { San Diego I-15 (Special) }\end{array}$ & $\begin{array}{r}2,000 \\
64\end{array}$ & $\begin{array}{l}0 \\
0\end{array}$ & $\begin{array}{r}112,500 \\
2,860\end{array}$ & 8 & $\begin{array}{r}112,500 \\
2,860\end{array}$ \\
\hline San Francisco I-280 & 320 & 74 & 18,000 & 1,788 & 19,788 \\
\hline Orange 1-405 & 256 & 69 & 11,439 & 1,667 & 13,106 \\
\hline $\begin{array}{l}\text { El Monte Busway (Buffer) } \\
\text { El Monte Busway (Barrier) }\end{array}$ & $\begin{array}{r}896 \\
64 \\
\end{array}$ & $\begin{array}{r}731 \\
0\end{array}$ & $\begin{array}{r}40,035 \\
3,230 \\
\end{array}$ & $\begin{array}{r}17,661 \\
0 \\
\end{array}$ & $\begin{array}{r}57,696 \\
3,230 \\
\end{array}$ \\
\hline TOTAL & 6,544 & 3,392 & $\$ 334,238$ & $\$ 81,951$ & $\$ 416,189$ \\
\hline
\end{tabular}

Monitoring. CALTRANS should monitor violation rates on all mainline HOV lanes at least twice yearly. Lane violation rates should be calculated and supplied directly to the captain of the local CHP Area responsible for enforcement. In addition, mainline lanes should be observed if complaints about violators rise markedly at any time or if the CHP plans to change enforcement levels or policies.

Special Enforcement. The following special enforcement programs are recommended for California's mainline HOV lanes during the coming fiscal year. 
Marin 101. Current special enforcement levels on the San Rafael segment of Marin 101 should be cut back to quarterly month-long assignments of three officers during each commute peak. During different months, the Corte Madera segment should be covered by a similar level of quarterly enforcement. To the extent possible, one motor officer should be continuously visible on the median shoulder during evening periods of special enforcement. CALTRANS should examine both HOV segments of Marin 101 to identify locations where the freeway can be widened to provide enforcement areas to protect special enforcement officers.

- Santa Clara 101 Special enforcement activities on Santa Clara 101 should be cut back to twice yearly assignments of a single officer enforcing two days per week, morning and evening, for a period of one month.

- $\quad$ Santa Clara 237. Santa Clara 237 should receive roughly twice the level of special enforcement applied to Santa Clara 101.

Orange 55. Special enforcement activities on OR 55 should be cut back to three officers covering both AM and PM peaks two days per week for two one-month periods each year. One motor officer should be continuously visible in the enforcement area near Katella Avenue. No more than one chase unit should be detailed to respond to violation sightings.

- Los Angeles 91. One officer should be assigned to work the LA 91 enforcement area twice a week for a period of four weeks, twice per year.

- San Diego -15. It is recommended that the CHP continue to assign a single motor officer to patrol I-15 on a daily basis. One additional officer should be assigned to assist the motor officer on two days per week for two different months each year.

- $\quad$ San Francisco 1-280. A single motor officer should be assigned to enforce I280 five days per week for four weeks on a quarterly basis in an attempt to reduce the relatively high violation rates on this lightly used and lightly enforced HOV lane.

- Orange County 1-405. An ongoing program of special enforcement should be established with one officer using the enforcement area during each commute peak twice a week for four weeks four times per year.

EL Monte Busway. Four officers should cover the buffer-separated segment of the busway during the morning peak two days each week for a month four times each year. This level of special enforcement can be reduced to three officers during the evening peak. Violations in the barrier-separated section are negligible and can be enforced by having one of the officers from the East Los Angeles Area drive through the busway at random times once in the morning.

Routine Enforcement. The proposed levels of special enforcement generally represent cutbacks in current special enforcement activities. This is possible because the levels of routine enforcement on most of California's mainline HOV lanes have been high enough to keep violation rates below $10 \%$. If the proposed special enforcement program is to succeed, it is essential that current levels of routine enforcement be maintained on all contiguous mainline HOV lanes. 


\subsubsection{Enforcement Costs}

Overtime Component. CHP personnel at all levels felt that special enforcement activities should be undertaken by officers on overtime assignments. The current costs of the four hours of overtime enforcement needed to cover a single peak commute period are $\$ 167.16$ for a traffic officer and $\$ 225.00$ for a motor officer. These costs bring the total overtime cost of the proposed program to $\$ 334,238$. Roughly $\$ 112,500$ of this amount is consumed by the dedicated enforcement requirements of San Diego I-15.

Routine Costs. At 1988 levels, the marginal cost of routine enforcement of California's contiguous mainline HOV lanes ranges from $\$ 1700$ on San Francisco I-280 to nearly $\$ 18,000$ on Orange 55 and the El Monte Busway (see Exhibit 1.13). The total marginal cost of routine enforcement is estimated to be $\$ 82,000$ per year.

Total Costs. Adding the marginal cost of routine to the estimated cost of the proposed special enforcement program brings the annual cost of enforcing California's mainline HOV lanes to $\$ 416,000$.

\subsection{ADDITIONAL CONCERNS}

\subsubsection{Innovative Enforcement Practices}

Mail-Out Warnings/Citations. Mailed warnings based on license plate observations have been used with reported success in enforcing HOV lanes on the San Francisco/Oakland Bay Bridge and on Interstate- 5 in Seattle. The impact of mailed warnings on HOV violations was not tested in the current study since such testing raised legal and public relations issues that were beyond the scope of the study. The possibility of mailed warnings based on electronic surveillance generated heated debates in focus group discussions, with half of the groups strongly opposing the concept.

Electronic Surveillance. It is possible that a videotape of HOV lane activities could provide more accurate violation counts, create a permanent record of violations, document the identity of violators, and supply a basis for mail-out warnings. To investigate this possibility, the current study has been extended to test both the feasibility and accuracy of video equipment in determining vehicle occupancy, documenting violator identity, and guiding HOV lane 
enforcement. The results of this additional investigation will be documented in a separate report to be prepared approximately six months after the completion of the current study.

Enforcement Implications. While innovative approaches to enforcement may reduce the need for special enforcement on mainline HOV lanes in the future, the existing high levels of routine enforcement are not likely to change. Beat officers should continue to pursue HOV violators passing them on the freeway, and an ongoing enforcement presence will be essential to the success of any future system of surveillance and mailed warnings. Hence the future possibility of innovative enforcement practices will not affect the need to incorporate enforcement aids such as refuge areas in current HOV lane designs. Refuge areas increase enforcement efficiency, provide officer protection and serve as a constant reminder of the enforcement presence.

\subsubsection{Additlonal Recommendations}

Improved Reporting In reviewing the historical records of most CHP areas, it was impossible to distinguish between 21655.5 citations issued to violators on mainline HOV lanes and citations issued to ramp violators along the same beat. To eliminate this problem, it was recommended that the CHP assign separate beat numbers to mainline HOV lanes throughout the state. This recommendation has already been adopted by the CHP.

Additional Research. CALTRANS and the CHP should consider exploring two additional areas of research into HOV lane enforcement.

(1) In the event that electronic surveillance of mainline HOV lanes proves to be feasible and documents violator identity with sufficient accuracy to support mail-out warnings, the impact of mailing warnings on violation rates should be field-tested through a program of public education, controlled enforcement, and follow-up surveys.

(2) In view of the increase in ramp meter bypass lanes throughout the state since 1981, and the current lack of information concerning violation rates on many of these lanes, the 1981 study of bypass lane enforcement should be reviewed and updated. HOV lanes on bridges should be investigated at the same time.

(3) As longer mainline HOV lanes come into use in California, the results of the current study should be reviewed in the light of actual experience with lanes more than 12 miles long. 


\subsection{INTRODUCTION}

\subsection{BACKGROUND}

In recent years, the growth of suburban populations and commuter travel has outstripped the growth of freeway capacity, causing increased traffic congestion in California's major metropolitan areas. Because both funds and space for additional freeway construction are severely limited, this imbalance is expected to continue in the foreseeable future. In an attempt to make California's freeways operate more efficiently, the California Department of Transportation (CALTRANS) has introduced a number of High Occupancy Vehicle (HOV) Lanes designed to give ridesharing vehicles an advantage over the single-occupant vehicle.

A number of factors have arisen to frustrate efforts to enforce the traffic laws associated with HOV lanes. As listed in a previous SYSTAN report, these factors include "...personnel constraints, enforcement priorities, public hostility toward certain preferential treatment projects,...confusion over new traffic concepts, and physical limitations imposed by the geometric and engineering features of specific projects." (Billheimer, et al., 1981).

The cited SYSTAN study documented the relationship between enforcement and violations on California HOV lanes in the early 1980's, developed specific guidelines for enforcing HOV bypass lanes on metered freeway ramps, and proposed more general guidance for enforcing mainline HOV lanes. Since the earlier SYSTAN study of HOV violation rates was completed, the number of mainline HOV projects in California has nearly doubled, as has the mileage devoted to these projects. More projects are scheduled to open in the near future, and recent Federal and State policy statements have placed increased emphasis on the implementation of HOV lanes.

As the number of mainline HOV projects has increased in California, the incidence of violations has increased as well. In early 1988, violation rates on California's mainline lanes ranged from $5 \%$ to $32 \%$. Lack of motorist compliance with the spirit and letter of the laws accompanying HOV strategies can lead to reduced freeway efficiency, increased accident levels, heightened public disaffection with the strategies themselves and, possibly, a contagious disregard for other traffic laws as well. As more and more HOV strategies are introduced in an attempt to improve freeway operations, the available enforcement personnel will be stretched thinner and thinner, and the violation problem is likely to become more acute. 
Because of the increase in the number and type of HOV lanes, CALTRANS and the CHP have initiated a joint research project designed to evaluate the effect of different enforcement measures and engineering features on violation rates in HOV lanes. SYSTAN, Inc. has contracted with CALTRANS (Contract No. 55 G710) to undertake this year-long research project. This final report documents the impact of different engineering designs and enforcement strategies on HOV violation rates, and recommends future engineering approaches and enforcement programs designed to reduce these rates.

\subsection{OBJECTIVES}

The general objective of the current study has been to investigate the engineering features, enforcement procedures, and public attitudes associated with mainline HOV lanes with the aim of identifying those factors which contribute to violation rates and developing countermeasures to reduce these rates.

This general objective can be broken down into a number of specific objectives. As stipulated by CALTRANS and the CHP, these specific objectives have been to:

1. Identify the nature and pattern of HOV lane violations, including vehicle occupancy and, where applicable, buffer violations.

2. Determine public attitudes toward HOV lane violations and public understanding of proper HOV lane use, and recommend measures to deal with public attitudes or misunderstandings,

3. Determine what engineering modifications and design features would most contribute to reductions in violations and facilitate enforcement. This includes enforcement refuge areas, signing, striping, and geometrics.

4. Test various enforcement strategies to identify enforcement measures which would efficiently and effectively reduce HOV lane and buffer violations.

5. Establish a basis for determining CHP personnel requirements for enforcing present and future HOV lane facilities and develop a formula for overtime CHP personnel hours needed for future HOV projects.

\subsection{KEY ISSUES}

This study has been designed to provide CALTRANS with a framework for future HOVlane design decisions, and the California Highway Patrol (CHP) with a basis for planning the 
strategies and personnel assignments needed to enforce present and future HOV lane projects. To accomplish this, it has been necessary to document and quantify a number of relationships between key variables, including:

- The relationship between enforcement strategies, personnel levels, and violation rates;

The impact of geometric and engineering design considerations (i.e., refuge areas, buffer lanes, access restrictions, signing, striping, operating hours, and carpool definitions) on violation rates and enforcement efficiency;

- The relationship of such operational considerations as speed differentials and past violation history to current violation rates;

- The relationship between public information, public understanding, public attitudes, public acceptance, and violation rates; and

- The impact of violations and enforcement on freeway operations.

\subsection{STUDY OVERVIEW}

To document the relationships between these key variables, SYSTAN developed a detailed plan (SYSTAN, 1988) for a year-long study. The year-long study was divided into a threemonth review period, two four-month enforcement waves, and a one-month reporting period. The study consisted of five distinct tasks:

Task 1. Review Existing Data and Background Studies;

Task 2. Observe and Evaluate Violations;

Task 3. Conduct License Plate Surveys;

Task 4. Analyze All Data; and

Task 5. Prepare Final Report.

Exhibit 2.1 shows the timing of each of these tasks and maps the interrelationships linking individual task elements. The content of the individual tasks is summarized below. 


\section{MONTHS FROM START OF STUDY}

\begin{tabular}{|l|l|l|l|l|l|l|l|l|l|l|l|l|}
\hline JUNE '88 & JULY & AUG & SEPT & OCT & NOV & DEC & JAN '89 & FEB & MAR & APRIL & MAY & JUNE \\
\hline
\end{tabular}

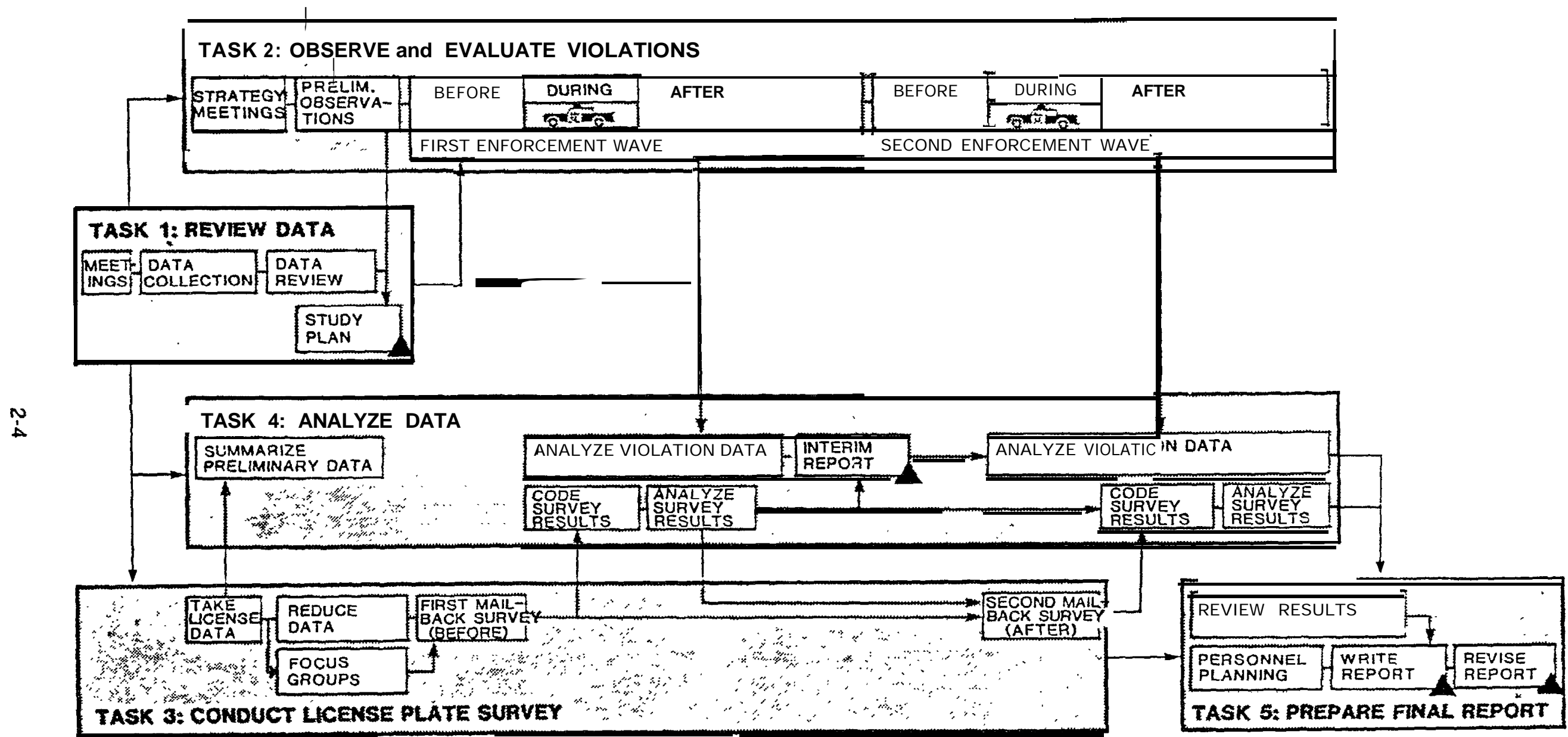

EXHIBIT 21

TASK INTERRELATIONSHIPS

A Indicates deliverable report 


\subsubsection{Task 1. Review Existing Data and Background Studies}

In this task, available data were assembled documenting design features, traffic levels, operating statistics, and enforcement data for ail mainline HOV lanes currently operating in California. CALTRANS and CHP personnel were interviewed to obtain qualitative insights into the operations of each project, and the data from earlier studies of HOV violation rates (i.e. Billheimer, et al., 1981) were reviewed and summarized to provide historical perspective. This review process led to the development of a detailed Study Plan (SYSTAN, 1988) that documented data collection and analysis procedures, defined qualitative measures of effectiveness, and related these measures to established objectives. Exhibit 2.2 provides an overview of the data collection process established in the plan.

\subsubsection{Task 2. Observe and Evaluate Vioiations}

Two waves of data collection and special enforcement were undertaken on four mainline HOV lanes which were operating at the start of the study, as well as two facilities which were opened as the study progressed.

Special Study Projects. Enforcement strategies were tested on four operating HOV lanes:

Orange 55 (OR 55);

Los Angeles 91 (LA 91);

Marin 101; and

Santa Clara 101 (SC 101).

in addition, with the assistance of CALTRANS, SYSTAN monitored start-up strategies on two new mainline projects:

interstate 15 in San Diego (which opened in October 1988); and interstate 405 in Orange County (which opened in January 1989). 


\section{EXHIBIT 2.2}

\section{OVERVIEW OF DATA COLLECTION ACTIVITIES}

\begin{tabular}{|l|}
\hline SETTING \\
CHARACTEAISTICS \\
\hline$\frac{\text { COCUMENT }}{- \text { COMMUTE PATtERHS }}$ \\
$\frac{\text { MONITOR }}{- \text { - MEOIA COVERAGE }}$ \\
\hline
\end{tabular}

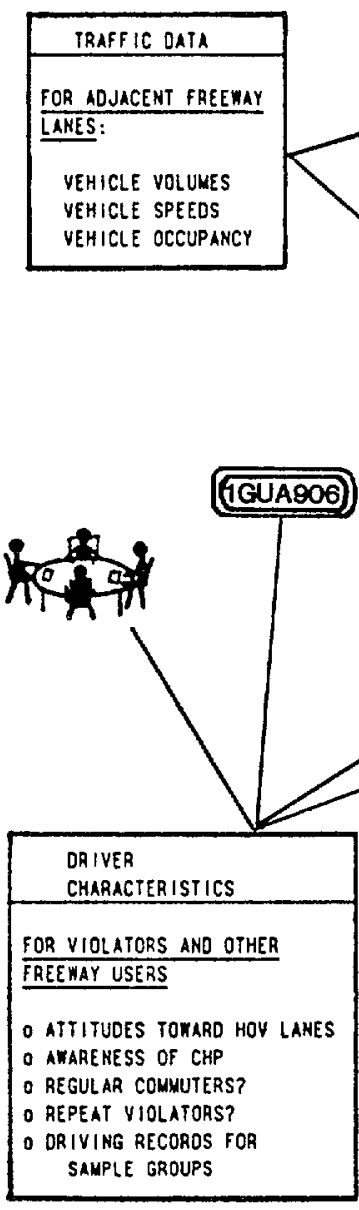

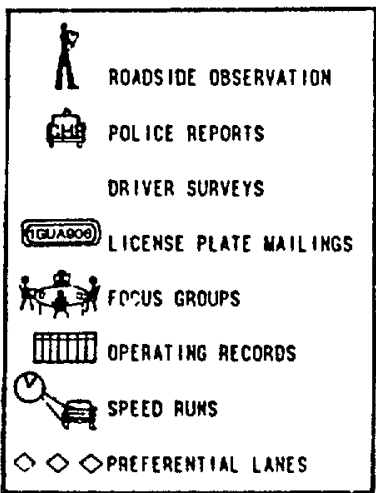

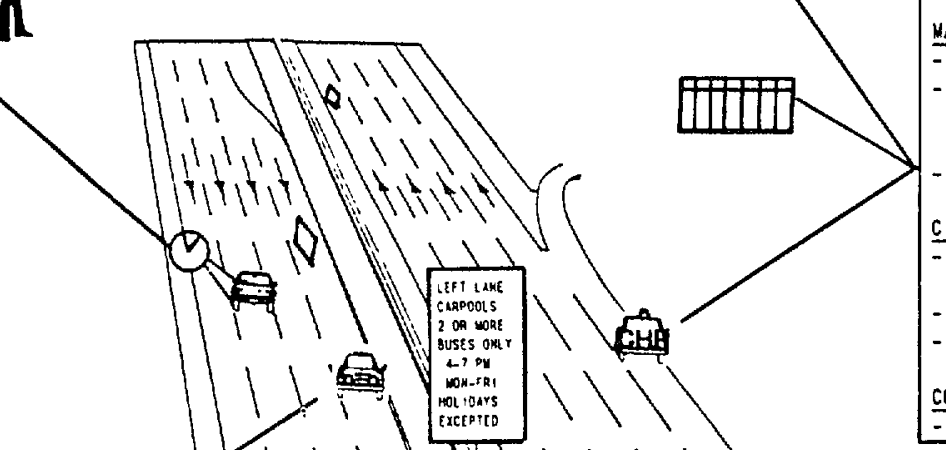

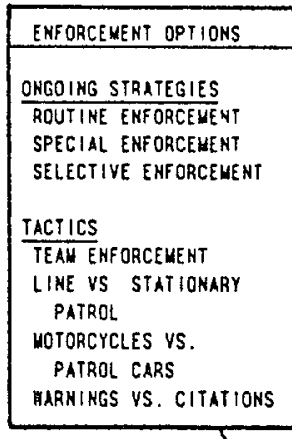

ONOOING STRXTEGIES

SPECIAL ENFORCEHENT

TACTICS

TEAM ENFORCEMENT

NE VS STATIONARY

HARMINOS VS. CITATIONS

MANPOWEA

- ROUTINE BEAT ASSIGMUENTS

- level, location aho DURATION OF SELECTIVE

EMFORCEMENT - ASSIGHMENT RULES

CITATIONS

- TABULATION BY TIME OF DAY BY PROJECT - DISPOSITION SAMPLE - aVERaGe fine COMPLAINTS - RECORDS 
Data Collection Patterns. Each wave of collection/enforcement activity lasted four months to accommodate the need for "before" data collection (one month), special enforcement activity (one month), and post-enforcement measurements (two months). Particular attention was paid to the behavior of motorists after special enforcement had ceased, to determine the residual effect of special enforcement in deterring violators. A typical pattern of field observations for a specific enforcement wave is shown in Exhibit 2.3.

\section{AM PEAK ENFORCEMENT ROADSIDE OBSERVATIONS Location 1 \\ Location 2}

PM PEAK

ENFORCEMENT

ROADSIDE OBSERVATIONS Location 1 Location 2

EXHIBIT 2.3 PATTERN OF FIELD OBSERVATIONS

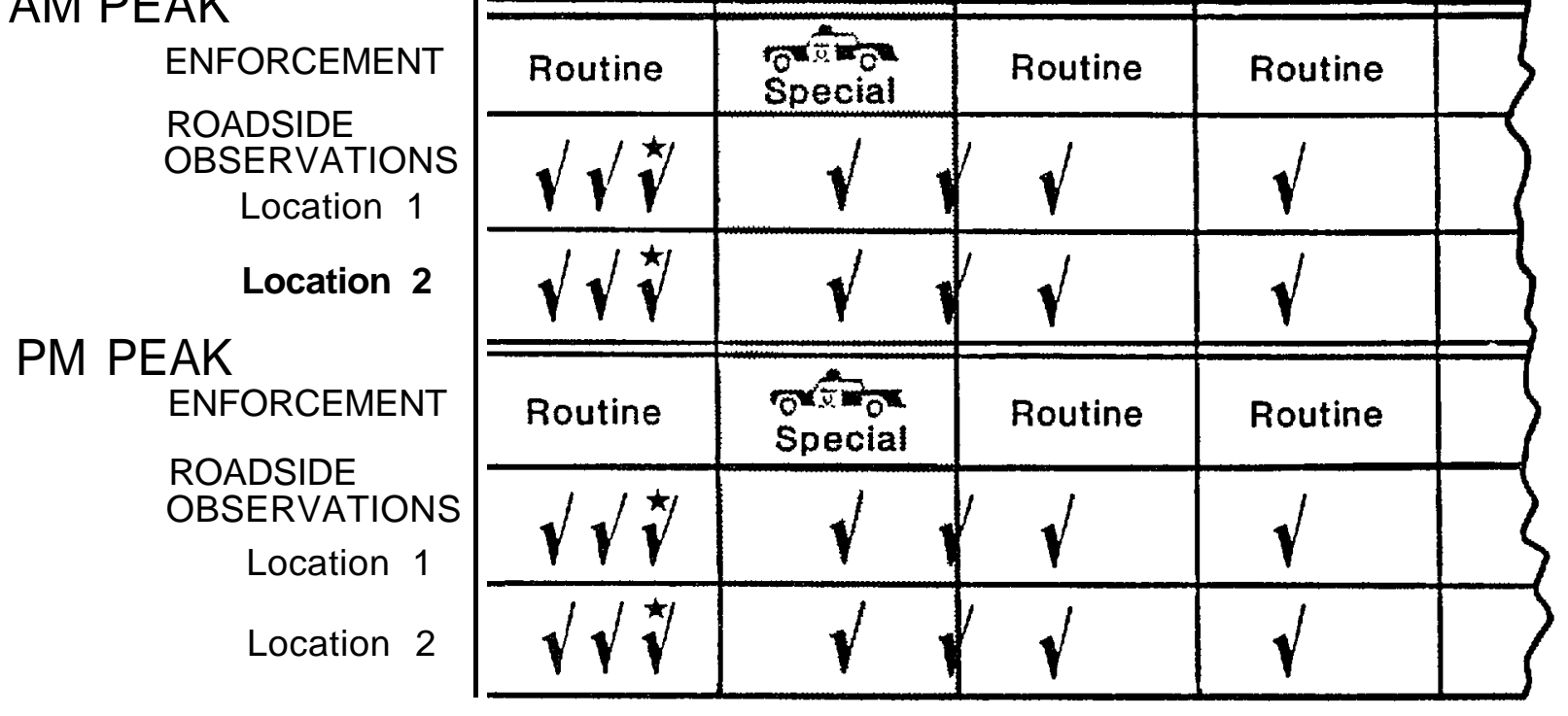

${ }^{*}$ As needed

In assembling data on the study projects, traditional procedures for documenting violations were enhanced in several ways: both occupancy and buffer violations were observed on study projects in Southern California; roadside observations were summarized at five-minute intervals; violations were also sampled from the viewpoint of law-abiding drivers in adjacent mixedflow lanes; the speed of mixed flow traffic was regularly sampled in the vicinity of the roadside observation points; and violations were sampled at two different locations along OR 55. 


\subsubsection{Task 3. Conduct License Plate Surveys}

Mail-Back Surveys. In order to document public attitudes toward HOV lanes, enforcement, and violations, two mail-back license plate surveys were conducted. Each mail-back survey produced a total of approximately 1,200 completed surveys from violators, carpoolers, and single-occupant drivers on four different HOV projects. The first mail-back survey was conducted before any special enforcement had taken place on three sample freeways, while the second survey was scheduled at the end of the second wave of special enforcement in an attempt to document drivers' awareness of enforcement activities.

Focus Group Discussions. The mail-back surveys were augmented with a series of focus group discussions designed to provide firsthand, in-depth responses to key issues regarding the design and enforcement of HOV lanes. Six discussion groups were held with a sampling of drivers from the four test freeways before any special enforcement had taken place.

\subsubsection{Task 4. Analyze All Data}

Data from roadside observations and license plate surveys have been analyzed and combined with the results of focus group discussions and interviews with CALTRANS and CHP personnel to produce recommendations regarding the enforcement measures, personnel levels, and engineering design features needed to control violation rates on California's mainline HOV lanes. In addition to determining what happens when enforcement levels are changed, or specific engineering features are tested, the analysis has explored the underlying causes of the observed results. Violation rates have been correlated with such contributing factors as the time saved by violators, perceived and calculated risks of apprehension, CHP deployment levels and measured citation rates.

\subsubsection{Task 5. Prepare Final Report}

This final report outlines data collection procedures, summarizes the operations of mainline HOV lanes (Chapter 3); analyzes the results of routine and special enforcement activities (Chapter 4); discusses various design options (Chapter 5); documents the findings of focus 
group discussions and mail-back surveys (Chapter 6); and recommends enforcement approaches, staffing requirements, and engineering features for mainline HOV lanes (Chapter 7). Special appendices summarize design and enforcement guidelines for planners and enforcement personnel.

\subsection{MANAGEMENT STRUCTURE}

The management organization for the study is diagrammed in Exhibit 2.4.

\subsubsection{Steering Committee}

A steering committee comprised of representatives from CALTRANS, the CHP, and the FHWA has been responsible for providing overall project guidance. Members of the steering committee have included:

Mr. Robert Anderson

CALTRANS District 4 (San Francisco)

Mr. Glen Clinton

FHWA

Mr. Philip Jang

CALTRANS (Sacramento)

Lt. Ron Phulps

CHP (Sacramento)
Mr. Ron Klusza

CALTRANS District 7 (Los Angeles)

Mr. Scott McGowen

CALTRANS (Sacramento)

Asst. Chief N.K. Newman

CHP Border Division

Lt. Shawn Watts

CHP (Sacramento)

\subsubsection{Study Team}

SYSTAN's study team contains many of the same personnel which accomplished the firm's previous investigation of HOV Violation Rates (Billheimer, et al., 1981). As on the previous study, Dr. John Billheimer of SYSTAN acted as project leader and principal investigator. Mr. Jesse Glazer of Crain \& Associates' Los Angeles office coordinated project activities on Southern California HOV Lanes. Mr. Kevin Fehon of DKS Associates coordinated data collection activities on HOV projects in Northern California. The block diagram of Exhibit 2.4 outlines the organizational responsibilities for the proposed study and identifies key personnel to be assigned to each element of the work. 


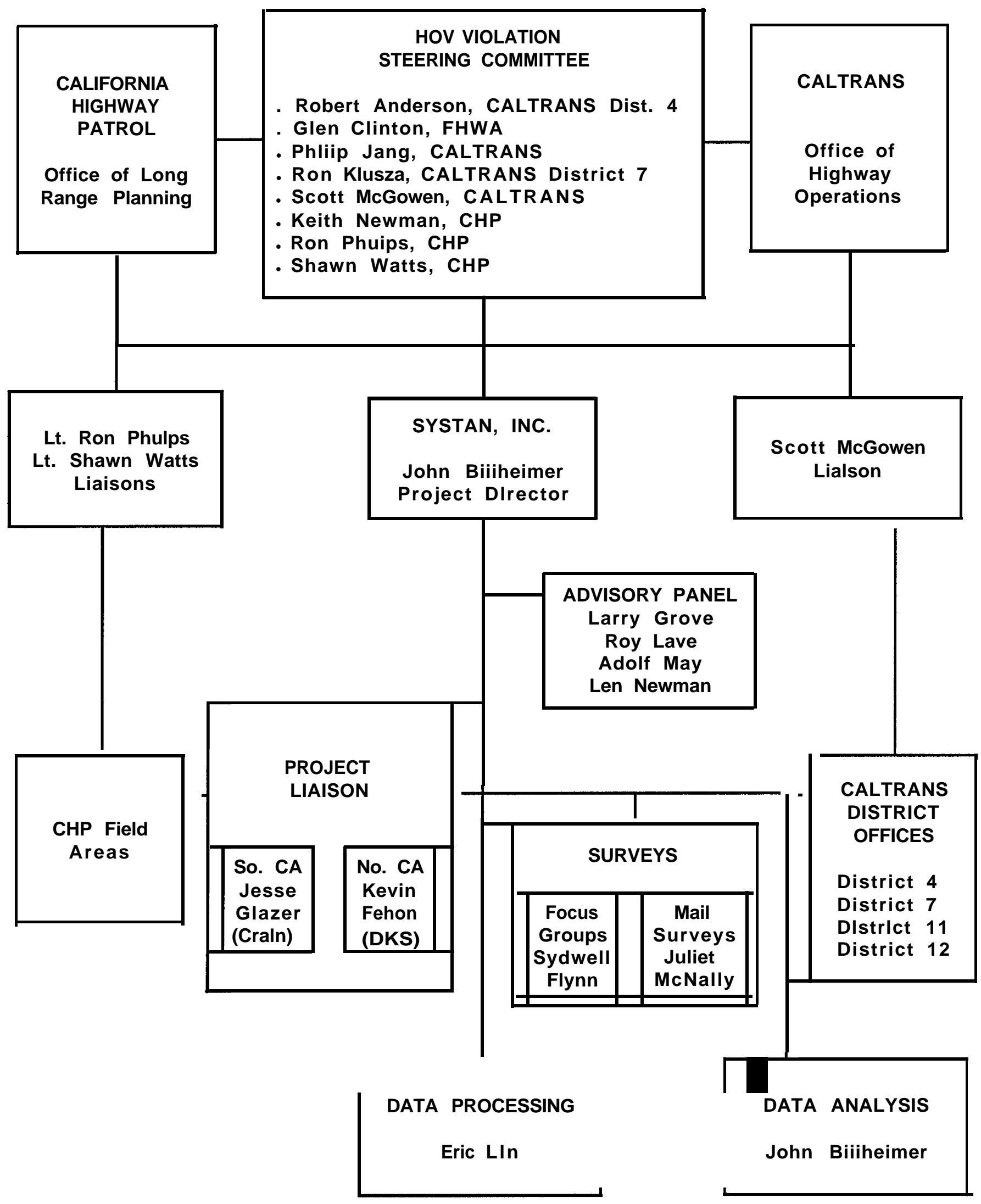

EXHIBIT 2.4 MANAGEMENT ORGANIZATION 


\subsection{MAINLINE HOV LANES}

This chapter reviews the historical performance of California's mainline HOV lanes in the light of the design and enforcement options tested during the current study. Violation rates and citation levels existing prior to the study are documented, and the impacts of speed differentials and operating hours on violations are discussed.

\subsection{OVERVIEW}

Exhibits 3.1 and 3.2 summarize design, operations, and enforcement data for California's mainline HOV lanes. For purposes of the exhibits, mainline HOV lanes have been divided into three main categories:

(1) Lanes operating at the start of the current study (June, 1988);

(2) Lanes which have operated in the past; and

(3) Lanes scheduled to open during the span of the study (June 1988-June 1989).

Exhibit 3.1 lists such operating characteristics as time savings, HOV lane volumes, peak period violations, and violation rates. Exhibit 3.2 contains such design characteristics as length, buffer separation, access restrictions, Carpool definitions, and operating hours, as well as historical citation rates.

\subsubsection{Violation Rates}

Definitions. The violation data of Exhibit 3.1 are expressed two ways: (1) Lane violation rates that document the percentage of vehicles in the HOV lane that are using the lane illegally, and (2) Freeway violation rates expressing the number of violators as a percentage of all vehicles using the facility. Precise definitions of these and other terms used in Exhibits 3.1 and 3.2 can be found in the Glossary of Appendix B. Exhibit 3.1 shows that the historical lane violation rates on California's mainline $\mathrm{HOV}$ lanes ranged from $4 \%$ to $34.6 \%$ at the start of the current study. The lane violation rate was lowest (3\% to $7 \%$ ) on the physically separated right-ofway at the western end of the San Bernardino Freeway. Lane violation rates were highest (34.6\%) during the afternoon commute along the section of Marin 101 opened in 1976. 
EXHIBIT 3.1

OPERATING CHARACTERISTICS

MAINLINE HOV LANES IN CALIFORNIA

Before Current Project

\begin{tabular}{|c|c|c|c|c|c|c|c|c|c|}
\hline \multirow[t]{2}{*}{ Mainline HOV Lane } & \multirow[t]{2}{*}{$\begin{array}{l}\text { Direction } \\
\text { Time }\end{array}$} & \multirow[t]{2}{*}{$\begin{array}{l}\text { Data } \\
\text { Year }\end{array}$} & \multirow[t]{2}{*}{$\begin{array}{c}\text { Carpool } \\
\text { Definition }\end{array}$} & \multicolumn{2}{|c|}{$\begin{array}{l}\text { Avg. Time } \\
\text { Savingls } \\
\text { (miin.) }\end{array}$} & \multirow[t]{2}{*}{$\begin{array}{c}\text { Avg. HOV } \\
\text { Lane Volume } \\
\text { (veh./peak hr.) }\end{array}$} & \multirow[t]{2}{*}{$\begin{array}{l}\text { HOV Lane } \\
\text { Violations } \\
\text { (peak period) }\end{array}$} & \multicolumn{2}{|c|}{$\begin{array}{c}\text { Violation } \\
\text { Rate } \\
(\%)\end{array}$} \\
\hline & & & & Peak Period & Peak Hour & & & Lane & Freeway \\
\hline EXISTING LANES & & & & & & & & & \\
\hline - $\quad$ Marin 101 (south) & $\begin{array}{l}\text { SB/AM } \\
\text { NB/PM }\end{array}$ & $\begin{array}{l}1988 \\
1988\end{array}$ & $\begin{array}{l}3+ \\
3+\end{array}$ & $\begin{array}{l}1.3 \\
1.6\end{array}$ & $\begin{array}{l}6.1 \\
4.8\end{array}$ & $\begin{array}{l}343 \\
381\end{array}$ & $\begin{array}{l}146 \\
245\end{array}$ & $\begin{array}{l}25.8 \\
34.8\end{array}$ & $\begin{array}{l}1.4 \\
1.8\end{array}$ \\
\hline . Marin 101 (north) & $\begin{array}{l}\text { SB/AM } \\
\text { NB/PM }\end{array}$ & $\begin{array}{l}1988 \\
1988\end{array}$ & $\begin{array}{l}3+ \\
3+\end{array}$ & $\begin{array}{l}4.0 \\
2.9\end{array}$ & $\begin{array}{l}6.0 \\
5.0\end{array}$ & $\begin{array}{l}273 \\
266\end{array}$ & $\begin{array}{r}99 \\
231\end{array}$ & $\begin{array}{l}26.8 \\
32.6\end{array}$ & $\begin{array}{l}1.6 \\
1.7\end{array}$ \\
\hline - Santa Clara 101 & $\begin{array}{l}\text { NB/AM } \\
\text { SB/PM }\end{array}$ & $\begin{array}{l}1987 \\
1987\end{array}$ & $\begin{array}{l}2+, . M / C O K \\
2+, M / C O K\end{array}$ & $\begin{array}{l}3.7 \\
3.2\end{array}$ & $\begin{array}{l}4.8 \\
6.3\end{array}$ & $\begin{array}{l}711 \\
970\end{array}$ & $\begin{array}{l}418 \\
365\end{array}$ & $\begin{array}{l}24.3 \\
17.3\end{array}$ & $\begin{array}{l}2.3 \\
2.3\end{array}$ \\
\hline Santa Clara 237 & $\begin{array}{l}\text { WB/AM } \\
\text { EB/PM }\end{array}$ & $\begin{array}{l}1988 \\
1988\end{array}$ & $\begin{array}{l}2+, M / C O K \\
2+, M / C O K\end{array}$ & $\begin{array}{l}2.4 \\
3.7\end{array}$ & $\begin{array}{l}4.4 \\
7.2\end{array}$ & $\begin{array}{c}1088 \\
892\end{array}$ & $\begin{array}{l}149 \\
241\end{array}$ & $\begin{array}{l}5.8 \\
9.6\end{array}$ & $\begin{array}{l}1.3 \\
2.4\end{array}$ \\
\hline San Francisco 280 & SB/PM & 1986 & $3+$ & $\mathrm{cl}$ & 2.5 & 271 & 108 & 31.5 & 1.1 \\
\hline $\begin{array}{l}\text { LA } 10 \text { (EI Monte } \\
\text { Busway/West) }\end{array}$ & $\begin{array}{l}\text { WB/AM } \\
\text { EB/PM }\end{array}$ & $\begin{array}{l}1981 \\
1981\end{array}$ & $\begin{array}{l}3+ \\
3+\end{array}$ & $\cdots$ & $\begin{array}{l}-\cdot \\
-\end{array}$ & $\begin{array}{l}895 \\
531\end{array}$ & $\begin{array}{r}114 \\
30\end{array}$ & $\begin{array}{l}6.6 \\
2.7\end{array}$ & $\begin{array}{l}\cdots \\
-\end{array}$ \\
\hline $\begin{array}{l}\text { LA } 10 \text { (EI Monte } \\
\text { Busway/East) }\end{array}$ & $\begin{array}{l}\text { WB/AM } \\
\text { EB/PM }\end{array}$ & $\begin{array}{l}1988 \\
1988\end{array}$ & $\begin{array}{l}3+ \\
3+\end{array}$ & $\begin{array}{r}13.3 \\
9.3\end{array}$ & $\begin{array}{l}\cdots \\
\cdots\end{array}$ & $\begin{array}{l}1215 \\
1188\end{array}$ & $\begin{array}{l}331 \\
241\end{array}$ & $\begin{array}{l}14.9 \\
11.9\end{array}$ & $\begin{array}{l}1.8 \\
1.5\end{array}$ \\
\hline . $\quad$ Los Angeles 91 & $\mathrm{~EB} / \mathrm{PM}$ & 1988 & $2+$ & 3.3 & 9.0 & 1384 & 160 & 7.8 & 1.0 \\
\hline . $\quad$ Orange 55 & $\begin{array}{l}\text { SB/AM } \\
\text { NB/PM }\end{array}$ & $\begin{array}{l}1988 \\
1988\end{array}$ & $\begin{array}{l}2+, M / C O K \\
2+, M C O K\end{array}$ & $\begin{array}{l}4.7 \\
3.7\end{array}$ & $\begin{array}{c}11.4 \\
8.9\end{array}$ & $\begin{array}{l}1300 \\
1500\end{array}$ & $\begin{array}{l}282 \\
214\end{array}$ & $\begin{array}{l}7.2 \\
7.4\end{array}$ & $\begin{array}{l}1.2 \\
1.8\end{array}$ \\
\hline PAST LANES & & & & & & & & & \\
\hline $\begin{array}{ll}\cdot & \text { LA } 10 \\
& \text { (Santa Monica) }\end{array}$ & $\begin{array}{l}\text { EB/AM } \\
\text { WB/PM }\end{array}$ & $\begin{array}{l}1976 \\
1976\end{array}$ & $\begin{array}{l}3+ \\
3+\end{array}$ & $\begin{array}{l}5.5 \\
6.3\end{array}$ & $\begin{array}{l}11.6 \\
12.2\end{array}$ & $\begin{array}{l}403 \\
458\end{array}$ & $\begin{array}{l}100 \\
348\end{array}$ & $\begin{array}{l}12.6 \\
19.0\end{array}$ & $\begin{array}{l}0.9 \\
1.3\end{array}$ \\
\hline - Alameda 580 & $\begin{array}{l}\text { WB/AM } \\
\text { EB/PM }\end{array}$ & $\begin{array}{l}1980 \\
1980\end{array}$ & $\begin{array}{l}3+ \\
3+\end{array}$ & $\begin{array}{l}1.5 \\
1.5\end{array}$ & -- & $\begin{array}{l}197 \\
219\end{array}$ & $\begin{array}{l}151 \\
138\end{array}$ & $\begin{array}{l}28.5 \\
32.7\end{array}$ & $\begin{array}{l}1.9 \\
2.2\end{array}$ \\
\hline
\end{tabular}


EXHIBIT 3.2

DESIGN CHARACTERISTICS AND CITATION RATES

MAINLINE HOV LANES IN CALIFORNIA

Before Current Project

\begin{tabular}{|c|c|c|c|c|c|c|c|c|}
\hline Mainline HOV Lane & $\begin{array}{l}\text { Length } \\
(\mathrm{mile} \mathrm{s})\end{array}$ & $\begin{array}{l}\text { Median } \\
\text { Shoulder } \\
\text { (width-ft.) }\end{array}$ & $\begin{array}{c}\text { Buffer } \\
\text { Separation }\end{array}$ & $\begin{array}{c}\text { Access } \\
\text { Unlimited? }\end{array}$ & $\begin{array}{l}\text { Carpool } \\
\text { Definition }\end{array}$ & $\begin{array}{l}\text { Operating } \\
\text { Hours }\end{array}$ & $\begin{array}{c}\text { Citation } \\
\text { Rate } \\
\text { (Cites/Day) } \\
\end{array}$ & $\begin{array}{c}\text { Apprehension } \\
\text { Rate } \\
\% \text { Violators Cited) }\end{array}$ \\
\hline \multicolumn{9}{|l|}{ EXISTING LANES } \\
\hline - Marin 101 (south) & 3.7 & $2^{\prime}$ to $5^{\prime}$ & Stripe & Yes & $3+\quad * *$ & $\begin{array}{l}0630-0830 \\
1630-1900\end{array}$ & 2.5 & $0.7 \%$ \\
\hline Marin 101 (north) & 3.0 & $2^{\prime}$ to $5^{\prime}$ & Stripe & Yes & $3+\quad * *$ & $\begin{array}{l}0630-1830 \\
1630-1900\end{array}$ & 7.5 & $2.3 \%$ \\
\hline - Santa Clara 101 & 3.0 & $11^{\prime}$ & Stripe & Yes & $2+, \mathrm{M} / \mathrm{C} \mathrm{OK}$ & $\begin{array}{l}0500-0900 \\
1500-1900\end{array}$ & $19.9+$ & $2.5 \%{ }^{* \star *}$ \\
\hline · $\quad$ Santa Clara 237 & 4.0 & - & Stripe & Yes & $2+, \mathrm{M} / \mathrm{C} \mathrm{OK}$ & $\begin{array}{l}0500-0900 \\
1500-1900\end{array}$ & 10.6 & $2.7 \%$ \\
\hline - $\quad$ San Francisco 280 & 1.9 & -- & Stripe & Yes & $3+$ & 24/day & 1.3 & $1.2 \%$ \\
\hline $\begin{array}{l}\text { - LA } 10 \text { (El Monte } \\
\text { Busway/West) }\end{array}$ & 4.0 & $10^{\prime}$ & $\begin{array}{l}\text { Concrete } \\
\text { Barrier }\end{array}$ & No & $3+$ & 24/day & $13.7+$ & $9.5 \% \%^{* * *}$ \\
\hline $\begin{array}{l}\text { LA } 10 \text { (El Monte } \\
\text { Busway/East) }\end{array}$ & 7.0 & 3 & 13' Buffer & No & $3+$ & 24/day & $9.7+$ & $1.7 \% \%^{\star \star \star}$ \\
\hline . $\quad$ Los Angeles 91 & 8.0 & $3 *$ & 2' Stripe & No & $2+$ & 24/day & $4.5+$ & $2.8 \% * * *$ \\
\hline - Orange 55 & 11.0 & $3^{\prime} *$ & 1' Stripe & No & $2+, \mathrm{M} / \mathrm{C} \mathrm{OK}$ & 24/day & 13.8 & $2.6 \%$ \\
\hline \multicolumn{9}{|l|}{ PAST LANES } \\
\hline $\begin{array}{l}\text { LA } 10 \\
\text { (Santa Monica) }\end{array}$ & 12.0 & $12^{\prime}$ & Stripe & Yes & $3+$ & $\begin{array}{l}0630-0930 \\
1500-1900\end{array}$ & 55 & $6.6 \%$ \\
\hline - Alameda 580 & 3.5 & $3.5^{\prime}$ & 8' Buffer & $\mathrm{NC}$ & $3+$ & 0600M-180OF & 4.1 & $1.4 \%$ \\
\hline \multicolumn{9}{|l|}{ FUTURE LANES } \\
\hline - $\quad$ I-405 (Orange Co.) & 5.0 & $--^{*}$ & Stripe & No & $2+$ & 24/day & NA & NA \\
\hline . $\quad$ I-15 (San Diego) & 8.0 & $10.8^{\prime}$ & $\begin{array}{l}\text { Concrete } \\
\text { Barrier }\end{array}$ & No & $2+, \mathrm{M} / \mathrm{C} \mathrm{OK}$ & $\begin{array}{l}0600-0900 \\
1500-1800\end{array}$ & NA & NA \\
\hline
\end{tabular}

*Median contains single enforcement area.

${ }^{* *}$ Changes to 2+ October 3, 1988.

${ }^{\star * \star}$ Maximum Rate (includes unknown number of ramp citations). 
Because lane violation rates depend on the number of ridesharing vehicles using the lane, as well as on the number of violators, these rates vary considerably from project to project. There is less variation in overall freeway violation rates, which range from $1 \%$ of all vehicles using Los Angeles Route 91 to $2.4 \%$ of all the vehicles using State Route 237 in Santa Clara County. Thus violators comprise a relatively low percentage of all the drivers using the freeways served by California's commuter lanes.

Combined Rates. Historical violation statistics for existing mainline lanes are plotted in Exhibit 3.3. This exhibit plots the combined number of violators during the morning and evening peaks, and expresses these violations as a percentage both of the total number of vehicles in the HOV lane (lane violation rate) and of the total number of vehicles using the freeway during the peak period (freeway violation rate). Freeways in Exhibit 3.3 are arranged in order of increasing lane violation rates (AM and PM combined). The combined lane violation rate was lowest $(4 \%)$ on the physically separated right-of-way at the western end of the El Monte Busway. Combined lane violation rates were highest $(31.5 \%)$ along the lightly enforced section of $1-280$ south of San Francisco. The average number of peak period violations was lowest ( 72 per peak period) on the El Monte Busway and highest (392 per peak period) on Santa Clara 101.

EXHIBIT 3.3

PEAK PERIOD VIOLATIONS

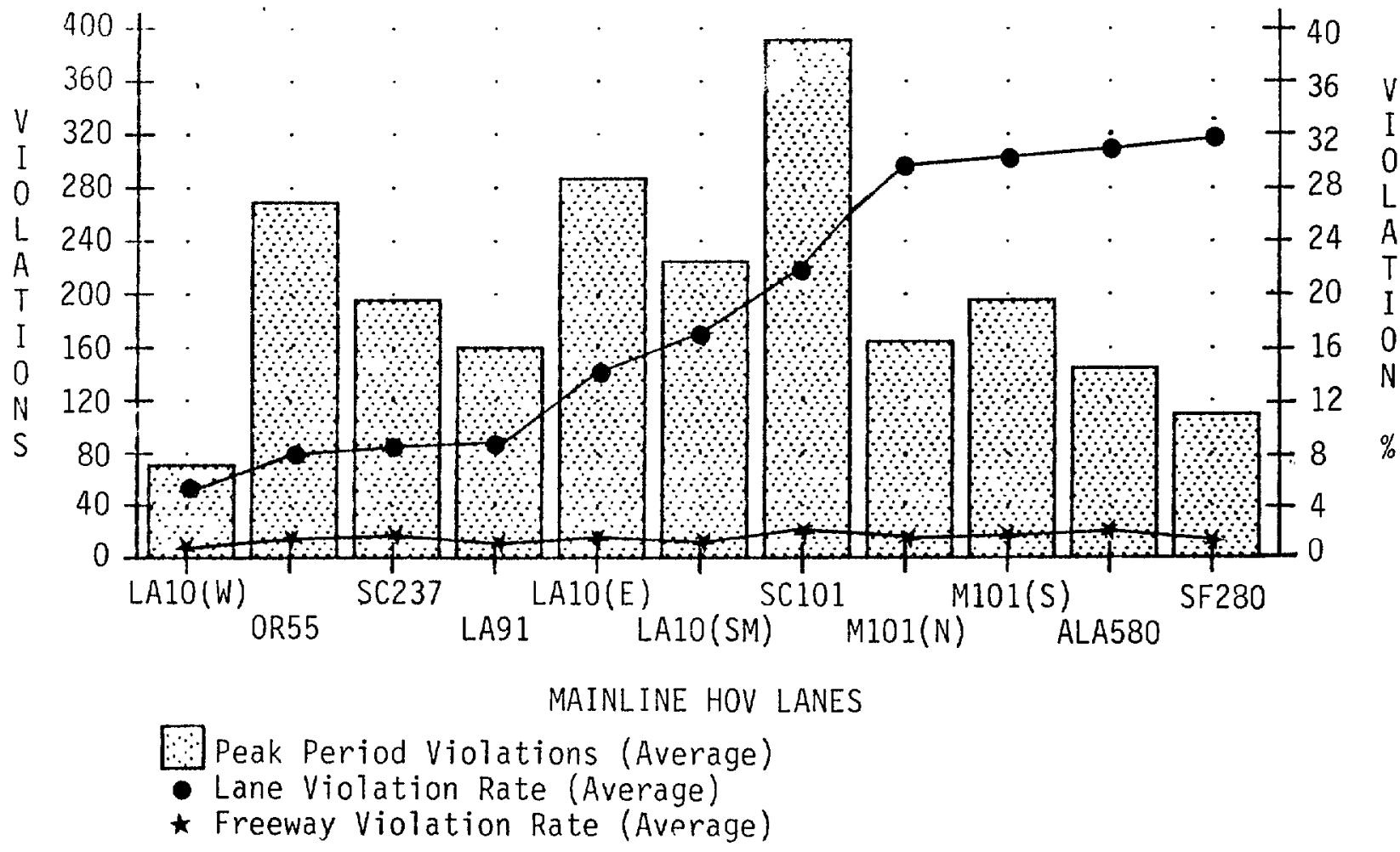




\subsubsection{Enforcement Activities}

Enforcement Levels and Apprehension Rates. On the average, roughly ten 21655.5 citations per day (five during each peak period) were issued for occupancy violations on each of California's mainline HOV lanes during 1987. Exhibit 3.2 documents the average enforcement activity on each freeway. When citation rates are considered in the light of violations, it appears that the percentage of violators who are ticketed ranged from $0.7 \%$ (on the southern segment of Marin 101) to 2.7\% (on Route 237 in Santa Clara County). The percentage of violators ticketed on each freeway is listed as the apprehension rate in Exhibit 3.2.

Record Ambiquity. The CHP has historically classified citation records by enforcement beat. When both HOV ramps and a mainline HOV lane exist on the same beat (as in the case of Santa Clara 101 or OR 55), it is generally impossible to distinguish between 21655.5 citations issued to mainline violators and citations issued to ramp violators along the same beat. This ambiguity makes it difficult to detect patterns in the enforcement of HOV lanes using historical data. The CHP's Santa Fe Springs Area solves this problem by assigning a unique beat number (Beat 93) to the mainline HOV lane on LA 91. This number differs from the ordinary LA 91 beat designation and enables the Area to keep track of all citations and accidents associated with the mainline HOV lane.

This practice of designating a separate beat number for mainline HOV lanes not only helps to isolate the number of citations issued to mainline violators, but also provides a more consistent picture of in-lane accidents. It is recommended that the CHP adopt this policy statewide.

\subsection{EXISTING MAINLINE LANES}

\subsubsection{Marin 101}

Design. Two separate carpool lanes are operating on Marin 101, across the Golden Gate Bridge from San Francisco. A 3.7-mile lane has operated in both northbound and southbound directions since 1976. Operating data from this lane are summarized in Exhibit 3.4. Ten years later, another three miles of Carpool lane were added north of this facility. The two lanes are separated by five miles of freeway. Because Marin 101 lacks a median shoulder, enforcing officers must escort violators across three lanes of traffic to a narrow eight-foot shoulder. It is 


\section{MARIN 101 HISTORICAL SUMMARY SHEET}

\section{DESIGN CHARACTERISTICS}

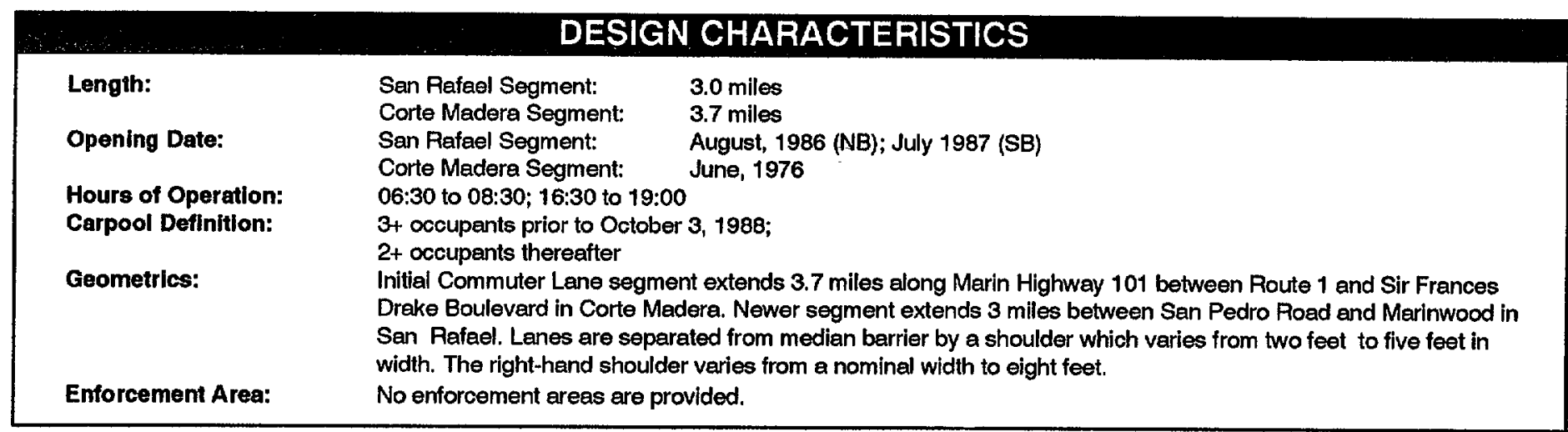

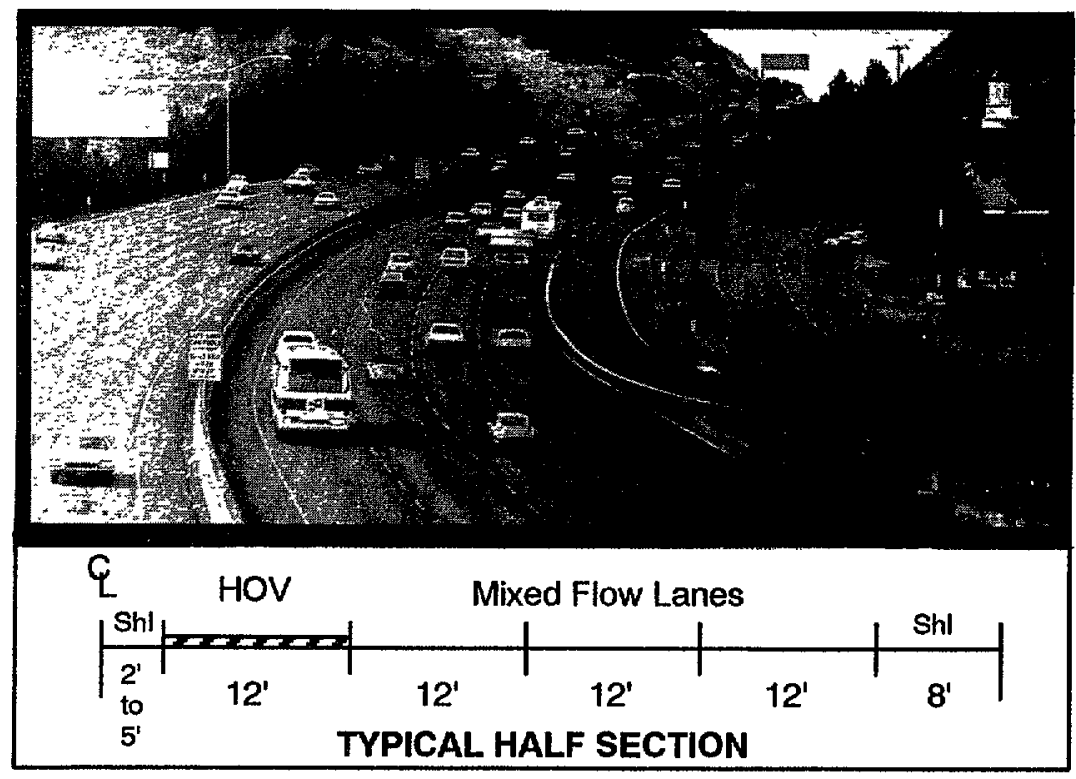

\begin{tabular}{|ccc|}
\hline \multicolumn{3}{|c|}{ OPERATING CHARACTERISTICS } \\
\hline SB-AM & NB-PM \\
LANE VOLUME & & \\
(vehicles/hour) & & \\
Sen Rafael HOV Segment & 785 & 1070 \\
Corte Madera HOV Segment & 865 & 860 \\
TIME SAVINGS & & \\
(minutes) & & \\
San Rafael HOV Segment & & \\
Average & 1.6 & 1.5 \\
Maximum & 4.7 & 5.5 \\
Corte Madera HOV Segment & 0.1 & 1.6 \\
Average & 0.7 & 3.9 \\
Maximum & & 10.3 \\
CITATIONS/DAY & & \\
\hline
\end{tabular}
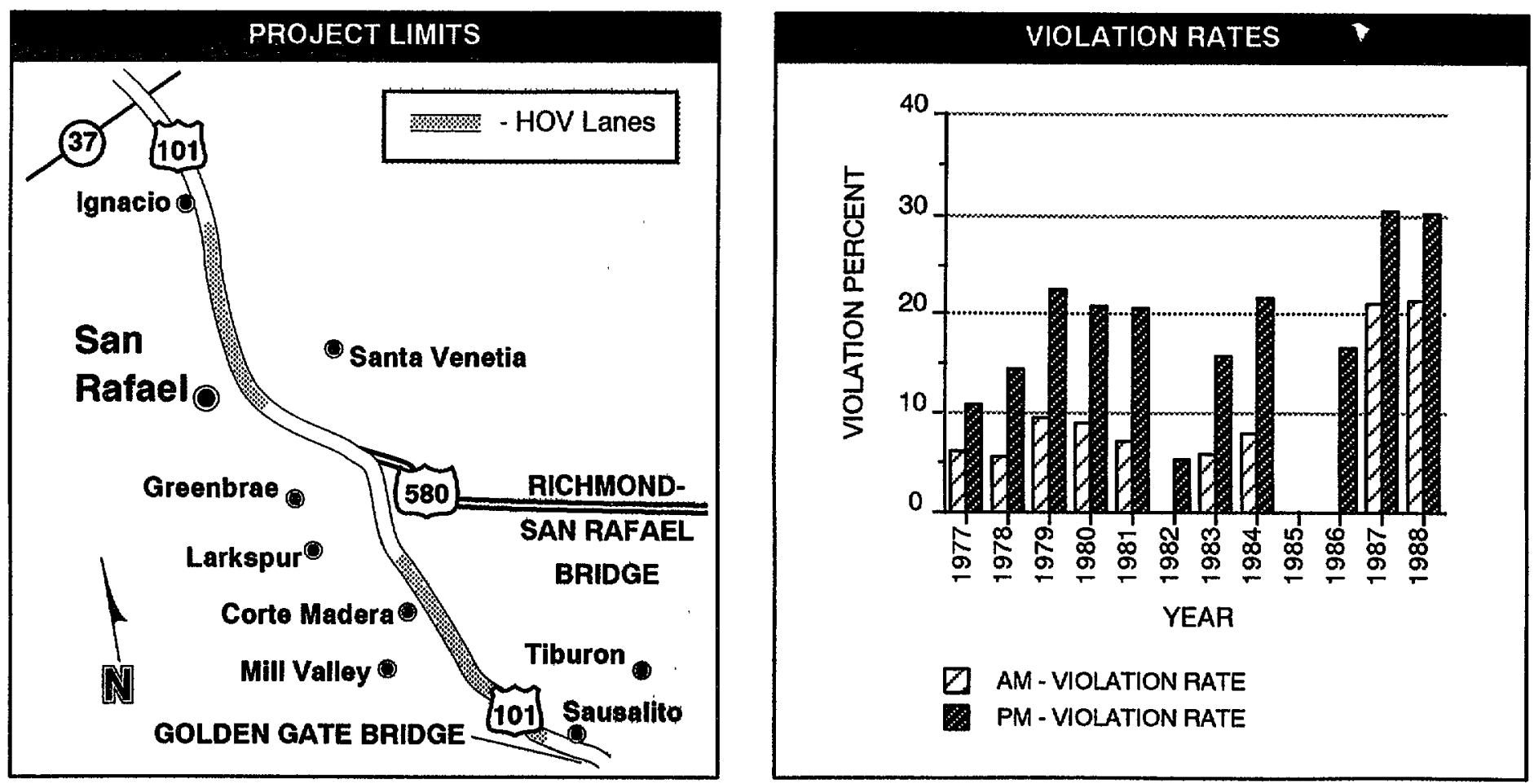
sometimes necessary to take violators all the way off the freeway to ticket them, eliminating any possibility that the ticketing activity itself will deter passing violators. The lack of a median also makes it more hazardous for officers to pursue violators in the HOV lane. The week before this study began, a CHP officer had an accident when a carpooler nosed into the HOV lane as he was pursuing a violator.

Violation History Marin 101 historically had higher lane violation rates than any other mainline HOV lane in California operating at the start of the study. This is largely because the lane's 3-person Carpool definition' produced relatively few legitimate users, so that violators comprised a relatively high percentage (between $25 \%$ and $35 \%$ ) of the vehicles in the lane. During 1987 and 1988 the violation rate increased significantly (see Exhibit 3.4), but this increase came about largely because of a decline in carpoolers rather than an increase in violators.

Enforcement Levels. The CHP's Marin office typically assigns two officers during the morning peak and two or three officers during the evening peak to enforce the Marin HOV lanes. These officers issue an average of 10 citations per weekday. Prior to 1986, all of those citations were issued on the southernmost section of the freeway. Since the second HOV segment was opened in 1986, roughly three-quarters of the 21655.5 citations issued by the Marin CHP have been given to drivers using the newer section illegally.

\subsubsection{Santa Clara 101}

Design. The Bayshore Freeway in Santa Clara County had three miles of HOV lane operating in each direction just north of San Jose, California at the start of the current study. (See Exhibit 3.5.) These lanes were opened for traffic in November, 1986. Between the first and second waves of special enforcement activity, these lanes were extended northward to the Santa Clara County line. The lanes are separated from the median barrier by a lo-foot shoulder which provides a useful observation post for enforcing officers. Some officers also use the median shoulder for ticketing violators.

\footnotetext{
* On October 3, 1968, just prior to the first wave of special enforcement, Marin County redefined Carpools on both mainline lanes to include vehicles with two or three occupants. This definition remained in effect for the duration of the study.
} 


\section{SANTA CLARA 101 HISTORICAL SUMMARY SHEET}

\section{DESIGN CHARACTERISTICS}

Length:

Opening Date:

Hours of Operation:

Carpool Definition:

Geometrics:
3 miles (extended to 12 miles in December, 1988)

November, 1986

05:00 to $09: 00$ and

15:00 to 19:00 - Monday through Friday

$2+$ occupants, Motorcycles OK

Section of six-lane freeway was widened to eight lanes, with \#1 lane in each direction designated as a Commuter Lane. The \#1 lane is separated from the median barrier by an 10'. median shoulder.

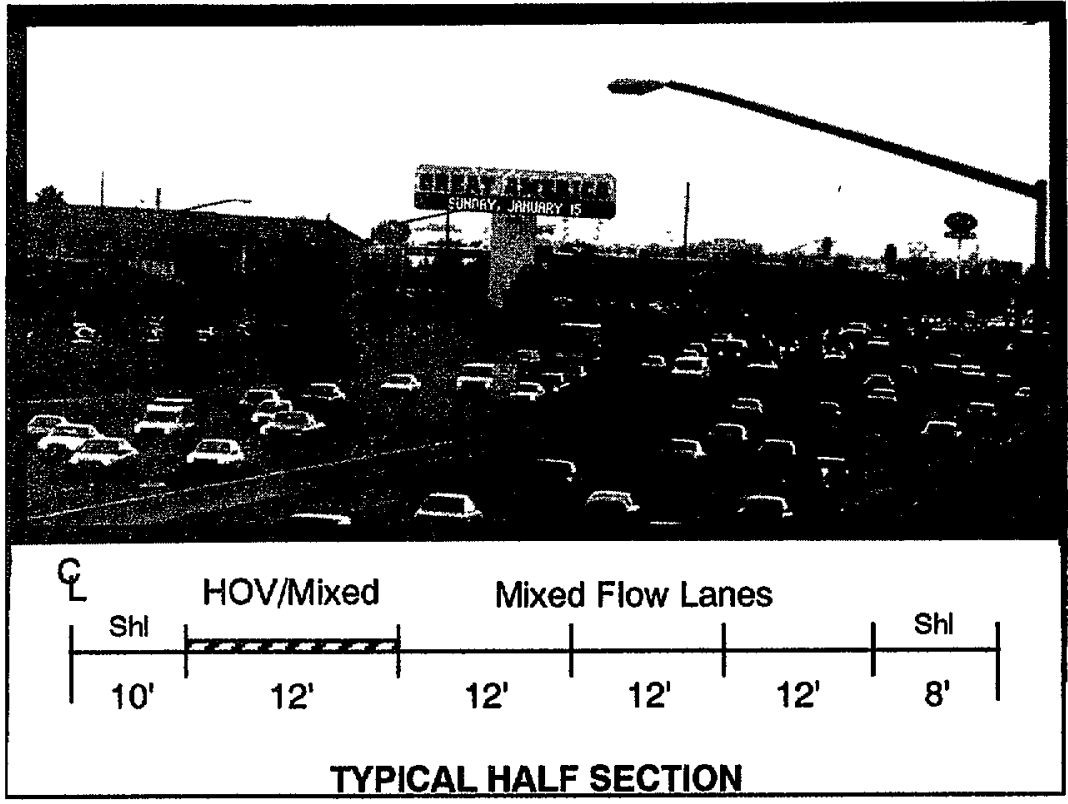

\section{OPERATING CHARACTERISTICS}

$\begin{array}{ccc}\begin{array}{c}\text { LANE vOLUME } \\ \text { (vehicles/hour) } \\ \text { HOV lane }\end{array} & \text { NB-AM } & \text { SB-PM } \\ \text { General } & 711 & 970 \\ & 1664 & 1535\end{array}$

TIME SAVINGS

(minutes/3 mile segment)

$\begin{array}{lll}\text { Average } & .4 & 4.2 \\ \text { Maximum } & 0.8 & 7.7\end{array}$

CITATIONS/DAY

18.1

(including ramps)
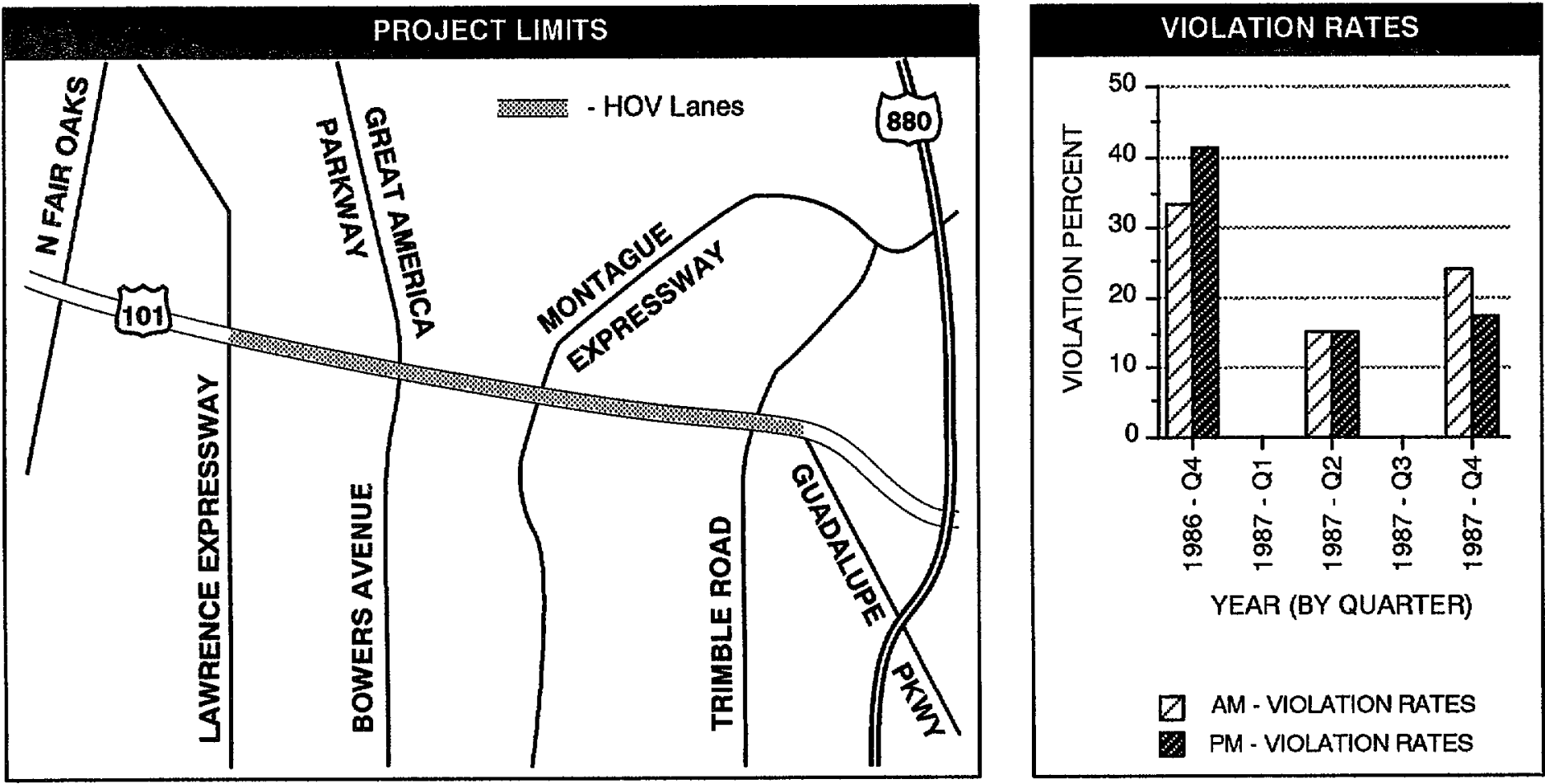
Violations and Enforcement. Historical CALTRANS observations of Santa Clara 101 document violation rates of $24 \%$ during the morning commute period and $17 \%$ during the evening peak. Between two and three officers are assigned to routine enforcement duties on SC 101 during each peak period. In addition, officers have been assigned to special HOV overtime enforcement roughly 2 or 3 times per week. Both motorcycle and ordinary patrol officers are assigned on overtime and have no regular traffic responsibilities when they are enforcing the HOV lane. In 1987, CHP officers issued an average of 20 citations per day for HOV occupancy violations on Santa Clara 101, but it is estimated that about four of these violations occurred on ramp meter bypass lanes.

\subsubsection{Santa Clara 237}

Route 237 in Santa Clara County has four miles of carpool lane in each direction. This facility, which opened to traffic in October, 1984, has the only mainline HOV lanes in the state which occupy the right-most lanes of a freeway. Historical lane violation rates are relatively low (5.8\% during the morning peak and 9.6\% during the evening peak). During 1987, CHP officers issued an average of 10.6 citations per day to occupancy violators on Santa Clara 237. These citations were all issued by the beat officers routinely assigned to enforce Santa Clara 237. No special enforcement activities were assigned to this freeway in 1987.

\subsubsection{San Francisco 280}

This 1.9 mile facility serves southbound traffic leaving San Francisco on Interstate Route 280. The HOV lane opened in 1975 and operates 24 hours per day for carpools of 3 or more persons. The lane has an ample median at its start, narrowing to no shoulder at all for the last halfmile of its length. The lane is lightly used (200 vehicles per peak hour--lower than any other mainline HOV lane in California) and is not heavily enforced by the CHP (Newman, 1987). On the average, only 1.3 citations per day are issued to lane violators. Violation rates were measured at $32.9 \%$ late in 1987.

\subsubsection{El Monte Busway (Los Angeles 10)}

Design. The El Monte Busway is 11 miles long and extends along Los Angeles Route 10 from downtown Los Angeles eastward to El Monte. The facility is open 24 hours a day to 
vehicles with three or more occupants. The westernmost four miles of the facility are physically separated from mixed flow traffic by a concrete barrier. The easternmost portion of the HOV lane is separated from mixed flow traffic by a 13 foot buffer lane. The buffer lane is dotted with plastic pylons placed at 50 foot intervals.

Violation Rates. Lane violation rates on the physically separated portion of the busway are estimated to be less than $4 \%$. Because violation rates have historically been comparatively low in the physically separated section of the El Monte Busway, occupancy counts are rarely made in that section. The most recent counts, made in 1986, showed the total number of peak period violations (AM and $\mathrm{PM}$ ) to be 144 , significantly lower than that on any other mainline lane.

During the peak morning hour, nearly 1300 vehicles per hour use the buffer-separated segment of the HOV lane. An estimated 103 of these users do not have the required three occupants. The evening peak experiences roughly the same percentage of lane violations, although the HOV traffic volume is somewhat lower (1100 vehicles per peak hour). It is illegal to cross the 13-foot buffer to use the HOV lane. Even though no signs are posted to warn against buffer crossings, the cross-hatched buffers and pylons discourage this activity. A videotape record of a 1500-foot segment of the westbound HOV lane showed that only 12 vehicles crossed the buffer illegally during the three-hour morning peak. This represented only $\mathbf{0 . 4 \%}$ of the 3200 vehicles using the HOV lane over the same period (Newman, 1987).

Enforcement. From four to six CHP officers regularly patrol the mixed-flow lanes adjacent to the busway. Tickets are issued both on the righthand shoulder and on the 13 foot buffer strip. Roughly ten 21655.5 citations per day were issued along this section of the roadway during 1987.

\subsubsection{Los Angeles Route 91}

Design. The HOV lane on Los Angeles Route 91 extends eight miles between Central Avenue and Route 605 in Southern Los Angeles. The lane occupies the left shoulder of the freeway and is separated from the general traffic lanes by a painted 2-foot "buffer" consisting of two yellow lines linked by ladder block stripes. Access to the lane is permitted only at a limited number of locations designated by broken double yellow lines and roadside signs. 
The HOV lanes on Route 91 opened on June 10, 1985. For the first three years of operations, the lanes were available for use only during the evening peak. Midway through 1988, however, the lanes were opened to buses and two-person Carpools 24 hours a day. Exhibit 3.6 summarizes operating data from LA 91.

Enforcement of LA 91 is aided considerably by a one-sided enforcement area located midway along the length of the lane. The enforcement area was created by widening the outside shoulder to provide a 14 foot median and constructing a barrier to protect enforcing officers from oncoming traffic. (Further discussion of enforcement areas may be found in Section 5.4). On LA 91 , the mouth of the potential enforcement area is just under 10 feet wide and is located downstream from a curve which causes traffic to slow as it passes the area. Some officers use the protected areas as a jumping-off point from which to pursue violators, while a few take advantage of the slowing traffic flow to stand in the enforcement area and wave violators over as they pass.

Enforcement and Violations. The Westminster CHP area typically assigns one officer to a four-hour tour of duty enforcing the LA $91 \mathrm{HOV}$ lane every weekday afternoon. On the average, 4.5 tickets per day are issued for occupancy violations along the freeway, and the historical lane violation rate is a relatively low $7.8 \%$. A limited study of buffer crossings suggests that the number of drivers entering and leaving the lane illegally by crossing the buffer may be greater than the number using the lane without the proper number of occupants. A videotape over three 1500-foot lengths of the freeway showed that 220 drivers crossed the buffer illegally within camera range during the peak two hours of lane operation (Newman, 1987). This number exceeds the 160 single-occupant violators counted at a single location in April 1988.

\subsubsection{Orange County Route 55}

Design. The HOV lanes on OR 55 stretch 11 miles and are separated from the mixed flow lanes by a one-foot barrier stripe. Northbound and southbound lanes were opened to HOV traffic in November 1985. The lanes operate 24 hours per day. The median shoulder is 3 feet wide, and a double-sided enforcement area has been provided at one location. However, the median lane and the mouth of the protected area are approximately three feet narrower than that of the enforcement area on Route 91. As a result, none of the CHP officers interviewed in the initial phase of this study used the Route 55 enforcement areas to write HOV lane tickets. The officers were concerned that the area's narrow width and short acceleration distance would make it too difficult for violators to re-enter the traffic stream after being ticketed. One CHP officer said 


\section{LA 91 HISTORICAL SUMMARY SHEET}

\section{DESIGN CHARACTERISTICS}

Length: $\quad 8$ miles

Opening Date: June 10,1985

Hours of Operatlon: 24 hours/day

(Originally 1400 to 1900 . However, several signing packages proved unsuccessful at returning lanes to shoulder use during off-peak hours.)

Carpool Definition: 2+ occupants

Geometrics: $\quad$ Commuter lane operates along eight miles of eastbound Route 91 freeway median shoulder beginning at Central Avenue and continuing east to the Route 605 freeway. The lane is separated from the mainline freeway traffic by a painted buffer two feet wide. Dashed breaks in the painted buffer permit vehicles to enter and exit at two different locations.

EnforcementArea: A single enforcement area is provided.

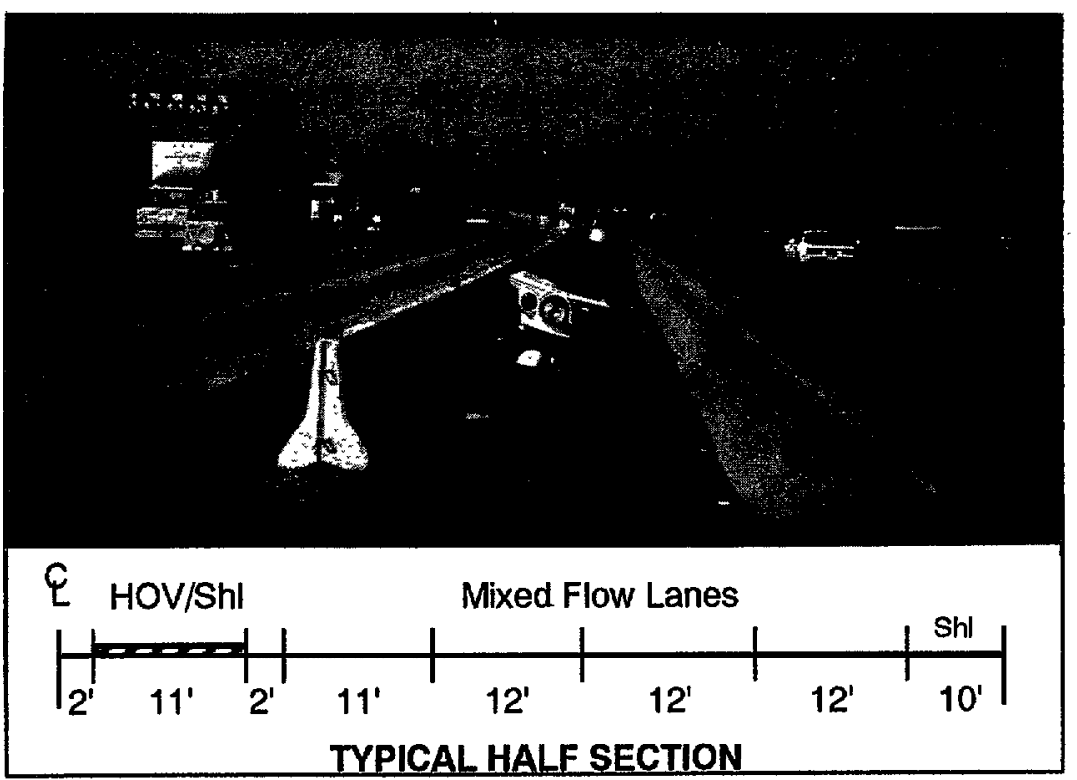

OPERATING CHARACTERISTICS

LANE VOLUME

(vehicles/hour)

HOV lane

1384

TIME SAVINGS

(minutes)

Average

Maximum

CITATIONS/DAY
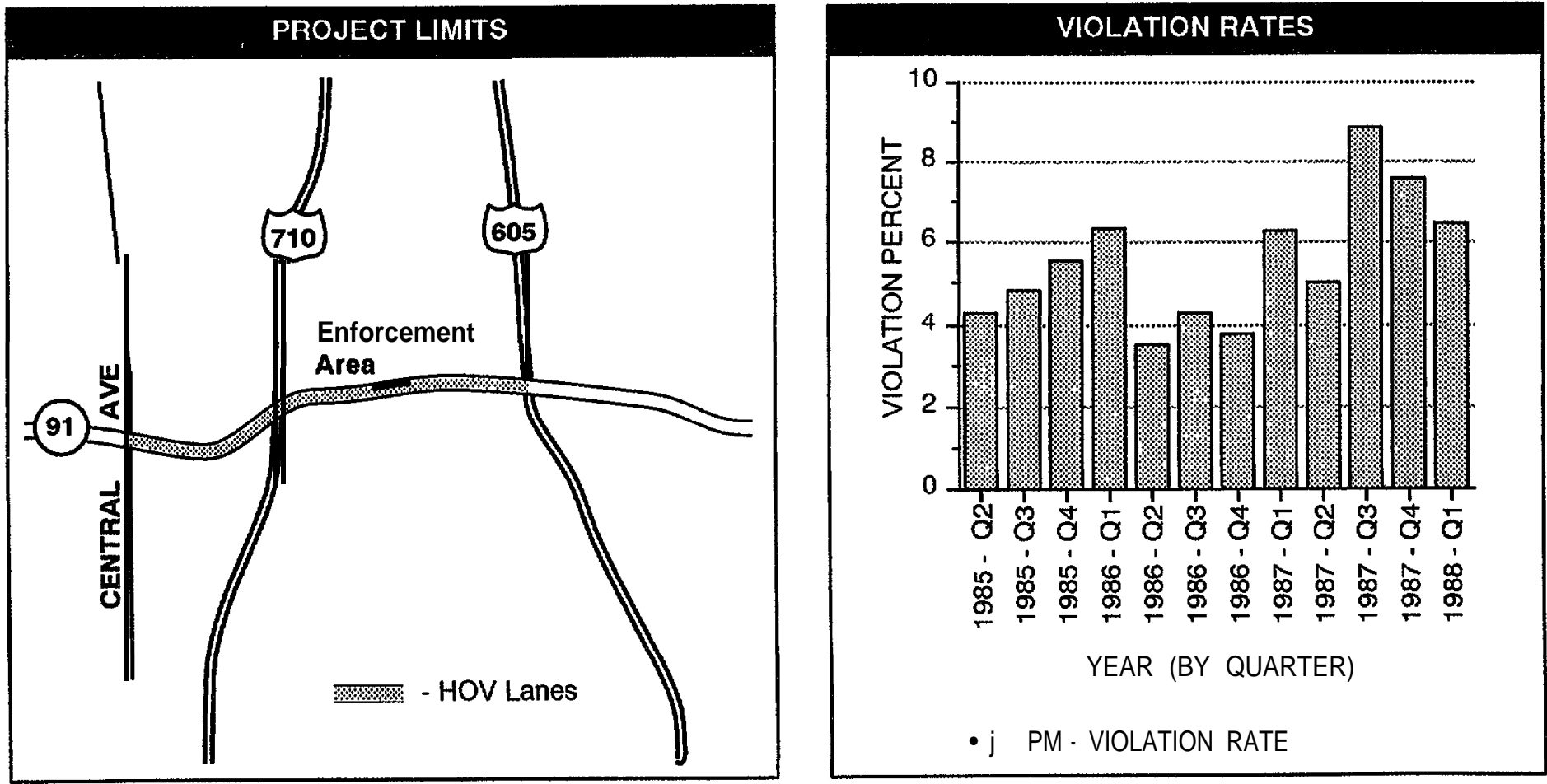
that he used the area as a jumping-off point for spotting and pursuing violators. He noted, however, that some officers felt that even this restricted use of the enforcement was too hazardous. Citations are generally issued only after officers have escorted violators across three lanes of traffic to the eight-foot right shoulder.

Violations. The OR $55 \mathrm{HOV}$ lanes carry more vehicles than any other mainline HOV lanes in California. Travel volumes range from 1300 vehicles per hour (vph) during the peak morning hour to 1500 vph during the peak evening hour. (See Exhibit 3.7.) Even though the lanes also carry a higher number of violators than any other mainline HOV lane in California, lane violation rates were only 7\% during both peak periods early in 1988 .

As in the case of LA 91, a number of drivers enter or leave the OR 55 lanes by crossing the buffer illegally. The number of illegal buffer crossings averaged 10 vehicles per hour along a 1500 -foot stretch of the southbound freeway, while an equal number of illegal crossings were observed over the same length of northbound lane.

Enforcement. The CHP's Santa Ana office, which is responsible for enforcement on OR 55, typically assigns one or two units per shift to special enforcement along the route. These officers, and the officers routinely assigned to enforce the freeway, issued an average of 14 citations per day during 1987 and 1988.

\subsection{START-UP PROJECTS}

Several new mainline HOV lanes are scheduled to be introduced on California's freeways in the near future. Two were opened within the time frame of the current study. These are $1-15$ in San Diego and I-405 in Orange County. Each of these new HOV lanes has certain unique features of interest from an enforcement standpoint. The I-15 lanes in San Diego are physically separated from flow of traffic by a concrete barrier. On I-405 in Orange County, a succession of enforcement areas have been planned to aid the enforcing officers. Startup activities on each of these two new HOV lanes were monitored in order to provide additional insights into the impact of each of these unique design features on violation rates.

\subsubsection{San Diego l-15}

The new HOV lanes on I-15 north of San Diego extend 7.2 miles from the State Route 163 interchange for a point just north of Poway Road. The lanes are reversible and are separated from the main flow of traffic by a concrete barrier. Carpools of two or more people are allowed access only at either end of the project. There are no intermediate access points. 


\section{OR 55 HISTORICAL SUMMARY SHEET}

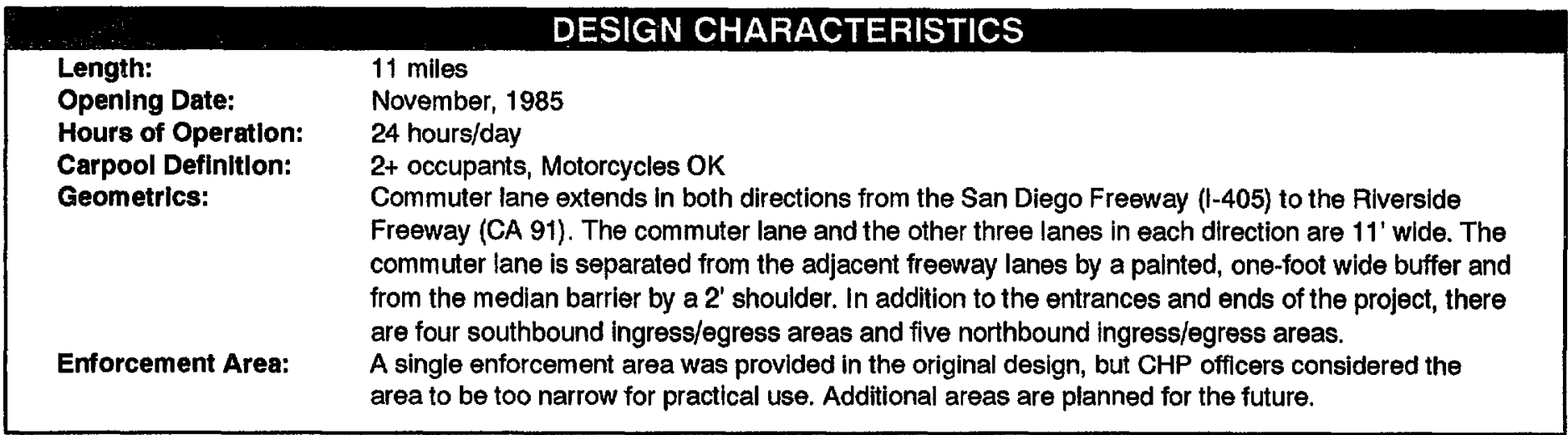

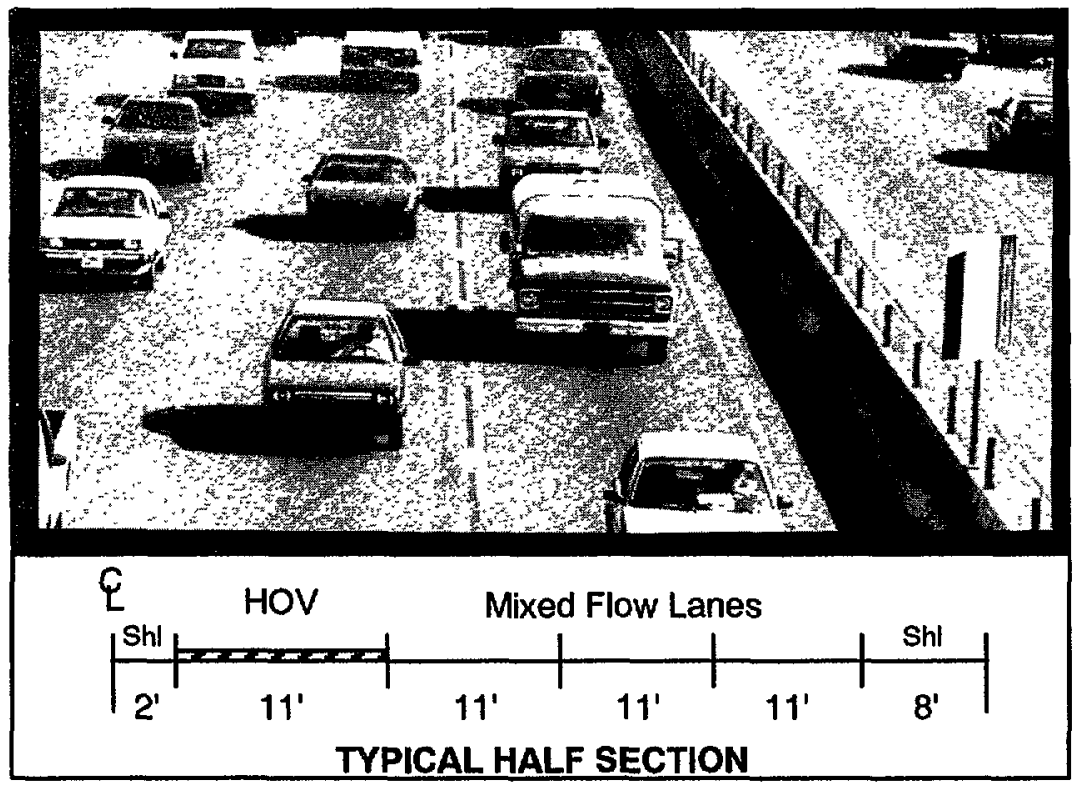

\begin{tabular}{|ccc|}
\hline \multicolumn{3}{|c|}{ OPERATING CHARACTERISTICS } \\
$\begin{array}{c}\text { LANE VOLUME } \\
\text { (vehicles/hour) } \\
\text { HOV lane }\end{array}$ & $\underline{\text { SB-AM }}$ & NB-PM \\
$\begin{array}{c}\text { TIME SAVINGS } \\
\text { (minutes) } \\
\text { Average }\end{array}$ & 3.6 & 1500 \\
Maximum & 11.5 & 16.3 \\
& & 15.7 \\
CITATIONS/DAY & (including ramps) \\
\hline
\end{tabular}
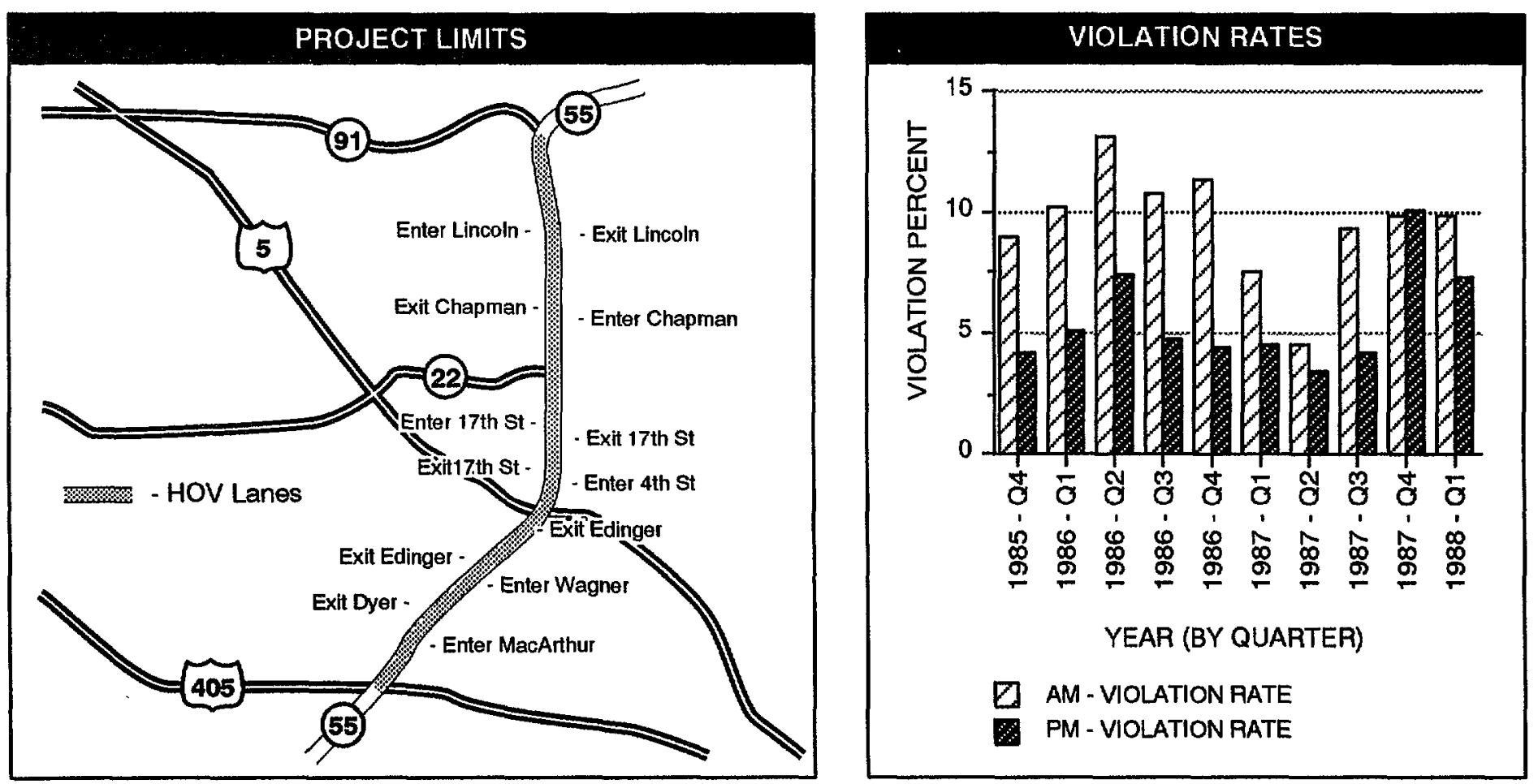
The reversible lanes are open in the inbound direction from 6:00 a.m. to 8:30 a.m. and in the outbound direction from 4:00 p.m. to 6:30 p.m. The lanes opened early in October 1988, with four weeks of special enforcement attention during the first month of operation. During the first week of operation violators were generally given verbal warnings. After the first month of operation, special enforcement was cut back to two days per week while CALTRANS documented the violation rates. CALTRANS' San Diego office monitored violation rates during the start-up phase, and SYSTAN has incorporate those findings in the current study.

\subsubsection{Orange County $1-405$}

An extensive HOV project is scheduled for installation on I-405 in Orange County. A number of enforcement areas will be built into the median along the length of the project. The first segment of the project opened in January, 1989. This segment runs from the Westminster Avenue interchange to the Orange County line, a distance of approximately five miles. One enforcement area exists along this segment of the HOV lanes. As in the case of San Diego I-15, CALTRANS assisted the SYSTAN team in monitoring start-up activities on the HOV lane.

\subsection{PAST PROJECTS}

Several mainline HOV lanes which once operated on California freeways are no longer in service. The Santa Monica Diamond Lanes were opened for 21 weeks in 1976 before being closed by a court order, and HOV lanes on Alameda 580 were opened in December 1977 and operated for five years before closing. Although these two lanes are no longer reserved for carpoolers, statistics recorded when the lanes were operating provide additional perspective for regarding the impact of enforcement and engineering design on violation rates in California. For this reason, operating statistics for these two projects have been included in Exhibits 3.1 and 3.2.

\subsubsection{Santa Monica Diamond Lanes}

The Santa Monica Diamond Lanes, a pair of concurrent-flow preferential lanes for buses and 3-person carpoolers, linked the city of Santa Monica with downtown Los Angeles eleven miles away. These lanes were created by removing the \#1 lane in each direction from mixed-flow traffic and erecting signs reserving the lanes for buses and three-person Carpools during the peak 
commute period. The lanes opened in March, 1976 and operated amid much controversy for 21 weeks until the U.S. District Court halted the project and ordered additional environmental studies. The full story of the Santa Monica Diamond Lanes is documented in an earlier SYSTAN report (Billheimer, et al., 1977).

The Santa Monica Diamond Lanes had no physical barriers to entry, no access restrictions, and an ample median shoulder which the CHP used for apprehending and citing violations. The freeway is one of the most heavily traveled in America, and officers issued an average of 55 occupancy citations per day when the lanes were operating, more than double the number issued on any other mainline HOV lane in California. Heavy enforcement kept the lane violation rate at an average of $15.7 \%$, relatively low for a lane requiring three or more persons in a Carpool.

To enforce the Santa Monica Diamond Lanes, the CHP doubled the number of officers assigned to the freeway during the first week of the project, and gradually reduced deployment levels to normal (9-10 units per peak period) by the thirteenth week of the 21 -week project. Most officers used the median shoulder adjacent to the Diamond Lanes as a refuge area when issuing citations.

\subsubsection{Alameda 580}

Whereas the Santa Monica Diamond Lanes were the most heavily enforced mainline HOV lanes in California, Alameda 580 received very little attention from enforcing officers. During the early years of the project, only four citations per day were issued to violators. As a result, lane violation rates increased to an average of 30 percent. Alameda 580 was most often enforced by patrol cars on routine assignment. Officers pulled violators over to a fairly wide shoulder with a dirt median or escorted them across the buffer lane and two lanes of traffic to the righthand shoulder. Routine enforcement usually consisted of one unit on a normal beat during the morning and afternoon peaks. Special enforcement was used infrequently.

The HOV lanes on Alameda 580 were constructed as part of an interstate highway improvement program, and covered 3.5 miles of freeway from Eden Canyon Road to San Ramon Boulevard in San Francisco's East Bay. The median lane in each direction was designated as a bus and Carpool lane and separated from mixed-flow traffic by an eight-foot common shoulder delineated with flexible pylons. The lanes were the target of a barrage of adverse publicity and in 
$198080 \%$ of the voters proposed that the lanes be eliminated in response to an advisory question on the local ballot. Federal legislation finally removed the lanes from operation.

\subsection{VIOLATION PATTERNS}

Violation statistics were recorded on the study freeways before, during and after the two waves of special enforcement. Violations were documented at 5 minute increments and relative speeds in the HOV lanes and in adjacent mixed flow lanes were recorded once during each fiveminute interval.

\subsubsection{Violations by Time of Day}

The pattern of violation rates by time of day differed dramatically between Southern California, where mainline HOV lanes typically operate 24 hours per day, and Northern California, where HOV restrictions are in effect only during the peak commute periods.

Fringe Effects. In Northern California, where HOV lanes operate only at specified times during the peak commute period, violation rates tend to be highest at the fringes of the operating period, just after the lanes are opened to HOV traffic, and just before they revert to general use. The HOV lanes on Marin 101, for example, are operational only between 6:30 a.m. and 8:30 a.m. during the morning peak and between 4:30 p.m. and 7:00 p.m. during the evening peak. Exhibit 3.8 plots violation rates for the morning commute along Marin 101. The Exhibit clearly shows that violation rates are highest just after 6:30 a.m., when the lanes open for HOV traffic, and just before 8:30 a.m., when they revert to general use. Whereas violation rates exceeded $40 \%$ for the first and last five minutes of the operating period, rates were well below $10 \%$ during the middle hours of the morning commute. It is likely that drivers on the road at the fringes of the operating hours are either unaware of the correct time or simply assume they won't be challenged. (As a practical matter, CHP officers on Marin 101 allow a grace period of 10 to 15 minutes before they begin enforcing HOV restrictions). Similar patterns were evident on Santa Clara 101 (where lanes operate from 5 a.m. to 9 a.m. and from 3 p.m. to 7 p.m.) and on those Northern California mainline lanes observed during SYSTAN's earlier study of HOV violation rates (Billheimer, 1981). 
Darkness Effects. Just as the violation rates increased at the fringes of the operating hours in Northern California, they also appeared to increase after dark and during other periods when visibility was limited. Traffic observers were instructed to identify periods of limited visibility

EXHIBIT 3.8

VIOLATION RATE VS. TIME

MARIN 101 AM/SB

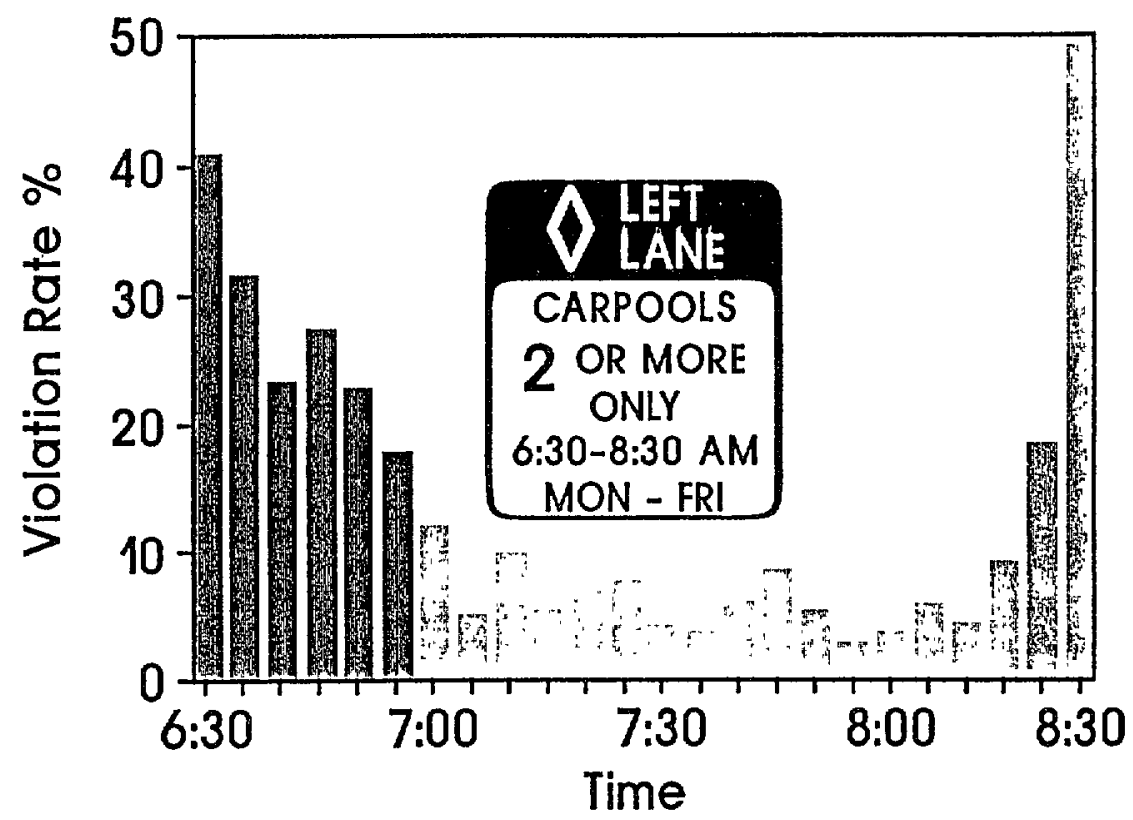

Rate Affected by Darkness

on their data sheets and to do their best to identify violators during these periods. Although the violation counts recorded during periods of limited visibility are suspect (because the observer had difficulty counting auto occupants at these times), the violation rates recorded under these conditions were consistently higher than the rates recorded during daylight hours. Exhibit 3.9 plots violation rates recorded at five minute intervals on seven different days along Marin 101 between 5:30 p.m. and 7:00 p.m. During the winter months, it was often difficult to see during this period, and the graph shows that the violation rates recorded during periods of darkness were significantly higher than rates recorded over the same time frame during daylight hours. The average violation rate recorded during perioss of darkness ( 3 days of observations) was $16.2 \%$, while the average recorded under clear conditions (4 days of observations) was $10.2 \%$. 
EXHIBIT 3.9

VIOLATION RATES VS. TIME OF DAY

DURING PERIODS OF LOW VISIBILITY

(MARIN 101 PM NB)

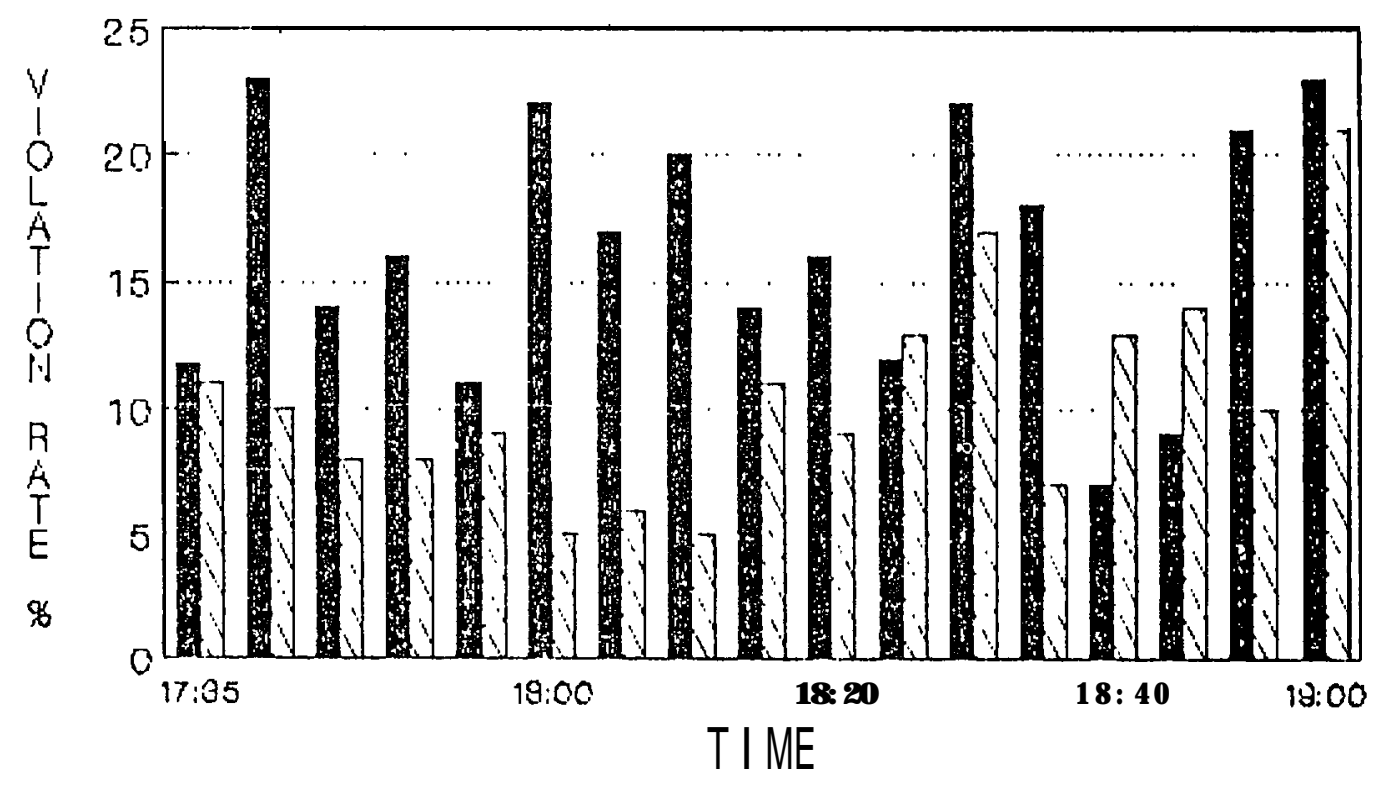

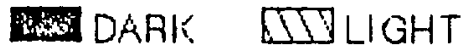

Impact on Overall Violation Rates. The combined effects of darkness and fringe violations can have a pronounced impact on overall violation rates. Exhibits 3.10 and 3.11 plot violation rates before, during and after special enforcement activities on Santa Clara 101 and Marin 101. In both cases, two graphs are shown. In the uppermost graph, all observed violations are used in computing violation rates. In the lower graph, violations recorded after dark and during the first and last ten minutes of the operating period have been omitted in computing violation rates.

The elimination of darkness and fringe effects from violation computations significantly reduces violation rates on both Marin 101 and Santa Clara 101. This is particularly true during the winter months between the two periods of special enforcement. In both cases, peak violation rates are drastically reduced. On Marin 101, violation rates during the morning peak were reduced in two instances from $20 \%$ to $10 \%$ by eliminating violations counted during the fringe period and before daybreak. A similar reduction occurred on Santa Clara 101 during the winter months between special enforcement activities. 


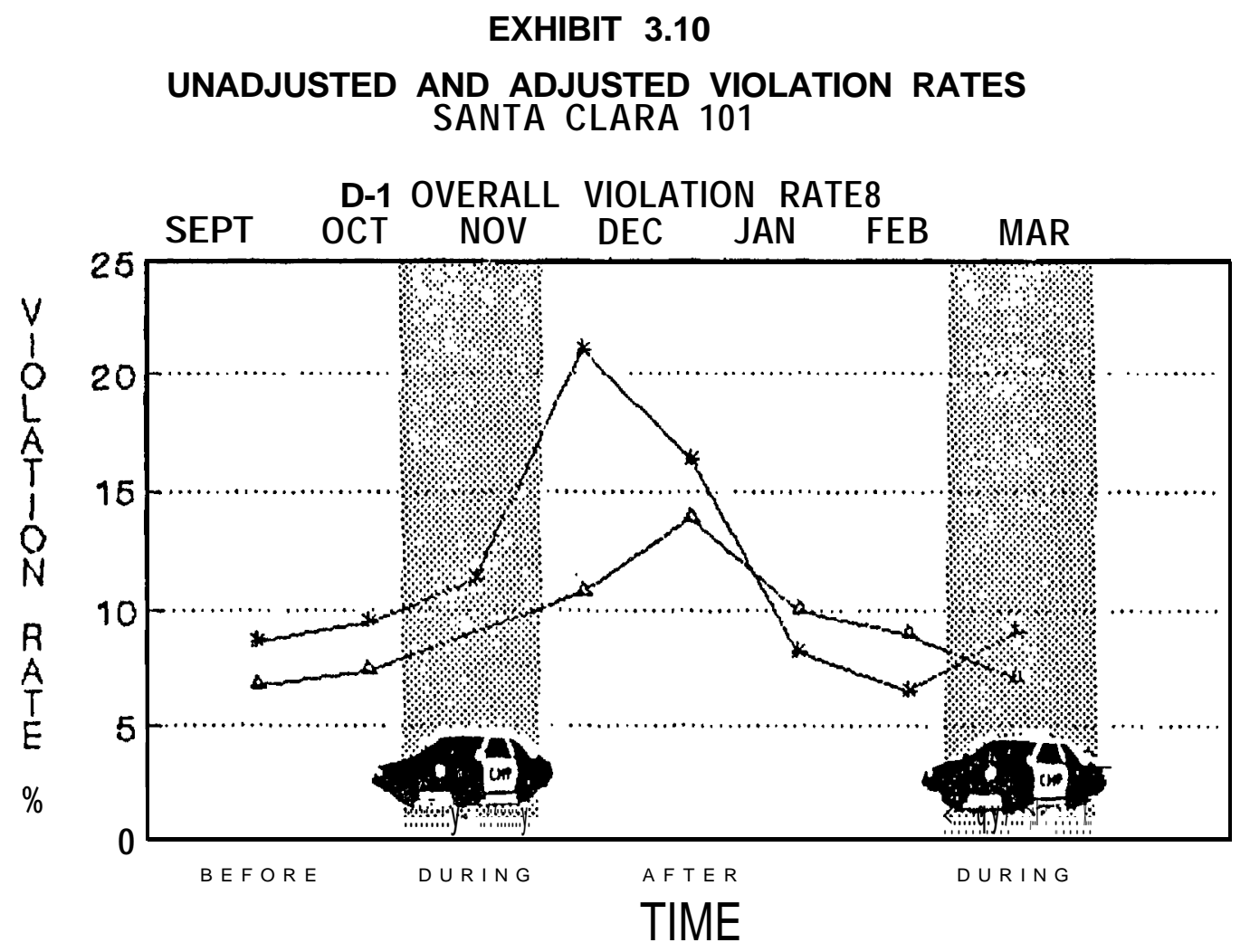

- N/B AM - S/B FM

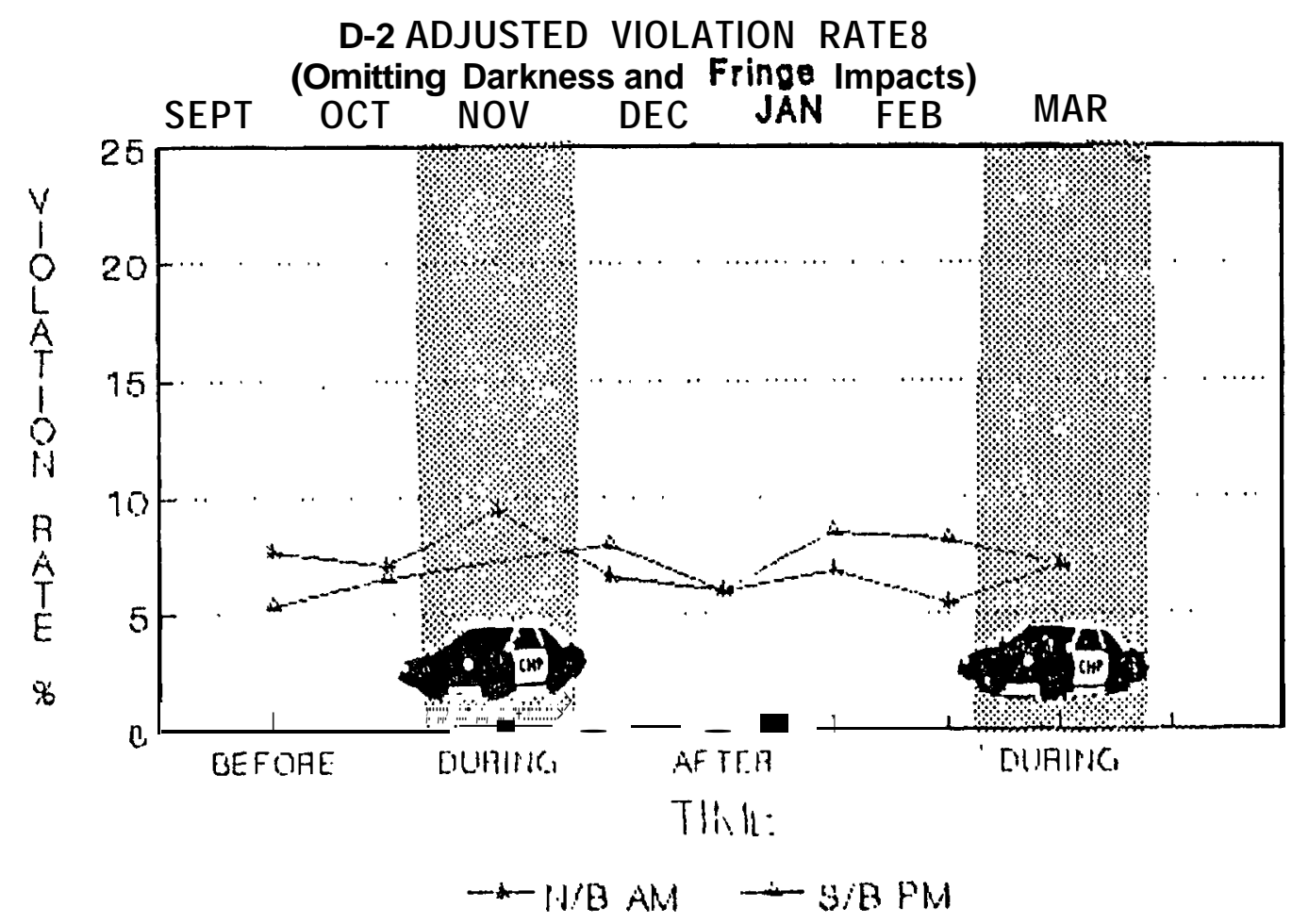




\section{EXHIBIT 3.11}

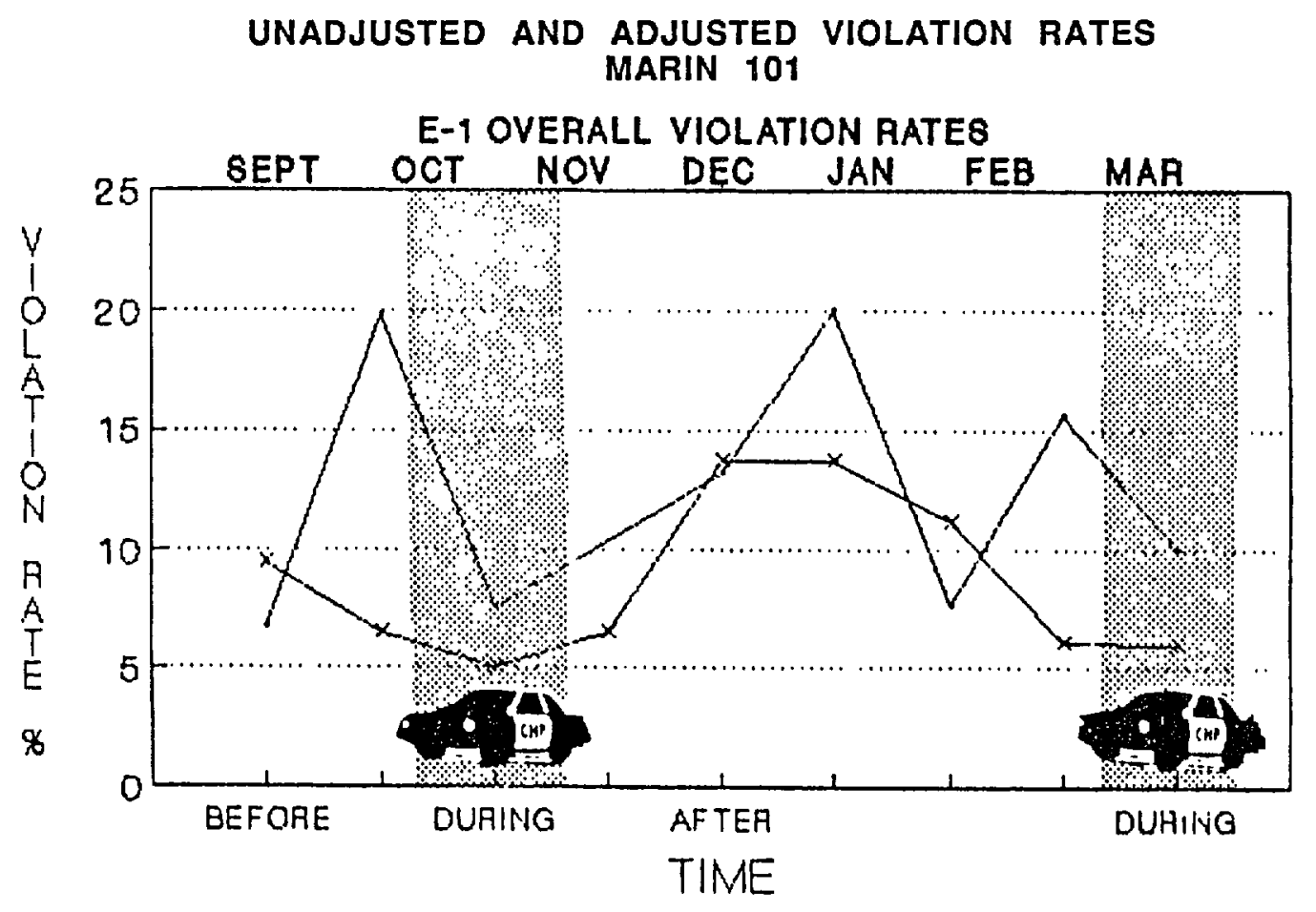

- S/B AM $\rightarrow$ NAP PM

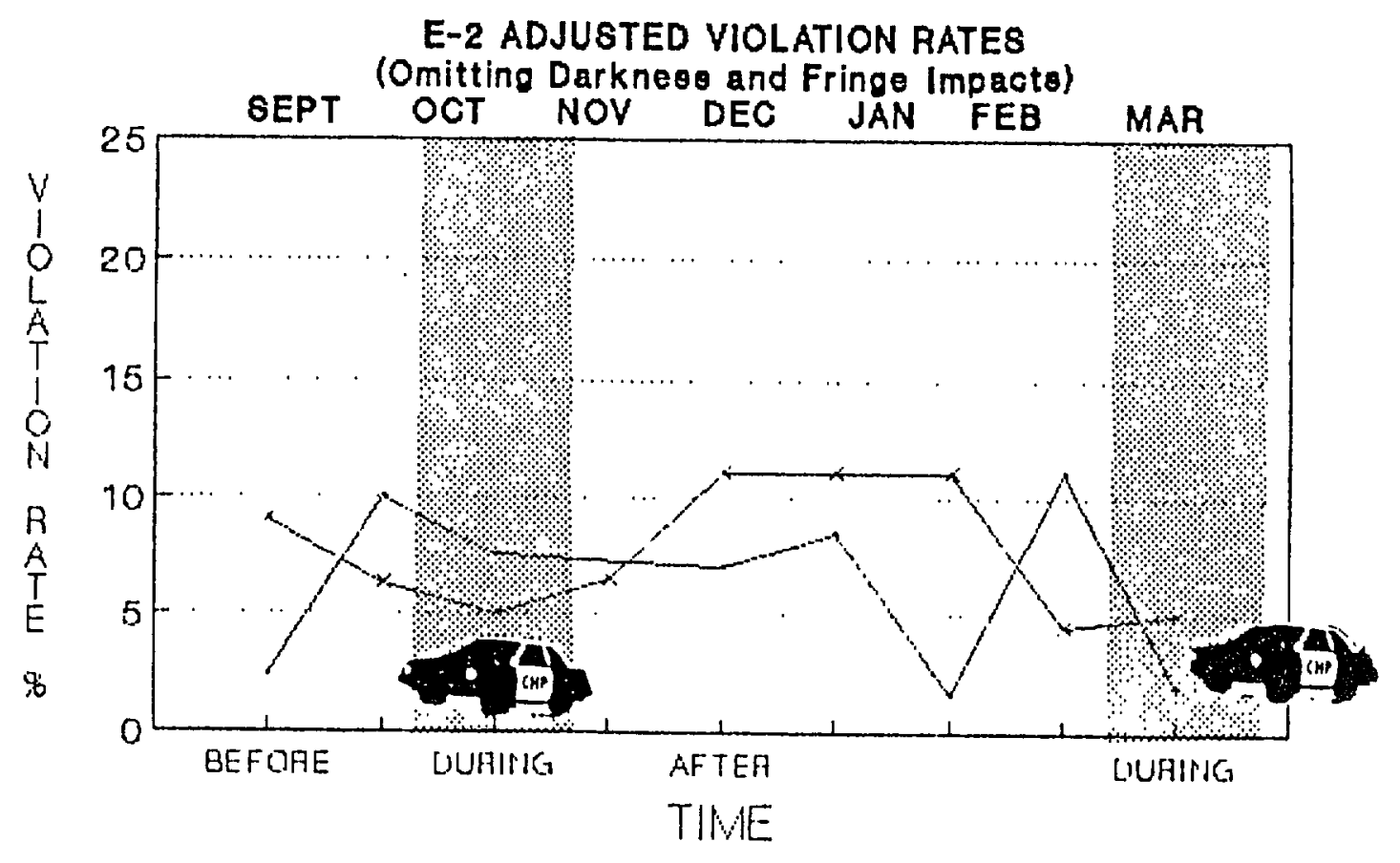

- s/B AM $\quad-$ W/B PM 


\section{EXHIBIT 3.11}

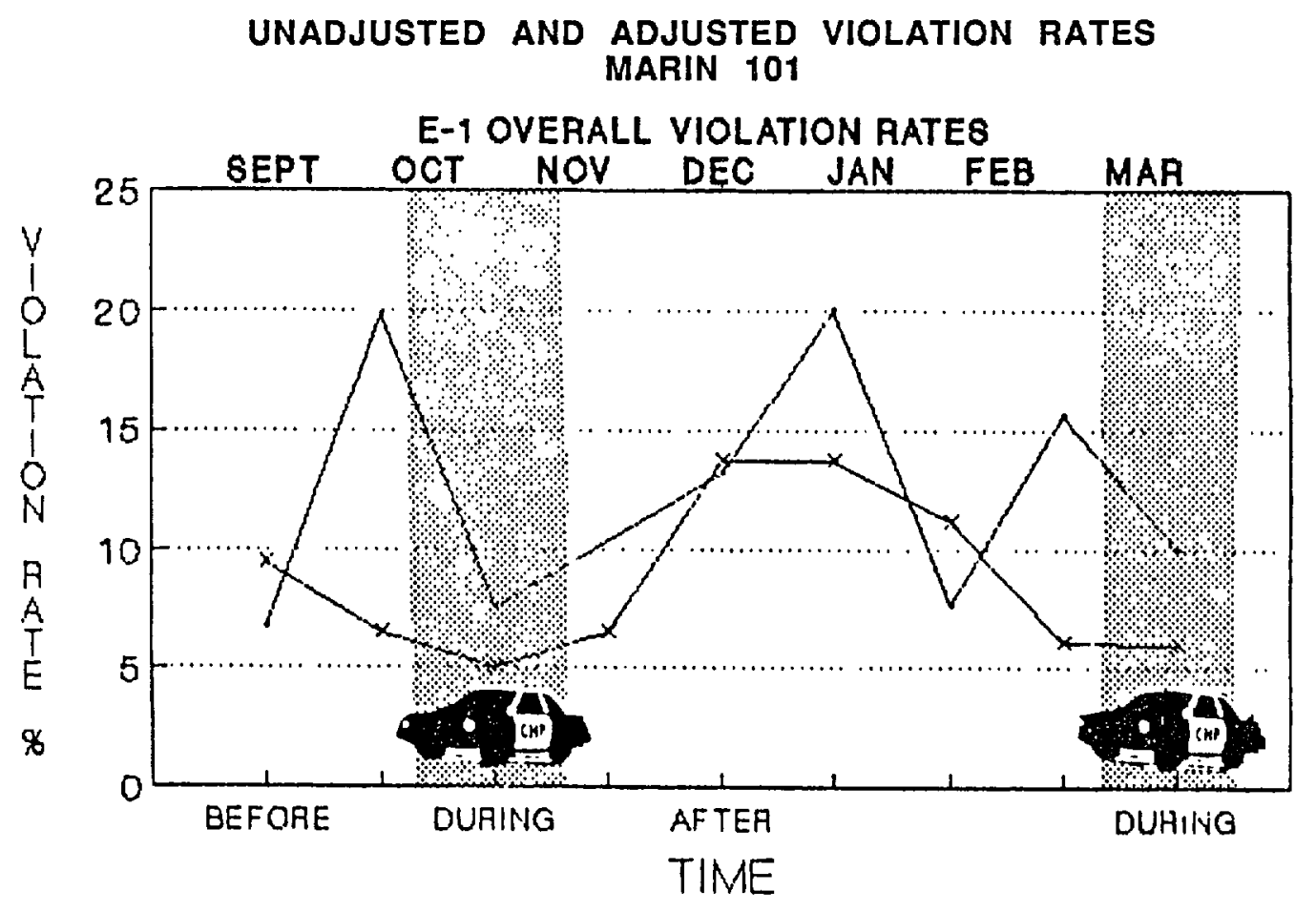

- S/B AM $\rightarrow$ NAP PM

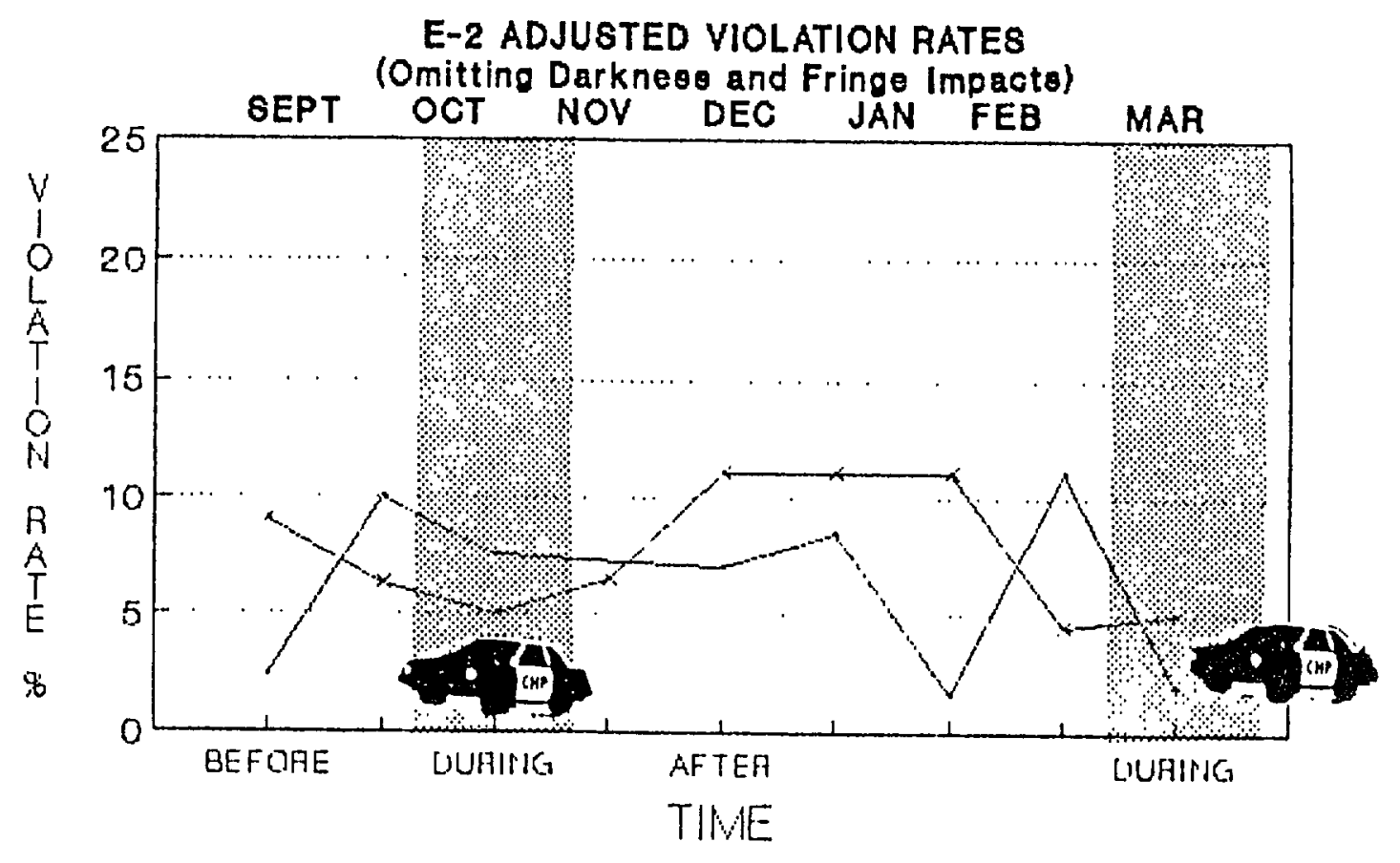

- s/B AM $\quad-$ W/B PM 
EXHIBIT 3.12

VIOLATION RATE VS. SPEED DIFFERENTIAL

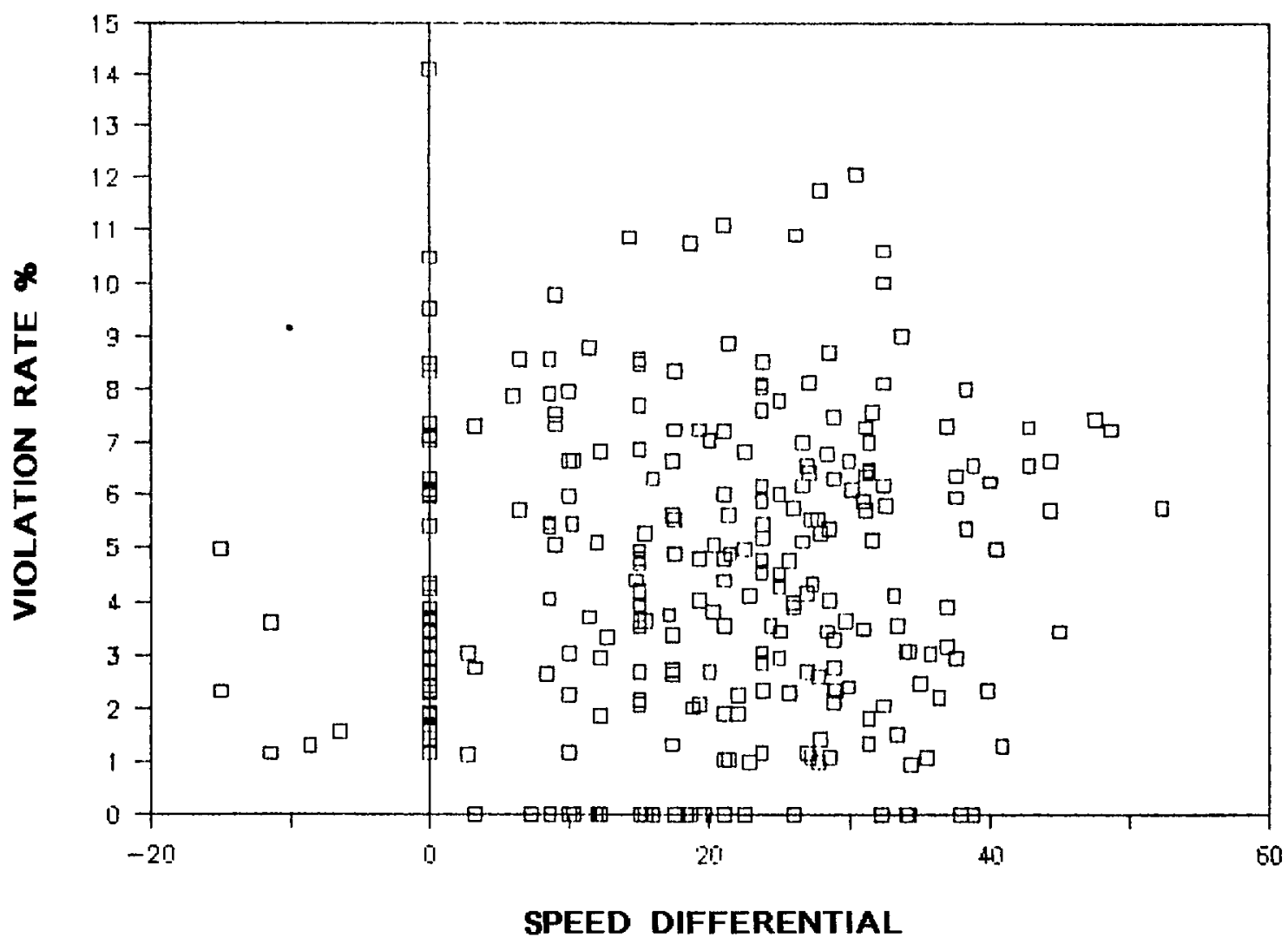

Correlation Evidence: Vlolations. Violation rates depend both on the number of violators and the number of legitimate users of the HOV lane. If the number of legitimate HOV lane users dropped with the speed differential, therefore, the violation rate might not change even if the number of violators declined. (This possibility is logical, since legitimate carpoolers might not bother to use the HOV lanes at times when there is no advantage to doing so.) To investigate this possibility, the variation on total violations was tested as a function of the speed differential between the HOV lane and adjacent lanes. Exhibit 3.13 plots violations vs. speed differential for LA 91. As in the case of violation rates, the speed differential was found to have little impact on the total number of violations observed on the HOV lane. 
EXHIBIT 3.13

\section{VIOLATIONS VS. SPEED DIFFERENTIAL}

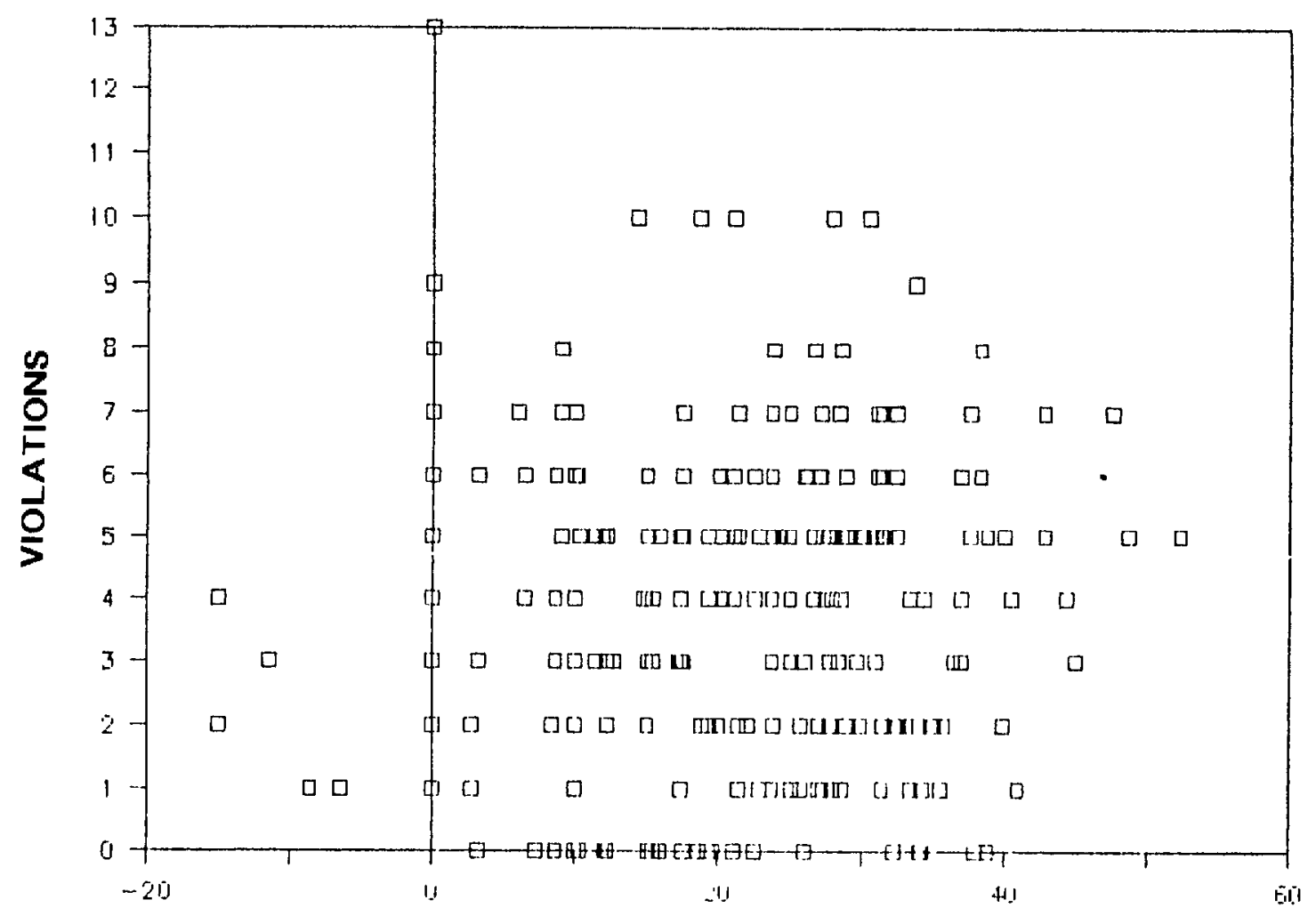

\section{SPEED DIFFERENTIAL}

Possible Explanations. Although it is somewhat surprising that violation rates do not appear to increase as HOV lane time savings increase, this finding is consistent with earlier observations on ramp meter bypass lanes (Billheimer et al., 1981) and also coincides with the observations of CHP officers. SYSTAN's earlier study found little correlation between the number of violators choosing to bypass a ramp meter queue and the time saved by doing so. A number of CHP officers have observed that traffic conditions seem to have little effect on HOV lane violations. One officer noted that drivers use the lanes illegally "...to save time when the adjacent lanes are clogged and as a passing lane when the adjacent lanes are free flowing."

The most likely explanation for the occurrence of HOV lane violations in the face of minimal time savings is that any time savings seems longer than it actually is when a driver is in rush-hour traffic. Surveys have shown that drivers wildly overestimate the time to be saved by using HOV lanes, especially when the savings are relatively small (see Chapter 6). 


\subsubsection{Buffer Violations}

Observers on OR 55 and LA 91 in Southern California were asked to record both occupancy violations and illegal buffer crossings when vehicles enter or leave the HOV lane. Buffer violations have been tabulated by time of day for each of these freeways.

OR 55 In Exhibition 3.14, are buffer violations for OR 55 are averaged over each hour of the morning and evening commute period. Observations were taken at two locations, the Meats Avenue overcrossing north of the OR 55 enforcement area, and the Walnut Avenue overcrossing about two miles south of Meats Avenue. Observation points bracketing the OR 55 enforcement area were selected in order to determine whether cars tended to leave the HOV lane illegally just before the enforcement area and reenter the lane illegally after passing the enforcement area. Observers were stationed so that they faced in the direction of the enforcement area from each overcrossing (i.e. looking south from Meats Avenue and north from Walnut Avenue).

Exhibit 3.14 suggests that the amount of illegal weaving on either side of the OR 55 enforcement area was not excessive. North of the area, at Meats Avenue, an average of five cars left the HOV lane illegally during the morning peak, before reaching the enforcement area, while twelve cars entered the lane illegally after passing the enforcement area in the evening. (Roughly 300 occupancy violations per day were observed from the Meats overcrossing, a far greater number than the seventeen buffer violations which might have been committed to avoid the enforcement area.) At Meats Avenue, more cars were observed weaving into the lane illegally in advance of the enforcement area and weaving out illegally after passing it. Counting crossings in both directions, an average of 37 vehicles were observed crossing the buffer illegally during the morning and evening compute periods for the Meats Avenue overcrossing.

An average of 52 buffer violations were counted from the Walnut overcrossing during the six hours comprising the morning and evening peak periods. As in the case of the Meats observation point, there was little evidence that violators were weaving in and out of the HOV lane to avoid the enforcement area.

If it is assumed that a driver is equally likely to commit a buffer violation at any point along the length of an HOV lane (a very poor assumption, since buffer violations are likely to be greatest just after legitimate access and egress points), then the average of eighty-nine buffer violations observed from the two observation points at Meat Avenue (37 violations) and Walnut Avenue (52 violations) can be translated to roughly 1,700 buffer violations along the length of the OR $55 \mathrm{HOV}$ 
TIME

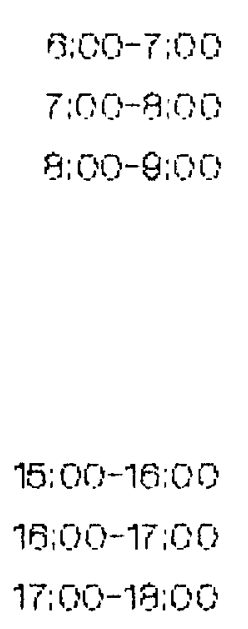

15:00-16:00

$17: 00-19: 05$
EXHIBIT 3.14

BUFFER VIOLATIONS BY TIME OF DAY OR 55 MEATS

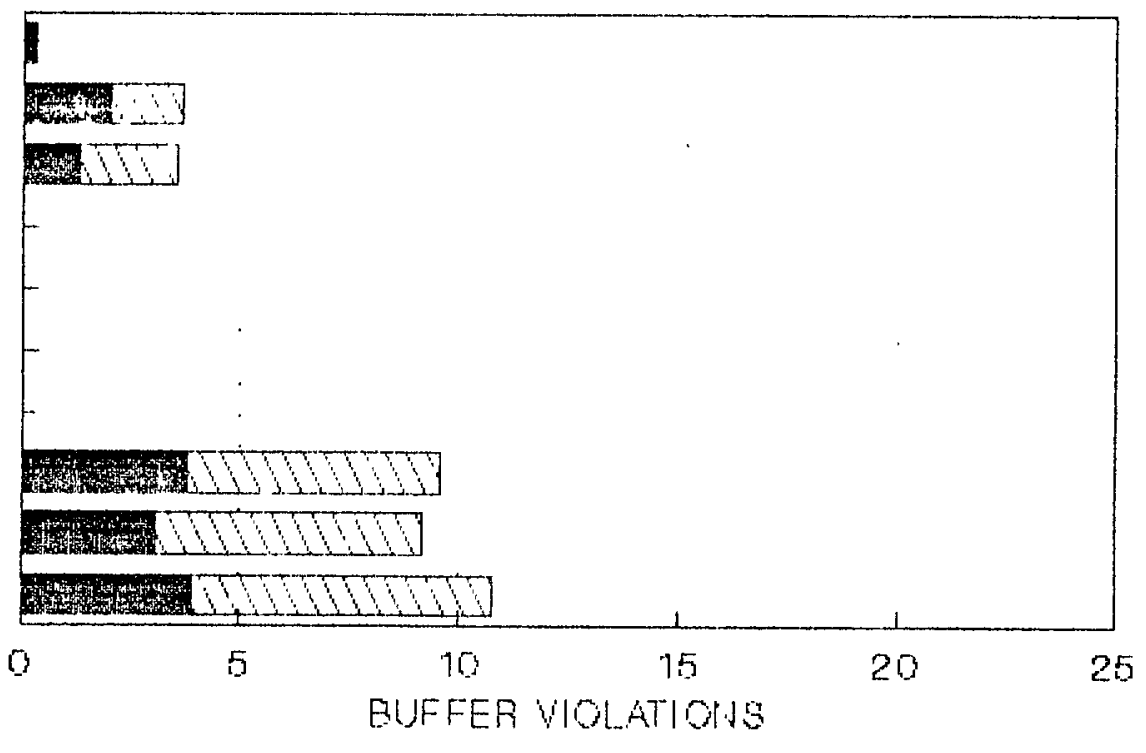

WEANE WIN WEAE OUT

BUFFER VIOLATIONS BY TIME OF DAY

OR 55 WALNUT

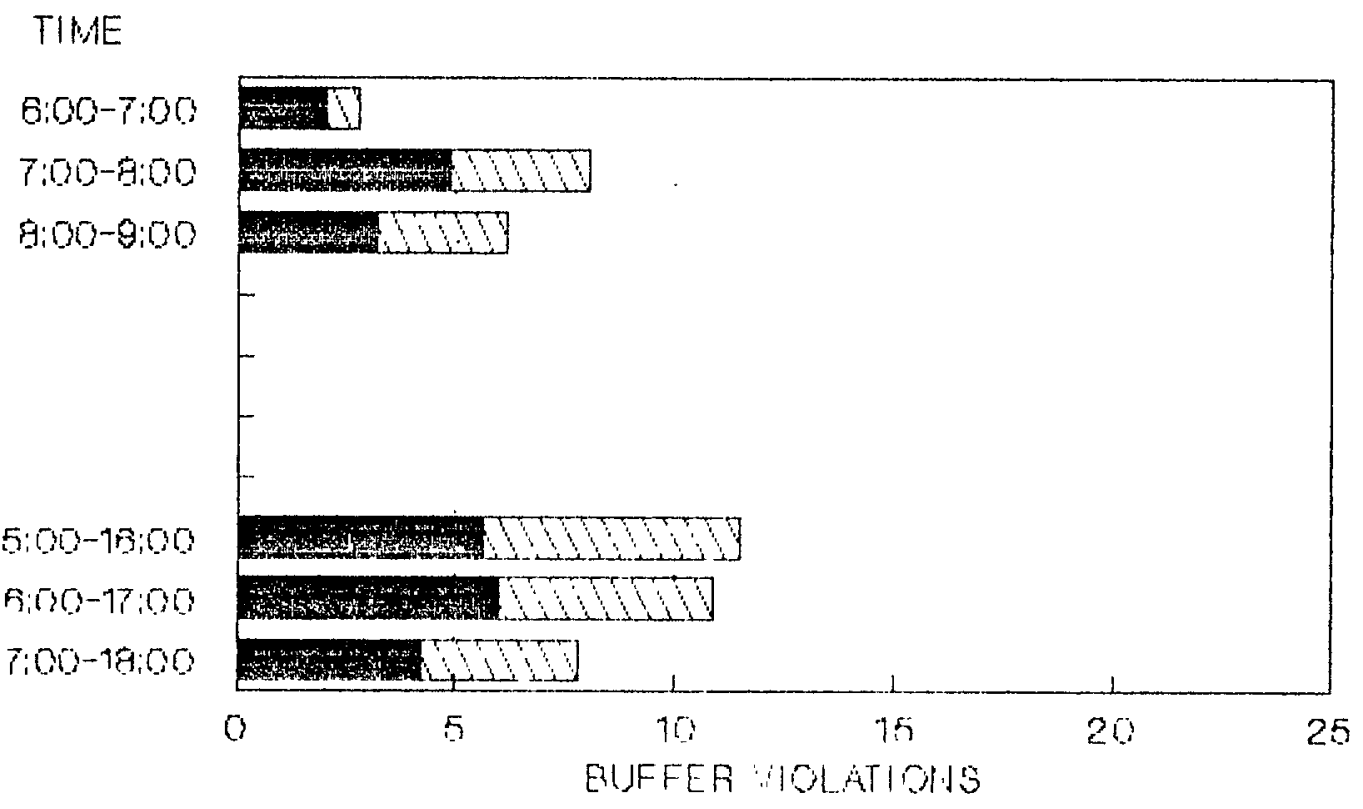

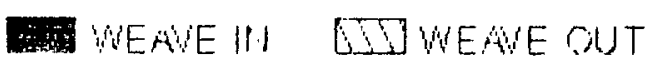


lane. An average of 7,500 vehicles passed the Walnut Avenue observation post in the HOV lane during the six hours of morning and evening observation. Since each of these vehicles must enter and leave the HOV lane at some point, these 7,500 vehicles represent a minimum of 15,000 opportunities for illegal buffer crossings. Since this is clearly a minimum number (other vehicles may have entered and left the lane before reaching the observation post), the data from the two observation points suggest that no more than $11.3 \%(1700+15,000)$ of the vehicles using the HOV lane cross the buffer illegally.

LA 91. Exhibit 3.15 charts the buffer violations observed from the Wilmington Street observation post over LA 91. The vast majority of these violators are entering the lane, since the Wilmington overcrossing is relatively close to the origin of the LA $91 \mathrm{HOV}$ lane. In all, an average of 56 illegal buffer crossings were observed during the evening commute along LA 91. If this rate of illegal access and egress were maintained throughout the length of the HOV lane, an estimated 1,500 buffer violations would be committed during the evening commute along LA 91, out of a minimum of 6,000 lane crossings. On the evidence of the Wilmington observation post, then, no more than $25 \%(1,500+6,000)$ of the users of the LA $91 \mathrm{HOV}$ lane enter or leave the lane illegally. This estimate is undoubtedly skewed by the fact that the Wilmington observation post is located near the beginning of the HOV lane, and so provides a view of an unusually high number of illegal entries.

Do Legitimate Carpools Cross the Buffer lllegally? On the basis of the violations recorded on special enforcement citations (see Section 4.3.2), legitimate carpoolers account for $72 \%$ of all buffer violations. Since carpoolers account for well over $90 \%$ of the vehicles in the HOV lane, it can be inferred that a randomly chosen occupancy violator is more likely to cross the buffer illegally than a legitimate carpooler. Nonetheless, as suggested in focus group discussions (see Section 6.2) many legitimate carpoolers do cross the buffer illegally.

\subsubsection{Drivers-Eye View}

Speed runs were made on each of the study freeways at various times before, during, and after special enforcement activities. Runs were made at approximate half-hour intervals during each peak period in the mixed flow lanes. Runs were also made in the HOV lanes to document the travel times available to carpoolers. The driver on each run was accompanied by a navigator who, in addition to recording time and mileage by trip segment, also recorded the 


\section{EXHIBIT 3.15}

\section{BUFFER VIOLATIONS BY TIME OF DAY}

\section{LA 91}

\section{THME}

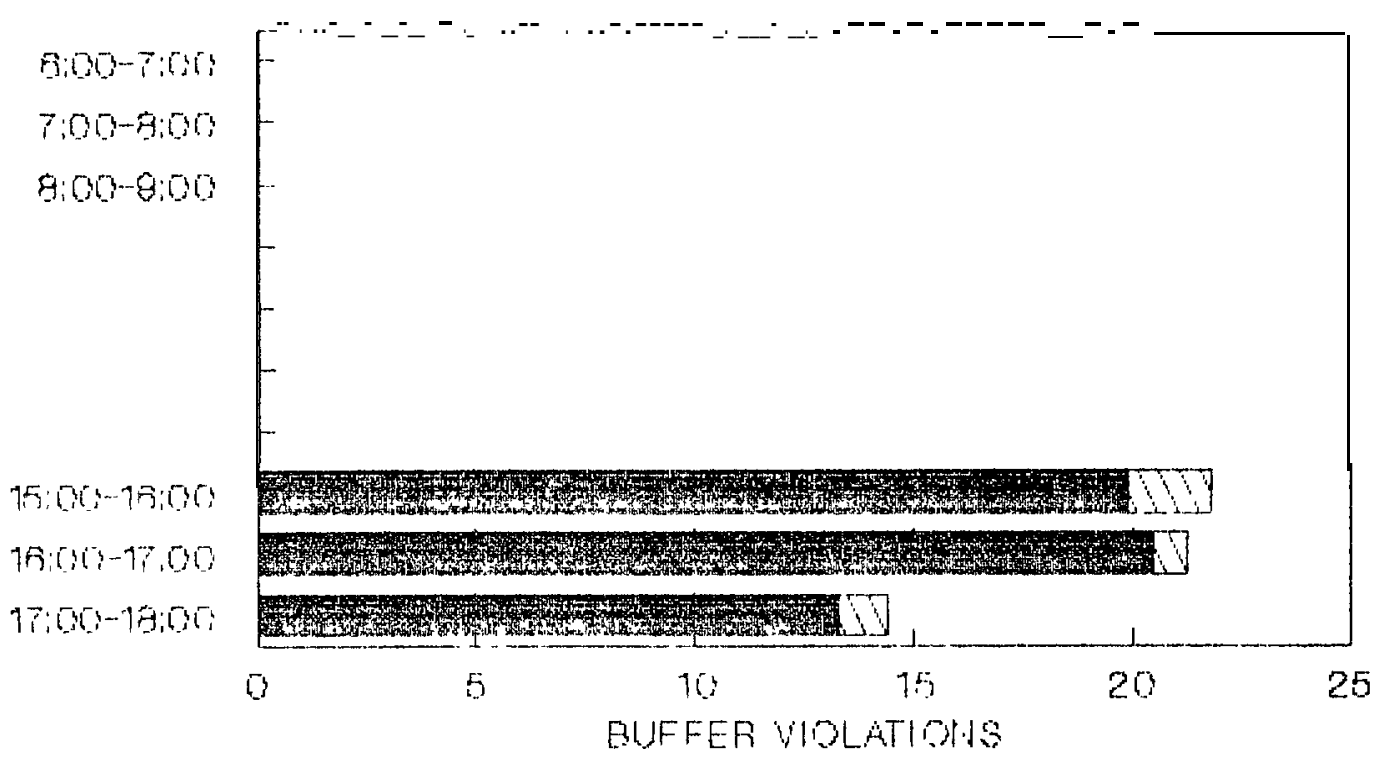

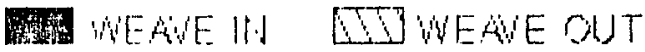


number of violators observed on each leg of the trip. This provides a "drivers-eye-view" of violations on each project as seen from the mixed-flow lanes.

Exhibit 3.16 summarizes the overall results of the speed runs made in the mixed-flow lanes of the four study freeways.

Occupancy Violations. As would be expected, the average number of occupancy violators passing a driver in the mixed flow lanes varies directly with the length of time the driver spends on the freeway. Drivers in the lane adjacent to the OR 55 HOV lanes would take an average of roughly 23 minutes to cover the full length of the lanes (21.8 minutes in the morning and 24.4 minutes in the evening). In that time, they would expect to be passed by 15 violators (12 in the morning and 18 in the evening).

On the Terra Linda segment of Marin 101, on the other hand, drivers in the mixed flow lanes spend roughly five minutes driving adjacent to the HOV lanes and can expect to see approximately 2 violators during that time. Taking all four freeways into consideration, drivers saw 0.64 occupancy violators for every minute they spent driving next to the HOV lane. The lowest number of sightings per minute (0.14) occurred during the morning commute on Santa Clara 101, where there is little congestion to slow traffic in the mixed flow lanes. The highest number of sightings per minute (1.9) was recorded on the same freeway during the evening peak, when congestion slows the mixed flow traffic and provides a more attractive time savings for carpoolers and violators.

Buffer Violations. In Southern California, where HOV-lane access and egress is restricted, observers also recorded the number of illegal buffer crossings seen during each speed run. Observers recorded far fewer buffer violations than occupancy violations. Roughly two buffer violations were recorded during each speed run on OR 55 and LA 91. At the same time, observers documented 15 occupancy violations on OR 55 and nine occupancy violations on LA 91. This does not necessarily mean that occupancy violations occur more frequently than buffer violations. Because buffer violations occur in the few seconds it takes to change freeway lanes, while occupancy violators remain in the HOV lane over a relatively long period of time, the driver in the mixed flow lane is much more likely to observe an occupancy violation than a buffer violation. 


\section{EXHIBIT 3.16}

\section{SUMMARY OF SPEED RUN DATA}

\begin{tabular}{|c|c|c|c|c|c|c|c|c|}
\hline \multirow[t]{3}{*}{$\begin{array}{l}\text { Freewayl } \\
\text { Direction }\end{array}$} & \multirow{3}{*}{$\begin{array}{l}\text { No. } \\
\text { Runs } \\
\text { (n) }\end{array}$} & \multirow{2}{*}{\multicolumn{3}{|c|}{$\begin{array}{c}\text { Average } \\
\text { Time } \\
\text { (mln ) }\end{array}$}} & \multicolumn{2}{|c|}{$\begin{array}{c}\text { Average } \\
\text { Violations Seen }\end{array}$} & \multirow{2}{*}{\multicolumn{2}{|c|}{$\begin{array}{l}\text { HOV Time } \\
\text { Samas }\end{array}$}} \\
\hline & & & & & (Occupa & Buffer) & & \\
\hline & & Overall & $\begin{array}{l}\text { Durrng } \\
\text { Enforcement }\end{array}$ & $\begin{array}{c}\text { Before } \\
\text { Enforcement }\end{array}$ & & & Average & Maximum \\
\hline SB AM & 49 & 21.8 & 17.3 & 23.6 & 12.3 & 1.6 & 3.6 & 6.7 \\
\hline NB PM & 38 & 24.4 & 30.4 & 22.5 & 17.5 & 2.6 & 11.5 & 16.3 \\
\hline EB PM & 37 & 19.1 & 18.7 & 19.2 & 8.6 & 2.1 & 2.9 & 5.9 \\
\hline SB AM & 33 & 48 & 3.2 & 60 & 1.9 & & 1.6 & 4.7 \\
\hline NB PM & 34 & 5.0 & 4.8 & 5.3 & 2.3 & - & 1.5 & ‘ 5.5 \\
\hline NB AM & 30 & 2.8 & 2.8 & 2.8 & 04 & - & 0.4 & 08 \\
\hline SB PM & 27 & 9.0 & 5.7 & 100 & 10.6 & - & 4.2 & 7.7 \\
\hline
\end{tabular}


Travel Times. Exhibit 3.16 also summarizes the travel times recorded by drivers traveling in the mixed flow lanes. Travel times logged during special enforcement days have been separated from general travel times to provide some indication of the impact of enforcement on freeway performance. In every case except one, travel times were actually faster during periods of special enforcement. The single exception was the evening commute on OR 55, when average travel times during special enforcement periods were eight minutes longer than travel times recorded on other days (30.4 minutes during enforcement vs. 22.5 minutes otherwise). This supports the observations of the CHP and airborne traffic observers, who noted that ticketing activities during the first enforcement wave caused a marked deterioration in traffic flow on OR 55. 


\subsection{ENFORCEMENT OPTIONS}

This chapter classifies and quantifies HOV enforcement strategies, tabulates historical enforcement levels, discusses problems encountered in enforcing mainline HOV lanes, outlines a variety of enforcement options, lists the options tested in the current study, and analyzes the results of these tests.

\subsection{OVERVIEW}

\subsubsection{Classifying Ongoing Enforcement Strategies}

Various strategies exist for assigning personnel to the enforcement of mainline HOV lanes. These strategies will vary from project to project and may vary over time for a single project. For example, the enforcement strategies employed during the opening weeks of a mainline lane may differ from the ongoing strategies used over the life of the project. Past studies (Miller and Deuser, 1978 and Billheimer, 1981) have classified ongoing enforcement strategies as follows:

Routine Enforcement, or those enforcement activities randomly conducted in concert with the normal assortment of a uniformed police officer's duties;

Special Enforcement, which entails the specific planning and application of police activities to an HOV facility for a period of time, as when a patrol car is specifically assigned to enforce a particular mainline HOV lane; and

Selective Enforcement, which constitutes a combination of both routine and special enforcement. The application of selective enforcement can vary in terms of time, location and level of effort, with the overall purpose of inducing "...a high level of motorist compliance by applying routine and special enforcement tactics in an unpredictable manner." (Miller and Deuser, 1978) Under a selective enforcement strategy, special enforcement procedures might be focused temporarily on a specific HOV lane either randomly, as personnel or overtime allocations become available, or in response to heavy violations or complaints.

With a few exceptions, selective enforcement strategies have historically been employed on most of the mainline HOV projects in California. 


\subsubsection{Past Enforcement Levels}

Routine and Special Enforcement. One of the key differences between the historical approach to enforcing ramp meter bypass lanes and the enforcement of mainline HOV lanes is the role of routine enforcement. Historically, there has been relatively little routine enforcement of ramp meter bypass lanes. Most of the citations issued on bypass lanes have been the work of special enforcement units. On California's mainline HOV lanes, however, citations issued by beat officers in the course of their routine duties constitute the dominant mode of enforcement. Exhibit 4.1 tabulates all 21655.5 citations issued in 1988. This tabulation shows that $69 \%$ of all citations issued on mainline HOV lanes during the year were the work of routine beat officers. On a project-by-project basis, the relative percentage of routine citations as a proportion of all 21655.5 citations ranged from $41 \%$ on Marin 101 to $100 \%$ on Santa Clara 237. Routine enforcement accounted for more than half of the occupancy citations issued on every one of California's mainline lanes except Marin 101.

EXHIBIT 4.1

ROUTINE VS. SPECIAL ENFORCEMENT AVERAGE CITATIONS PER DAY (1988)

$\begin{array}{lrccc}\text { Lane } & \text { Routing } & \text { Special } & \text { Total } & \text { \% Routine } \\ \text { OR 55 } & 11.8 & 3.9 & 15.7^{*} & \mathbf{7 5 \%} \\ \text { LA 91 } & 2.4 & 2.2 & 4.7^{* *} & \mathbf{5 3 \%} \\ \text { SC 101 } & 11.3 & 6.8 & 18.1^{*} & \mathbf{6 2 \%} \\ \text { Marin 101 } & 4.2 & 6.1 & \mathbf{1 0 . 3} & \mathbf{4 1 \%} \\ \text { SC 237 } & 7.5 & 0.0 & 7.5 & \mathbf{1 0 0 \%} \\ \text { SF I-280 } & 1.2 & 0.1 & 1.3 & \mathbf{9 2 \%} \\ \text { LA 10 } & \mathbf{1 1 . 7} & 3.3 & 15.0 & \mathbf{8 8 \%} \\ \text { TOTAL } & \mathbf{5 0 . 1} & \mathbf{2 2 . 4} & \mathbf{7 2 . 6} & \mathbf{6 9 \%}\end{array}$

*Includes some ramp citations.

‘*Includes only citations issued by Westminster and Santa Fe Springs CHP Areas.

Implications. Since many routine citations are issued for violations committed in full view of the beat officer, it is likely that the relatively high levels of routine enforcement experienced on California's mainline HOV lanes will continue. These high levels can be expected to continue regardless of the special enforcement strategies accompanying routine enforcement. Even if an area focuses primarily on higher fines or mail-out warnings, existing levels of routine enforcement would not be likely to change. Whatever long-term enforcement strategy is 
adopted, it will undoubtedly be augmented by continuing levels of routine enforcement. The alternative (i.e. no routine enforcement) is likely to be untenable, since it would put the CHP in the position of asking their beat officers to turn their backs on violations committed in their presence.

\subsubsection{Enforcement Problems}

CHP officers on each of California's existing mainline HOV lanes were interviewed to obtain an officer's eye view of design issues, explore enforcement problems, and identify enforcement strategies worthy of testing. In discussing the enforcement of mainline HOV lanes, the officers identified the following common enforcement problems:

- babies on board;

- lack of median;

- nested violators;

- mirror watching;

- hazardous pursuits; motorcycle confusion;

escorting violators to shoulder.

Babies on Board. Officers on all projects cited the problem of pulling over a suspected violator only to find that a sleeping adult or a small child below window level made the vehicle a legitimate Carpool. One officer noted that he would not pursue a car having a child's carseat, even if it appeared that the carseat was unoccupied.

Lack of Median Shoulder. Most of California's existing mainline HOV lanes have no median shoulder. This means that officers usually drive warily in the adjacent lane when watching for violators, have no escape hatch when pursuing violators in the HOV lane, and must escort violators across mixed flow lanes to the right-hand shoulder once they are apprehended.

'Nested Violators". Officers found it difficult to pursue violators who were "nested" in a group of cars, particularly if the violating vehicle was followed closely by a truck or bus. This was particularly true when there was no median lane that the officers could use to accelerate.

Mirror Watching. The most common method officers use to enforce California's mainline HOV lanes is to drive in the adjacent lane while watching for violators in their rear-view mirror. This mirror-watching takes a good deal of the driver's attention, and some officers said that 
they felt uncomfortable driving in congested traffic while devoting so much attention to their mirror.

Hazardous Pursuit. The lack of a median shoulder also makes it more hazardous to pursue violators in the HOV lane. Shortly before the study began, a Marin CHP officer had an accident when a carpooler nosed into the HOV lane as he was pursuing a violator.

Motorcycle Confusion. Motorcyclists cannot legally use the HOV lanes on Marin 101, the El Monte Busway, of LA 91. However, they are allowed on Santa Clara County's HOV lanes, Orange County Route 55, and most ramp meter bypass lanes. This inconsistency causes some confusion and much ill will.

Escorting Violators to Shoulder. In the absence of a median shoulder or enforcement area, officers must escort violators across mixed-flow traffic to get to the right-hand shoulder. When there is no right-hand shoulder, violators must be escorted all the way off the freeway. The escort process disrupts traffic, and the fact that tickets are issued away from the HOV lanes minimizes the possibility that the ticketing activity will deter passing violators.

\subsubsection{Citation Characteristics}

Bail Schedules. Prior to January 1989, the reported cost of a citation for an occupancy violation ranged from $\$ 35$ (plus court costs) on LA 91 and the El Monte Busway to \$65 on OR 55 . In January 1989, the California Legislature raised the level of fines for occupancy violations of HOV lanes. Legislation in Senate Bill (SB) 236 dictated the following fine structure.

\section{Offense}

First Conviction

Second Conviction

Third Conviction

\section{Penalty}

\section{Maximum}

$\$ 100$

$\$ 150$

$\$ 150$

$\$ 200$

$\$ 250$

$\$ 500$

Surveys taken in March 1989 (see Section 6.3.2) suggest that the driving public was not generally aware of this revised fine structure. 
Moving Violation Status. Visits to various mainline HOV projects at the start of the current study revealed that considerable confusion existed among different CHP areas (and among project team members) regarding the exact status of the 21655.5 violation. Officers in Orange County and Los Angeles County felt that the illegal use of an HOV lane constituted a moving violation which contributed to a driver's point count. Officers in Marin and Santa Clara counties indicated that local judges had informed them that it was not a moving violation.

Subsequent checking by Sacramento headquarters personnel confirmed that the 21655.5 citation does not constitute a moving violation. Nor is the related 21655.8 citation for crossing an HOV buffer lane a moving violation. Since this was not common knowledge among police officers, it can be assumed that the general public is not aware that HOV violations are not considered moving violations. (Focus group discussions support this assumption.) To clear up confusion among enforcing officers, CHP officers in all urban areas should be apprised of the status of HOV violations. In instances in which violators have been observed driving unsafely as well (i.e. speeding, or changing lanes unsafely) they should be cited for the more serious moving violation as well as for their HOV offense.

\subsection{TEST STRATEGIES}

In the course of the current study, different levels and combinations of routine and special enforcement were tested to ascertain their effectiveness in controlling violations on mainline HOV lanes. During two one-month periods, special CHP officers were assigned, singly and in teams, to particular projects for a specified number of days. Violation rates were measured before, during, and after these special enforcement activities. Particular attention was paid to the behavior of motorists after special enforcement activities have ceased, to determine the residual effect of special enforcement in deterring violators.

\subsubsection{Strategies Tested on Mainline Lanes}

The enforcement strategies tested on the four existing mainline lanes during the two waves of special enforcement focused on:

- Measuring the relative effectiveness of routine and special enforcement: 
- Investigating the personnel levels required to achieve and maintain low violation levels;

- Documenting the impact of highly visible enforcement approaches;

- Testing the effectiveness of team enforcement tactics; and

Demonstrating the use of enforcement areas and median shoulders.

Exhibit 4.2 lists the enforcement strategies tested on each freeway during the two enforcement waves.

\subsubsection{Tactical Alternatives}

In addition to testing different deployment levels, different tactics for surveillance, detention, apprehension, and citation were also studied. Tactical alternatives which were suggested through past experience, observation of existing procedures, and discussions with CHP personnel are discussed below.

Warings vs. Citations. The possibility of having officers issue warnings rather than citations is generally of interest only as a start-up strategy during the first few weeks of a new project. Following an unannounced policy, verbal warnings were generally issued to violators in place of citations during the first week of operation on San Diego l-15. Except when warnings are issued in a unique fashion (for instance, by mail--see below), the relative effectiveness of warnings, as opposed to citations, was not considered as an ongoing strategy.

Mail-Out Warnings or Citations. Mailed warnings based on license plate observation have been used with reported effectiveness on the preferential HOV toll lanes on the San Francisco/Oakland Bay Bridge (Miller and Deuser, 1978), and on Interstate 5 in Seattle (Orange County Transit District, May 1987). However, the precise impact of mail-out warnings on HOV violations has not been well documented. Although mail-out warnings may be used in the future on California freeways, the HOV Steering Committee advised against sending warning letters to violators as part of the current study. It was felt that the field testing of such letters raised legal issues and potential public relations problems that were beyond the scope of the study. However, the potential public acceptance of this approach was probed in focus groups where the possibility of mailed warnings based on electronic surveillance generated heated discussion. (See Section 6.1.4.) Participants in three of six focus groups favored the concept, while the remaining three groups strongly opposed it. 
EXHIBIT 4.2

\section{SPECIAL ENFORCEMENT STRATEGIES}

\begin{tabular}{|c|c|c|}
\hline FREEWAY & $\begin{array}{c}\text { FIRST WAVE } \\
\text { (October } 17 \text { to November 11) }\end{array}$ & $\begin{array}{l}\text { SECOND WAVE } \\
\text { (March } 6 \text { to March 31) }\end{array}$ \\
\hline OR 55 & $\begin{array}{l}\text { Highly visible team enforcement } \\
\text { with a motor officer continuously } \\
\text { visible in the enforcement area } \\
\text { two days per week (AM \& PM). } \\
\text { Officers worked in teams of } \\
\text { three, with two motor officers } \\
\text { pursuing violators while the third } \\
\text { occupies the enforcement area. }\end{array}$ & $\begin{array}{l}\text { Hiahly visible enforcement with } \\
\text { a motor officer continuously } \\
\text { visible in the enforcement area } \\
\text { two days per week (AM \&PM). } \\
\text { A single chase vehicle was } \\
\text { used in an attempt to avoid } \\
\text { disrupting traffic. }\end{array}$ \\
\hline LA 91 & $\begin{array}{l}\text { Heavy enforcement. Assign two } \\
\text { officers to work the enforcement } \\
\text { area nearly every day for a month. }\end{array}$ & $\begin{array}{l}\text { - Routine enforcement. Revert } \\
\text { to routine enforcement only. }\end{array}$ \\
\hline Marin 101 & $\begin{array}{l}\text { - Team enforcement with one } \\
\text { officer acting as a spotter and } \\
\text { radioing violator descriptions } \\
\text { ahead to waiting officers. } \\
\text { Concept tested eight mornings } \\
\text { and six afternoons. }\end{array}$ & $\begin{array}{l}\text { - Team enforcement PM only. } \\
\text { Two motor officers were used } \\
\text { as spotters, with a single } \\
\text { patrol car serving as a chase } \\
\text { vehicle. Enforcement supplied } \\
\text { ten days during four-week } \\
\text { enforcement period. }\end{array}$ \\
\hline $\begin{array}{l}\text { Santa Clara } \\
101\end{array}$ & $\begin{array}{l}\text { AM-Only enforcement. Half-day } \\
\text { enforcement was tested by } \\
\text { concentrating special enforcement } \\
\text { (one officer) during the AM peak } \\
\text { two days per week. }\end{array}$ & $\begin{array}{l}\text { - Heavy enforcement. Three } \\
\text { officers were assigned to special } \\
\text { enforcement five days per } \\
\text { week, splitting assignments } \\
\text { between AM and PM peaks. }\end{array}$ \\
\hline $\begin{array}{l}\text { San Diego } \\
\text { I-15 }\end{array}$ & $\begin{array}{l}\text { Start-up strategy. Assign single } \\
\text { officer to full-time enforcement of } \\
\text { separated lane, with heavy special } \\
\text { enforcement (daily during first } \\
\text { week, three days per week, AM } \\
\text { and PM, during next three weeks). } \\
\text { Unannounced policy of verbal } \\
\text { warnings during first week. }\end{array}$ & $\begin{array}{l}\text { Routine enforcement. Rely } \\
\text { exclusively on single officer } \\
\text { assigned to routine enforce- } \\
\text { ment to keep violation rates } \\
\text { low. }\end{array}$ \\
\hline
\end{tabular}


Line Patrol versus Stationary Patrol. The relative use of line patrol, where officers travel by motor vehicles over a particular section of roadway, and stationary patrol, where officers and vehicles are deployed in a fixed position, are most often dictated by the geometric attributes and operating characteristics of the HOV project itself. For instance, the enforcement area on LA 91 tends to encourage stationary enforcement efforts. Even so, some officers adopt a combination of line patrol and stationary patrol when enforcing LA 91, driving in the adjacent lane when enforcing upstream from the enforcement area, then waiting in the enforcement area until a violator passes, then adopting a line patrol strategy downstream from the enforcement area. In cases in which both strategies appear feasible and the choice is not obvious (as in the case of a mainline HOV lane with a median wide enough to accommodate a stationary patrol car or motorcycle), officers tended to use both tactics. The different geometric configurations on the study freeways offered the possibility of comparing the use of stationary enforcement areas with the results achieved by assigning comparable personnel levels to line patrol duties.

Motorcycles vs. Patrol Cars. In the general case, the relative merits of motorcycles and patrol cars have been studied by the CHP and are fairly well understood (California Highway Patrol, March 1978). Certain HOV projects (i.e., the I-280 preferential lanes) can be enforced more readily through the use of motorcycle officers. In other instances, enforcement can be accompanied just as readily with patrol cars. There were special instances in the current study in which circumstances dictated the use of motorcycles rather than patrol cars. These included the use of spotters on Marin 101, where the median was too narrow to accommodate a patrol car, and the team enforcement testing on OR 55, where officers driving patrol cars were reluctant to use the narrower enforcement area. Aside from noting these instances, the current study has made no effort to assemble data comparing motorcycle enforcement and patrol car enforcement.

Team Enforcement. Team enforcement efforts involving more than one officer at a single location were used successfully on both Marin 101 and OR 55. In the past, teams of two or more officers have sometimes been used to enforce the Carpool lanes on the San Francisco/ Oakland Bay Bridge, where the refuge area is large enough to accommodate a string of automobiles. In using this refuge area, one officer waves violators over, while other team members write tickets. This tactic has also been employed on several ramp meter bypass lanes and on the El Monte Busway. A single officer operating on his own is limited by his ability to write more than one ticket over a specific"r?eriod of time. While one ticket is being written, several violators may pass by Scot-free, to the consternation of the ticketed violator. A team of officers in the right setting can often collar more violators than either could separately, and the wait in line to be ticketed would serve as an additional deterrent to violators. Unfortunately, the presence of 
vehicles waiting to be ticketed alongside California's mainline HOV lanes off en caused congestion as gawkers slowed to look at a line of stopped vehicles. Enforcement-caused congestion was noted during the first enforcement wave on OR 55, when a spotter was used in conjunction with two chase vehicles.

Team enforcement tactics were also used to provide highly visible enforcement on both Marin 101 and OR 55. On OR 55, at least one team member maintained a visible presence in the enforcement area while partners pursued violators. In another application on Marin 101, one officer served as a stationary spotter, radioing vehicle descriptions ahead to fellow officers who apprehended violators at locations more suitable for pursuit, apprehension, and ticketing.

Electronic Surveillance. The possibility of using video equipment in HOV lane surveillance and enforcement activities has arisen over and over in the current investigation of $\mathrm{HOV}$ lane violations. It is possible that a videotape of HOV lane activities could provide more accurate violation counts, a permanent record of violation activity, documentation of the identity of violators, and even a basis for mail-out warnings or citations. Talks with different manufacturers of video equipment have indicated that it is possible to videotape both the license plate and the windows of vehicles using HOV lanes, even when those vehicles are traveling at rapid rates of speed. What is less well understood is the ability of the video camera to document with certainty the exact number of vehicle occupants. To investigate this possibility, the current study of HOV lane violations has been extended to test both the feasibility and accuracy of the use of video equipment in determining vehicle occupancy, documenting violator identity, and ordering HOV lane surveillance and enforcement.

In the course of the expanded investigation:

1. A three-camera video system operating from a mobile unit will be installed to provide a videotape record of HOV lane operations. The license plates of suspected violators will be recorded, along with different views of the interior of these vehicles, and the time and place of the suspected violation will be documented;

2. Violation rates determined through the use of video equipment will be compared with the rates reported by roadside observers;

3. CHP officers will explore the possibility of using the equipment as an enforcement aid and stop a sufficient number of suspected violators to document the accuracy of the equipment; and

4. A cost-effectiveness analysis will assess the utility of the video equipment both as a surveillance tool and as an enforcement aid. 
The results of this additional investigation will be documented in a separate report to be prepared approximately six months after the completion of the current study.

\subsection{ENFORCEMENT LEVELS}

\subsubsection{Citations Issued}

Citation totals for each of the two one-month enforcement waves are listed below in Exhibit 4.3. The exhibit lists total officer hours, recorded citations, and a breakdown of citations issued per hour of special enforcement activity.

\section{EXHIBIT 4.3}

\section{SPECIAL IENFORCEMENT LEVELS}

\section{FIRST ENFORCEMENT WAVE}

\begin{tabular}{lcccccc} 
Project & Officer & Total & & \multicolumn{3}{c}{ Citations Per Commute Day } \\
OR 55 & Hours & Citations & Cites/Hr. & AM & PM & Total \\
LA 91 & 187.25 & 468 & 2.5 & 9.4 & 14.0 & 23.4 \\
Marin 101 & 128.00 & 105 & 0.8 & -- & 5.3 & 5.3 \\
Santa Clara 101 & 44.25 & 38 & 0.9 & 0.8 & 1.1 & 1.9 \\
Total (First Wave) & 5500 & 105 & 1.9 & 5.2 & .05 & 5.3 \\
& 414.50 & 716 & 1.7 & 15.4 & 20.4 & 35.8
\end{tabular}

\section{SECOND ENFORCEMENT WAVE}

$\begin{array}{lrrrrrr}\text { OR 55 } & 128 & 235 & 1.8 & 5.7 & 6.1 & 11.8 \\ \text { LA 91 } & 0 & 0 & 0 & 0 & 0 & 0 \\ \text { Marin 101 } & 67^{*} & 92 & 1.4 & 0 & 4.6 & 4.6 \\ \text { Santa Clara 101 } & \underline{240} & 524 & 2.2 & 9.1 & 17.1 & 26.2 \\ \text { Total (Second Wave) } & 405 & 851 & 2.1 & 14.8 & 27.8 & 42.6\end{array}$

${ }^{*}$ Includes 37 hours for motorcycles and 30 hours for a single patrol car chase unit. 
First Wave. The average number of citations issued per officer hour over the first enforcement period ranged from just under one per hour on Marin 101 and LA 91 to 2.5 citations per hour on OR 55. The low citation rate on Marin 101 is consistent with historical levels and reflects the difficulty of enforcing $\mathrm{HOV}$ restrictions in the absence of a median lane and suitable enforcement areas. On LA 91, the low level reflects a lack of violators. Citation rates were highest during the first few weeks of special enforcement. During the later weeks, however, there weren't enough violators to keep the two-officer team busy. OR 55 experienced the heaviest enforcement rate during the first enforcement wave, as the three-person enforcement team issued an average of 2.5 citations per officer hour. Reports from the area indicated that this heavy citation rate severely disrupted traffic on days when special enforcement was scheduled.

Second Wave. During the second wave of enforcement, the enforcement team on OR 55 was cut back to a single chase vehicle, the number of citations issued was nearly cut in half, and reports of traffic disruption disappeared. LA 91 reverted to routine enforcement. Teams of two motorcyclists and a chase car were used during the evening commute in Marin, raising the number of citations per hour to 1.4. The motor units themselves produced over two citations per officer-hour, more than double historical citation rates. On Santa Clara 101, heavy officer assignments produced 524 citations (2.2 per officer hour), the highest number achieved during either enforcement wave.

\subsubsection{Violations Cited}

Exhibit 4.4 tabulates the different violations listed on citations issued by special enforcement officers during each wave of special enforcement. Because each citation could include more than one violation, the number of violations exceeded the number of citations issued by $42 \%$ during the first enforcement wave used and by $24 \%$ during the second wave.

HOV Violations. As would be expected, the HOV occupancy violation appeared on over three-quarters of the citations issued. In Southern California, buffer violations (cited as 21655.8 or 21461 A, "failure to obey signs and signals") appeared on $11.3 \%$ of the citations issued to drivers on OR 55 and LA 91. Of the 3921655.8 citations issued for illegal buffer crossings during the second enforcement wave, eleven (28\%) were issued in conjunction with occupancy violations. Although the apprehending officer has a good deal of latitude in deciding which violation or violations to list on a ticket, the fact that $28 \%$ of the buffer violations were 
EXHIBIT 4.4

VIOLATIONS CITED BY SPECIAL ENFORCEMENT

FIRST WAVE

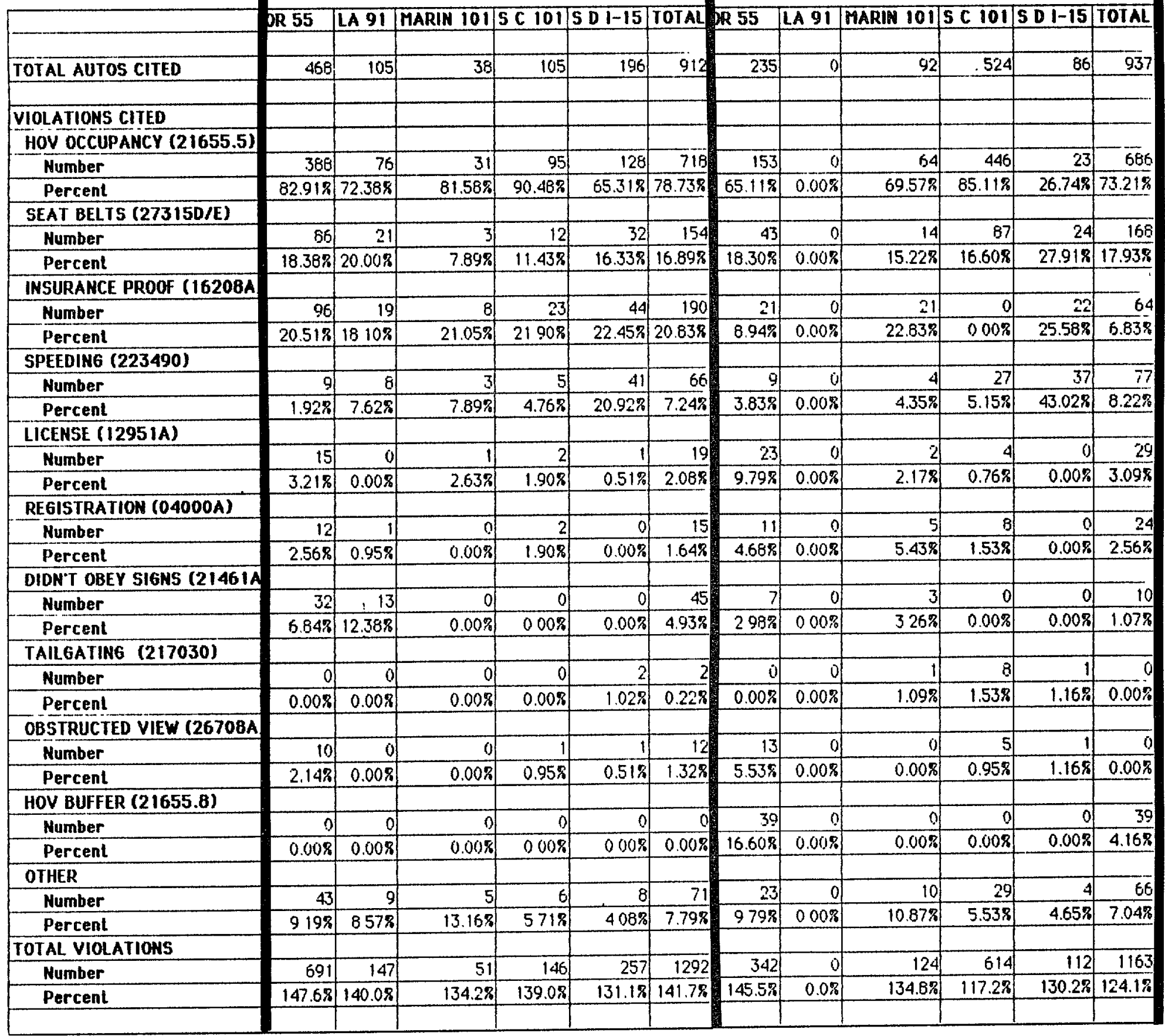

\section{SECOND WAVE}


committed by occupancy violators (who accounted for less than $10 \%$ of the vehicles in the HOV lane) confirms the CHP suspicion that occupancy violators are over-represented among buffer violators. At the same time, legitimate carpoolers appear to account for the majority of buffer violations. It is difficult to develop more specific interpretations of this data, because of the latitude given the apprehending officer and because occupancy violators often bail out of the HOV lanes when they see a CHP officer, adding a buffer violation to their occupancy violation.

Speeding Violations. Speeding infractions were listed on $21 \%$ of the citations issued by officers on the barrier-separated lanes of San Diego's I-15 during the first enforcement wave. By the second enforcement wave speeding violations accounted for $43 \%$ of the citations issued, while HOV occupancy violations were listed on only $27 \%$ of the tickets.

\subsection{ENFORCEMENT IMPACTS}

This subsection discusses the impact of the two waves of special enforcement on violation rates and freeway performance.

\subsubsection{Orange County Route 55}

Exhibit 4.5 plots violation rates on OR Route 55 before, during, and after the two waves of special enforcement. The exhibit also plots the number of 21655.5 citations issued during the special enforcement period against the average levels experienced during 1988 and 1989 . The exhibit shows that violation rates dropped significantly during the first enforcement wave at the two OR 55 observation points (Meats Avenue and Walnut Avenue), generally remained low following the first wave, and have continued to register below 5 percent during and after the second enforcement wave.

First Enforcement Wave. During the first enforcement wave, officers worked in three-person teams, with two officers pursuing violators spotted by the third officer, who was continuously visible in the enforcement area. This strategy was followed two days per week during the four-week enforcement period. Officers following this strategy issued an average of 2.5 citations per officer hours over the four-week period. The number of special enforcement citations issued more than doubled the average number issued at other times during 1988. 
EXHIBIT 4.5

VIOLATION RATE VS. TIME: OR 55

OR 55 MEATS

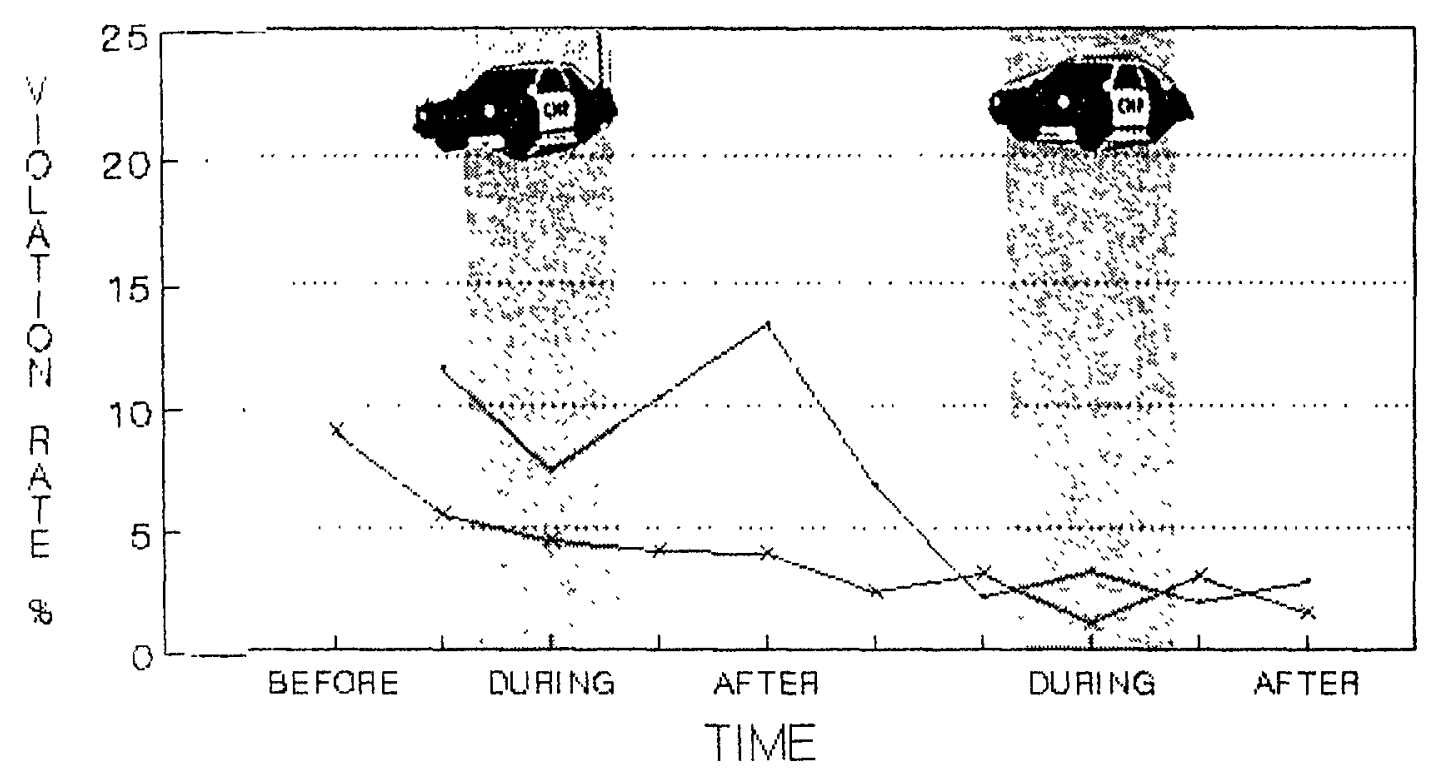

$-\mathrm{s} / \mathrm{AM} \longrightarrow \mathrm{AM} \mathrm{PM}$

OR 55 WALNUT

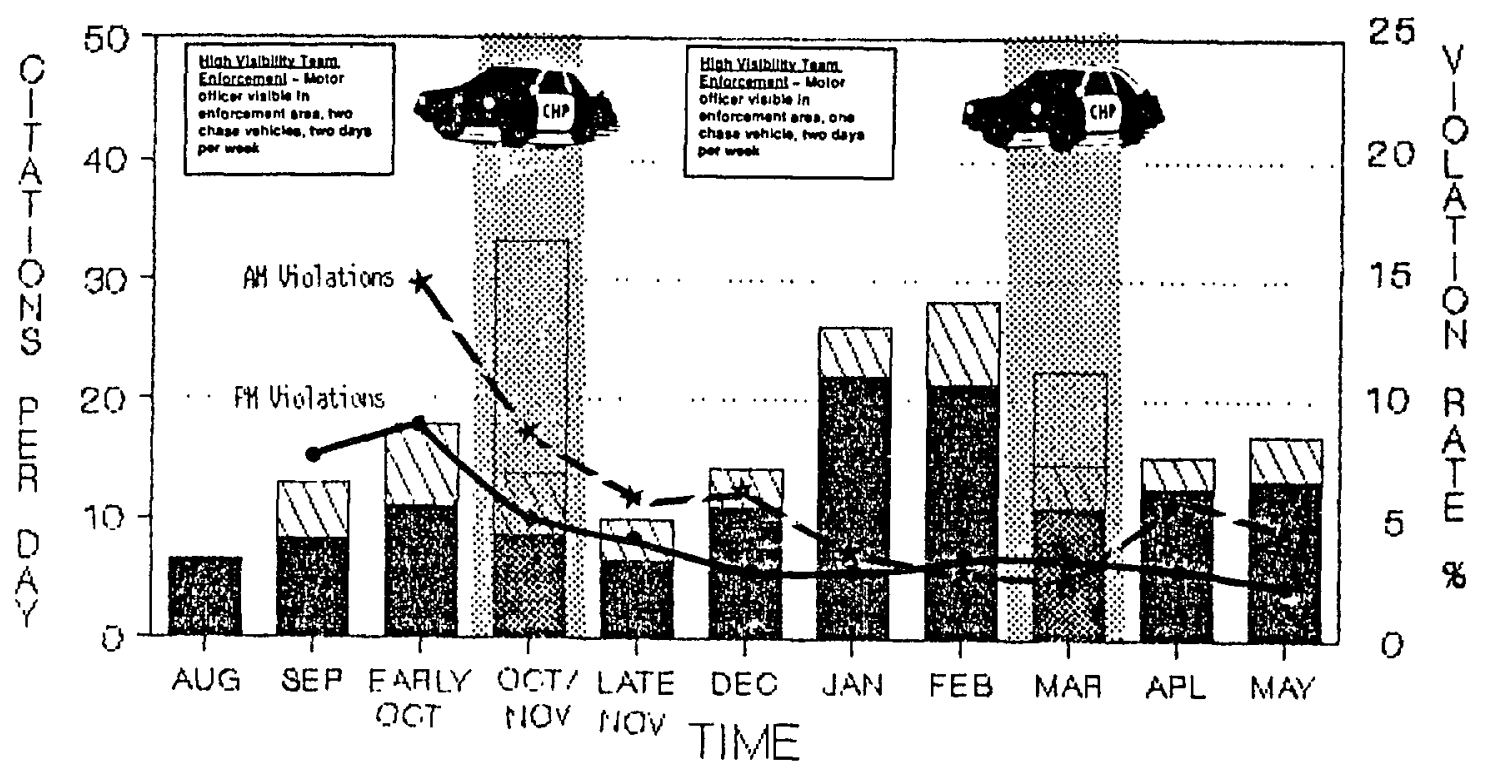

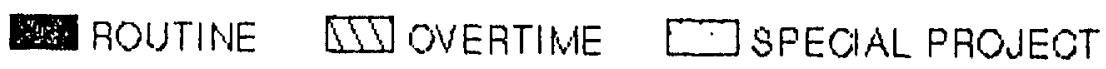


Violation rates dropped appreciably at both observation points during the special enforcement period. The most striking drops occurred during the morning peak. At the Meats Avenue observation point, the violation rate for southbound traffic dropped from $11.6 \%$ to $7.4 \%$ while the rate for northbound traffic dropped from $13.4 \%$ to $5.6 \%$. A similar drop, from $14.3 \%$ to $8.4 \%$, was observed in the peak southbound direction at the Walnut Avenue observation point. While violation rates measured at the Walnut observation point remained low long after special enforcement ended, those measured at Meats Avenue during the morning peak returned to preenforcement levels briefly before dropping below $5 \%$ prior to the second wave of enforcement. Both the CHP and local traffic reporters noted the first wave of enforcement activity severely disrupted traffic when all units were operating.

Second Enforcement Wave. During the second enforcement wave, the high visibility enforcement program employed during the first wave was modified in an attempt to avoid disrupting traffic flow. As part of this program, a motor officer was continuously visible in the enforcement area two days per week (AM and PM). The officer relayed information on violators to a single chase vehicle. One chase vehicle was used instead of the two employed during the first wave to reduce the impact on traffic flow. The violation rate recorded at observation points upstream and downstream from the enforcement area was below $5 \%$ during both the morning and and evening peaks (See Exhibit 4.5). These levels were lower than the levels recorded before, during and after the first enforcement wave and reflect a consistent downward trend in violation rates on OR 55 since the initial enforcement wave.

The use of a single chase vehicle caused the number of citations issued to drop to 1.7 citations per officer hour, down from 2.5 citations per officer hour during the first enforcement wave. Reports from the Santa Ana CHP area indicated that the traffic disruption noted during the first enforcement wave did not recur during the second wave when the enforcement level was reduced to a single chase vehicle.

Off-Peak Direction. At the time of the first enforcement wave, CALTRANS District 12 personnel monitored violation rates in the off-peak direction during the morning peak at the Meats Avenue and Walnut Avenue observation points. Exhibit 4.6 plots the violation rates observed in both directions before, during and after the first wave of enforcement. The exhibit shows that changes in violation rates in the off-peak direction paralleled those in the peak direction. At the Meats Avenue location, violation rates in both directions dropped during the period of special enforcement, and then rose again after the enforcement levels returned to normal. At the Walnut Avenue location, violation rates in both directions dropped during the enforcement activity and continued to decline after special enforcement ended. 
EXHIBIT 4.6

VIOLATION RATE VS. MME

PEAK AND OFF-PEAK DIRECTION: OR $5 E$ "AEAT'

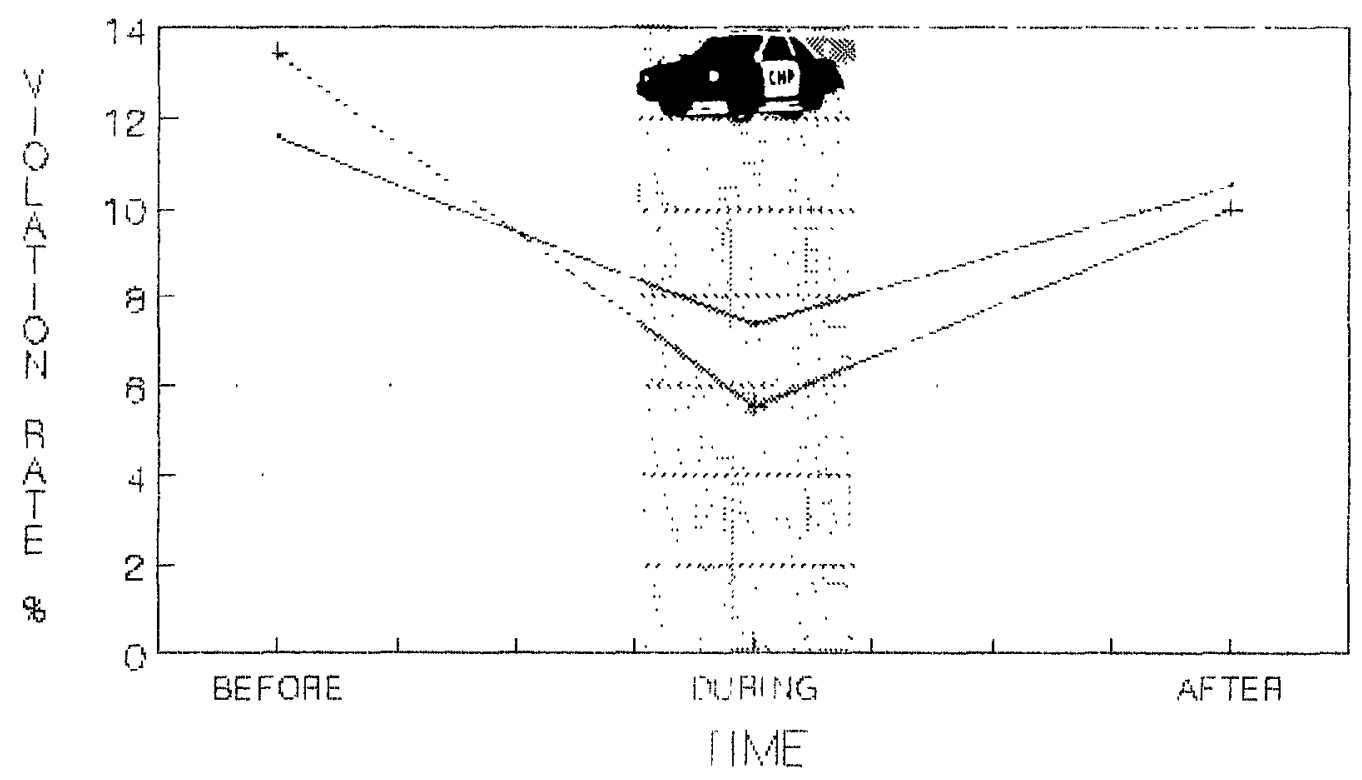

-

VIOL. ATION RATE VS. TIME

PEAK AND OFF-PEAK DIRECTIONS: OR 55 WALHUT

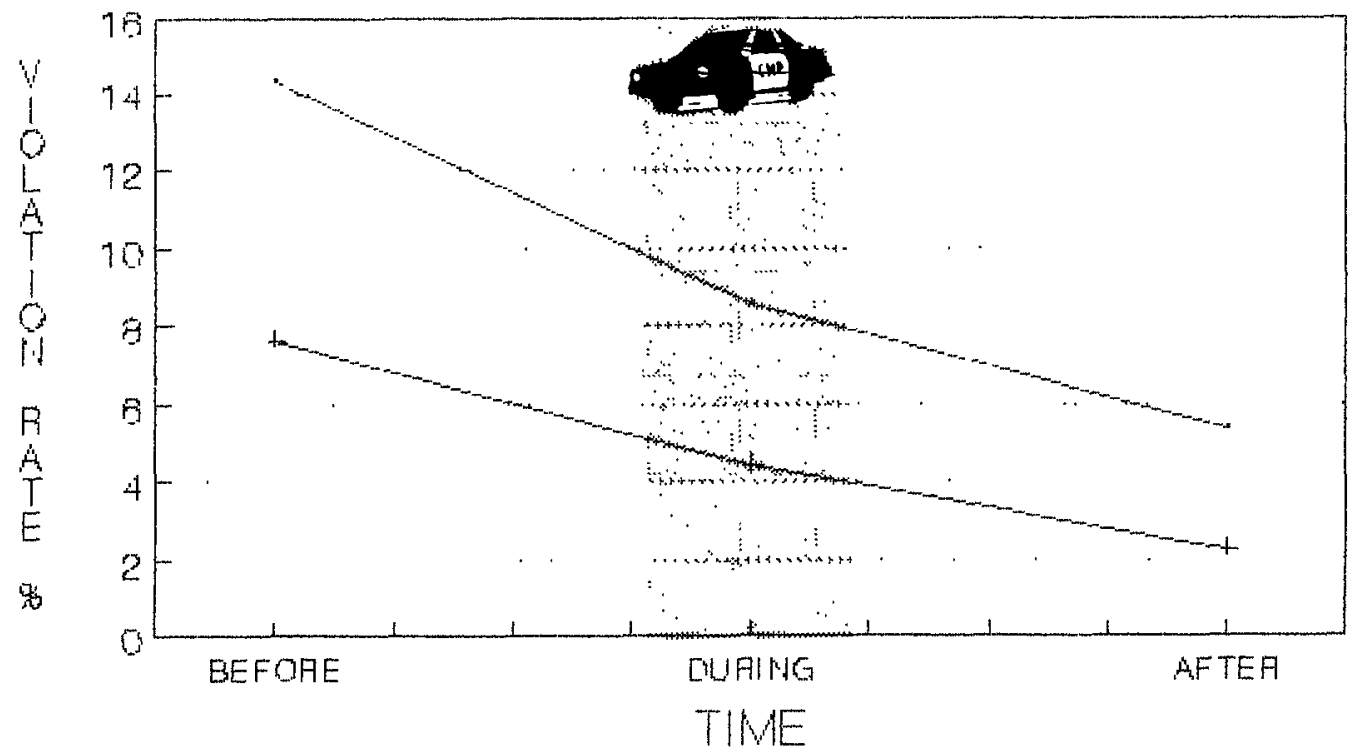

- SE AM + W AM 
Officers enforcing HOV lanes in the peak direction of flow must spend a certain amount of time traveling in the off-peak direction to return to the head of the lanes or to the enforcement area. When they do, their presence evidently has an impact on travelers in the off peak direction. It is possible that the two-way design of the enforcement area on OR 55 causes motor officers using the area to have a deterrent effect on travelers in both directions. In any event, it is clear that violations in both the peak and off-peak direction were affected by the first wave of special enforcement on OR 55.

\subsubsection{Los Angeles Route 91}

Violation rates have historically been low along Los Angeles Route 91, which features a 14' wide, 1300' long enforcement area that has been accepted and used by the CHP since the project opened. Exhibit 4.7 plots violation rates on LA 91 before, during, and after the two waves of special enforcement. The already-low violation rates on LA 91 remained low before, during, and after each wave of special enforcement.

First Enforcement Wave. During the first enforcement wave, two officers were assigned to work out of the enforcement area four days per week for the four-week enforcement period. These special officers issued an average of 5.3 citations per day during the four-week enforcement period. Prior to the enforcement activity, violation rates of $2.7 \%, 3.5 \%$, and $7.1 \%$ were recorded. During the enforcement period, the observed violation rate was $6.1 \%$. Thus the heavy enforcement activity had no demonstrable impact on the already low violation rate, which remained low during the post-enforcement period.

Second Enforcement Wave. In view of the consistently low violation rates, LA 91 reverted to routine enforcement enly during the second wave in March 1989. The violation rate remained below $5 \%$, suggesting that acceptable violation rates may be achieved with lower levels of special enforcement, so long as existing levels of routine enforcement are maintained and magnified by the presence of enforcement areas.

\subsubsection{Marin 101}

Exhibit 4.8 plots violation rates on Marin 101 before, during, and after the two waves of special enforcement. The violation rates shown in the illustration have been adjusted to eliminate the impacts of darkness and fringe effects on the overall violation rates. 


\section{VIOLATION RATE VS. TIME LA91 PM Wilmington}

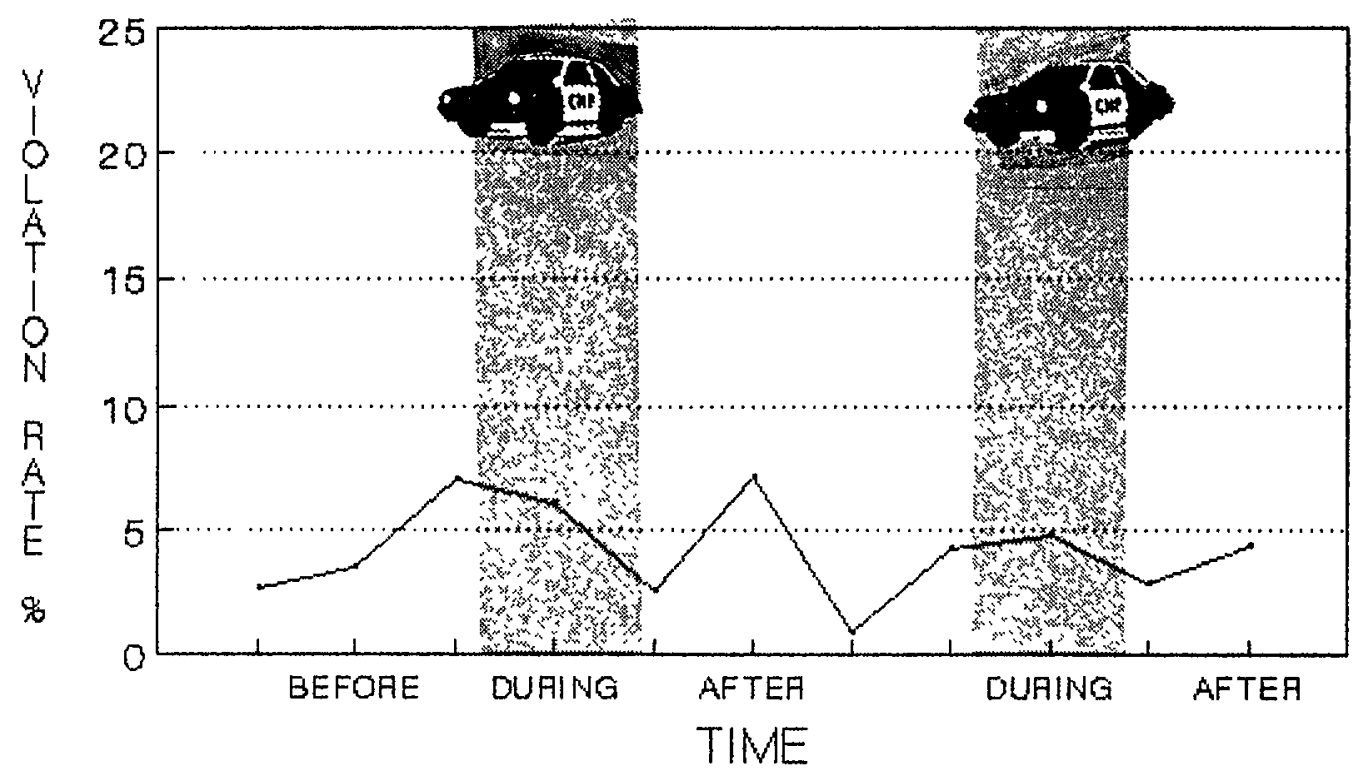

\section{CITATION COUNT OF 21655.5 VIOLATIONS LA91 PM Wilmington}

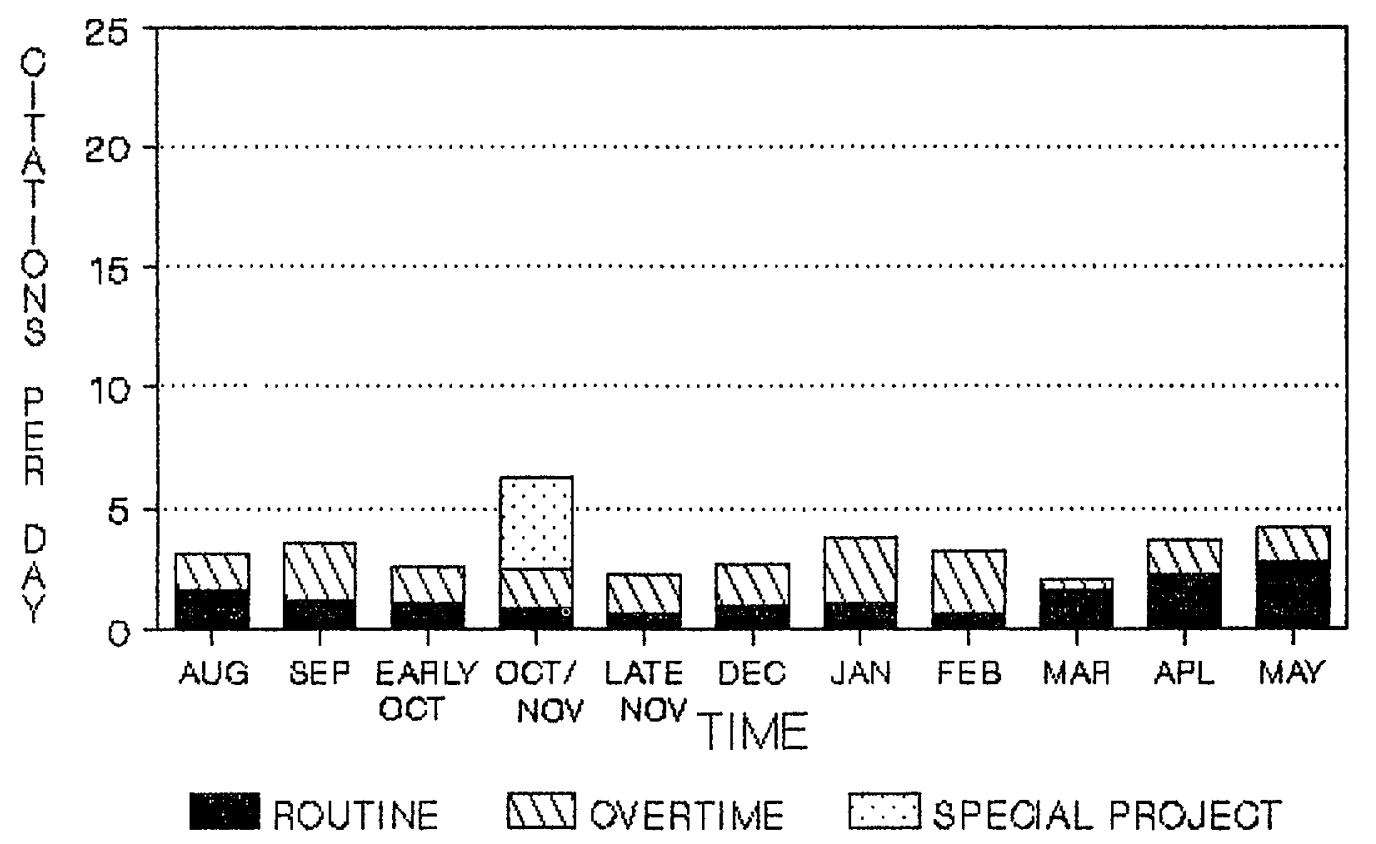


EXHIBIT 4.8

\section{VIOLATION RATE VS. TIME MARIN 101}

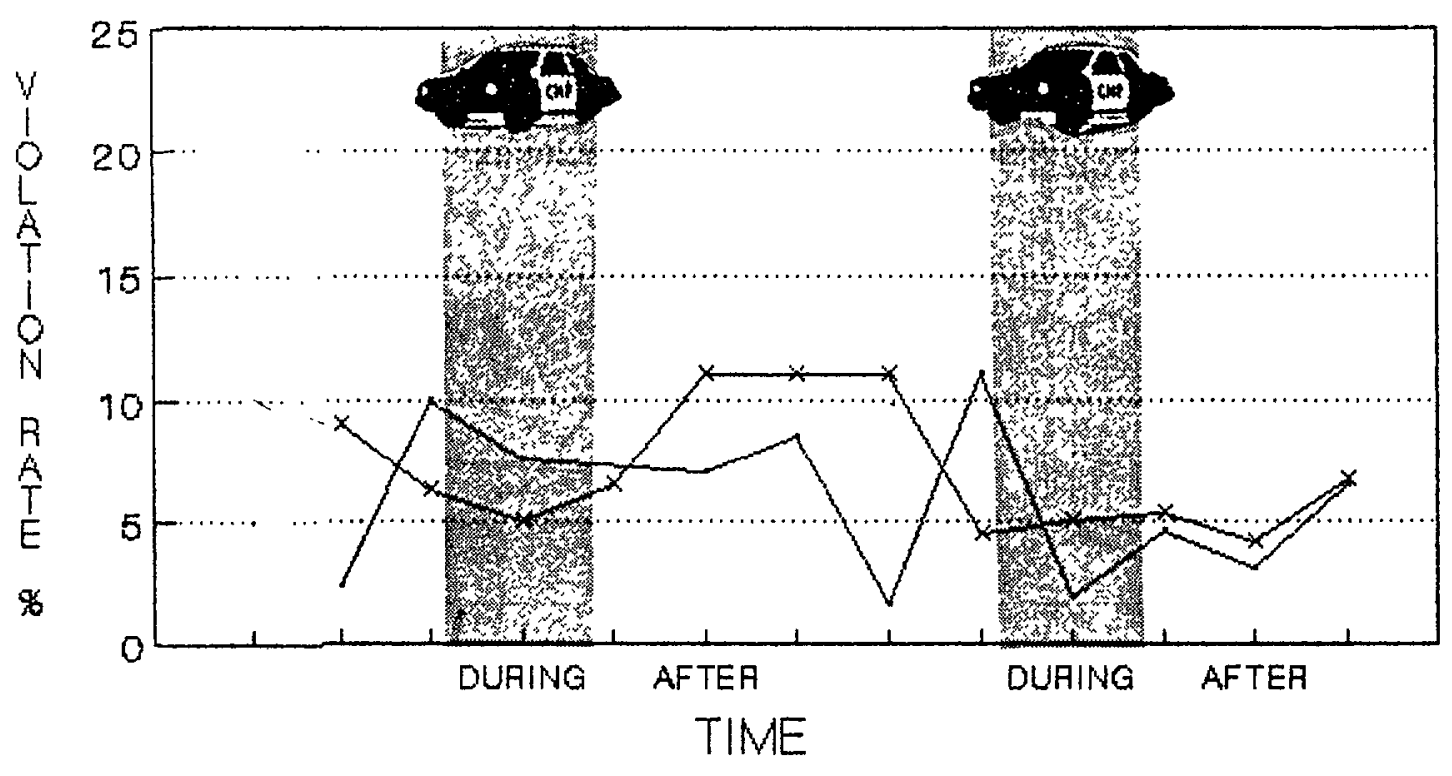

- B/B AM $\quad$ - N/B PM

LEANE OUT DAFK, FIFST \& LAST 10 MINUTES

\section{CITATION COUNT OF 21655.5 VIOLATIONS MARIN 101}

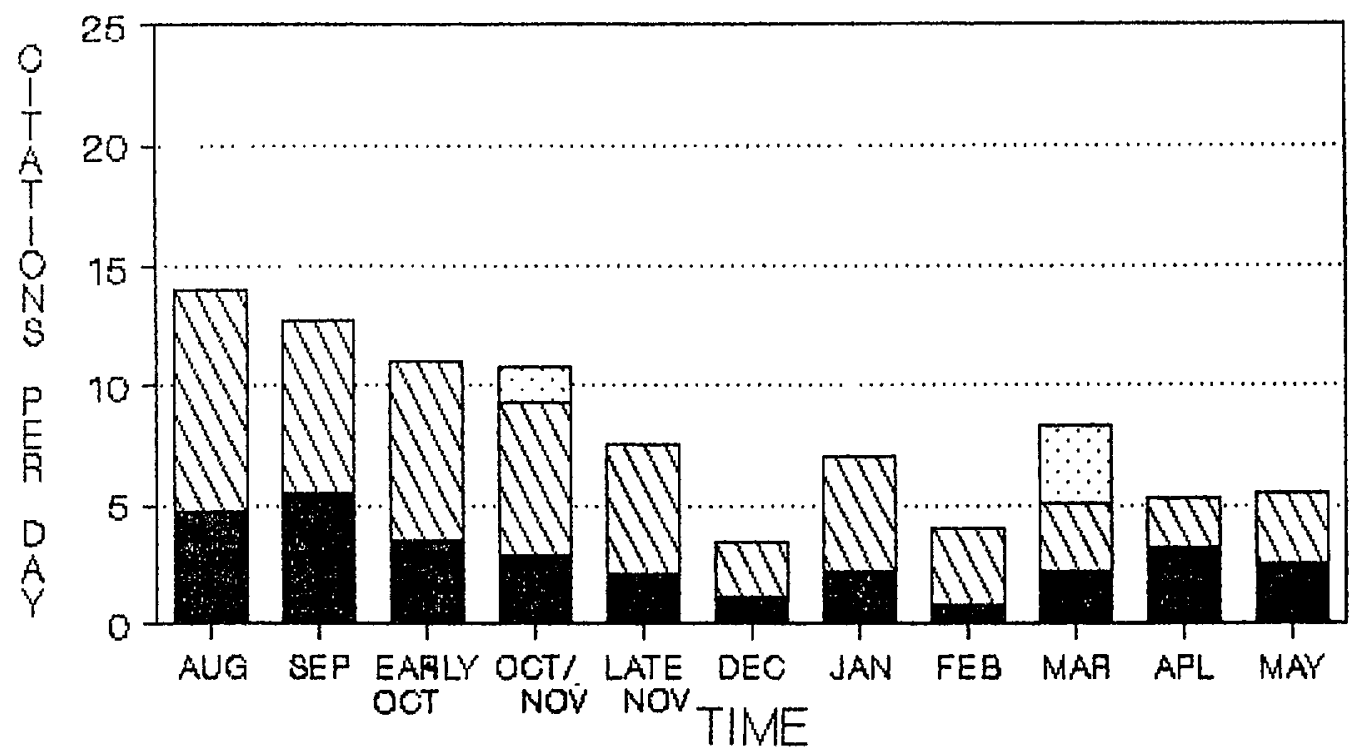

ROUTINE BOVERTIME $\because$ SPECIAL PROJECT 
On Marin 101, the carpool definition had been changed from three persons to two persons just two weeks in advance of the first enforcement wave. During the years preceding this change, violation rates of $20 \%$ had been recorded during the morning peak. Violation rates were even higher during the evening peak, averaging 30\% during 1987 and early 1988 . The change in Carpool definition caused the violation rate measured at the Terra Linda overcrossing to drop below ten percent. Special enforcement activities caused the violation rate to drop still further, to $5 \%$ during the evening peak and $7.5 \%$ during the morning peak. After the first period of special enforcement ended, violation rates rose slightly, before dropping prior to the second enforcement wave.

First Enforcement Wave. During the first four-week period of special enforcement, the Marin CHP added a spotter to their traditional HOV enforcement team during eight morning commute periods and six evening commute periods. The spotter took a visible position at one of the few locations where the center median was wide enough to accommodate a motorcycle and broadcast the identity of violators as they passed. Chase teams of up to three vehicles pursued the violators, producing an average of three citations per peak period. The task of pursuing violators was time consuming, as officers had to thread their way through traffic to pursue a violator and thread their way back again once the violator was apprehended. Chase units were often busy pursuing and citing violators as new violator descriptions were broadcast. During an average commute period, spotters would broadcast the identities of 26 violators, chase units would be available to answer nine of these broadcasts, and the broadcasts would result in an average of three citations by the special enforcement team.

Marin officers interviewed regarding this procedure observed that the stationary spotter did not have a significantly better view than an officer driving in the adjacent lane, since "...cars went by too fast," and that drivers quickly learned where the spotter was located. They noted, however, that "Once violators passed the spotter, they tended to bail out of the commute lane, which...made them sitting ducks if there were any chase cars around."

The Marin CHP captain and his sergeants felt that the spotter/chaser operation was unsafe. They observed that the spotter was in an exposed location in the southbound direction, and that in the northbound direction the early November darkness made the spotter's job more difficult and hazardous. The captain, Kevin Mince, noted that the spotters did not produce many more citations than if they had been assigned to ordinary HOV enforcement. Sergeant Val Daniels, who had patrolled as a chase unit, observed that the chase cars felt an additional impetus to pursue particular violators (perhaps at the expense of their own safety) because another officer 
had spotted them. He felt that officers spotting violators on their own would be more circumspect regarding the risks involved in pursuing a particular violator.

Marin officers felt that if a protected enforcement area could be constructed for the spotter, the spotter/chaser arrangement might be made to work. Perhaps because of the visibility of the spotter, the special enforcement activity (following in the wake of the Carpool definition change), dropped the violation rate to the lowest level in the ten years of the lane's operation.

Second Enforcement Wave. In view of the low violation rates observed following the first enforcement wave, a version of the visible enforcement program was repeated during the second wave. In an effort to improve overall safety, however, special enforcement activities were limited to daylight hours during the evening shift. A visible spotter with a single chase vehicle patrolled the freeway at this time. Motor officers were used as spotters, while a patrol car staffed by an overtime officer served as the chase vehicle. One motor officer was constantly on view in a small, partially sheltered indentation in the northbound median barrier.

Special enforcement activities occurred on ten afternoons during the four week enforcement period. Violation rates during the evening peak were recorded at $5 \%$, down from an average of $8.8 \%$ between the two enforcement waves. Violations were also lower than average ( $2 \%$ vs. a between-wave average of $7 \%$ ) during the morning peak, which received no special enforcement activity. No special enforcement activity took place during the morning commute, largely because the lack of a median provided no safe refuge for the motor officers acting as spotters. Area command personnel and officers again noted the need for enforcement areas in both directions. Speaking of the slight indentation in the northbound median barrier that motor officers used for an observation point, Marin's lead motor officer noted, "It's not a particularly dangerous place (to sit on a motorcycle)...it's just not particularly safe."

Violation rates continued to remain at $5 \%$ or lower during both morning and evening peaks following the second enforcement wave.

\subsubsection{Santa Clara 101}

Santa Clara 101 has a full lo-foot median shoulder that CHP officers regularly use for surveillance and enforcement. Exhibit 4.9 plots violation rates on Santa Clara 101 before, during, 
EXHIBIT 4.9

\section{VIOLATION RATE VS. TIME SANTA CLARA 101}

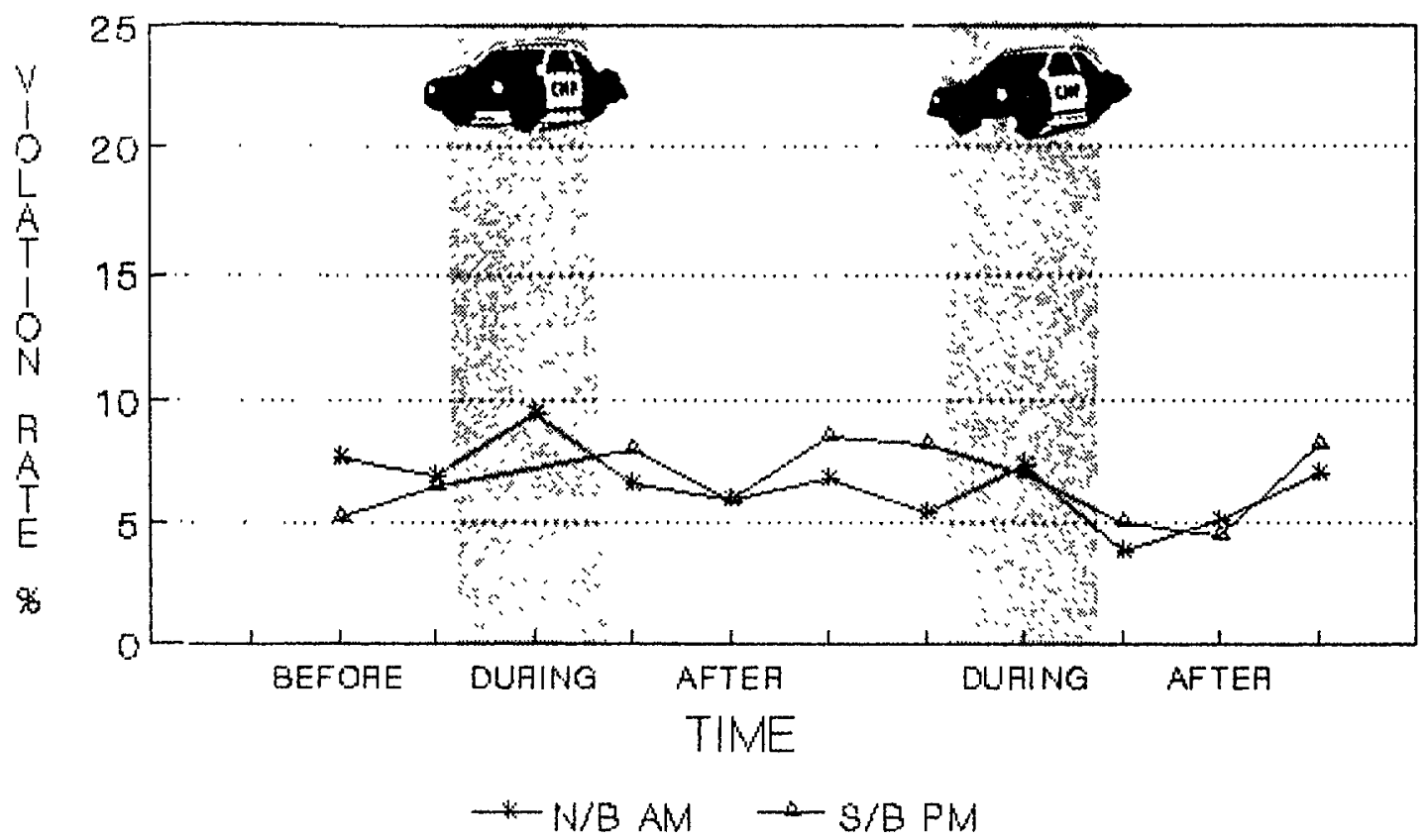

LEANE OUT DARK, FIAST \& LAST 10 MINUTES

\section{CITATION COUNT OF 21655.5 VIOLATIONS SANTA CLARA 101}

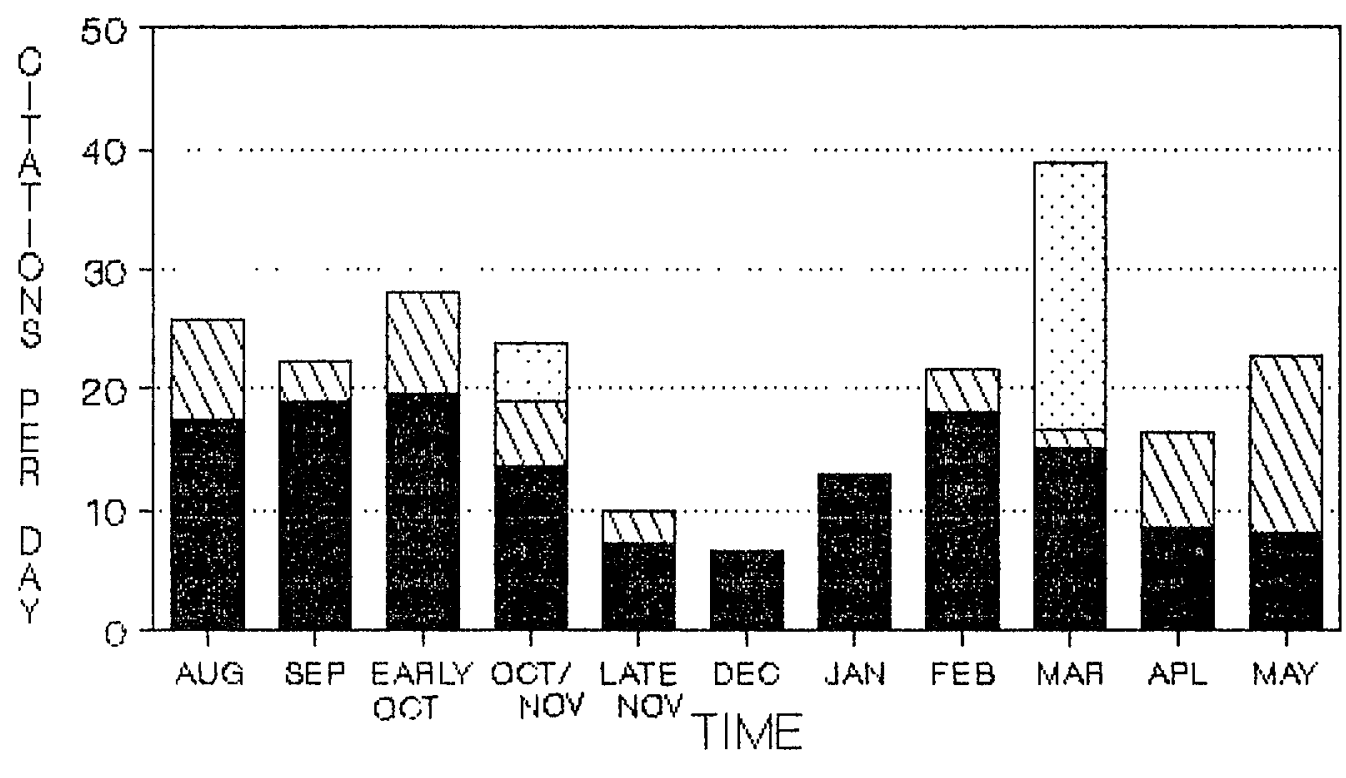

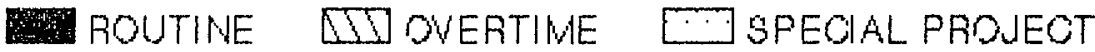


and after the two waves of special enforcement. After adjusting for darkness and fringe effects*, the violation rates on Santa Clara 101 ranged between 5 and 10 percent before, during, and after the first wave of enforcement, dropping slightly below 5 percent immediately after the second enforcement wave.

First Enforcement Wave. Special enforcement activities concentrated on the morning commute period during the first wave of enforcement on Santa Clara 101. Officers on HOV overtime issued an average of 5.2 citations per morning commute period. This enforcement level was not significantly higher than the combined levels of routine and special enforcement recorded historically, and had no measurable impact on violation rates, which remained low (between $5 \%$ and $10 \%$ ) before, during, and after the first wave of enforcement.

Second Enforcement Wave. During the second enforcement wave, special enforcement levels on Santa Clara 101 were increased to more than double the usual level of enforcement activity. Three officers were assigned to special enforcement activities five days per week. This heavy dose of special enforcement was split evenly between the morning and evening peaks and produced an estimated 2.2 citations per officer hour. Violation rates during this period averaged $7.5 \%$, almost exactly the average level achieved before, during, and after the first wave of enforcement. Following the second enforcement wave, the violation rates dropped below $5 \%$ for the first time during the study period, but subsequently returned to the $7.5 \%$ average.

The 10' median shoulder on Santa Clara 101 provides a continuous refuge area for officers citing violators. Surveys showed that drivers were most aware of enforcement activities on this freeway (See Section 6.3.1), and special enforcement officers consistently recorded a high rate of citations per hour. Officers praised the convenience of the median shoulder, although at least one officer was rear-ended while citing a violator by a driver mistakenly using the shoulder as a through lane.

\subsubsection{San Diego I-15}

Barrier-separated HOV lanes on San Diego I-15 opened in mid-October 1988, at the same time that the first enforcement wave was beginning on the four existing HOV lanes. Exhibit

\footnotetext{
* A discussion of the impact of darkness and fringe effects on violation rates on Santa Clara 101 appears in Section 3.5.1.
} 
4.10 traces violation rates for the first eight months of lane operations. Although violation rates of $6 \%$ and $7 \%$ were recorded during the first month of lane operations, violation rates well under $5 \%$ were common in subsequent months.

Start-Up Strategy. When the new lanes became operational, they received four weeks of daily special enforcement attention. In addition to the special enforcement activities, a single motor officer was assigned to patrol the separate facility during each peak period to assist stranded motorists, monitor traffic, and respond to accidents.

During the first week of lane operations, officers were encouraged to make the public aware of laws relating to HOV lane usage, and motorists violating these laws were generally given verbal warnings. These enforcement procedures were not publicly announced, and officers did issue citations to obvious violators. After the first week of operation, all apprehended violators were cited, and special enforcement was reduced to three days per week for the next three weeks.

After the first month of operation, enforcement was reduced to two days per week as CALTRANS monitored violation rates. After four months of operations, overtime assignments were cut back to four special HOV shifts per month in recognition of the low violation rates. A single motor officer continued to be dedicated to the barrier-separated operation during each commute period.

Second Enforcement Wave. By the time of the second enforcement wave in March 1989, the motor officers assigned to routine enforcement appeared to have the violation rate well under control. As a result, the San Diego command agreed to reduce special overtime assignments to two HOV shifts during the entire month of special enforcement activity. This cutback did not result in any measurable increases in violation rates. In fact, of the 86 citations issued on $\mathrm{I}-15$ by routine and special enforcement officers during the four weeks of special enforcement, only $23(27 \%)$ were issued for occupancy violations. Speeding infractions on the separate right-of-way accounted for 37 citations, or $43 \%$ of all the citations issued.

\subsection{ENFORCEMENT OBSERVATIONS}

A summary of key findings of primary interest to enforcement agencies may be found in Appendix E. 


\section{EXHIBIT 4.10 \\ SAN DIEGO I-15 VIOLATION RATES}

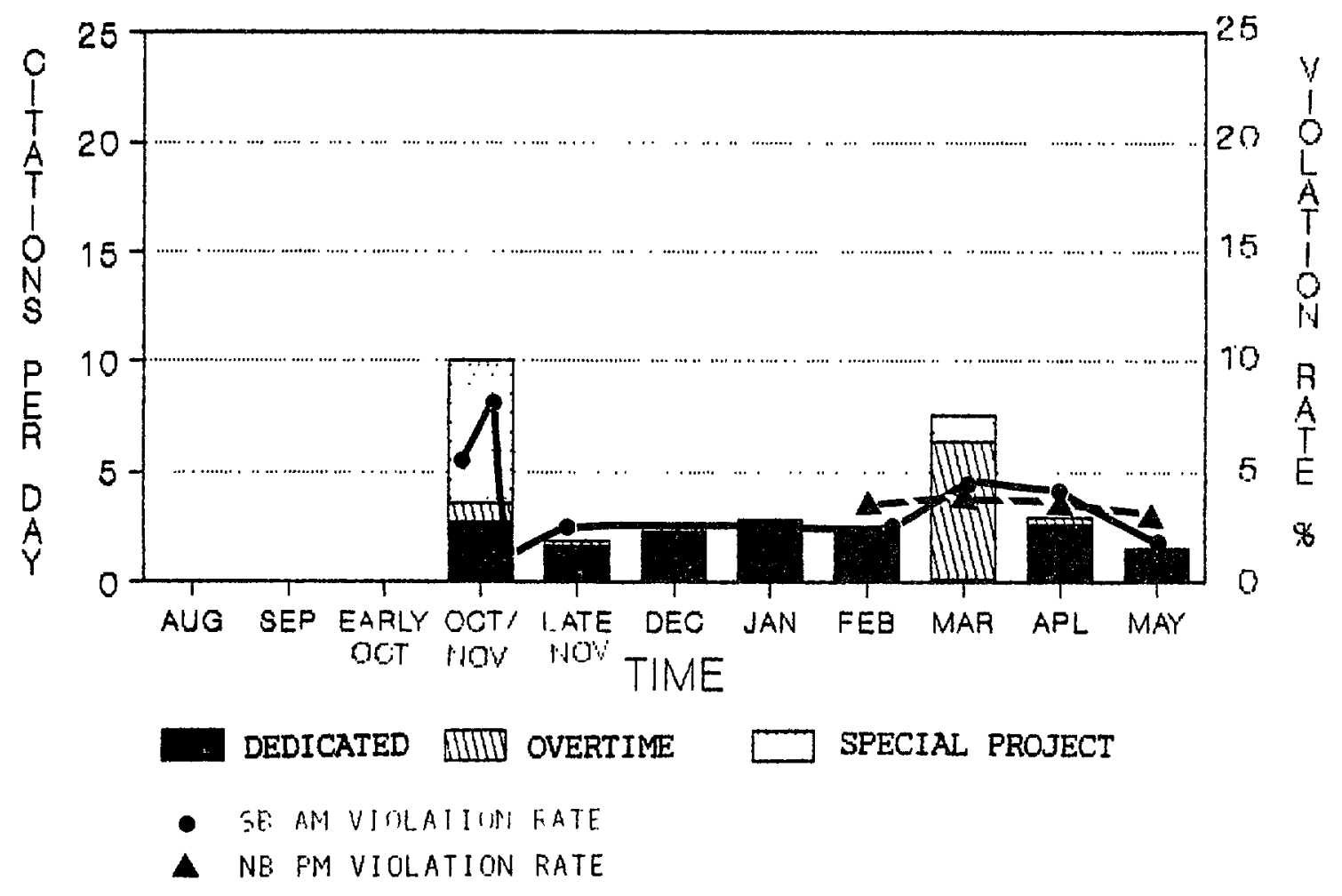




\subsubsection{Mix of Special and Routine Enforcement}

All the mainline HOV lanes included in the current study had been receiving significant levels of routine enforcement prior to the introduction of special enforcement activities. These levels of routine enforcement continued during and after both waves of special enforcement. In this regard, mainline HOV lanes proved to be vastly different from the ramp meter bypass lanes studied in the earlier SYSTAN investigation of HOV violation rates (Billheimer, et al., 1981). Prior to the start of the earlier study, routine enforcement was so rare on ramp meter bypass lanes that roughly one ticket per week was issued on the typical Los Angeles and San Diego ramp, and less than $0.2 \%$ of the ramp violators were apprehended.

In the case of mainline lanes, however, roughly five citations per peak period were issued to violators on California's mainline HOV lanes during 1988. The majority of these citations were issued by traffic officers in the course of their daily routines. This level of enforcement activity meant that officers were citing approximately $2.5 \%$ of those drivers using the lanes illegally. This apprehension rate is roughly 10 times the rate experienced on ramp meter bypass lanes before the introduction of special enforcement activities during the earlier study. With an apprehension rate of $2.5 \%$, the typical violator could expect to use mainline lanes illegally 40 times before being caught. Although this may seem to be a large number of "free" violations, a daily commuter using mainline lanes illegally would expect to be caught within a month. The corresponding figure for an apprehension rate of $.25 \%$ once recorded on ramp meter bypass lanes was 400 trips, or ten months for a daily commuter. In the broadest of interpretations, therefore, the levels of routine enforcement historically applied to mainline HOV lanes have been sufficient to catch a full-time violator once a month. In the absence of special enforcement, a full-time violator could expect to be caught about once a year on ramp meter bypass lanes.

\subsubsection{Effectiveness of Special Enforcement}

Initial Impact. In two instances during the first enforcement wave, visible enforcement strategies on OR 55 and Marin 101 effectively lowered violation rates on those two freeways. These rates remained low as enforcement levels returned to the historical mix of routine and overtime enforcement following the first wave and stayed in the $5 \%$ to $10 \%$ range during and after the second wave of special enforcement. On two other test freeways, Los Angeles 91 and Santa Clara 101, the levels of special enforcement applied during the current study did not have a 
significant impact on the already low lane violation rates existing at the start of the study. Rather, the enforcement activity helped to keep the violation rates in the range between $5 \%$ and $10 \%$. On LA 91, in fact, violation rates did not change significantly when enforcement was cut back to routine levels during the second enforcement wave. On each of these freeways, the presence of enforcement areas (a protected pocket on LA 91 and a 10' shoulder on Santa Clara 101) contributed to a high awareness of enforcement activity and low ongoing violation levels.

Residual Impacts. Special attention was directed to the violation levels measured after special enforcement strategies had been completed on the test freeways. Violations were observed for a period of three-and-a-half months following the first wave of enforcement, and twoand-a-half months following the second wave. On every freeway, the levels of routine enforcement applied after special enforcement ceased were sufficient to keep violation rates below $10 \%$. On LA 91, I-15 and OR 55, in fact, violation rates lower than 5\% were maintained during the subsequent periods of routine enforcement. Thus routine enforcement efforts were equal to the task of maintaining low violation rates in the periods between special enforcement activities. In fact, there is reason to believe that the driving public was unable to distinguish between applications of special enforcement and ongoing levels of routine enforcement. Over two-thirds of all drivers surveyed during the second wave of special enforcement felt that enforcement levels had ". ..stayed about the same" over the past three months (see Section 6.3.1). That is, most drivers did not perceive the change from routine enforcement to special enforcement during the second enforcement wave.

\subsubsection{Lessons from Previous Studies}

A number of lessons learned from SYSTAN's earlier investigation of HOV violation rates (Billheimer, et al., 1981) can help to identify promising enforcement strategies and eliminate unpromising strategies. A few of these lessons are cited below:

Length of Special Enforcement Periods. The previous study showed clearly that lengthy three-month periods of special enforcement were not appreciably more effective than shorter one-month periods in reducing violation rates. Accordingly, special enforcement strategies did not extend for more than one month during the current study. This duration was sufficient to keep violation rates low. 
AM/PM Splits. Certain results in the earlier study suggested that special enforcement concentrated in the morning peak on a mainline HOV lane lowered violation rates during the evening peak as well, and vice versa. This tentative finding could potentially save significant amounts of officer time, and was further tested in the current study. Special enforcement was restricted to the morning peak on Santa Clara 101 during the first wave of enforcement and to the evening peak on Marin 101 during the second wave of enforcement. in both cases routine enforcement levels were maintained during the morning and evening commute periods, and in both cases violation rates remained low during both periods. That is, violation rates were just as low during the period receiving routine enforcement as during the period receiving special enforcement. However, special enforcement did not have a pronounced impact on the already low level of violation rates in either of the two test cases. Thus it is just as likely that the continuing low level of violations reflected the ongoing impact of routine enforcement rather than any carryover effect between peak periods.

\subsubsection{Freeway Impacts}

In both focus groups and mail-back surveys, drivers observed that heavy HOV enforcement often caused freeway traffic to break down as gawkers slowed to watch the ticketing process. The earlier SYSTAN study (Billheimer, et al., 1981) documented an average loss of 80 vehicle hours per peak period when ramp enforcement was conducted in full view of the passing freeway traffic. During the current study, speed runs were made before, during and after periods of special enforcement and traffic volumes recorded by loop detectors in the OR 55 and LA 91 freeways were assembled for representative days.

OR 55: First Enforcement Wave. On OR 55, the first wave of special enforcement reportedly brought freeway traffic to a standstill on several days. This phenomenon was reported by traffic officers and airborne traffic observers from local radio stations, and was the only instance during the current study in which observers reported that special enforcement had an adverse effect on freeway flow. Speed runs showed an increase of eight minutes in travel times during the evening commute on special enforcement days. On the other hand, morning travel times dropped by six minutes during special enforcement. However, these comparisons are based on a limited sampling of special enforcement days (one day per freeway per period). A broader sampling of vehicle volumes at key freeway locations failed to show significant differences in traffic volumes measured at fifteen-minute intervals on days with and without special enforcement. 
OR 55: Second Enforcement Wave_. To avoid disrupting freeway flow during the second enforcement wave, the number of chase vehicles used in team enforcement was reduced to a single patrol car. The use of a single chase vehicle (rather than the two used during the first enforcement wave) reduced the number of citations issued, but also eliminated any reports of traffic disruption.

Minimizing Disruption. Although the effect has been difficult to quantify, it is clear that special enforcement activities can cause traffic disruption as gawkers slow to observe ticketing activities. To minimize the effect of these activities on mainline flow special enforcement officers should work separately, avoid bunching together, limit stacking so that no more than one car is waiting to be ticketed at any time (in addition to the vehicle being cited), release motorists cited in the median back into the HOV lane rather than into the mainline lanes, and avoid pursuing violators across several lanes of traffic.

\subsubsection{Confounding Impacts}

The evaluation plan (Billheimer, 1988) identified several influences or threats to validity which might complicate the task of interpreting the impacts of special enforcement. To the extent possible, countermeasures were developed to mitigate the effects of these threats. However, at leas two unanticipated threats arose during the study to complicate the analysis task. These were:

(1) A legislatively mandated increase in fines for HOV violations; and

(2) Ambiguous reporting procedures which combined mainline citations with bypass lane citations.

Fine Structure. As reported in Section 4.1.4, in January 1989, the California State legislature raised the minimum fine for a first offender using the HOV lanes illegally. The new minimum fine of $\$ 100$ was introduced midway between the first and second waves of special enforcement. Thus there is no way of knowing whether the low violation rates recorded after this change reflected the residual impact of the first wave of special enforcement, the ongoing deterrence of routine enforcement, or an awareness of the new penalty structure. Although the relative influence of the newly implemented fine structure on violation rates is unknown, responses to the second wave of surveys suggest that relatively few drivers were aware of the higher penalties (see Section 6.3.2). Sixty-two percent of the drivers surveyed in March 1989 
said that they didn't know the penalty for a first-time HOV offender, and those Northern California drivers who reported that they knew the penalty thought that the fine was close to $\$ 50$.

Ambiguous Reporting. As has been noted, in most CHP areas it is impossible to distinguish between 21655.5 citations issued to mainline HOV lane violators and citations issued to ramp violators along the same beat. In cases in which both HOV ramps and a mainline lane exist on the same beat (as on Santa Clara 101 or OR 55, for instance), it is difficult to reconstruct the ongoing level of routine enforcement activity present on the mainline lanes. To eliminate this problem, it is recommended that the CHP assign separate beat numbers to mainline HOV lanes throughout the state. 


\subsection{ENGINEERING OPTIONS}

This chapter discusses the interrelationships between engineering design and the enforcement of mainline HOV lanes, identifies a number of design options which affect enforcement strategies, and addresses the impact of each of these options on violations and enforcement.

\subsection{OVERVIEW}

\subsubsection{Engineering/Enforcement Interrelationships}

The complexity of the interrelationships between engineering design and enforcement levels and the resulting motorist violation rates for a particular HOV project is sketched in Exhibit 5.1. For a specific HOV project, each geometric configuration presents a different enforcement problem, depending on such factors as the availability of an enforcement area, the width of the median shoulder, and the accessibility of the lane itself. The enforcing agency, the CHP, must make a number of interrelated decisions regarding enforcement of each mainline HOV lane. These include such budget-related decisions as the assignment of manpower immediately following the opening of the lane and thereafter, and such strategic decisions as the duration of an initial grace period (it any), the relative merits of random enforcement strategies, and the levels of violations or complaints needed to trigger intensive enforcement activity. Most of these decisions are directly related to lane design. For example, the barrier-separated right of way on a lane such as San Diego I-15 demands the assignment of an officer dedicated to that right-of-way.

The act of enforcement itself is also directly affected by lane design. Depending on the geometric configuration, the apprehension of violators may disrupt the orderly flow of traffic, and the act of issuing tickets during peak commute periods can cause rubber-necking on the part of passing motorists, which in turn impedes freeway operations.

The interrelationship between HOV lane engineering and enforcement are so tightly knit and so complex that it is essential that design and enforcement agencies collaborate closely from the inception of an HOV project. If the project is to be a success, this collaboration must continue through the implementation and operation stages. 


\section{INTERRELATIONSHIPS OF KEY STUDY ELEMENTS}

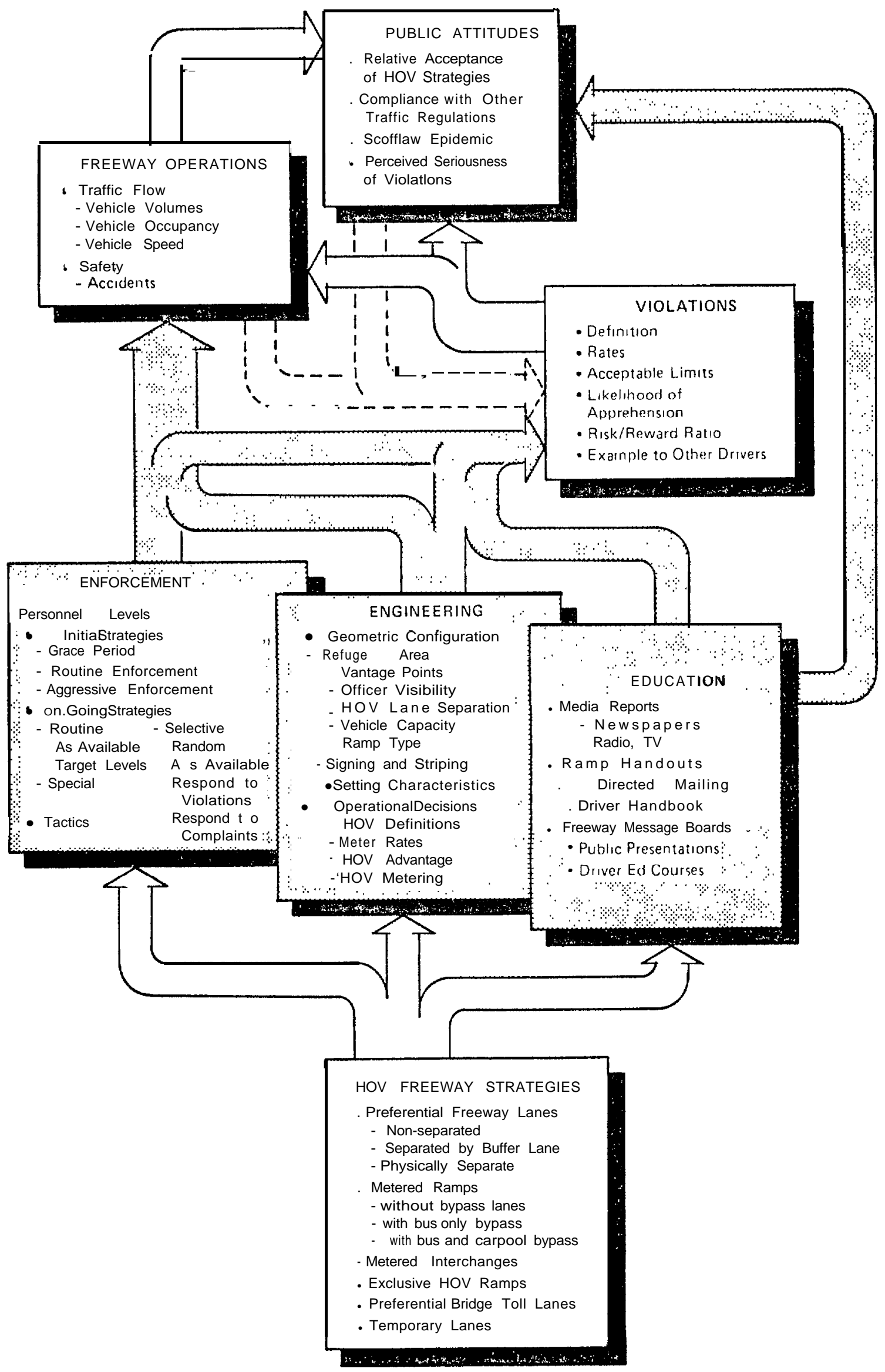




\subsubsection{Public Information Interactions}

As indicated in Exhibit 5.1, motorists violating the HOV lanes affect, and are affected by, the climate of public opinion at the time they are using the freeway. This climate, and the attitudes of the individual motorists, may be influenced by media attention, public education programs, or the past history of HOV lanes in the area. Previous studies have shown that this climate can differ from city to city, and even from location to location within a single city. For example, Los Angeles residents expressed a far more favorable opinion toward the El Monte Busway than toward the controversial Santa Monica Diamond Lanes a few miles to the west along the same Interstate (Billheimer, 1981).

\subsubsection{Key Design Factors}

In addressing engineering design options, the key considerations are the need to (1) describe and classify those geometric configurations, design factors, signing techniques, and operational decisions which are likely to affect 'enforcement policies and violation rates for specific mainline HOV lanes, and (2) document the relationships among geometric, design, signing, and operational characteristics and such issues as costs, violations, and freeway performance. A key concern is the classification of a meaningful but manageable number of geometric, design, and operational factors. If too many individual classifications are defined, each of the different mainline lanes in California will represent a separate case, and few projects can be considered comparable in establishing sampling controls. On the other hand, if important engineering distinctions are overlooked, the resulting number of classifications may be manageable, but meaningless in explaining violation rates. To assist in the classification process, each mainline HOV project in California was visited, and violation rates on existing and past projects were studied in an attempt to isolate those geometric and engineering factors likely to have an influence on violations.

Visits to each mainline HOV project in California, accompanied by discussions with the enforcing officers and local CALTRANS personnel, led to the identification of the following key engineering design factors:

Lane Separation

Access/Egress Limitations

Enforcement Areas

Median Shoulders

Operating Hours
- Carpool Definitions

- Signing and Striping

- Time Savings

- Length 
Exhibit 3.2 has classified each of California's current, past, and planned mainline HOV lanes with respect to these engineering design factors. The following subsections discuss the possible relationship of each factor to violations and enforcement.

\subsection{LANE SEPARATION}

Mainline HOV lanes can be separated from mixed-flow traffic by a physical barrier, painted buffers of different widths, or striping. From the standpoint of safety, operations, and enforcement it is generally conceded that "given no funding or other constraints, most operating officials would prefer an exclusive facility." (Cechini, 1988) As has been noted, however, a separate facility requires dedicated enforcement on a daily basis.

\subsubsection{Physically Separate Lanes}

Two of California's mainline HOV lanes have physical barriers which separate the HOV lanes from the general flow of traffic. These physically separate facilities are the western segment of the El Monte Busway and the recently opened HOV facility on $1-15$ in San Diego. Drivers using these physically separated facilities illegally are effectively trapped so that they can be intercepted and ticketed at the exit point, assuming a suitable refuge area exists at that point. in addition, since there are a limited number of entrance points, CHP officers have the option of intercepting potential violators at the mouth of the lane and waving them away before they enter the facility.

Violation Impacts. As would be expected, the barrier-separated lanes on the El Monte busway and I-15 in San Diego have the lowest violation rates of any of California's mainline HOV lanes. The violation rates on the separate portion of the El Monte Busway have traditionally averaged below $5 \%$. After six months of operation, violation rates on San Diego l-15 averaged just over $3 \%$, and most of the citations issued by special enforcement officers were for speeding rather than for occupancy violations.

Enforcement Impacts. Regardless of the anticipated violation rates, a barrierseparated facility will require some separate patrol units to assist stranded motorists, remove abandoned vehicles, and perform those patrol activities which cannot be accomplished from the adjacent roadway. The CHP assigns a single motor officer to patrol San Diego I-15 during each 
morning and evening peak. This level of routine enforcement was supplemented with relatively heavy levels of special enforcement during the early months of operation. As operations have progressed, however, special enforcement has been progressively cut back, and it appears that the existing level of dedicated enforcement is more than adequate to the task of maintaining low violation rates. Even so, the minimum level of dedicated enforcement required to support such a lane is 2000 hours per year ( 8 hours per day $\times 250$ working days per year), more than double the special enforcement levels required in support of contiguous mainline lanes.

Officers assigned to enforce violations on barrier-separated lanes can elect to station themselves at either end of the facility or to patrol the facility as they would the adjacent freeway. Officers enforcing i-15 prefer to start at the upstream end of the lanes, wait along the median shoulder until a violator passes, pursue the violator, issue a citation and then station themselves at the point where the citation was issued to wait for the next violator. In this way they "leap frog" the length of the lane with a minimum amount of backtracking.

\subsubsection{Buffer Separation}

The easternmost segment of the El Monte Busway is separated from the main flow of traffic by a 13-foot buffer. A narrower 8-foot buffer separated the now-defunct HOV lanes on Alameda 580 from mainline traffic. The wider buffer on the El Monte Busway is sometimes used for enforcement, although many officers feel that making stops on the buffer is hazardous because traffic is moving on both sides of the stopped vehicles. The wider buffer also invites use as a refuge area for disabled vehicles, a potentially hazardous use given the presence of high speed traffic on both sides of the buffer. This safety concern has led to the consensus that buffer areas separating mainline HOV lanes from mixed-flow traffic should be no wider than four feet to prevent their use as a refuge area (Cechini, 1988).

Occupancy Violation Impacts. There is no evidence to suggest that the presence of a wider buffer instead of a simple stripe has an impact on occupancy violations. The two California HOV facilities with wider buffers have both had relatively high violation rates $13.5 \%$ on the El Monte Busway and $31 \%$ on Alameda 580), although both have required 3 or more occupants for legitimate occupancy, and one (Alameda 580) was generally unpopular with the public and lightly enforced. 
Buffer Violation Impacts. It is difficult to determine the effectiveness of a painted buffer area in discouraging illegal crossings into and out of a mainline HOV lane. Buffer violations are too location-dependent to be readily comparable from project to project. A two-person count of buffer violations on the El Monte Busway recorded 38 illegal crossings per day prior to the first wave of special enforcement conducted during the previous SYSTAN study (Billheimer, et al., 1981). The number of illegal crossings dropped to 30 per day during the enforcement effort, and to 21 per day after enforcement had ended. To create an inexact comparison, two observers on OR 55, where the HOV lane separation is a one-foot stripe, counted an average of 89 illegal crossings per day (37 at Meats Avenue and 52 at Walnut Avenue) near the end of the HOV lane. On LA 91, a single observer watching half as much freeway for half the time (because the HOV lane only operates in the afternoon) counted an average of 56 illegal buffer crossings during the evening commute.

On the strength of these inexact comparisons, it appears that the wider buffer on the El Monte Busway may well discourage illegal crossings into and out of the HOV lane during normal conditions. However, the thirteen foot buffer on the El Monte Busway does not eliminate all such crossings (as a physical barrier does) and poses a potential safety hazard to vehicles using the wider buffer zone as a refuge area.

Enforcement Impacts. In discussing the desirability of a buffer area separating the mainline HOV lane from mixed-flow traffic, Cechini observes "...the consensus is that even if the buffer does not discourage crossings, this space gives more time for drivers to perceive a vehicle entering their lane and therefore a better chance to avoid a multi-vehicle accident." This safety issue should be the chief concern of the designer considering the proper width of a buffer zone. This concern is beyond the scope of the current study. From an enforcement standpoint, however, the buffer zone should be no more than four feet wide to discourage officers from issuing citations in the buffer area. Furthermore, if the additional space devoted to a buffer zone can be used to create a useful median shoulder to the left of the HOV lane, officers would prefer to see the additional space used to separate the lane from the Jersey barrier rather than to separate the lane from mixed flow traffic. (See Section 5.5.2.) Strictly from an enforcement standpoint, additional space for a continuous median shoulder, or even for shorter enforcement areas, is preferable to space used as a buffer to separate the mainline HOV lane from mixed traffic. 


\subsubsection{Stripe Separation}

Most of California's mainline HOV lanes are separated from the general flow of freeway traffic by painted stripes. In some cases (i.e., Marin 101, Santa Clara 101, Santa Clara 237), motorists are allowed to cross these stripes at any point along the length of the lane. On other projects (i.e., Orange 55 and LA 91), access to the HOV lane is limited to certain clearly defined entrance and exit points.

Violation Impacts. Violation rates on stripe-separated lanes vary considerably throughout the state. Rates have historically been low (between $5 \%$ and $10 \%$ ) on LA 91, while rates between $15 \%$ and $20 \%$ were common during the first two years of operations on Santa Clara 101.

Enforcement Impacts. From a design standpoint, the chief concern in deciding whether to use a barrier, buffer, or stripe to separate HOV lanes from mixed flow traffic should be safety. Successful enforcement efforts have been launched on each of California's stripeseparated lanes and striped separations appear to be no more difficult to enforce than bufferseparated lanes. In the absence of a physical barrier, such design aspects as enforcement areas, median shoulders, and access/egress limitations are more crucial to enforcement than the width of the lane separation.

\subsection{ACCESS/EGRESS LIMITATIONS}

Drivers can enter physically separated HOV lanes only at designated access points. Wider buffers separating mixed flow traffic from commuter lanes are theoretically just as uncrossable, but some drivers do cross such buffers illegally when entering or leaving the HOV lane. In the case of striped lane separations, entry to the HOV lane is unrestricted on Marin 101, Santa Clara 101, Santa Clara 237, and San Francisco 280 (all in Northern California). Signs warn drivers against crossing the striped lane divider on two Southern California HOV lanes, OR 55 and LA 91. Intermediate access points, marked by signs and breaks in the solid striping, are provided on each of these HOV lanes.

The decision to limit access to contiguous HOV lanes should be made largely on the basis of traffic engineering (rather than enforcement) concerns. Newman argues that "...when a design does not provide adequate speed change lanes at access points, there should be no restriction 
in access anywhere along the length of a lane." (Newman, et al., 1987) On the other hand, restricting access to preselected points, as is done on OR 55 and LA 91, discourages abrupt (and possibly dangerous) lane changes over most of the length of the HOV lane, makes it difficult for drivers to use the lane for shot-I trips, and provides a measure of control over weaving at key interchanges. if access is to be restricted on a contiguous lane, the preferred design from the standpoint of enforcement and engineering would be a four-foot painted buffer which widens to a 12 foot merging lane at access/egress points.

Safety perceptions played a key role in limiting access and egress on Southern California's more recent mainline HOV lanes. On both LA 91 and OR 55, public concern for safety required the adoption of access/egress limitations so that the high initial accident levels experienced on the Santa Monica Diamond Lanes (which had unlimited access) would not be repeated.

\subsubsection{Violation Issues}

As has been seen, the fact that an HOV lane is striped to prevent entry at certain locations, does not guarantee that drivers will observe these restrictions. Legitimate carpoolers and occupancy violations alike have been counted crossing the painted buffers on the E1 Monte Busway, LA 91 and OR 55. There is some indication that the 13-foot buffer on the E1 Monte Busway may be more of a deterrent to illegal crossings than the one- and two-foot stripes on LA 91 and OR 55. However, there is no evidence to suggest that the two-foot stripe on LA 91 is any more of a deterrent to illegal crossings than the one-foot stripe on OR 55. Additional research is needed to determine whether the four-foot buffer suggested by enforcement officers would be more of a deterrent than the two-foot buffer already in existence on LA 91.

\subsubsection{Enforcement Issues}

Access/egress restrictions provide one more way for drivers to use HOV lanes illegally, and one more activity for enforcing officers to observe. When access/egress restrictions are in force, motorists using the lane illegally often compound their problems by diving out of the lane when they see a CHP officer, thereby breaking another law by crossing the lane divider. $28 \%$ of the citations issued on OR 55 for illegal buffer crossings were given to occupancy violators. 
However, the remaining $72 \%$ were issued to legitimate carpoolers entering or exiting the lane illegally.

Prior to January 1989, CHP officers in Southern California tended to cite buffer violations for "...failure to obey signs and signals" (Vehicle Code Section 21461A). This transgression was a moving violation which added points to a driver's record. Since the vehicle code was amended to incorporate the new fine structure in January 1989, HOV buffer violations have their own designation, 21655.8. Like the occupancy violation (21655.5) this violation is not considered a moving violation. in cases in which a buffer violator has been manifestly unsafe in entering or leaving the HOV lane, the enforcing officer has the option of citing the violator for an "...unsafe lane change" or for ...failure to obey signs and signals," thereby ensuring that the violation is classified as a moving violation.

During special enforcement periods, the percentage of citations issued on LA 91 and OR 55 for illegal buffer crossings ranged from $12 \%$ to $16 \%$ of the total number of citations. Although buffer violations exist on both these freeways, there is no reason to believe that they are any more prevalent than occupancy violations, which occupied most of the time of the special enforcement officers. This suggests that the decision to limit access and egress to a contiguous HOV lane through a buffer zone or painted stripe imposes a marginal additional load on the enforcing officer. For this reason, the decision to impose such limitations should be made largely on the basis of traffic safety and engineering concerns, with enforcement a lesser consideration. The impact of access/egress limitations on safety is an important issue which deserves more study.

\subsection{ENFORCEMENT AREAS}

Enforcement areas are protected refuge areas adjacent to mainline HOV lanes where officers can observe traffic conditions and issue citations. A conceptual plan for a sample mainline enforcement area appears in Exhibit 5.2. This design flares the median barrier to provide a protected observation and enforcement post between the HOV lane and the existing barrier.

\subsubsection{Existing Enforcement Areas}

Both OR 55 and LA 91 have enforcement areas modeled roughly after the sample concept depicted in Exhibit 5.2. Exhibit 5.2 also contains a photograph of a motorcycle officer using the LA 91 enforcement area as an observation post. The recently opened HOV lanes on I405 contain a series of similar enforcement areas. 
EXHIBIT 5.2

SAMPLE ENFORCEMENT AREA

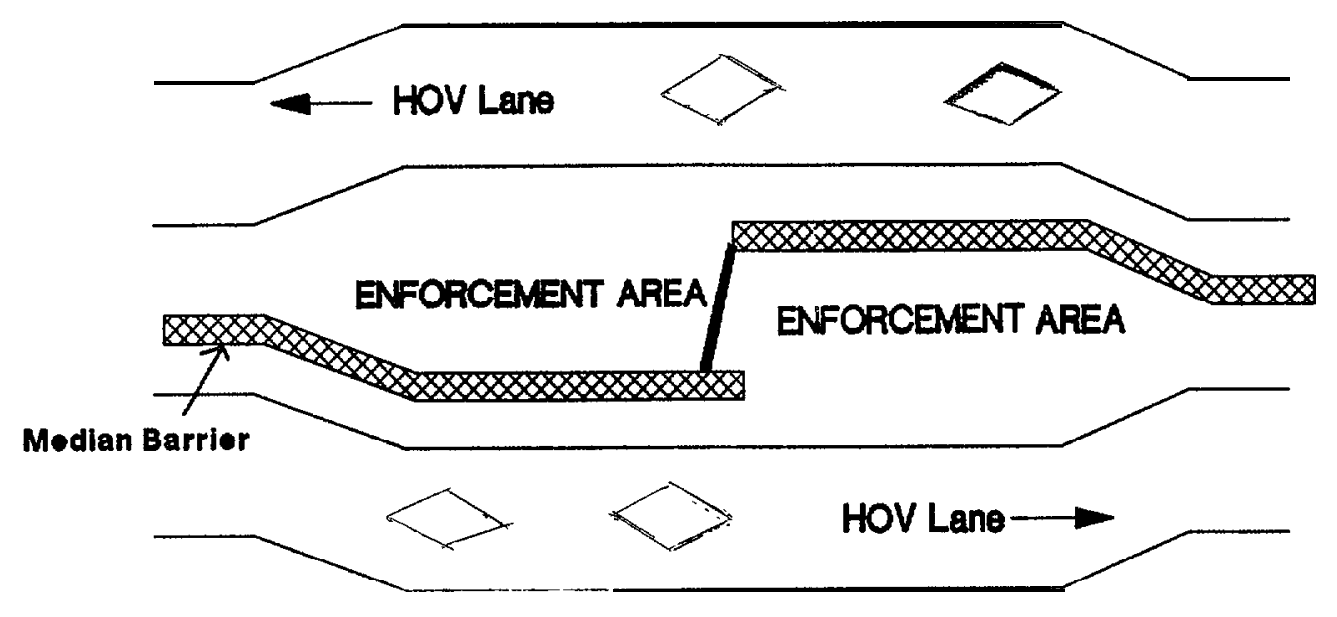

A . CONCEPTUAL DESIGN

BI-DIRECTIONAL ENFORCEMENT AREA

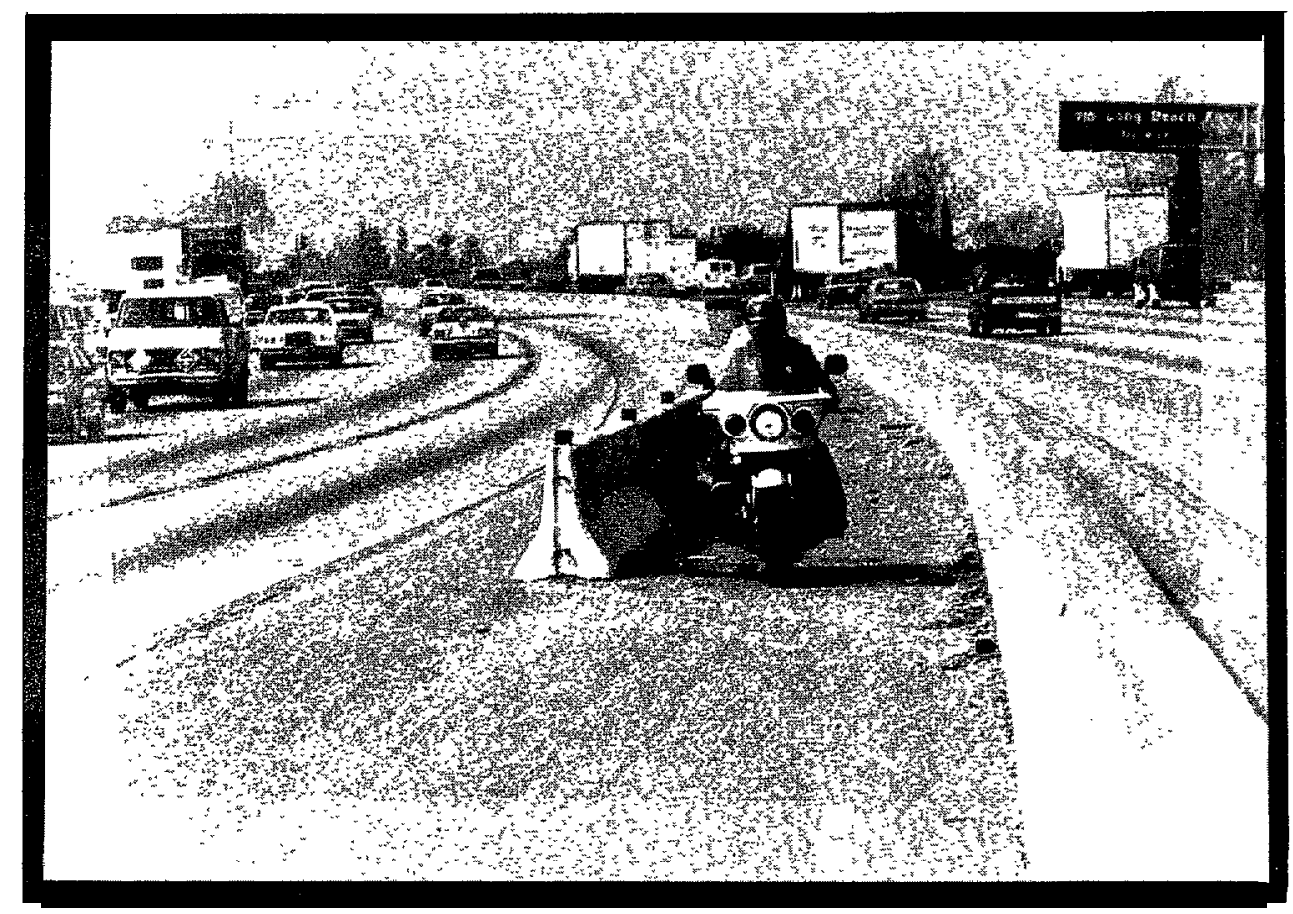

B. MOTOR OFFICER USING UNI-DIRECTIONAL

LA 91 ENFORCEMENT AREA 
OR 55. A two-sided enforcement area has been constructed on OR 55. The width of the median at the location of the enforcement area is ten feet, and the mouth of the enforcement area itself is seven feet wide. This narrow mouth and median severely restrict the acceleration/deceleration lanes available beyond the enforcement area. As a result, none of the CHP officers from the Santa Ana area responsible for enforcing OR 55 reported using the enforcement area to write HOV lane tickets. The officers were concerned that the narrow width and short acceleration distance would make it too difficult for violators to re-enter the traffic stream after being ticketed. One Santa Ana motorcycle officer said that he used the area as a jumping-off place for spotting and pursuing violators, but he noted that some fellow officers felt that the short acceleration lane, coupled with the absence of a median lane, made even this restricted use of the enforcement area too hazardous.

LA 91. On LA 91, the one-sided enforcement area has a wider mouth (9' -8") in a wider 14-foot median and the area is positioned downstream from a curve which causes all freeway traffic to slow somewhat as it passes the area. As a result, officers are able to stand in the enforcement area and wave violators over as they pass. Some officers use this mode of enforcement, while others patrol the freeway, pull violators over into the protected area, and, after issuing a ticket, wait in the enforcement area for another violator to pass. CHP officers noted that the LA 91 enforcement area was useful, but some felt that ".. now that violators know where it is they tend to leave the lane early to avoid capture." ${ }^{*}$ Drivers on LA 91 showed a far greater awareness of enforcement than drivers on OR 55 (See Section 6.3.1), presumably because of the active use of the LA 91 enforcement area adjacent to the HOV lane. Photos taken at the mouths of the OR 55 and LA 91 areas may be found in Exhibit 5.3.

\subsubsection{Enforcement Area Design}

Clearance Issues. A sample enforcement area design appears in Exhibit 5.4. This design shows an enforcement area with a 9'-8" mouth built into a 14 foot median, similar to the design on LA 91. At the mouth of the enforcement area, the 4-foot buffer separating the HOV lane from mixed flow traffic narrows to provide a 6 -foot clearance between the edge of the enforcement area and the HOV lane itself. The width of the clearance between the mouth of the

- This study was unable to document the reported tendency of violators to bail out of the HOV lane in advance of the enforcement areas on OR 55 and LA 91. It was obvious from ride-alongs and separate observation that some violators tended to bail out of the HOV lane upon spotting a $\mathrm{CHP}$ officer. This is not quite the same thing, and may account for the officers' perceptions that drivers bail out in advance of enforcement areas. On both LA 91 and OR 55, the act of bailing out of the lane adds a buffer violation to the occupancy violation. 
EXHIBIT 5.3

ENFORCEMENT AREA MOUTHS

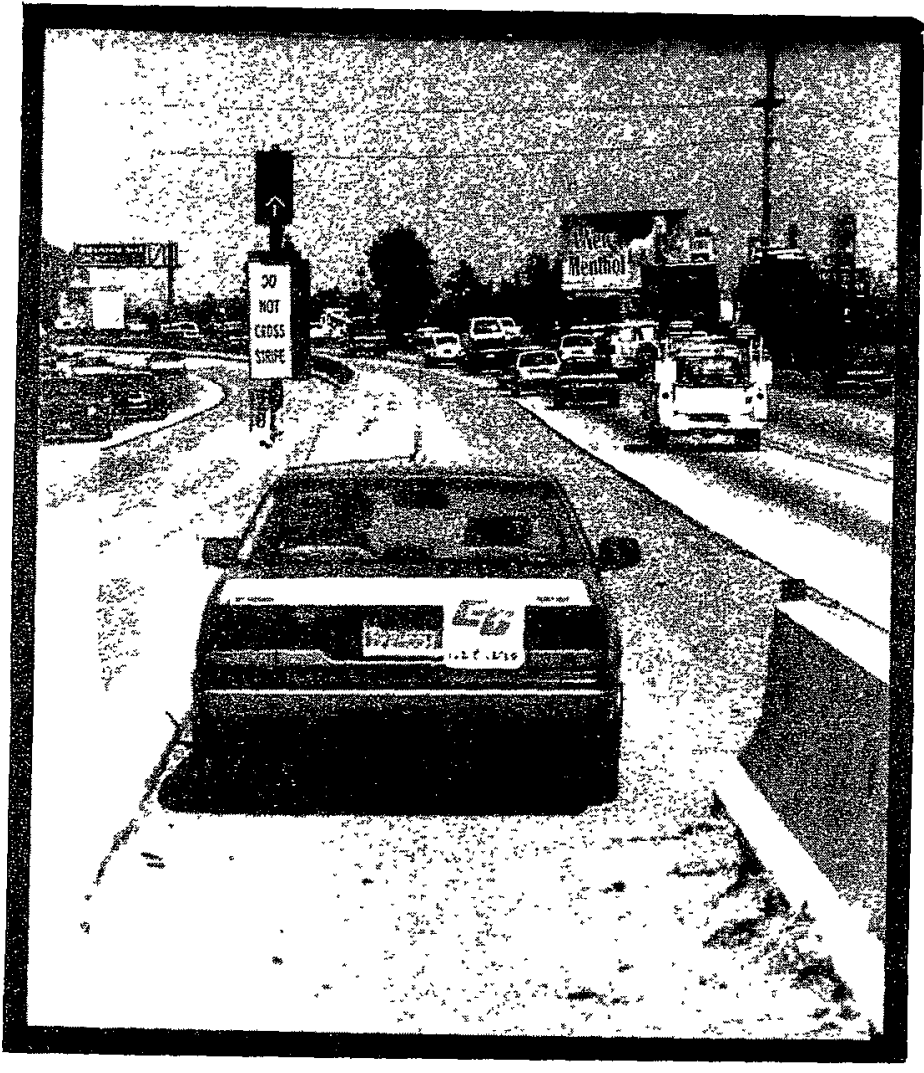

(A) MOUTH OF LA-91 ENFORCEMENT AREA LOOKING EASTBOUND

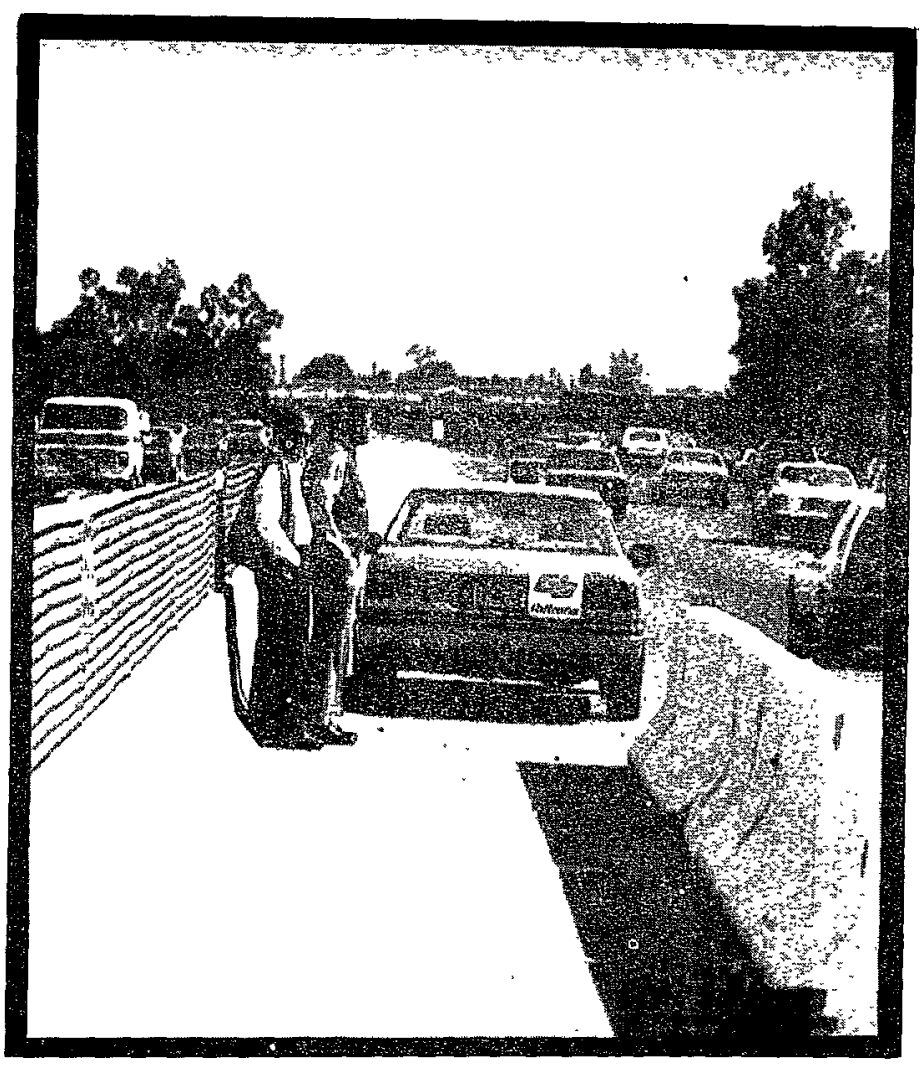

(B) MOUTH OF OR-55 ENFORCEMENT AREA LOOKING SOUTHBOUND 
EXHIBIT 5.4

TYPICAL CHP ENFORCEMENT AREA

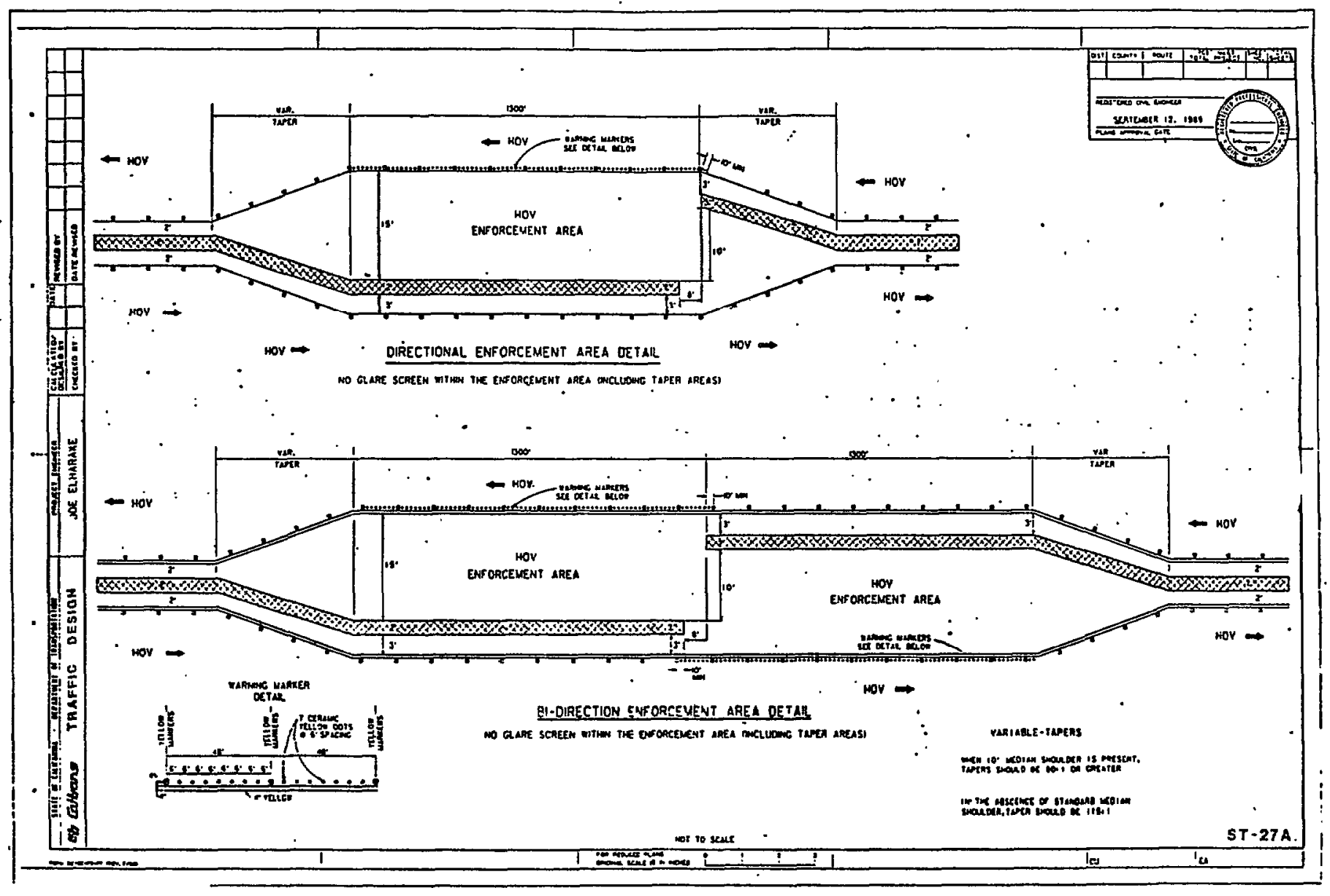


enforcement area and the HOV lane has been the subject of some discussions between CALTRANS and the FHWA. When space is limited, the FHWA prefers that the 6 foot clearance be maintained by cutting back on the dimensions of the enforcement area itself. Both the CHP and local CALTRANS personnel prefer to see the clearance width cut, perhaps by as much as 3 feet, in order to maintain the width of the enforcement area and provide a protected pocket so that an errant vehicle cannot drive unimpeded down the shoulder or into an officer assisting a motorist or writing a citation.

The FHWA's preference for a 6 foot shoulder separation reflects a desire to provide a continuous shoulder with no fixed objects encroaching in it so that a driver mistakenly using the shoulder as a right-of-way can pass unencumbered between the HOV lane and the mouth of the enforcement area. CHP officers contemplating the task of issuing tickets on the 14 foot median beyond the enforcement area exhibited a strong preference for a narrower 3 foot clearance that would keep drivers from using the median shoulder as a thoroughfare and endangering the lives of officers parked in the median. The safety issues of this debate remain unresolved. Since the experience on OR 55 demonstrates that CHP officers will not use substandard enforcement areas, the CHP and CALTRANS conducted a field test of different designs in an attempt to resolve enforcement-related issues.

Test Procedures. On February 24, 1989, representatives from CALTRANS Districts 7 and 12 and the CHP's Westminster and Santa Ana areas assembled to test the feasibility of different enforcement area widths, as measured at the mouth of the area. The test was conducted in the median of the eastbound LA-91 freeway at the site of the existing enforcement area. Two different widths of the protected area were simulated using traffic cones and the mouth of the existing enforcement area.

(1) A 7'-8" width (proposed to accommodate a 6 foot shoulder separation from the HOV lane); and

(2) A 9'-8" width.

CHP officers tested each of these proposed area widths using a patrol car and a motorcycle. Photos of the simulated layout and test procedure appear in Exhibit 5.5.

Findings. The five CHP officersagreed that the 7'-8" protected area was too narrow for effective enforcement. This width left a corner of the patrol car exposed to oncoming traffic (See Exhibit 5.5). When officers attempted to reduce their exposure by parking closer to the median barrier, they could not open the car door wide enough to exit on the driver's side. 
EXHIBIT 5.5

ENFORCEMENT AREA TEST PHOTOS
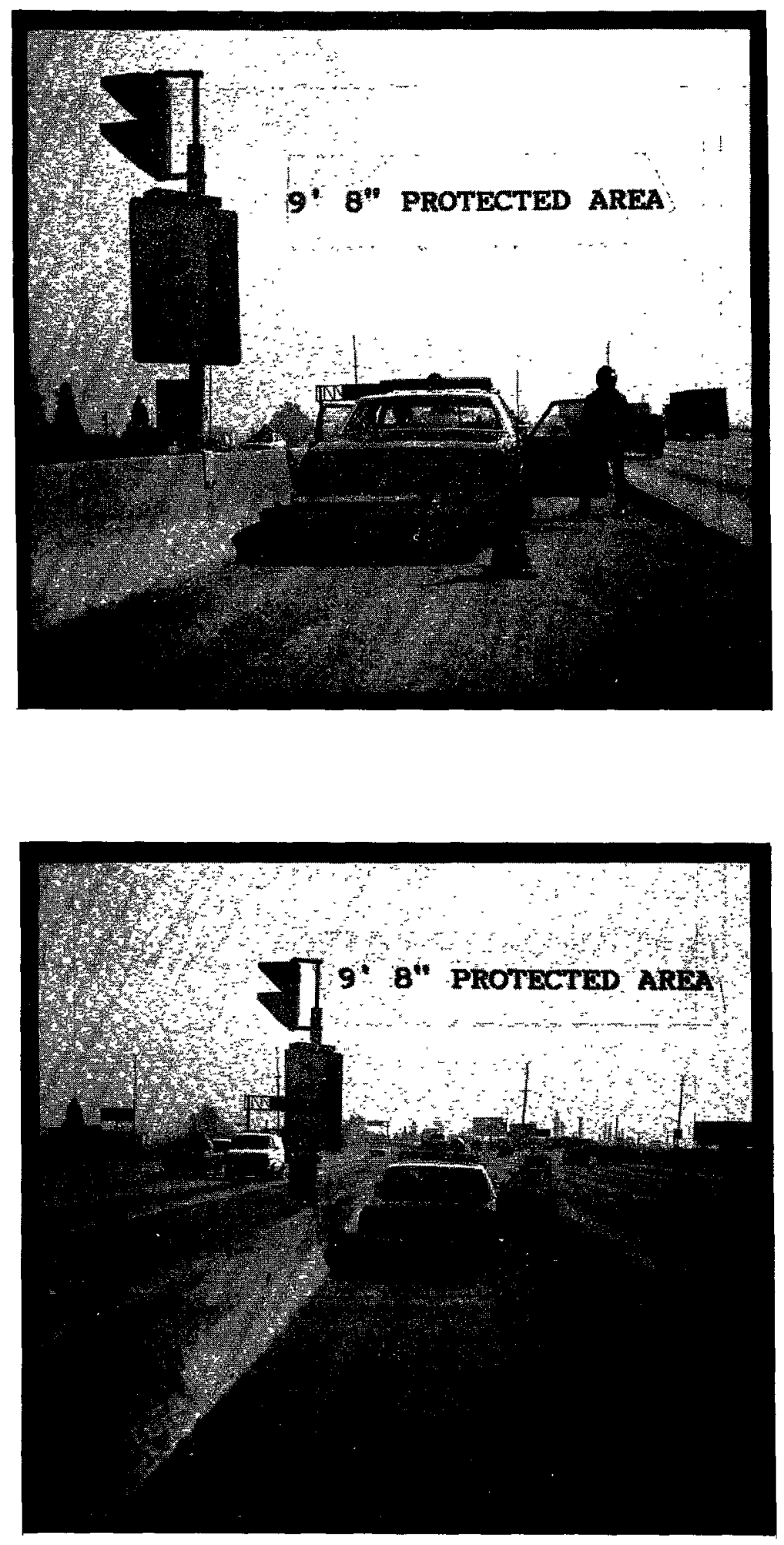
CHP officers were also concerned about the false sense of security provided when a 6 foot shoulder adjacent to the barrier enabled cars to travel in the median and pose a potential threat to enforcing officers and motorists with disabled vehicles. The CHP officers present at the test clearly put a high value on the ability of the protected area to shield officers and disabled motorists from drivers who mistakenly use the shoulder lane as a through lane.

All officers felt comfortable with the 9'-8" enforcement area. This is the width of the existing LA-91 enforcement area and the area sketched in the sample design of Exhibit 5.4.

Additional Observations The CHP officers also discussed other aspects of enforcement area design, including the desirability of a turn-around for motorcycles in a two-way enforcement area. The officers noted that such a turn-around enhanced the flexibility of the area, since it would give officers easier access to the opposite side of the freeway, thereby providing faster emergency response and making certain stationary enforcement tasks (i.e. ramp enforcement) more efficient by providing a quicker turn-around capability. As mentioned earlier, this design may also enhance the perception of enforcement by vehicles traveling in the off-peak direction.

Given the lack of use of the enforcement area on OR 55 and the results of the joint CALTRANS/CHP field test, it seems clear that a usable enforcement area must have a mouth of at least 9'-8" and provide, at a minimum, a 14 foot shoulder between the HOV lane and the median barrier beyond the enforcement area. To provide adequate acceleration/deceleration distances, the 14 foot shoulder should extend at least 1300 feet beyond the mouth of the enforcement area.

\subsection{MEDIAN SHOULDERS}

\subsubsection{Existing Designs}

Of the mainline HOV lanes currently operating in California, only Santa Clara 101 and San Diego I-15 have median shoulders wide enough for officers to use to cite violators or sit and observe traffic. Surveys show that drivers using Santa Clara 101 have a higher awareness of enforcement than drivers on any other mainline lane (see Section 6.3.1), presumably because many citations are issued on the median shoulder adjacent to the HOV lanes. 
Most of the officers interviewed in the current study preferred a continuous 14 foot median shoulder to a single enforcement area, because the median shoulder gave them many opportunities to wait for violators alongside the HOV lane, as well as a limitless acceleration/deceleration lane. Those officers expressing a preference for a single enforcement area were generally concerned that a continuous median might prove too enticing to careless or drunk drivers and hence too dangerous for enforcing officers.

\subsubsection{Officer Preferences}

In the course of the current study, a focus group discussion was conducted with twelve CHP officers responsible for enforcing Southern California's mainline HOV lanes. Officers representing CHP areas in Westminster (LA 91), Santa Ana (OR 55), Baldwin Park (El Monte Busway), East Los Angeles (LA 91) and Santa Fe Springs (LA 91) were interviewed regarding pursuit tactics, enforcement problems, motorist behavior, citation concerns, and specific design issues.

Ranking. In the course of the discussion, the officers were shown six alternative designs for mainline HOV lanes and asked to rank the six from the standpoint of ease of enforcement. The alternative designs featured a variety of median widths, enforcement areas, and buffer separations. The ranking arrived at by the officers is listed below and illustrated in Exhibit 5.6.

Number

1 (Easiest to Enforce)

2

3

4

5

6 (Hardest to Enforce)
Design

Median shoulder varies regularly from 14' to 3', with long (at least a mile) stretches of each width;

Multiple enforcement areas;

14' median shoulder;

13' buffer separating mixed flow traffic from HOV lane (i.e. El Monte Busway);

Single enforcement area (i.e. LA 91);

3' median shoulder (i.e. Marin 101). 


\section{EXHIBIT 5.6}

\section{OFFICER RANKINGS OF ALTERNATIVE HOV LANE DESIGNS}

\section{STAGGERED MEDIAN}

Legend:

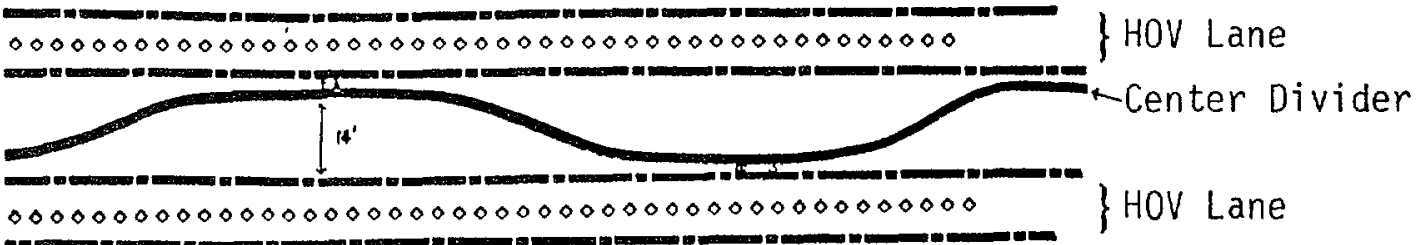

\section{MULTIPLE ENFORCEMENT AREAS}

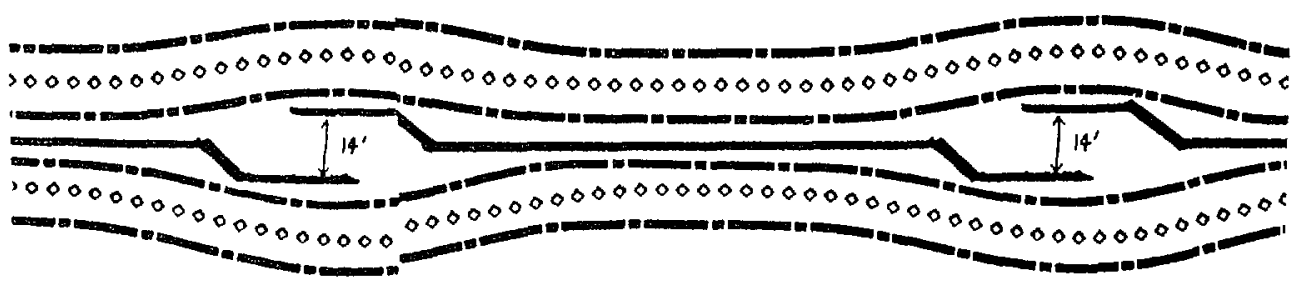

\section{14 FOOT MEDIAN}

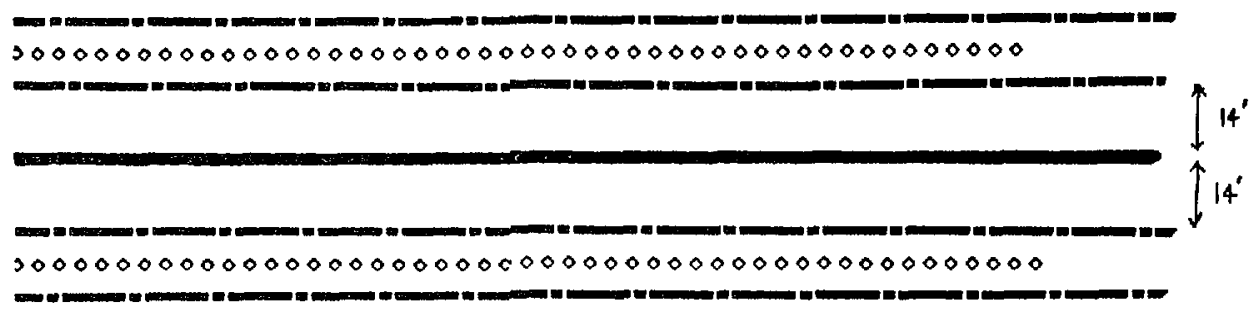

\section{13 FOOT BUFFER LANE}

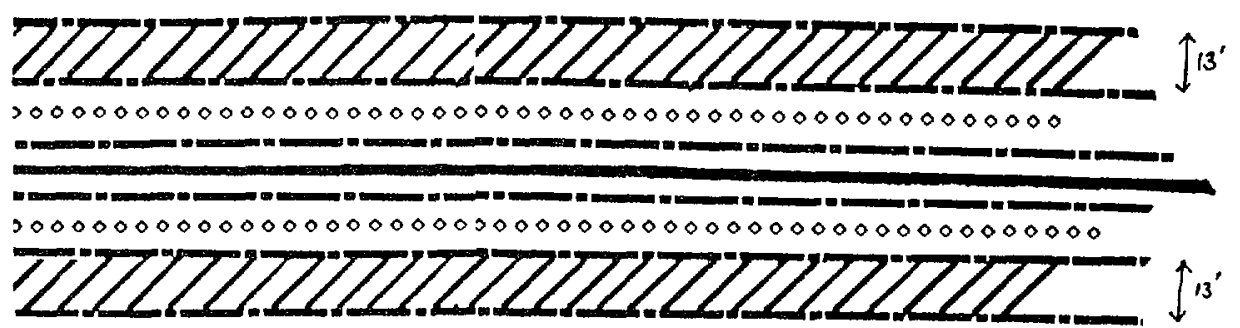

\section{SINGLE ENFORCEMENT AREA}

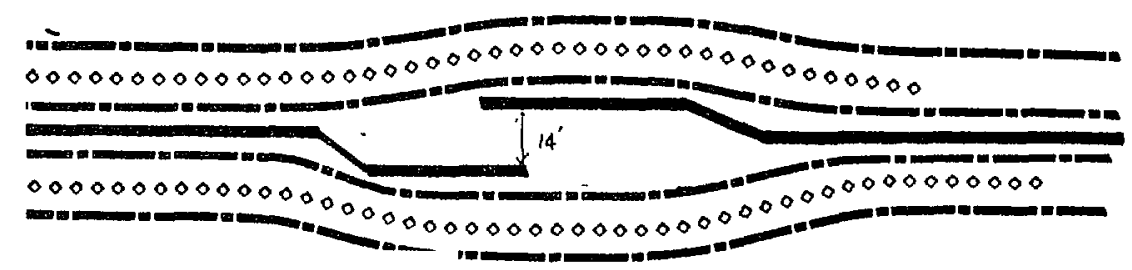

\section{3 FOOT MEDIAN}

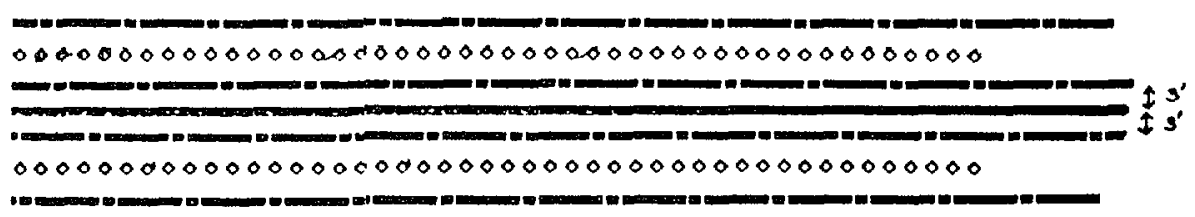


Discussion. Officers attending the focus group preferred a design featuring a continuous shoulder of 14 feet to a single enforcement area of the type in place on LA 91. They reasoned that the continuous shoulder allowed them to enforce any place along the freeway, so that their presence wasn't predictable.

A design with multiple enforcement areas (i.e. areas every 4 or 5 miles) was preferred to the continuous 14 foot median. Surprisingly, the design which the officers preferred over all other alternatives featured a staggered median which ranged from 3 feet to 14 feet, but remained at 14 feet for a long enough distance to permit enforcement. Officers reasoned that the staggered median, which shrunk to 3 feet in spots, was not likely to invite use by drunk drivers and others who did not realize it was a shoulder lane. This safety aspect understandably ranked high with enforcing officers, who feared that a drunk driver might decide to drive along the continuous 14-foot median at the same time they were using the median to ticket a violator. One officer suggested placing diagonal Botts Dots at intervals along continuous medians to warn drivers that the widened median was not a traveled way and alert officers using the median to the presence of an oncoming vehicle.

After the officers had ranked the six designs presented to them, CALTRANS and CHP observers from the agencies' Sacramento headquarters asked how the officers would rank a design which combined the staggered median with multiple enforcement areas. The officers agreed that this design would be preferable to any of the six considered earlier.

Conclusion. The successful enforcement of LA 91 has shown that a well-designed enforcement area can be used effectively to control violations along a mainline HOV lane. Where space is available, a continuous 14 -foot median should be provided along the length of the HOV lane for both safety and enforcement purposes. This median may be enhanced through the addition of enforcement areas. However, a properly designed enforcement area should be the minimum acceptable enforcement element accompanying future mainline HOV lane designs. The difficulties encountered in enforcing Marin 101 suggest that mainline HOV lanes lacking a substantial median shoulder should not be contemplated if space cannot be found for at least one well-designed enforcement area.

\subsection{OPERATING HOURS}

The question of operating hours for mainline HOV lanes is usually a question of peak period operation versus all-day operation. All of the mainline HOV lanes in the Los Angeles and 
Orange County areas have gone to round-the-clock operations. In Northern California, however, Marin 101, Santa Clara 101, and Santa Clara 237 are still governed by posting operating hours. Outside operating hours, those lanes are open to mixed flow traffic. In San Diego, the new reversible lanes on San Diego I-15 are only open during prescribed hours.

\subsubsection{Violation Issues}

The current study has shown that when operating hours are posted to conform to the morning and evening peaks on concurrent lanes, violations tend to cluster at the fringes of the posted times. (See Section 3.5.1.) This clustering tendency has been observed in earlier studies (i.e. Billheimer, et al., 1981). On Marin 101, for example, a high proportion of violations occurs just after restrictions come into play at 6:30 a.m. and 4:30 p.m. and just before they are removed at 8:30 a.m. and 7:00 p.m. The higher violation rates recorded at this time can artificially inflate violation reports and introduce sizable swings in time-series data that depend more on the promptness of observers and the accuracy of their watches than on the violation tendencies of drivers. For the sake of consistency, violation rates observed during the first and last ten minutes of a prescribed operating period should be discounted. In Marin County, elimination of fringe and darkness effects caused overall violation rates to drop from $12.6 \%$ to $8.7 \%$ during the morning peak and from $8.6 \%$ to $7.7 \%$ during the evening peak.

When HOV lanes operate around the clock, officers report that occupancy violations fall off somewhat during the midday and at other times when adjacent mixed-flow lanes are relatively uncongested. Even when there is no congestion in the mixed-flow lanes, however, singleoccupant vehicles sometimes use,the adjacent HOV lane illegally as a passing lane.

\subsubsection{Enforcement Concerns}

Grace Period. CHP officers in Northern California tend to observe a 10-to 15-minute "grace period" at the beginning and end of prescribed operating periods. This unofficial grace period undoubtedly contributes to the clustering effect documented at the fringes of HOV lane operating hours. In designing mainline HOV lanes, therefore, it is well to recognize that the lanes will not be enforced at the fringes of the official operating period and define operating hours accordingly, perhaps by arbitrarily lengthening the operating period.

Enforcement Hours. Lanes operating 24 hours per day require little in the way of additional enforcement over lanes operating for a specified time during peak commuting hours. 
Even though HOV lanes may operate around the clock, it is virtually impossible to enforce occupancy restrictions after dark, and special enforcement assignments should be concentrated during the peak periods. Shortening the period of HOV lane operations reduces the number of overtime hours needed for special enforcement somewhat, but overtime officers still need time to report in, set up operations, and report out, so that cutting lane operating hours by $25 \%$ will not cause a similar percentage reduction in special enforcement hours.

Additional Concerns. Newman notes that opening HOV lanes to mixed flow traffic during the off-peak hours will reduce accident rates, even if there is no recurring congestion during the off-peak hours (Newman, et al., 1987). Cechini offers the counter-observation that traffic control signing and marking is greatly simplified for round-the-clock operations.

Summary. From the standpoint of enforcement, there is little to choose between roundthe-clock and peak-period operation of mainline HOV lanes. Opening lanes to all-day operations does not appear to increase either violation levels or enforcement requirements appreciably, and may simplify signing problems and reduce confusion (and violation rates) at the changeover times. At the same time, it is impossible to enforce occupancy restrictions after dark, off-peak accident rates are likely to be lower if more lanes are available to mixed-flow traffic, and the additional hours of operation at times when there is no time advantage to be gained from using the HOV lanes are not likely to encourage many additional Carpools. More study is needed to isolate the impact of operating hours on safety, signing, clean air, and other issues.

\subsection{CARPOOL DEFINITIONS}

The Carpool definition on Marin 101 changed from 3-or-more occupants to 2-or-more occupants on October 3, 1988. This left the El Monte Busway and San Francisco 280 as the only mainline HOV lanes in California requiring 3-person carpools. (Several HOV bridge lanes in Northern California still define Carpools as 3-or-more persons.)

\subsubsection{Violation Issues}

Marin 101 with $3+$ Carpools. Lane violation rates have historically been higher on Marin 101 than on other California mainline HOV facilities because the 3-person carpool definition has caused overall volumes in the HOV lane to be relatively low. Prior to the change in Carpool 
definition, peak-hour volumes on the Marin HOV lanes were historically under 400 vehicles per hour, lower than the volumes for any California mainline facility other than San Francisco 280. Low HOV lane usage on this $3+$ Carpool facility lead to high lane violation rates. On the basis of historical evidence, however, the freeway violation rates on Marin 101 (which take into account total travel volumes) prior to the change in carpool definition were actually lower than the corresponding rates on Santa Clara 101 and Santa Clara 237, which have always had 2-person Carpool definitions. Prior to the definition change, approximately $1.6 \%$ of all drivers on Marin 101 used the HOV lanes illegally during both peak periods. The corresponding figures for Santa Clara 101 and Santa Clara 237 were $2.3 \%$ and $1.8 \%$ respectively.

Marin 101 with 2+ Carpools. With the change in carpool definition, the lane violation rate on Marin 101 dropped precipitously, falling from just under $30 \%$ to under $10 \%$. At the same time, the average number of violators per day dropped slightly, from 330 to 299 . Thus the drop in the violation rate did not reflect a decline in violations nearly so much as an increase in legitimate users of the lane. The actual number of violators dropped by $9 \%$, reflecting a drop in the pool of potential violators. (After the change, only single drivers could use the lanes illegally. Prior to the change, however, autos carrying either one or two persons were potential violators.)

\subsubsection{Enforcement Concerns}

The task of enforcing mainline HOV lanes is much the same whether Carpools are defined as two persons or three persons. Officers report that it is somewhat easier to enforce an underused lane than an over-used lane, since the problem of "nested" violators is not so prevalent when there are fewer legitimate carpoolers in the lane. They agreed, however, that this was a minor concern.

\subsection{SIGNING AND MARKING}

The signing and marking of preferential lanes is one engineering design feature with a potential impact both on violations and on public perceptions of HOV lanes. In March of 1979, CALTRANS instituted a set of uniform standards for the signing and marking of bus and Carpool lanes throughout the state. These standards have been in effect for over ten years, so that signing has been effectively standardized on California's mainline HOV lanes. Some variation exists in the designation of the painted buffer separating HOV lanes from mainline traffic. These 
buffers range from a one-foot stripe on Orange 55 to a 13-foot crosshatched lane on the El Monte Busway.

Focus group discussion indicated that there was little confusion among regular commuters regarding the purpose or use of carpool lanes. (See Section 6.1.) Officers enforcing Santa Clara 101, which feeds the San Jose Airport, noted that out-of-state drivers of rental cars sometimes are confused by the carpool lanes and use them illegally before they realize that the lanes are reserved for vehicles with more than one occupant.

\subsubsection{LA 91}

Prior to the installation of round-the-clock service for the LA 91 HOV Lane, CALTRANS experimented with three signing packages in an attempt to remove the median shoulder from use during the off-peak period. (See Klusza, 1988). The signing for the project was originally limited to regulatory signing posting HOV hours of operation. This signing failed to keep traffic off the shoulder when the HOV lane was not in use. Shoulder violations during the first three months of use ranged from 400 to 1000 per weekend day.

CALTRANS replaced fixed message signs with manually operated changeable signs four months after the HOV lane was opened. These signs showed a regulatory message noting that the lane was in use during the evening peak period. At other times, the signs announced that the lane was restricted to normal shoulder functions. These changeable message signs lowered shoulder violations to a range of 100 to 400 per weekend day.

The next signing experiment on LA 91 used electronically operated changeable message signs in conjunction with a traffic signal. The signal indicated with a red or green arrow whether the commuter lane was closed or open to HOV traffic. This dual signing strategy reduced the weekend violation rate to a range of one to 30 per day. Even with this marked reduction in violations, CALTRANS did not feel that the lane could be safely returned to shoulder use during the off-peak hours. As a result, the Route 91 HOV lane was opened to buses and Carpools 24 hours per day. 


\subsubsection{Alameda 580}

The experience on LA 91 shows that proper signing can drastically reduce violation rates when violations are the result of driver confusion. The experience on Alameda 580 shows that signing can also help to create confusion and increase violation rates. In the case of Alameda 580, preferential lane restrictions began officially on Monday at 6:00 AM and were legally in force until Friday at 6:00 PM. Signs used on the now-defunct project are shown in the inset. SYSTAN's previous study of HOV lane violations (Billheimer, 1981) found that an unusually high proportion of violations occurred between 6:00 PM and 7:00 PM every weekday, suggesting that a large number of drivers wrongly interpreted the operating hours to be 6:00 AM to 6:00

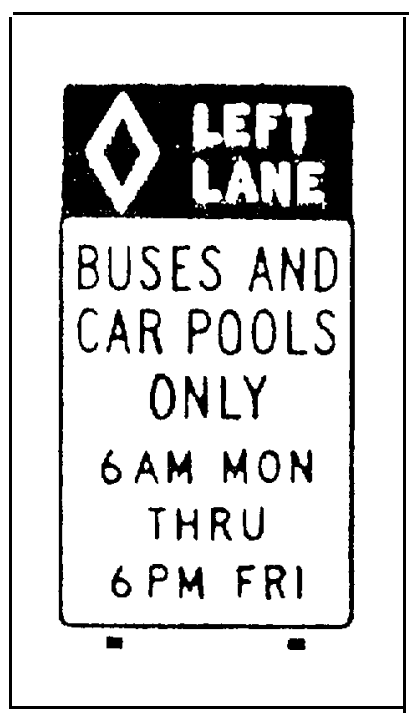
PM, Monday through Friday.

\subsection{TIME SAVINGS}

The average amount of time saved by drivers traveling the length of California's HOV lanes ranges from 1.5 minutes on Marin 101 to over 13 minutes on the El Monte Busway. When an incident causes additional congestion in the mixed flow lanes, this time savings can be much greater. In an attempt to document the impact of potential time savings on violation rates, observers counting violations also recorded speeds in the HOV and mixed-flow lanes at 5-minute intervals. Subsequent comparisons of violation rates with the time savings afforded by the HOV lane showed no correlation between time savings and violations (see Section 3.5.2).

\subsubsection{Perceived Savings vs. Actual Savings}

One explanation for the apparent lack of correlation between time savings and violation rates is found in the fact that drivers overestimate the time savings available from the use of the HOV lane (see Section 6.3.3). Thus any time savings, even the smallest, looks much larger than it actually is and looms as a temptation to potential violators. 


\subsubsection{Inter-Project Comparisons}

Although inter-project comparisons are hardly exact, there is no indication that projects offering greater time savings (i.e. the El Monte Busway and OR 55) have higher lane or freeway violation rates than projects offering relatively small savings (i.e. Marin 101). As a case in point, the time savings available to carpoolers on Santa Clara 101 changed dramatically in the course of the current study when the lanes were extended 9 miles to the Santa Clara/San Mateo County Line. The lengthening of the HOV lanes significantly increased the time savings available to drivers traveling the length of the project. However, the violation rates measured on the original segment of the project did not change significantly when the lanes were lengthened, remaining between $5 \%$ and $10 \%$ before and after the change.

\subsection{PROJECT LENGTH}

Strictly speaking, the amount of time saved by traveling in the HOV lane is not an engineering design option, since it depends on changing freeway conditions. However, total time savings is a function of the speed differential resulting from congestion and the length of the HOV lane. The lengths of California's existing mainline HOV lanes vary from just under 2 miles (San Francisco 280) to over 11 miles (OR 55 and the extended Santa Clara 101).

\subsubsection{Violation Implications}

Although there are not enough mainline HOV lanes of different lengths in California to support a definition statistical analysis of the impact of lane length on violation rates, there is no indication that longer lanes lead to higher violation rates. Violation rates did not increase significantly on Santa Clara 101 when the HOV lane was lengthened from 3 miles to 12 miles. Violations are currently below $12 \%$ on all of California's mainline HOV lanes (except I-280), but some of the longer lanes (LA 91, OR 55) have historically had lower violation rates than such shorter lanes as Marin 101 and the original 3-mile length of Santa Clara 101.

While violators may save more time on longer HOV lanes, they are also exposed to capture for longer periods of time. Hence there may be a greater perceived risk of capture as lane length increases. Strictly speaking, the shortest HOV lanes in California are ramp meter bypass lanes. Violators bypassing meter queues in these lanes are exposed to capture for relatively short 
periods of time. Although ramp meter bypass lanes were not a part of the current study, the average lane violation rate measured on a sampling of Los Angeles bypass lanes prior to the start of special enforcement on the previous SYSTAN study was 37.7\% (Billheimer, et al., 1981). While special enforcement activities nearly cut these rates in half, at the close of the study the average lane violation rate on California's bypass ramps was significantly higher than the rates currently experienced on California's mainline HOV lanes.

\subsubsection{Enforcement Implications}

Barrier-Separated Lanes. Special enforcement requirements are clearly independent of lane length in the case of barrier-separated lanes. A single officer stationed at the mouth of such a lane provides the same enforcement presence, and the same deterrence to occupancy violators, whether the lane is ten miles long or twenty miles long. As noted elsewhere, a lengthy barrier separation creates a need for special enforcement assignments. A relatively short section of separated right-of-way (such as the four-mile section at the western-end of the El Monte Busway) might be enforced by the occasional diversion of officers on routine patrol.

Contiguous Lanes. Because violators can weave in and out of contiguous lanes at different points, the impact of lane length on enforcement requirements is not so clear-cut when no barrier separates HOV lanes from mixed flow traffic. The longer violators remain in contiguous mainline HOV lanes, however, the longer they are exposed to capture by routine patrol. When violators travel the full length of the lanes, the situation is analogous to the barrier-separated case. Doubling the length of the lanes does not double the need for special enforcement hours. In fact, doubling the length of mainline HOV lanes doubles the length of time that most violators are exposed to capture by routine patrol, which may lessen the need for special enforcement.

In general, the shorter a contiguous HOV lane is, the more likely that special enforcement will be required to keep it free from violations. At one extreme, ramp meter bypass lanes get relatively little routine enforcement (routine patrol officers tend to pass quickly by these short stretches of road). At the other extreme, on long mainline lanes, violators are exposed to capture by routine patrol for longer periods, lessening the need for special enforcement. 


\subsection{SUMMARY OF ENGINEERING DESIGN ISSUES}

This subsection reviews the impacts of key engineering design issues upon HOV lane enforcement. A summary of key findings of interest to agencies charged with HOV lane design appears in Appendix E.

\subsubsection{Lane Separation}

From the standpoint of safety, operations, and enforcement, physical separation is desirable. Physically separate lanes have lower violation rates. They also require a daily enforcement commitment, since officers in adjacent mixed-flow lanes do not have ready access to the barrier-separated HOV lanes.

Painted buffer lanes separating mixed flow lanes from HOV lanes are no more effective than a simple stripe in discouraging occupancy violations. However, the wider buffer lanes do appear to discourage (but not eliminate) illegal buffer crossings. To keep cars from stopping on the buffer itself, it is recommended that buffer lanes be no more than four feet wide. Striped separations of one-foot and two-foot widths are no more difficult to enforce than wider buffer separations.

\subsubsection{Access/EgressLimitations}

Access/egress limitations on contiguous HOV lanes appear to impose a marginal additional load on enforcing officers. Less than $16 \%$ of the tickets issued by Southern California CHP officers during periods of special enforcement cited drivers for illegal buffer crossings. Accordingly, the decision to limit access and egress to HOV lanes (as is common in Southern California) or to allow unlimited access (as is common in Northern California) should be made on the basis of traffic engineering and safety concerns, with enforcement a minor consideration.

\subsubsection{Enforcement Areas}

Experience on LA 91 shows that a well-designed enforcement area can be used effectively to control violations along a mainline lane. A usable enforcement area constructed 
from a flared median barrier must have a mouth of at least 9'-8" and be set in a 14-median lane. To provide adequate acceleration/deceleration distances the 14-median shoulder should extend at least 1,300 feet beyond the mouth of the enforcement area.

\subsubsection{Median Shoulder}

Where space is available, a continuous 14 -foot median should be provided along the length of the HOV lane for both safety and enforcement purposes. This median may be enhanced through the addition of enforcement areas. However, a properly designed enforcement area should be the minimum acceptable enforcement element accompanying future mainline HOV lane designs. The difficulties encountered in enforcing Marin 101 suggest that mainline HOV lanes lacking a substantial madian shoulder should not be contemplated if space cannot be found for at least one well-designed enforcement area.

\subsubsection{Operating Hours}

From the standpoint of enforcement, there is little to choose between round-the-clock and peak period operation of mainline HOV lanes. When HOV operations are restricted to the peak period, violations tend to cluster at the fringes of operating hours, and officers don't generally enforce HOV restrictions until the lanes have been operating for at least 10 minutes. Opening lanes to all-day operations does not appear to increase either violation levels or enforcement requirements appreciably, and may simplify signing problems and reduce confusion (and violation rates) at the changeover times. At the same time, it is impossible to enforce occupancy restrictions after dark, off-peak accident rates are likely to be lower if more lanes are available to mixed-flow traffic, and the additional hours of operation at times when there is no time advantage to be gained from using the HOV lanes are not likely to encourage many additional Carpools.

\subsubsection{Carpool Definitions}

The task of enforcing mainline HOV lanes is much the same whether Carpools are defined as two persons or three persons. Violation rates tend to be much lower when carpoolers are defined as two-or-more persons, but this largely reflects the dramatic increase in the number of 
legitimate HOV lane users. The actual number of violators does not appear to drop appreciably when carpool restrictions are relaxed from $3+$ to $2+$ persons.

\subsubsection{Signing and Marking}

Most drivers appear to understand the use of HOV lanes and recognize the standard signs and painted diamonds which are used throughout the state to designate bus and carpool lanes. Signs and signals must be totally unambiguous if HOV lanes are returned to shoulder use during off-peak hours. Confusion regarding shoulder use can create serious hazards for disabled vehicles and the creation of HOV lanes through the use of part-time shoulder conversion is not generally recommended. After considerable experimentation on LA 91, including the use of electronically operated message signs and traffic signals, CALTRANS concluded that no signing system was sufficiently unambiguous to permit the lanes to be returned to shoulder use during off-peak hours. As a result, the LA 91 HOV lane was opened to buses and Carpools 24 hours per day.

\subsubsection{Time Savings}

No correlation was found between violation rates and the actual time savings afforded by HOV lanes, perhaps because drivers overestimate the time savings available from HOV lanes. As a result, any savings, even the smallest, looks much larger than it actually is and looms as a temptation to potential violators.

\subsubsection{Project Length}

In general, the shorter a contiguous HOV lane is, the more likely that special enforcement will be required. At one extreme, the shortest HOV lanes in California, ramp meter bypass lanes, get relatively little routine enforcement and rely almost exclusively on special enforcement. At the other extreme, long mainline HOV lanes such as OR 55 and Santa Clara 101 expose violators to capture by routine patrol for longer periods, lessening the need for special enforcement. So long as the population of freeway drivers does not change dramatically over the length of a mainline HOV lane, special enforcement requirements appear to be nearly independent of lane length. 


\subsection{PUBLIC AWARENESS}

This chapter addresses the attitudes and awareness of California drivers with respect to HOV lanes, as revealed in a series of focus group discussions and mail-back surveys. Six group discussions and two waves of mail-back surveys were conducted with a sampling of drivers from the four study projects. The procedures followed in conducting group discussions and mail-back surveys are summarized, and driver attitudes toward such issues as enforcement, violations, and HOV lanes are documented and analyzed.

\subsection{FOCUS GROUP DISCUSSIONS}

A focus group discussion is a flexible research technique used to gather rich, in-depth data in a relatively unstructured manner. Discussion groups of ten to fifteen people are allowed to interact freely on a set of predetermined topics under the direction of a trained group leader. The resulting interpersonal interactions can be quite informative, particularly when the topics address issues, such as HOV lane operation, which inherently contain a high degree of public interest.

Because focus groups are relatively small, they are not designed to provide precise statistical quantification of the issues under discussion. Rather, they are designed to explore key issues in greater depth and highlight related attitudes and convictions. In-depth insights are obtained at the expense of the precise quantification available through the larger sample sizes of survey research. The insights obtained through focus group discussions can, however, be applied in the development of formal surveys designed to permit more precise statistical quantification of key issues.

\subsubsection{Timing and Protocol}

Schedule. Focus group discussions were held prior to the start of the first wave of special enforcement activities with drivers using each of the four study freeways. A schedule of discussion group activities appears below. 


$\begin{array}{lllc}\text { Freeway } & \text { Date } & \text { Location } & \text { Participants } \\ \text { Marin 101 } & \text { September 29 } & \text { Marin County } & 10 \\ \text { LA 91 } & \text { October 5 } & \text { Anaheim } & 10 \\ \text { Orange 55 } & \text { October 6 } & \text { Anaheim } & 11 \\ \text { LA 91 } & \text { October 11 } & \text { Anaheim } & 10 \\ \text { Orange 55 } & \text { October 12 } & \text { Anaheim } & 10 \\ \text { Santa Clara 101 } & \text { October 13 } & \text { Sunnyvale } & 8\end{array}$

Participants. Participants were chosen from license plates recorded during the peak commute period on each freeway. The mix of participants invited to each group discussion included $40 \%$ carpoolers, $40 \%$ single drivers, and $20 \%$ observed violators. Exhibit 6.1 contains a profile of the drivers who participated in each focus group discussion.

Protocol. The focus group discussions were designed to provide first-hand, in-depth responses to key issues regarding public perceptions of HOV lane use, enforcement activities, and violations. A detailed outline of the topics addressed in the six focus groups may be found in Appendix A.

Although the focus group outline of Appendix A was adapted in each discussion to address topics directly related to the local HOV lanes, all discussions followed the same general sequence. Participants introduced themselves and described their commuting habits and their use of the study freeway and other local roadways. Reasons for their choice of route and carpooling status were discussed; preliminary observations regarding local HOV lanes were explored; and HOV lanes were identified as the primary topic of discussion.

Once HOV lanes were identified as an issue, personal driving habits vis-a-vis the local Carpool lane were explored; perceptions of travel time and safety were documented; attitudes toward HOV lanes were addressed: surveillance and enforcement issues were talked over; perceptions of violations were discussed; and opinions regarding hypothetical design changes were sought. In addition, drivers were asked their opinion of mail-out citations backed by photographic evidence. Any misunderstanding regarding the intent, design, or signing of the local HOV lane was discussed in detail. The results of these discussions are summarized in subsequent sections under three primary topic headings: 


\section{EXHIBIT 6.1 \\ DRIVER PROFILE \\ FOCUS GROUP PARTICIPANTS}

Freeway Use Patterns

1. Frequency of Use

Once a month or less

2-5 times a month

2 or 3 times a week

4 times a week or more
LA 91 OR 55 SC 101 Marin 101

$\begin{array}{cc}0 & 0 \\ 0 & 0 \\ 1 & 0 \\ \frac{7}{8} & \frac{10}{10}\end{array}$

$\begin{array}{r}0 \\ 1 \\ 1 \\ 19 \\ \hline 21\end{array}$

Total

$\begin{array}{rr}\mathbf{n} & \% \\ 0 & 0.0 \\ 2 & 3.4 \\ 2 & 3.4 \\ \frac{55}{59} & \frac{93.2}{100.0}\end{array}$

2. Time (Minutes) to

Complete Trip

In the morning (Avg.)

In the afternoon (Avg.)

3. Length of One-Way Trip Average in Miles

4. Trip Mode

Drive alone

Bus

Carpool

Other

No. of People in

Carpool (Avg.)

$\begin{array}{rr}51 & 3 \\ 57 & 4 \\ & \\ 29.5 & \\ & \\ & \\ 11 & \\ 0 & \\ 9 & \\ 0 & \end{array}$

2.1

8

$34 \quad 38$

4138

38

30

31

$57 \quad \frac{\mathrm{n}}{39.8}$

$58 \quad 44.3$

$\frac{n}{7} \quad$ Avg.

$\begin{array}{lll}18.3 & 16.2 \quad 15.4\end{array}$

$57 \quad 21.2$

$\frac{\mathrm{n}}{34} \quad \frac{\%}{57.6}$

$1 \quad 1.7$

$24 \quad 40.7$

$0 \quad 0.0$

$\frac{n}{23} \quad \frac{\text { Avg. }}{2.5}$

\section{Demographic Characteristics}

1. Cars per household (Avg.) Licensed drivers per household (Avg.)

2.4

3.1

2.4

Avg.

$2.3 \quad 2.3$

2.4

2.3

$5 \frac{n}{9}$ 2.4

2. Sex Female
Male

$\begin{array}{rr}4 & 9 \\ 16 & 12\end{array}$

5
3

4

6

58

2.3

3. Age Group

Under 20

20-29

30-44

45-64

65 and over

$\begin{array}{rr}0 & 0 \\ 5 & 3 \\ 5 & 7 \\ 10 & 10 \\ 0 & 1\end{array}$

$\begin{array}{ll}1 & 0 \\ 2 & 4 \\ 4 & 4 \\ 1 & 2 \\ 0 & 0\end{array}$

$\begin{array}{ll}\frac{\mathrm{n}}{22} & \% \\ 37 & 37.3\end{array}$

$\begin{array}{ll}37 & 62.7\end{array}$

$\frac{\mathrm{n}}{1} \quad \frac{\%}{1.7}$

$14 \quad 23.7$

$20 \quad 33.9$

$23 \quad 39.0$

39.0
1.7 


\section{Carpool Lane Perceptions \\ 2. Violation Perceptions \\ 3. Enforcement Perceptions}

\subsubsection{Carpool Lane Perceptions}

HOV Lane Purpose. All participants were asked the purpose of the Carpool lane in their area. Exhibit 6.2 summarizes the answers of drivers in each focus group. At all six focus groups, participants said one purpose of the lanes was "...to encourage carpooling," Two other purposes were listed at five of the six discussion groups: "...to save time" and "...reduce congestion." Purposes mentioned at more than one focus group are listed below:

\section{Purpose}

Encourage carpooling

Save time

Reduce congestion

Cut pollution

Save gasoline

Reduce stress

Reduce number of cars
Number of Groups Listing

6
5
5
4
3
3
2

In general, although the members of different focus groups disagreed on how well a particular lane fulfilled its purpose, there was a good understanding of what that purpose was.

Lane Descriptions At each focus group, participants were asked to list a series of adjectives describing their Carpool lane. Exhibit 6.3 lists the result of this exercise. Negative adjectives outnumbered positive adjectives by nearly a 2:1 margin. Comments listed by more than one group were "dangerous" (four groups - OR 55 and LA 91), "scary" (three groups - OR 55 and LA 91) and "progressive" (two groups - LA 91 and Marin 101).

It seems significant that the words "scary" and "dangerous" recurred when drivers described the two Southern California lanes (OR 55 and LA 91), but were not mentioned at all by Northern California drivers using SC 101 and Marin 101. The features mentioned by drivers finding the Southern California lanes "scary" were the (1) speed differential, (2) the threat of people pulling into the lane unsafely, and (3) the nearby Jersey barrier. 


\section{EXHIBIT 6.2 \\ PERCEIVED PURPOSES OF \\ CALIFORNIA HOV LANES}

\begin{tabular}{|c|c|c|c|c|c|c|}
\hline \multirow{2}{*}{$\begin{array}{l}\text { Freeway } \\
\text { Purpose }\end{array}$} & \multicolumn{2}{|c|}{ LA 91} & \multicolumn{2}{|c|}{ OR 55} & \multirow[t]{2}{*}{ Marin 101} & \multirow[t]{2}{*}{ SC 101} \\
\hline & $\underline{\text { GRP } 1}$ & $\underline{\text { GRP } 2}$ & $\underline{\text { GRP } 1}$ & GRP 2 & & \\
\hline Save gas & & $x$ & & $x$ & & $\mathbf{x}$ \\
\hline Induce carpooling & $\mathrm{X}$ & $x$ & $x$ & $\mathrm{x}$ & $\mathrm{x}$ & $\mathbf{x}$ \\
\hline Cut pollution & $x$ & & $x$ & $x$ & & $x$ \\
\hline Save time & & $x$ & $x$ & $x$ & $\mathrm{x}$ & $x$ \\
\hline Reduce congestion & & $x$ & $x$ & $x$ & $x$ & $x$ \\
\hline Reduce stress & & & $x$ & & $x$ & $x$ \\
\hline Improve safety & & & & & & $x$ \\
\hline Reduce fast cars & $\mathrm{x}$ & & & & & \\
\hline $\begin{array}{l}\text { Twist arms to } \\
\text { form Carpools }\end{array}$ & $x$ & & & & & \\
\hline Political & & & $x$ & & & \\
\hline Reward carpoolers & & & & & $x$ & \\
\hline Expedite traffic & & & & & $x$ & \\
\hline $\begin{array}{l}\text { Keep buses on } \\
\text { schedule }\end{array}$ & & & & & $x$ & \\
\hline Get Federal funds & & & $x$ & & & \\
\hline Increase revenue & & $x$ & & & & \\
\hline Airport access & & & $x$ & & & \\
\hline Emergency access & & & $x$ & & & \\
\hline $\begin{array}{l}\text { Increase freeway } \\
\text { capacity }\end{array}$ & & & & & & \\
\hline
\end{tabular}




\section{EXHIBIT 6.3 \\ ADJECTIVES USED TO DESCRIBE \\ CALIFORNIA HOV LANES}

Freeway

Descriptive Words

POSITIVE

Great

Fast

Rewarding

Progressive

Convenient

Fair

Efficient

Well used

NEGATIVE

Scary

Dangerous

Waste of space

Mickey Mouse

Nerve-wracking

Aggravating

Tense

Fearful

Risky

Frustrating

Rough

Empty

Non-Functioning

Insulting

Unfair

Inefficient

Unused

IN-BETWEEN

Good but not great

Exciting

Narrow

Expedient

Lonely

Well-intentioned

Open season for CHP

Too late arriving
LA 91

OR 55

Marin 101

SC 101

\section{GRP 1 GRP 2 GRP1 GRP2}

$\begin{array}{ll}\mathbf{X} & \\ \mathbf{X} & \mathbf{X} \\ & \mathbf{X} \\ & \mathbf{X} \\ & \mathbf{X}\end{array}$

$\mathbf{X}$

$\mathrm{x}$

$x$

$\mathbf{X}$
$\mathbf{X}$
$\mathbf{X}$

$\begin{array}{ll}\mathbf{x} & \mathbf{x} \\ \mathbf{x} & \mathbf{x} \\ \mathbf{x} & \\ \mathbf{x} & \\ & \mathbf{x} \\ & \mathbf{x} \\ & \mathbf{x}\end{array}$

$\mathbf{x}$
$\mathbf{x}$
$\mathbf{x}$
$\mathbf{x}$
$\mathbf{x}$

$\mathbf{X}$
$\mathbf{X}$

$\mathbf{x}$

$\mathbf{x}$

$\mathbf{X}$

$\mathbf{X}$

$\mathbf{x}$
$\mathbf{x}$
$\mathbf{x}$

$x$

$\mathbf{X}$

$x$<smiles>[V]</smiles>

$\mathbf{x}$
$\mathbf{x}$
$\mathbf{x}$

$\mathbf{X}$ 
One LA 91 Driver noted:

"It's nervous driving (on LA 91) when you have cars virtually standing still and you're driving at $60 \mathrm{mph}$. The differential speed makes for very nervous driving. And the ever-present threat of people pulling in...that's scary."

\title{
Another LA 91 Driver:
}

"That wall gets kind of nerve-wracking, too, 'cause you've only a foot and a half off that wall."

On SC 101, where a 10-foot median lane separates carpoolers from the Jersey barrier, none of the participating drivers volunteered the words "scary" or "dangerous" in describing the carpool lane. Although Marin 101 has no median lane, the speed differential separating the carpool lane from general traffic was not nearly so great as on the other three study lanes. Moreover, Marin drivers were interviewed in late September, before the carpool definition was changed from three persons to two persons. At that time, the lanes were relatively little used.

"Empty. That's the perfect word (for Marin 101 before the change in carpool definition). You're sitting there and you're mad because you see a car go by every two minutes, at $60 \mathrm{mph}$, and you're doing 25 . Then you get mad."

One carpooler on OR 55 found the lane so nerve-wracking that he didn't use it, even though he was qualified to do so.

\begin{abstract}
"In the carpool lane you have on one side of you the fast lane, which is not really fast...and in the other direction you have a block wall. When somebody cuts in front of a person in the carpool lane, they've really only got one way to go and that's either to crash into the person, or go into somebody else's lane, or go into a block wall."
\end{abstract}

Estimated Time Savings. Participants were asked to estimate the time savings available in the carpool lane. Each group's estimates are listed below, along with the actual savings measured in past speed runs.

\section{Freeway}

Group Estimate (min.)

Avg. Peak Period Savings (min.)

Avg. Peak Hour Savings (min.)
LA 91

15.0

3.3

9.0
OR 55

17.8

4.2

10.2
Marin 101

0 to 10

$4.9^{*}$

$11.0^{*}$
SC 101

12.5

3.5

5.6

*Combined savings from both sections

Thus group members tended to over-estimate the average savings available from using the carpool lane. 
Several non-carpoolers perceived that the carpool lanes had improved their travel time as well. One driver observed that:

"I take (SC) 101 more often now. It was so bad before the Carpool lane that you'd try any route just to keep the wheels rolling."

Do the Lanes Work? Participants were asked whether they felt the HOV lanes in their area were (1) effective, (2) safe, and (3) fair.

(1) Are They Effective? The clear majority (roughly $80 \%$ ) of the participants felt that the Carpool lanes on OR 55, LA 91, and SC 101 were effective in encouraging Carpools and moving them faster. The group discussing Marin 101 was more divided. In view of the scanty use of the lane at the time of the discussion, they felt that the lane had not fulfilled its purpose of generating 3-person Carpools. ("Most of us think the darn think isn't doing its job.").

(2) Are They Safe? Well over $80 \%$ of the Southern California participants perceived LA 91 and OR 55 to be unsafe. As noted above, these perceptions were not shared by the majority of the Northern California participants using SC 101 and Marin 101. However, a few drivers felt that the speed differentials on SC 101 were likely to lead to more accidents.

(3) Are They Fair? Over $80 \%$ of the participants felt that the Carpool lanes were fair. On SC 101 drivers noted that they were "unfair only for those who absolutely could not Carpool."

Suggested Improvements. A potential improvement suggested by carpoolers and some non-carpoolers on each of the four study freeways was an extension of the existing Carpool lane. A few non-carpoolers on each freeway argued that the lanes should be opened to all traffic. Suggested improvements are listed below for each freeway.

\section{LA 91}

- Open in both directions;

- Lengthen entrance and exit points;

. $\quad$ Provide more entrance and exit points;

- $\quad$ Extend Carpool lane from the Harbor Freeway past I-605 to OR 55;

- Allow motorcycles; and

. $\quad$ Design more space between the Carpool lanes and the center divider;

\section{OR 55}

- $\quad$ Post a speed limit for the Carpool lane;

- Lengthen entrance and exit points;

- $\quad$ Provide a buffer lane or a physical barrier; 
- Widen all lanes;

Limit number of access points, and put them further from entrance ramps to allow more merge time;

Open to general traffic during the off-peak;

Keep commercial trucks out of Carpool lane;

Provide more separation between the Carpool lane and the center divider: and

Extend Carpool lane to LA 91.

(One non-carpooler noted "The 55 Carpool lane stops short of 91 and dumps carpoolers into general traffic. But I sure don't feel like letting you guys in.")

\section{SC 101}

Reduce operating hours, stopping at 6:30 p.m. instead of 7:00 p.m.; and

Extend lane to South San Jose ("Right now it's too restricted. We've got such a commuting problem. What is the point of carpooling to save 5 minutes out of a onehour trip?")

\section{Marin 101}

. Change the Carpool definition to two or more occupants; and

. Join the two segments of carpool lane, marking one continuous lane.

\subsubsection{Violation Perceptions}

All participants had seen drivers using their Carpool lanes illegally and roughly one-third admitted that they themselves had been occupancy violators. Every Southern California driver who used the Carpool lane regularly admitted that they had crossed the double yellow lines to enter or leave the lanes at one time or another. An LA 91 carpooler said:

"I get on at Lincoln. Sometimes I violate getting across the yellow line. People won't let you in."

Estimated Occupancy Violation Rates. Drivers were asked to estimate the relative percentage of drivers that used the lane without enough occupants to qualify as a Carpool. The average response from drivers on each freeway is listed below, along with the results of counts taken just before the focus groups were held. 


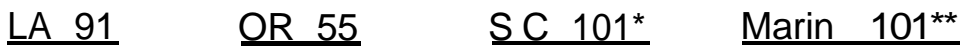

Estimated Violation Rates

Recently Observed Violation Rates

$8.7 \% \quad 12.1 \%$

$\begin{array}{llll}7.8 \% & 7.3 \% & 20.8 \% & 29.9 \%\end{array}$

$18.5 \%$

$\begin{array}{llll}7.8 \% & 7.3 \% & 20.8 \% & 29.9 \%\end{array}$

$11 \%$

*Subsequent violation counts prior to initial enforcement wave found SC 101 violation rates to be under $10 \%$.

${ }^{* *}$ Focus group conducted when Carpool definition was still three or more.

Except in the case of Marin 101, focus group drivers proved to have a relatively good sense of the level of violation rates on the freeway they were using.

Estimated Buffer Violation Rates. Drivers on both LA 91 and OR 55 estimated that roughly $17.5 \%$ of the drivers using the Carpool lanes entered or exited the lane illegally by crossing the double yellow line. They felt that buffer violations were more common than occupancy violations. Although it is difficult to compare the relative frequencies of the two types of violation, data from speed runs suggests that occupancy violations are much more evident to mixed flow drivers than buffer violations (see Section 3.5.3).

Violation Observations. Drivers on all four freeways felt that there were a large number of repeat offenders among the violators. A Marin 101 driver summed up the group's feelings by saying, "If they do it once (and get away with it), why not do it over again?" There was a general feeling among Southern California drivers that occupancy violators tended to go over the double yellow line as well.

"Most (occupancy) violators come in on double yellow and go out on double yellow."

"People who use the lane illegally are darters. They weave in and out."

"If catpoolers jump the yellow line they stay in. Single guys go in and out." (Another Driver: "Once you cross the yellow line with two people, you can't get caught.")

Drivers were aware of several ruses used by repeat violators. The following exchange occurred in the discussion among SC 101 drivers.

"Driver \#1 : "Some violators are really slick. There's this woman who puts an empty baby seat in her car."

"Driver \# 2 (Admitted repeat violator): "I'm gonna get me a carriage."

Means for Lowering Violations. When asked how violations might be lowered, all groups suggested increasing enforcement levels, although the Marin 101 group specified that enforcement must be made visible than it has been. At every focus group except OR 55 , at least 
one member of the group proposed raising fines and posting the size of the minimum fine along the freeway as a means of discouraging violators.

On three of the four freeways, some members of the group suggested using video surveillance with mail-out warnings and citations. In subsequent discussions, (see Enforcement Section 6.1 .4 below), this proved to be a controversial measure. Other driver suggestions for lowering violation rates included citizen action (phone in license plates of violators - another controversial measure), special permits for lane users (LA 91), and capital punishment for repeat violators (OR 55).

Seriousness of Violations. Drivers were asked to rate the seriousness of various traffic violations on a scale of 0 (not at all serious) to 10 (extremely serious). The ratings assigned by all focus group participants are listed below in order of decreasing seriousness.

\section{CONSENSUS OF SERIOUSNESS}

\section{Offense}

Running a Red Light

Speeding on a Residential Street

Crossing Carpool Buffer

Tailgating

Running a Stop Sign

Speeding on a Freeway

Carpool Occupancy Violation

Parking in a Handicapped Lane

Overtime Parking

\section{Rating}

10.0

9.4

$9.0^{*}$

8.7

8.4

7.1

$\underline{4.8}$

4.1

0.6

*Rated only by Southern California drivers.

Thus crossing the double yellow line to enter and leave a carpool lane was viewed as an extremely serious offense by Southern California drivers. It was only slightly less serious than speeding on a residential street and more serious than tailgating or running a stop sign. Occupancy violations were viewed as less serious, but non-trivial, offenses.

Because of the social issues involved, carpool occupancy violations received an average rating of 4.8 , considerably higher than the lowest ranked offense. The offense ranked lowest, overtime parking, was rated 0.6 on the 0 to 10 scale of seriousness. 


\subsubsection{Enforcement Perceptions}

Observations. Drivers in all focus groups were asked whether they had ever seen a driver ticketed for using the Carpool lane illegally. The percentage of drivers responding that they had seen enforcement activity is listed below.

$\begin{array}{cc}\text { Seen Enforcement } & \text { Activity? } \\ \text { Yes } & \text { No } \\ & \\ 100 \% & 0 \% \\ 82 \% & 18 \% \\ 80 \% & 20 \% \\ 73 \% & 27 \%\end{array}$

Thus drivers were most aware of enforcement activity on SC 101, where officers sometimes use the 10 foot median lane to ticket violators. Drivers were least aware of ticketing activity on Marin 101, which has no adjacent buffer lane and where drivers must be escorted to the right shoulder (or off the freeway) to be ticketed.

Direct Experience. Seven percent of the drivers participating in the discussions had themselves been ticketed.

Recent Trends. When asked whether they felt enforcement had been increasing or decreasing in recent months, drivers on three of the four study freeways felt that it had "...stayed about the same." Seventy percent of the drivers using LA 91 felt that enforcement had decreased recently, at least in comparison with the levels they remembered when the lane opened.

General Attitudes. The prevalent attitude toward enforcement on all four freeways was well summarized by a driver from LA 91 :

"The police are doing a fairly good job, but stopping people on the freeway slows things down."

Perceived Risk. Drivers were asked what percentage of violators they thought were caught and ticketed. Guesses from different focus groups are listed below, along with measured estimates formed on the basis of citation counts and occupancy observations. 


\section{APPREHENSION RATE}

\section{Perceived Estimated}

LA91

OR 55

SC 101

Marin 101

$\begin{array}{cl}4.2 \% & 2.8 \% \text { (maximum) } \\ 3.8 \% & 2.6 \% \\ 17.8 \% & 2.5 \% \text { (maximum) } \\ 1 \% \text { to } 10 \% & 1.5 \%\end{array}$

Thus drivers generally perceive their chances of getting caught to be higher than they actually are, although their perceived risk of apprehension is still relatively low. One driver on LA 91 reported. "I did it (violated) 20 times before I was caught once."

Mail-Out Tickets. In most focus groups, the possibility of video surveillance with mailout enforcement was suggested by the group themselves. At the close of each group discussion, this possibility was outlined and participants were asked their opinion of the concept. Discussions were invariably heated, with strong feelings on either side of the issue. In the end, participants in three focus groups favored using mail-out citations, while participants in the three remaining groups were opposed. A summary of each group's opinions appears below.

\section{OPINION ON MAIL-OUT CITATIONS}

Eocus Group

LA 91

Group 1

Group 2

OR 55

Group 1

Group 2

Marin 101
In Favor

$$
10 \%
$$

$60 \%$

$100 \%$

$70 \%$
Opposed

$90 \%$

$40 \%$

$100 \%$

$0 \%$

$30 \%$

\section{SC 101}

*No vote taken. Group generally opposed on technological grounds.

(1) Arguments For. One OR 55 driver noted that "Mail-out tickets is the best way (to enforce HOV lanes). Pulling violators over is almost out of the question...It really messes up the traffic pattern." Another OR 55 driver felt that mail-out tickets would "...free police for more important duties But that doesn't mean the CHP should disappear. That visibility is important." Several drivers made the point that before mailing out tickets, the state "... needs to educate the public first." The public needs to understand both the need for compliance with HOV regulations and, in particular, the need for video surveillance. 
(2) Arguments Against. "Shades of Big Brother" was the most frequently cited argument against mail-out citations. Many drivers expressed concern over the technological problems involved in making sure that the camera hadn't missed a baby or a sleeping adult. Even when the majority of the group favored mail-out tickets, there was generally a vocal minority which felt strongly that they were an invasion of privacy.

\subsection{SURVEY PLAN}

\subsubsection{Overview}

Significant numbers of single drivers, carpoolers, and Carpool-lane violators on four HOV projects were surveyed at two points in the study: (1) At the beginning of the study, just prior to the first wave of special enforcement, and (2) At the end of the study, following the second wave of special enforcement. The populations surveyed were contacted by sampling the license plates of vehicles in Carpool lanes and adjacent lanes, using DMV records to obtain the addresses of vehicle owners and mailing surveys to the owners' homes. The beginning survey addressed a wide range of topics, including individual travel characteristics, Carpool lane use, perceptions of violations, awareness of enforcement, demographic data, and opinions regarding various HOVrelated topics. The ending survey addressed those same topics in an attempt to detect any changes in perceptions and attitudes which might have occurred.

\subsubsection{Survey Questionnaires}

Appendix B contains a copy of the mail-back survey questionnaire mailed to freeway users prior to the first wave of special enforcement. The questionnaire was reviewed and approved by the HOV Steering Committee and consisted of the following major elements:

1. Introduction and Freeway Use. Introductory remarks designed to screen for licensed drivers who use the particular freeway and document the current extent of that use (i.e., How long have they used Marin 101? How often? As carpooler or lone driver?).

2. Personal History vis-a-vis Carpool Lane. Specific questions designed to document any changes in travel time, route, trip timing, or Carpool formation resulting from the introduction of the Carpool lane. This may include questions regarding illegal use of the lane and personal citations for illegal use.

3. Perceptions. Questions designed to explore drivers' perceptions of such key issues as travel time and HOV lane enforcement. Past studies (i.e., Billheimer, et al., 
1981) have shown that carpoolers and non-carpoolers alike tend to overestimate the amount of time to be saved by using a Carpool lane. Such information is of importance in understanding both mode choice and violation decisions.

4. Attitudes and Awareness. Questions designed to probe attitudes toward HOV lanes and awareness of surveillance and enforcement efforts. During the second survey, a question was added probing driver's awareness of the level of fines associated with HOV lane violations.

5. Opinions. Questions designed to document drivers' opinions of the HOV lanes themselves and explore public attitudes toward any contemplated changes in lane operations (i.e., Carpool definition, operating hours, etc.).

6. Demographics Questions designed to document the age, sex, and auto ownership status of the respondents.

\subsubsection{Sampling Procedures}

License Plate Samples. License plates were originally sampled on three selected HOV projects (OR 55, LA 91, and Marin 101) during the first six weeks of the study. At this time, observers recorded the license plates of all HOV lane violators on three successive weekdays. At the same time license plates of at least 2,400 carpoolers and 2,400 law-abiding drivers from the mixed-flow lanes were sampled from each project. This produced over 5,000 license plates from each project. These license plates were used to provide names and addresses for the focus groups as well as for the mail-back survey. As the study progressed, Santa Clara 101 was added to the list of study projects. Although the project budget could not support a full sampling of 5,000 license plates on this additional freeway, a smaller sampling of over 700 plates was made to support a focus group discussion and a limited mail-back survey.

The license plate listings obtained by the observation teams were coded, keypunched, and submitted to the DMV so that the information could be translated into names and addresses for focus group formation and subsequent survey sampling. A final tally on the number of plates submitted to the DMV appear below.

\begin{tabular}{|c|c|c|c|c|c|}
\hline Project & Violators & $\begin{array}{c}2+ \\
\text { Carpoolers } \\
\end{array}$ & $\begin{array}{c}3+ \\
\text { Carpoolers } \\
\end{array}$ & General & TOTAL \\
\hline $\begin{array}{l}\text { Marin } 101 \\
\text { Orange } 55 \\
\text { L.A. } 91 \\
\end{array}$ & $\begin{array}{r}795 \\
462 \\
330 \\
53\end{array}$ & $\begin{array}{r}1280 \\
2528 \\
2457 \\
170\end{array}$ & 1150 & $\begin{array}{r}3574 \\
2423 \\
2495 \\
156\end{array}$ & $\begin{array}{r}6799 \\
5413 \\
5282 \\
279\end{array}$ \\
\hline S.C. 101 & 53 & 170 & $\longrightarrow$ & 156 & 379 \\
\hline TOTAL & 1640 & 6435 & 1150 & 8648 & 17,873 \\
\hline
\end{tabular}


Sample Populations Three primary population segments were addressed in the survey:
1. Violators
2. Carpoolers
3. Non-carpoolers

A simple population sampling plan would have selected drivers in direct proportion to their appearance on the freeway (i.e., interview every $\mathbf{n}^{\text {th }}$ driver from the freeway observation records). However, since non-carpoolers outnumber carpoolers by a factor of at least five to one, and carpoolers outnumber violators by a similar ratio, such a strategy would have made it necessary to draw extremely large samples in order to guarantee that enough violators and carpoolers would be contacted to provide a statistically significant sample. Accordingly, it was necessary to sample the populations of violators, carpoolers, and non-carpoolers separately, with the aim of achieving statistical significance for all three populations with a minimum number of interviews.

After business plates, errors, and duplicates were pulled from the license plate sample, the 17,873 license plates recorded by observers produced a total of 14,131 useable names and addresses for use in the mail-back survey. The early survey was sent to half of this sample, while the final survey went to the remaining half. Surveys were printed separately for each project, and color-coded so that the responses of violators, carpoolers, and general drivers could be analyzed independently. To ensure the anonymity of respondents, no attempt was made to link the surveys to a particular driver.

Survey Response Rate. The overall response rate for all projects averaged $17.4 \%$ for the first survey, and $17.5 \%$ for the second survey. Exhibit 6.4 tabulates overall response for the various project categories. The highest response rate came from drivers responding to the first survey on Los Angeles Route 91 (20.3\%), while the lowest (13.5\%) came from drivers using Marin 101. Among the three user types, general drivers were most responsive, with a $19.1 \%$ overall return rate. The corresponding figures for carpoolers and violators were $16.6 \%$ and $13.0 \%$ respectively. 
EXHIBIT 6.4

SURVEY RESPONSE RATES

\begin{tabular}{|c|c|c|c|c|c|c|c|c|c|}
\hline \multirow[b]{2}{*}{ PRONECT } & \multicolumn{4}{|c|}{ FIRST SURVEY } & \multicolumn{4}{|c|}{ SECOND SURVEY } & TOTAL \\
\hline & JIOLATORS & CARPOOLS & GENERAL & TOTAL & VIOLATORS & CARPOOLS & GENERAL & TOTAL & ALL SURVEYS \\
\hline \multicolumn{10}{|l|}{ ORAN6E 55} \\
\hline Delivered & 196 & 1117 & 1066 & 2379 & 172 & 987 & 944 & 2103 & 4482 \\
\hline Completed & 22 & 205 & 208 & 435 & 14 & 162 & 154 & 330 & 765 \\
\hline 2 Complete & $11.22 \pi$ & 18.358 & 19.518 & 18.288 & 8.148 & 16.418 & 16.318 & 15.698 & 17.078 \\
\hline & & & & & & & & & \\
\hline \multicolumn{10}{|l|}{ LA 91} \\
\hline Delivered & 129 & 1089 & 1127 & 2345 & 119 & 959 & 974 & 2052 & 4397 \\
\hline Cemploted & 26 & 214 & 237 & 477 & 9 & 150 & 271 & 430 & 907 \\
\hline 3 Complete & 20.168 & 19.658 & 21.038 & 20.348 & 7.568 & $15.64 \%$ & 27.828 & 20.968 & 20.638 \\
\hline & & & & & & & & & \\
\hline \multicolumn{10}{|l|}{ MARIM 101} \\
\hline Delivered & 327 & 924 & .1214 & 2465 & $\underline{276}$ & 869 & 1114 & 2259 & 4724 \\
\hline Comploted & 51 & 121 & 162 & 334 & 34 & 134 & 196 & 364 & 698 \\
\hline 5 Complete & $15.60 \%$ & 13.108 & 13.348 & 13.558 & 12.328 & 15.428 & 17.598 & 16.118 & 14.788 \\
\hline & & & & & & & & & \\
\hline \multicolumn{10}{|l|}{ Sc 101} \\
\hline Delivered & 43 & 126 & 117 & 286 & 25 & 99 & 118 & 242 & 528 \\
\hline Completed & 8 & 20 & 24 & 52 & 3 & 16 & 22 & 41 & 93 \\
\hline 2 Complete & 18.608 & 15.878 & 20.518 & 18.188 & $12.00 \mathrm{x}$ & $15.16 \%$ & 18.648 & 16.948 & 17.618 \\
\hline \multirow{2}{*}{\multicolumn{10}{|c|}{ ALL PRQJ_ECTS }} \\
\hline & & & & & & & & & \\
\hline Delivered & 695 & 3256 & 3524 & 7475 & 592 & 2914 & 3150 & 6656 & 14131 \\
\hline Completed & 107 & 560 & 631 & 1298 & 60 & 462 & 643 & 1165 & 2463 \\
\hline 3 Complete & $15.40 \%$ & 17.208 & 17918 & 17.368 & 10.148 & 15.852 & 20.418 & 17.508 & 17.438 \\
\hline & & & & & & & & & \\
\hline & & & & & & & & & \\
\hline
\end{tabular}




\subsection{SURVEY FINDINGS}

\subsubsection{Enforcement Awareness}

Ticket Spotting. Driver awareness of enforcement differed widely among study projects. Driver responses to the question "Have you ever seen the Highway Patrol stopping a driver for using the bus/carpool lane illegally?" are plotted in Exhibit 6.5. The exhibit charts the percentage of drivers who reported that they had never seen an HOV enforcement stop before and after the two special enforcement waves. After two waves of special enforcement, this percentage dropped on all four study projects.

The percentage of drivers reporting they had never seen an HOV violator ticketed was lowest on Santa Clara 101, where officers often give tickets on the median strip next to the cat-pool lane. Prior to the first wave of special enforcement, $11.8 \%$ of the drivers using Santa Clara 101 said that they had never seen an HOV enforcement stop. After the second wave of special enforcement, which was particularly heavy on Santa Clara 101, this percentage had dropped to $4.9 \%$.

On Marin 101, where the CHP must escort violators to the side of the freeway before issuing citations, $28.1 \%$ of all respondents initially reported that they had never seen an occupancy citation issued. This percentage dropped to $23.8 \%$ after the second wave of special enforcement.

Like Marin 101, OR 55 has a narrow median shoulder. Although there is an enforcement area adjacent to the northernmost section of the HOV lanes, CHP officers feel that this area is too narrow for comfortable use. (See Section 5.4.) Consequently, enforcement practices on OR 55 resemble those on Marin 101, with the CHP escorting violators to the side of the road. As a result, one-third of the OR 55 drivers surveyed initially said they had never seen an HOV violator ticketed. This percentage dropped slightly (to $28.1 \%$ ) after special enforcement activities.

Enforcement awareness was greater on LA 91 than on Marin 101 or OR 55, possibly because the officers make use of the enforcement area. On LA 91, only $21.7 \%$ of the drivers surveyed at the start of the study said they had never seen an enforcement stop. This percentage had dropped to $18.0 \%$ by the study's end. 
EXHIBIT 6.5

DRIVERS REPORTING THEY HAVE NEVER SEEN

HIGHWAY PATROL TICKETING AN

HOV LANE VIOLATOR

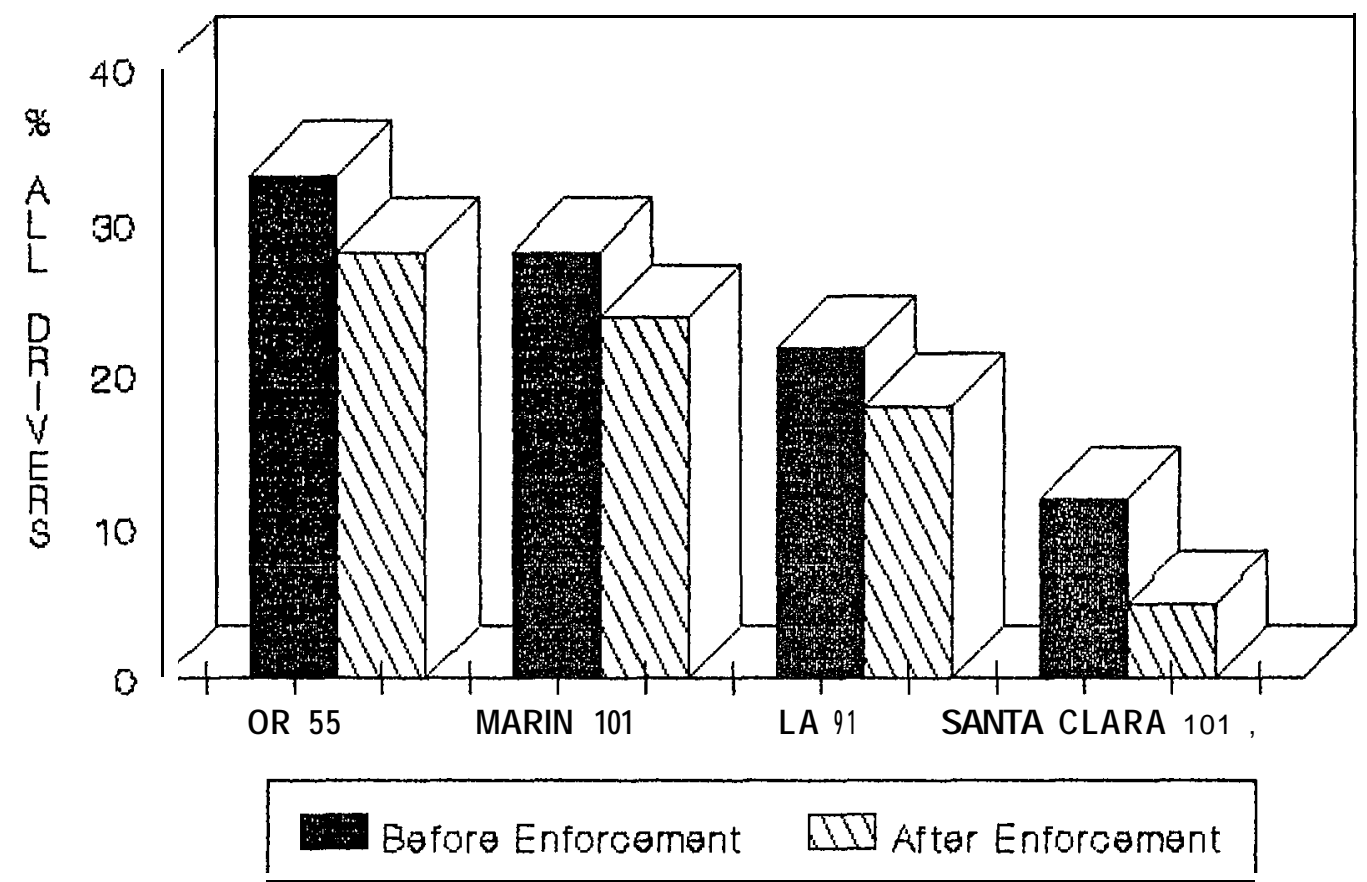


Over the course of the study, therefore, driver awareness of enforcement increased on all four study freeways. However, the relative ranking of the freeway in terms of awareness did not change. Driver awareness of enforcement was greatest on those freeways, Santa Clara 101 and Los Angeles 91, where enforcement is often carried out in the median. Awareness is lowest on those freeways, Marin 101 and OR 55, where the median is too narrow for enforcement and there are no usable enforcement areas.

Perceived Changes in Enforcement. The post-enforcement survey posed the following question to drivers using the sample freeways:

"During the past three months, do you feel that Highway Patrol enforcement of special bus and Carpool lanes has:
1 increased
( ) decreased
( ) stayed about the same

Exhibit 6.6 summarizes the responses elicited from drivers on individual projects.

\section{EXHIBIT 6.6 \\ PERCEIVED ENFORCEMENT CHANGES REPORTED BY DRIVERS FOLLOWING SECOND WAVE OF SPECIAL ENFORCEMENT}

Project

(n)

OR 55

LA 91

Marin 101

Santa Clara 101

Overall

$(1,088)$
\% Believing Enforcement Has

\section{Increased Decreased Not Changed Don't Know}

$26.1 \%$

$5.4 \%$

$67.5 \%$

$0.5 \%$

$10.7 \%$

$24.3 \%$

$63.7 \%$

$1.0 \%$

$9.5 \%$

$15.1 \%$

$71.7 \%$

$3.7 \%$

$20.5 \%$

$56.4 \%$

$0.0 \%$

$15.3 \%$

$16.0 \%$

$67.0 \%$

$1.8 \%$

Thus the majority of drivers on all four projects felt that enforcement had "stayed about the same" over the past three months. Of the drivers who thought enforcement levels had changed, more drivers on both OR 55 and Santa Clara 101 perceived an increase in enforcement than perceived a decrease. On LA 91 and Marin 101 however, more drivers perceived that enforcement had decreased. This was an accurate perception on LA 91, since the second wave of enforcement cut back special enforcement activities and relied exclusively on routine 
enforcement efforts. It is somewhat surprising in the case of Marin 101, although the second wave of special enforcement activity was limited to the afternoons of enforcement during daylight hours, and resulted in only 92 additional citations over the four weeks of enforcement. Driver's perceptions of changes in enforcement are influenced by the surprisingly high proportion of drivers who had never seen any occupancy violators cited, and who, therefore, reported perceiving "no change" in enforcement levels.

Preferred Changes In Enforcement. Whereas most drivers had perceived no recent changes in enforcement activity, the vast majority agreed that they would like to see more enforcement of HOV lanes. When asked during the follow-up survey whether they agreed with the statement "The Highway Patrol should enforce bus and Carpool lanes more often," $71.6 \%$ of all drivers agreed with the statement, $11.7 \%$ disagreed, and $19.7 \%$ were indifferent. These results paralleled the preference stated during the pre-enforcement survey and the earlier SYSTAN study (Billheimer, 1981). Results for the individual projects are summarized below in Exhibit 6.7.

\section{EXHIBIT 6.7}

\section{DRIVER REACTIONS TO THE STATEMENT "HOV LANES SHOULD BE ENFORCED MORE HEAVILY" (post-enforcement survey)}

\begin{tabular}{lrrrr|l|lcr|} 
Project & $(n)$ & $\begin{array}{c}\text { Agree } \\
\text { Stronaly }\end{array}$ & $\begin{array}{c}\text { Agree } \\
\text { Sliahtly }\end{array}$ & $\begin{array}{c}\text { Agree } \\
\text { Total }\end{array}$ & Indifferent & $\begin{array}{c}\text { Disagree } \\
\text { Stronaly }\end{array}$ & $\begin{array}{c}\text { Disagree } \\
\text { Slightly }\end{array}$ & $\begin{array}{c}\text { Disagree } \\
\text { Total }\end{array}$ \\
OR55 & $(316)$ & $57.0 \%$ & $21.2 \%$ & $78.2 \%$ & $14.2 \%$ & $2.9 \%$ & $4.8 \%$ & $7.7 \%$ \\
LA91 & $(404)$ & $57.4 \%$ & $20.3 \%$ & $77.7 \%$ & $16.6 \%$ & $4.0 \%$ & $1.7 \%$ & $5.7 \%$ \\
Marin 101 & $(331)$ & $35.7 \%$ & $23.6 \%$ & $59.3 \%$ & $28.1 \%$ & $5.4 \%$ & $7.3 \%$ & $12.7 \%$ \\
Santa Clara 101 & $(38)$ & $34.2 \%$ & $26.3 \%$ & $60.5 \%$ & $26.3 \%$ & $5.3 \%$ & $10.5 \%$ & $15.8 \%$ \\
Overall & $(1,089)$ & $49.9 \%$ & $21.7 \%$ & $71.6 \%$ & $19.7 \%$ & $4.1 \%$ & $4.6 \%$ & $8.7 \%$
\end{tabular}

Exhibit 6.7 shows that the perceived need for more enforcement is greater in Southern California than in Northern California. Responses were remarkably similar by region. In Southern California, $78 \%$ of the drivers on both OR 55 and LA 91 thought enforcement should increase, while in Northern California, corresponding percentages for Marin 101 and Santa Clara 101 were $59 \%$ and $60 \%$ respectively. 
There was substantial agreement among the different driver types on the need for more enforcement. Carpoolers tended to favor heavier enforcement slightly more than general drivers and violators, but the differences were statistically insignificant.

\subsubsection{Penalty Awareness}

Fine Structure. One of the common suggestions made by focus group participants for lowering violation rates was "Raise the fine for a first offense and post the level of the fine along the freeway." In January, 1989, the California legislature raised the level of the fines for occupancy violations of HOV lanes. Legislation in Senate Bill (SB) 2361 dictated the following fine structure:

\section{Offense}

First Conviction

Second Conviction (within a year)

Third and Subsequent Convictions (within 2 years)

\section{Minimum}

$\$ 100$

$\$ 150$

$\$ 250$
Penalty

\section{Maximum}

$\$ 150$

$\$ 200$

$\$ 500$

Thus the penalty for a first-offense HOV violation was raised to a minimum of $\$ 100$ early in 1989 .

Driver Awareness. To test whether or not California drivers were aware of the increased penalty for HOV violations, drivers responding to the March 1989 survey were asked "What is the penalty for a first offender caught using the Carpool lane illegally?" and "What is a fair penalty?" The answers to these questions are summarized in Exhibit 6.8 for each of the sample freeways.

\section{EXHIBIT 6.8}

\section{AWARENESS OF FIRST-OFFENSE FINE}

\begin{tabular}{lccc}
\multicolumn{2}{c}{$\begin{array}{c}\text { What is Level of Fine? } \\
\text { Freeway }\end{array}$} & What Should Fine Be? \\
OR 55 & $\frac{\text { Don't Know }}{(\%)}$ & $\begin{array}{c}\text { Average } \\
(\$)\end{array}$ & $\frac{\text { Average }}{(\$)}$ \\
LA 91 & $55.8 \%$ & $\$ 109.80$ & $\$ 143.91$ \\
Marin 101 & $64.0 \%$ & $\$ 81.66$ & $\$ 116.32$ \\
Santa Clara 101 & $65.4 \%$ & $\$ 52.91$ & $\$ 59.10$ \\
Overall & $63.4 \%$ & $\$ 56.15$ & $\$ 51.48$ \\
& $62.1 \%$ & $\$ 81.56$ & $\$ 105.77$
\end{tabular}


Thus $62 \%$ of the drivers responding didn't know what the fine was for illegal use of a Carpool lane. Those drivers who professed to know set the average level at $\$ 81.56$. Southern California drivers were much closer to the actual minimum level of $\$ 100$ than Northern California drivers, who thought the fine for a first offense was around $\$ 50.00$.

When asked to identify a fair penalty for a first offender, drivers tended to set fines slightly higher than their perception of existing levels. The average penalty recommended by all drivers was $\$ 105$. The fine structure recommended by Southern California drivers was significantly higher than the structure recommended by drivers in Northern California. Drivers on OR 55 and LA 91 set fines in the $\$ 100-\$ 150$ range mandated by the legislature, while drivers in Santa Clara 101 and Marin 101 favored fines closer to $\$ 50$. Among driver groups, carpoolers tended to have a higher estimate of the current fine structure than violators or single drivers. Not unexpectedly, carpoolers also favored higher penalties than the other two driver groups. The average first offense penalty recommended by carpoolers was $\$ 114$, as compared with $\$ 104$ by drive-alones and $\$ 68$ by violators.

Implications. The fact that $62 \%$ of the drivers surveyed said that they didn' $t$ know the fine for a first-time HOV offender indicates that the newly mandated structure should be better publicized. This is particularly true in Northern California, where drivers thought the penalty was in the $\$ 50.00$ range.

There is no guarantee that wider publicity for the increased penalties will have a lasting impact on violation rates. SYSTAN's earlier study of HOV violation rates (Billheimer, 1981) suggested that the difference between a fine of $\$ 35.00$ and a fine of $\$ 50.00$ had no discernible impact on violations. In the case of DUI offenses, other researchers (Ross, 1981) have reported that heavy penalties tend to act as a deterrent for a while, but that violation rates eventually return to pre-penalty levels when drivers realize that their chances of being caught haven't changed. In any event, the survey evidence suggests that relatively few drivers are aware of the heavier HOV penalties imposed by SB 2361. If the legislation is to have any impact, the increased fine structure needs to be more widely publicized. 


\subsubsection{Perceived Time Savings}

Drivers were asked to estimate the amount of time saved through the use of the HOV lane on each of the four study projects. As in the focus group discussions and the previous SYSTAN study, violators, carpoolers, and general drivers alike greatly overestimated the average time savings afforded by HOV lanes. Exhibit 6.9 illustrates this point, comparing perceived time savings with the actual time saving recorded on the four study projects. Perceived savings for the first and second survey have been combined for each project. The Exhibit shows that during the evening commute period, drivers perceived HOV time savings that were approximately double the average savings recorded during the heaviest traffic period, and nearly four times the average time savings realized by all drivers throughout the commute period.

In reporting on this phenomenon in the earlier study, SYSTAN noted:

"One interpretation for the wide discrepancy between perceived time savings and actual time saved may be that differences tend to be amplified when one lane (i.e., the Carpool lane) is moving while the other is not. In addition, the surveyed drivers may tend to cite the time savings available during the worst freeway congestion (or longest meter delay) that they remember. This tendency to perceive greater time savings in the Carpool lane, however, undoubtedly makes the carpool lanes appear more attractive to drivers than to statisticians comparing raw numbers, and indicates that there may be a psychological advantage in providing a carpool lane even when the available time savings appear minimal."

\subsubsection{Perceived Violation Rates}

Estimated and Actual Levels. Drivers on each freeway were asked "What percentage of the drivers in the bus/carpool lane would you estimate use the lane illegally?" Exhibit 6.10 plots the violation rates estimated by drivers responding to the first survey, along with the violation rates observed at the time the survey was conducted. Drivers on all four study projects consistently overestimated violation rates during both survey waves. Estimated violation rates ranged from $15 \%$ to $20 \%$, while actual measured rates ranged between $5 \%$ and $10 \%$. These findings are consistent with those of the earlier SYSTAN study (Billheimer, 1981), which found that "...drivers tend to overestimate low violation rates and underestimate high violation rates."

The estimated violation rate reported by drivers averaged $17 \%$ both before and after special enforcement actions. In general, non-carpoolers tended to provide higher violation estimates (roughly 18\%) than carpoolers (16\%), who in turn provided higher estimates of violation rates than known violators (14\%). 
EXHIBIT 6.9

ESTIMATED AND ACTUAL TIME SAVING

HOV LANE TIME SAVINGS - AM

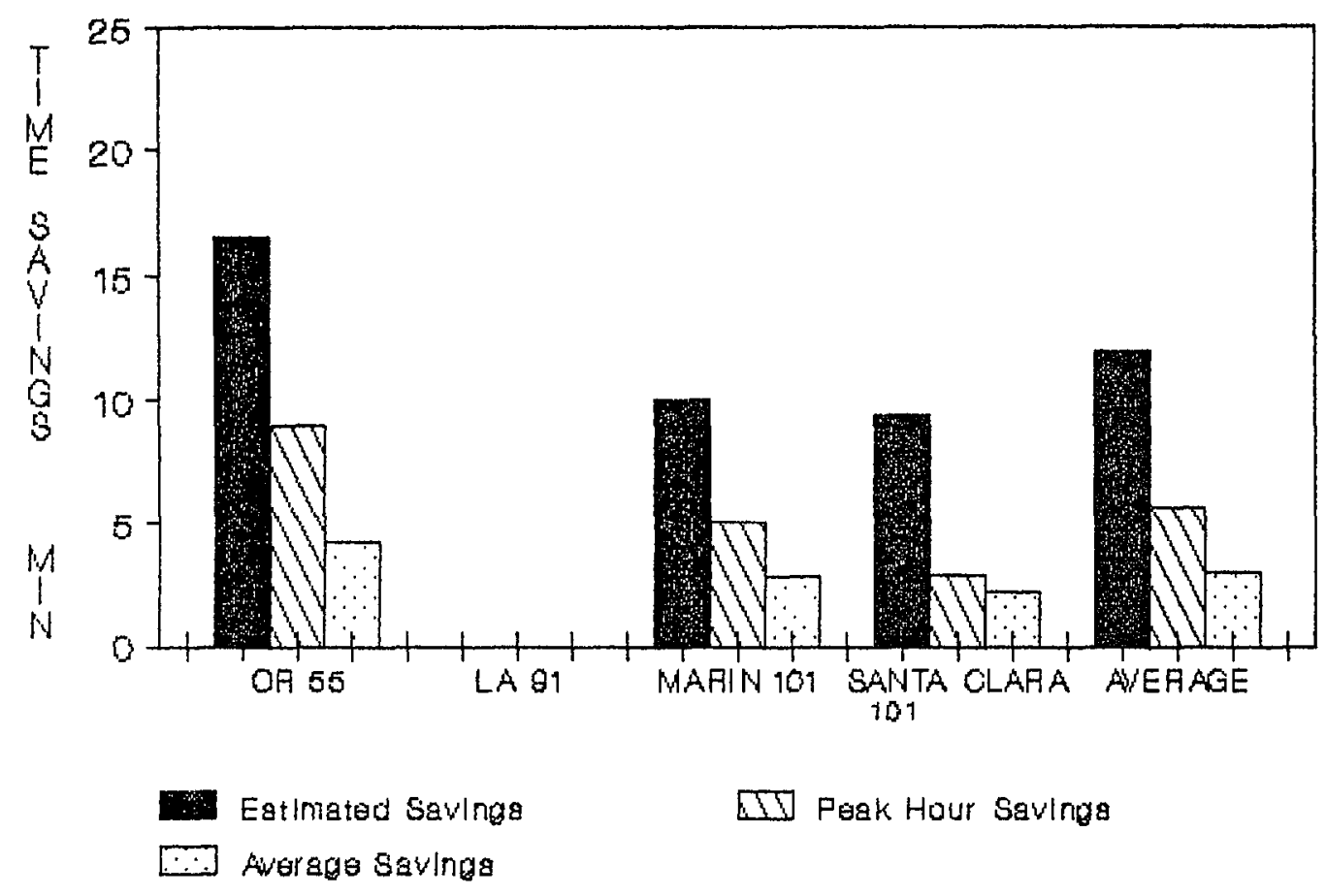

HOV LANE TINE SAINGS - PM

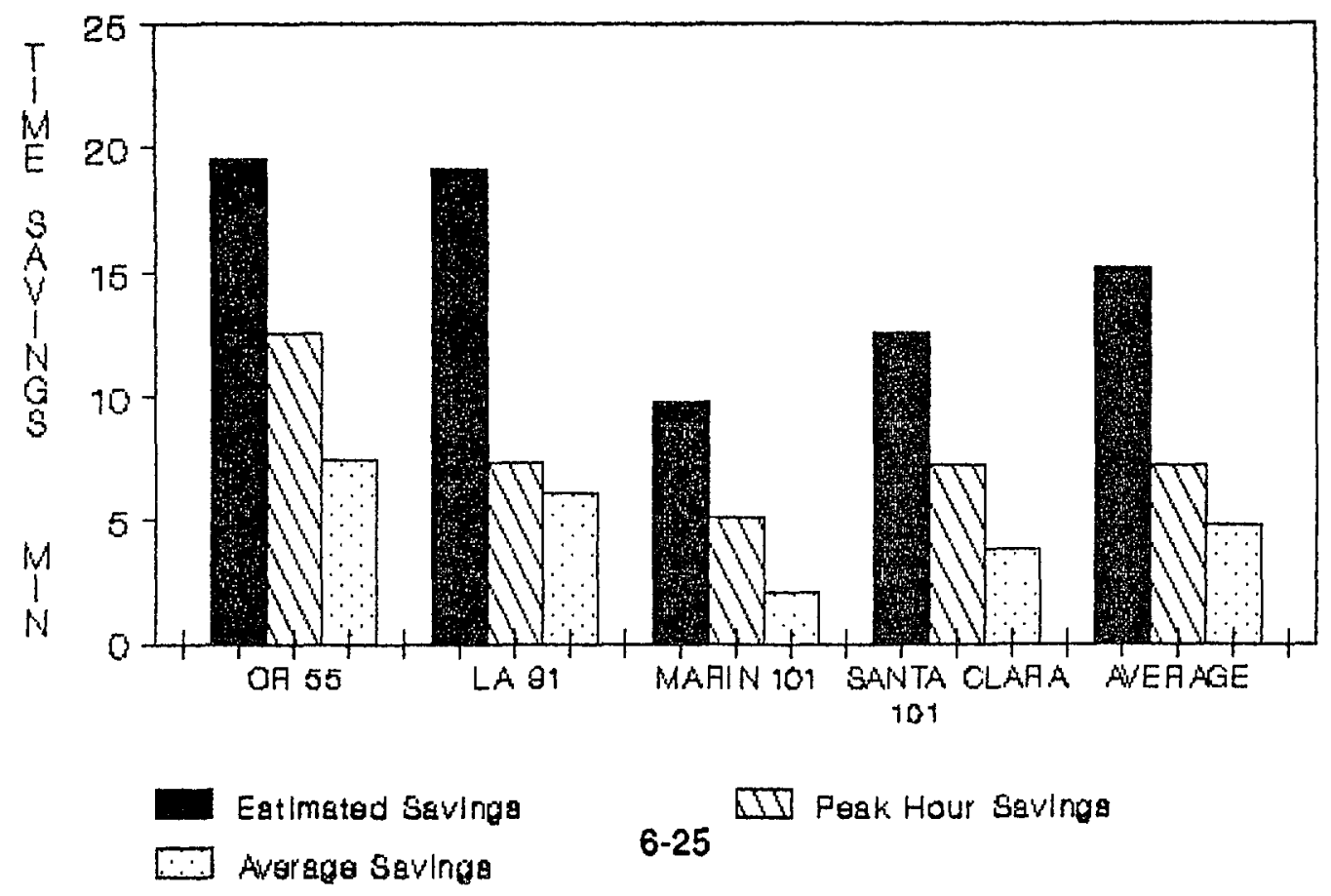


EXHIBIT 6.10

ESTIMATED AND ACTUAL VIOLATION RATES

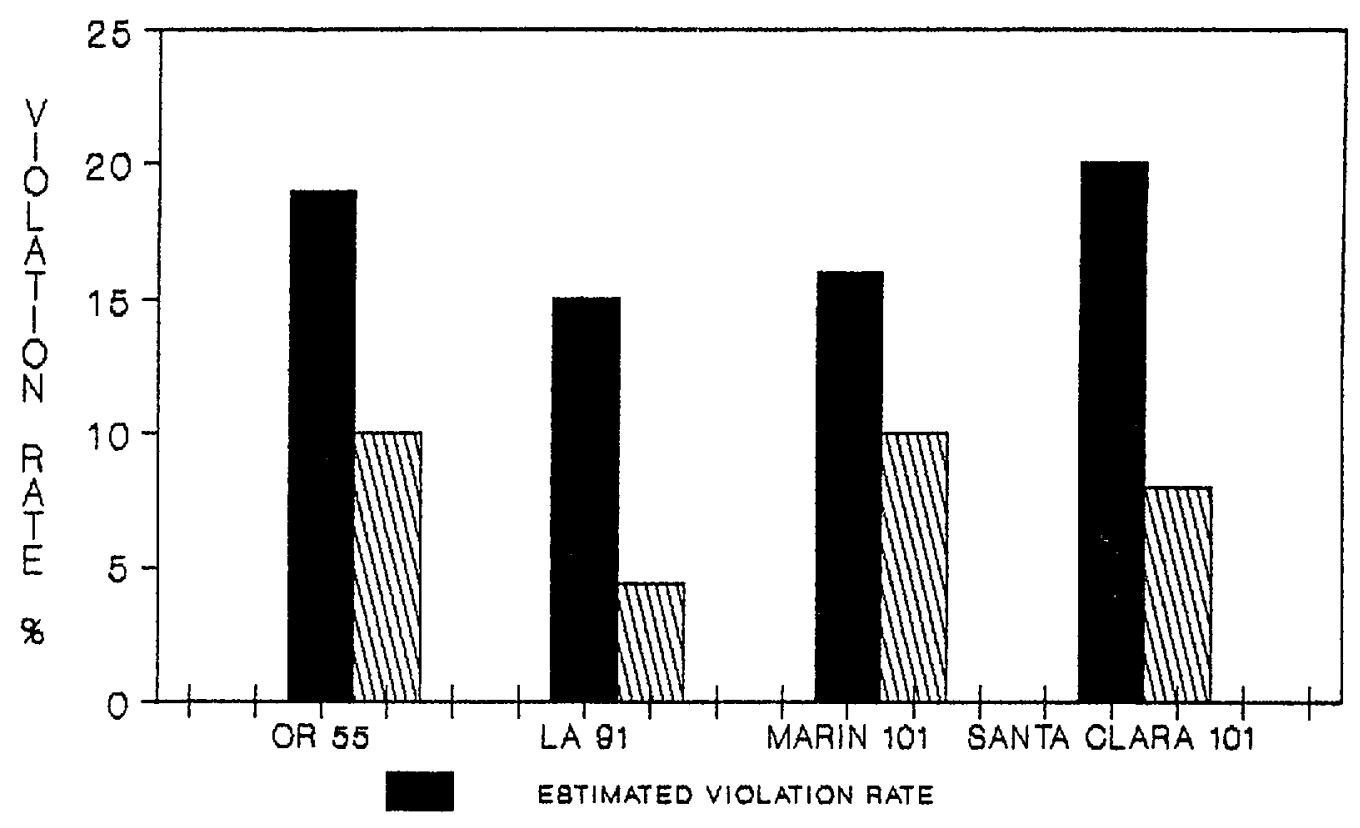

WIIII VIOLATION RATE MEAgURED BEFORE FIRBT ENFOACEMENT WAVE 
Attitudes Toward Violations. Exhibit 6.10 below tabulates the post-enforcement responses of drivers on different projects to the question:

"Do you feel that the use of the bus/carpool lane by non-carpoolers is a:

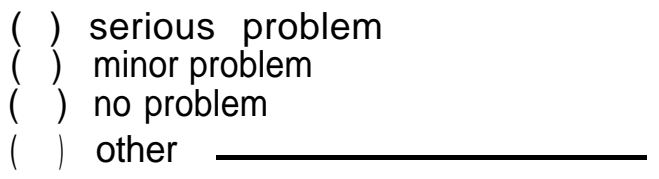

\section{EXHIBIT 6.11}

\section{PERCEIVED SERIOUSNESS OF HOV VIOLATIONS}

$\begin{array}{lcccccc}\text { Project } & \begin{array}{c}\text { Serious } \\ \text { Problem }\end{array} & \begin{array}{c}\text { Minor } \\ \text { Problem }\end{array} & \begin{array}{c}\text { No } \\ \text { Problem }\end{array} & \text { Other } & \begin{array}{c}\text { Don't } \\ \text { Know }\end{array} \\ \text { OR 55 } & 39.6 \% & 50.9 \% & 6.3 \% & & 2.5 \% & 0.0 \% \\ \text { LA 91 } & 36.1 \% & 53.7 \% & 6.3 \% & 3.6 \% & 0.2 \% \\ \text { Marin 101 } & 23.5 \% & 58.1 \% & 12.6 \% & 3.8 \% & 2.0 \% \\ \text { Santa Clara 101 } & 35.0 \% & 50.0 \% & 12.5 \% & 2.5 \% & 0.0 \% \\ \text { Overall } & 33.2 \% & 54.1 \% & 8.5 \% & 3.3 \% & 0.7 \%\end{array}$

Roughly one third of the drivers surveyed felt that the illegal use of a Carpool lane was a serious problem, while an additional $54 \%$ rated it only a minor problem. Only $8.5 \%$ of all drivers felt violators were no problem. Drivers on Marin 1'01 were slightly more relaxed about the problem of violations than drivers on other routes - only $23.5 \%$ of the Marin 101 drivers felt violations were a serious problem.

Among driver types, carpoolers rated the seriousness of violations slightly higher than violators and general drivers (thirty-eight percent of the carpoolers surveyed felt that the violation problem was serious). These findings are consistent with those of the earlier SYSTAN study (Billheimer, 1981). 


\subsubsection{Other Perceptions}

Perceived Accident Impacts. Drivers were asked whether they agreed or disagreed with the statement that the Carpool lanes ". ..increase accident potential." Exhibit 6.12 plots the percentage of drivers who agreed with this statement on each study freeway. Drivers responses were not significantly different for the "before" and "after" survey, so Exhibit 6.12 presents a composite of both surveys. As in the case of the focus groups, there was a pronounced split between Southern California drivers and Northern California drivers in their perception of the HOV lanes' accident potential. Agreement that HOV lanes increased accident potential was highest among Southern California drivers (58\% on OR 55 and $43 \%$ on LA 91), and lowest among Northern California drivers $34 \%$ on Marin 101 and 33\% on Santa Clara 101).

Perceived Flow Improvement. Over 72 percent of all drivers surveyed agreed that the HOV lanes in their area "contributed to better freeway flow." (Nine percent were neutral on this question, and 18 percent disagreed). Agreement was highest (81\%) among drivers using LA 91 and lowest (62\%) among drivers using Marin 101. Exhibit 6.13 plots responses from the users of each of the study freeways.

\subsection{SUMMARY OF KEY PUBLIC AWARENESS FINDINGS}

\subsubsection{HOV Lane Perceptions}

- Drivers understand the puropse of HOV lanes. The vast majority (over $75 \%$ ) of the drivers believe that the lanes are effective in inducing Carpools and improving traffic conditions. Over $60 \%$ felt that the HOV lanes were fair.

- Southern California drivers perceived the lanes on OR 55 and LA 91 to be "scary" and "dangerous." Reasons cited included the high speed differential, the close proximity of the median barrier, and weaving drivers. Northern California drivers did not express similar levels of concern regarding the safety of Marin 101 and Santa Clara 101.

Violators, carpoolers, and general drivers alike greatly overestimate the average time savings afforded by HOV lanes. This tendency to perceive greater time savings in the Carpool lane undoubtedly makes the Carpool 


\section{EXHIBIT 6.12}

DOES HOV LANE INCREASE ACCIDENTS?

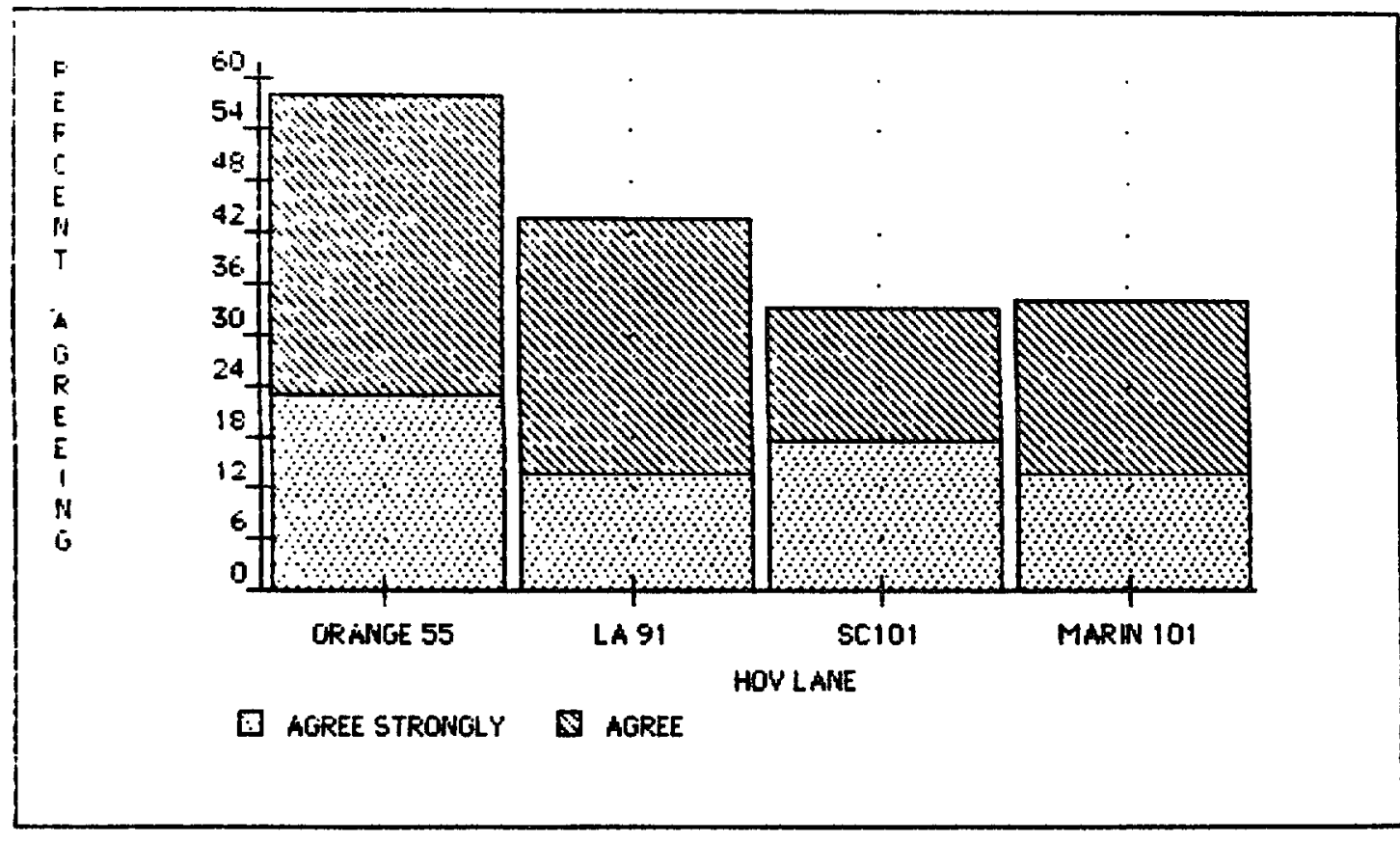

EXHIBIT 6.13

DO HOV LANES IMPROVE FREEWAY FLOW?

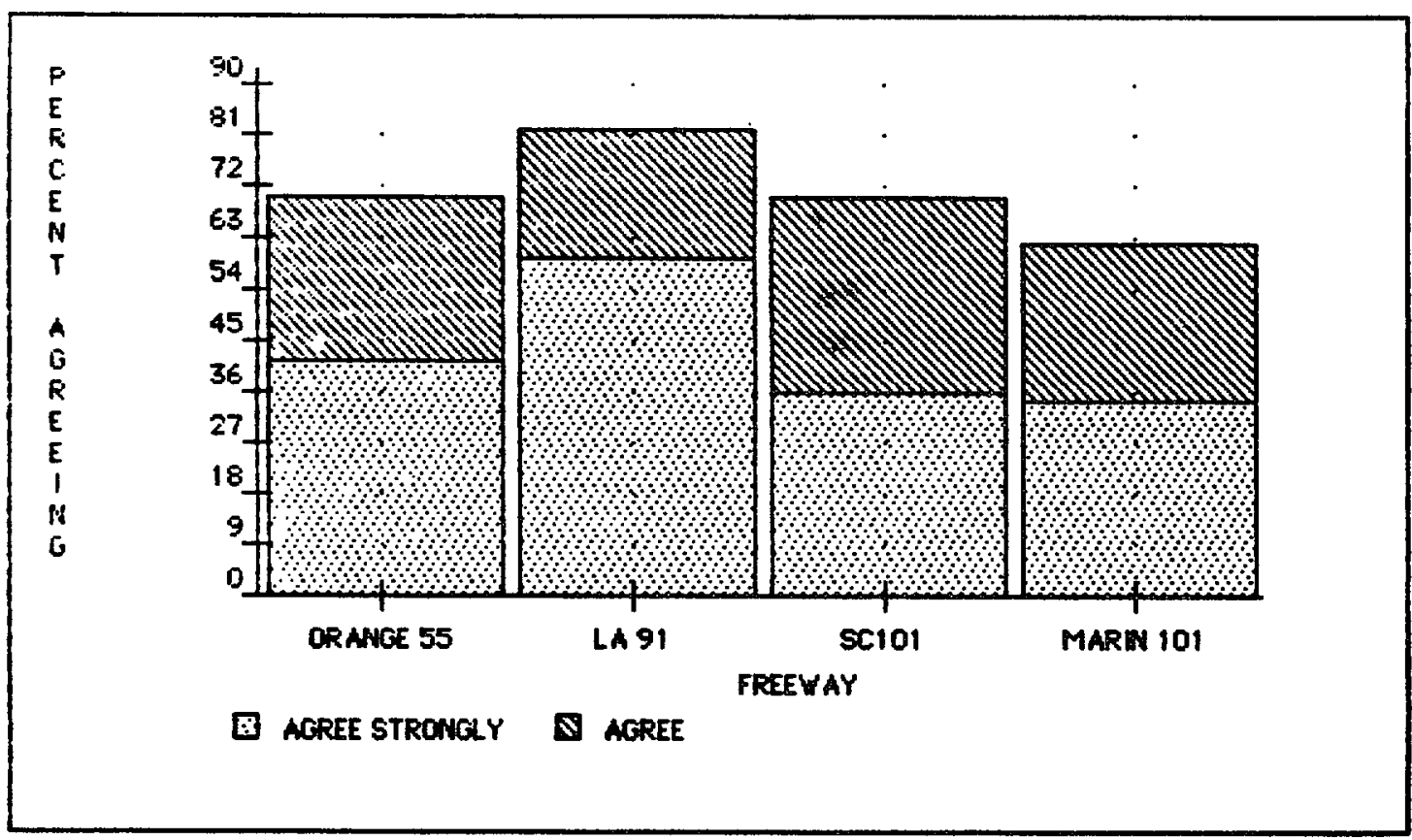


lanes appear more attractive to drivers than to statisticians comparing raw numbers, and indicates that there may be a psychological advantage in providing a Carpool lane even when the available time savings appear minimal.

Drivers felt that existing lanes should be extended. Other suggestions for improving lane operations included lengthening the entry and exit points on OR 55 and LA 91, opening LA 91 in both directions, and reducing the Carpool definition on Marin 101 to two or more occupants.

\subsubsection{Violation Perceptions}

All drivers are aware of violations. and tend to overestimate the number of violations. Earlier work suggests that drivers are likely to be insensitive to violation changes in the $10 \%$ to $20 \%$ range.

Drivers acknowledge that HOV occupancy violations are a problem, but most consider them a minor problem. Southern California drivers viewed buffer violations as far more serious than occupancy violations.

Drivers felt that raising fines and posting the minimum level along the freeway would deter violations. Sixty-two percent of the drivers surveyed were unaware of the minimum fine level, and Northern California drivers who professed to know the level greatly underestimated it.

\subsubsection{Enforcement Perceptions}

- Enforcement awareness is greatest on freeways with median lanes or enforcement areas adjacent to the HOV lane. Over 90 percent of all drivers on Santa Clara 101 (which has a 10 -foot median that is often used for enforcement) had seen the CHP ticketing an HOV violator at one time or another. On the other hand, less than 75 percent of the drivers on OR 55 and Marin 101 (which have no median lanes or usable enforcement areas) reported that they had seen tickets issued for HOV violations. 


\section{Drivers themselves perceive a need for more enforcement. Over}

seventy percent of those surveyed thought that enforcement should be heavier. Most drivers perceived no change in enforcement rates during the period of special enforcement, possibly because of the relatively heavy year-round incidence of routine enforcement. Drivers generally felt that "...the police are doing a good job," but noted that ". ..stopping people on the freeway slows things down."

Drivers tend to overestimate the risk of being caught using an HOV lane illegally. Risk levels estimated by focus group participants ranged from $1 \%$ to 18\%. The actual range on the study freeways appears to be between $1.5 \%$ and 2.8\%. Northern California drivers tended to feel that the likelihood of getting a ticket was higher than Southern California drivers.

- Driver opinion split dramatically on the desirability of videotape surveillance and mall out citatlons. The possibility of using videotape surveillance to trigger mail-out citations generated heated focus group debates. Opponents cited "big-brotherism" while proponents argued that freeway ticketing caused significant traffic slowdowns. Most drivers agreed that the public would have to be educated regarding the need both for HOV lanes and mail-out citations if such a procedure were to succeed. 


\subsection{PROPOSED ENFORCEMENT PROGRAM}

This chapter addresses the issue of "tolerable" violation rates, outlines future enforcement programs for California's mainline HOV lanes, and computes the costs of these enforcement programs.

\subsection{TOLERABLE VIOLATION RATES}

\subsubsection{Considerations}

The question of "tolerable" or "acceptable" violation rates can be viewed from several different aspects, including safety, freeway operations, public attitudes, legal integrity, and practicality. Key issues in the consideration of "acceptable" violation levels on mainline HOV lanes are discussed below.

Safety. Past studies suggest that it is impossible to correlate accident rates with violation rates on any of California's mainline projects (Billheimer, et al., 1981). Nonetheless, the practice of weaving illegally in and out of a mainline HOV lane creates a direct safety hazard. Unsafe weaving has been and should continue to be the primary focus of officers assigned to HOV lane enforcement.

Freeway Operations. The practical capacity of a mainline HOV lane is estimated to range between 1500 and 1700 vehicles per hour (Cechini, 1988). On barrier-separated lanes, the limit is close to 1500 vehicles per hour, while some concurrent flow lanes with no physical separation can accommodate 1700 vehicles per hour before performance begins to deteriorate. Most of California's mainline HOV lanes are comfortably below these capacity limits, so that existing violation rates could increase substantially on nearly all HOV projects without substantially affecting flow in the Carpool lane.

Violators do not improve general traffic conditions appreciably by leaving the mainline flow to enter the HOV lane. During congested periods, latent demand easily replaces the small number of violators drawn off into the Carpool lanes. At less congested times, the potential for improvement is minimal. 
Public Attitudes. Over three-quarters of the drivers surveyed felt that illegal use of Carpool lanes is a problem, although most classify it as a minor problem. This is consistent with findings on earlier studies. Even in the case of unpopular projects such as the Santa Monica Diamond Lanes and Alameda 580, where public sentiment ran high against commuter lanes, drivers recognized violations as a problem. Drivers tend to overestimate violation rates on most mainline projects, and to be insensitive to changes in the range from $0 \%$ to $10 \%$.

Practicality. Experience suggests that steady doses of routine enforcement combined with moderate applications of special enforcement can keep mainline HOV lane violation rates in the $5 \%$ to $10 \%$ range. Heavy, consistent doses of special enforcement would be necessary to drive violation rates below $5 \%$ on barrier-free mainline lanes, and the difference between $10 \%$ and $5 \%$ would have little effect on freeway performance or driver perceptions.

\subsubsection{Current Performance}

Violations and Capacity. Exhibit 7.1 plots the violation rates on California's existing mainline lanes as a function of the number of legitimate vehicles using the lane during the peak hour. Congestion conditions in the carpool lane itself are approached when flow rates are roughly 1500 vehicles per hour on a barrier-separated lane or 1700 vehicles per hour on a concurrent-flow lane.

Exhibit 7.1 suggests that most of California's mainline HOV lanes currently operate below recognized congestion levels. Severe peaking may cause traffic to slow on OR 55 or Santa Clara 101 , the lanes which are closest to capacity. At current flow rates, however, violation Yates could increase to well over $10 \%$ on most lanes without causing HOV travel times to deteriorate.

Enforcement Implications. Although higher violation rates of $25 \%$ or more could theoretically be tolerated on most mainline HOV lanes without affecting flow adversely, such violation levels should be intolerable from a lane enforcement standpoint. Violation rates in excess of $25 \%$ appear to be unacceptable to the general driving public. A combination of routine and special enforcement has caused violation rates on most of California's mainline lanes to drop below $10 \%$ and it is proposed that this level be set as a target level throughout the state. This limit should prevent any public disgruntlement over violation levels, and should be supplanted by lower levels when peak operating conditions on the HOV lane approach 1500-1700 vehicles per hour. Under current operating levels, however, a $10 \%$ violation limit is not likely to threaten operating conditions on any of California's mainline lanes. Exhibit 7.1 shows that the proposed $10 \%$ limit is currently exceeded only on the easternmost segment of the El Monte Busway and the lightly-enforced and lightly-traveled 2-mile HOV segment on I-280 south of San Francisco. 
EXHIBIT 7.1

VIOLATION RATE VS. LEGITIMATE VEHICLES

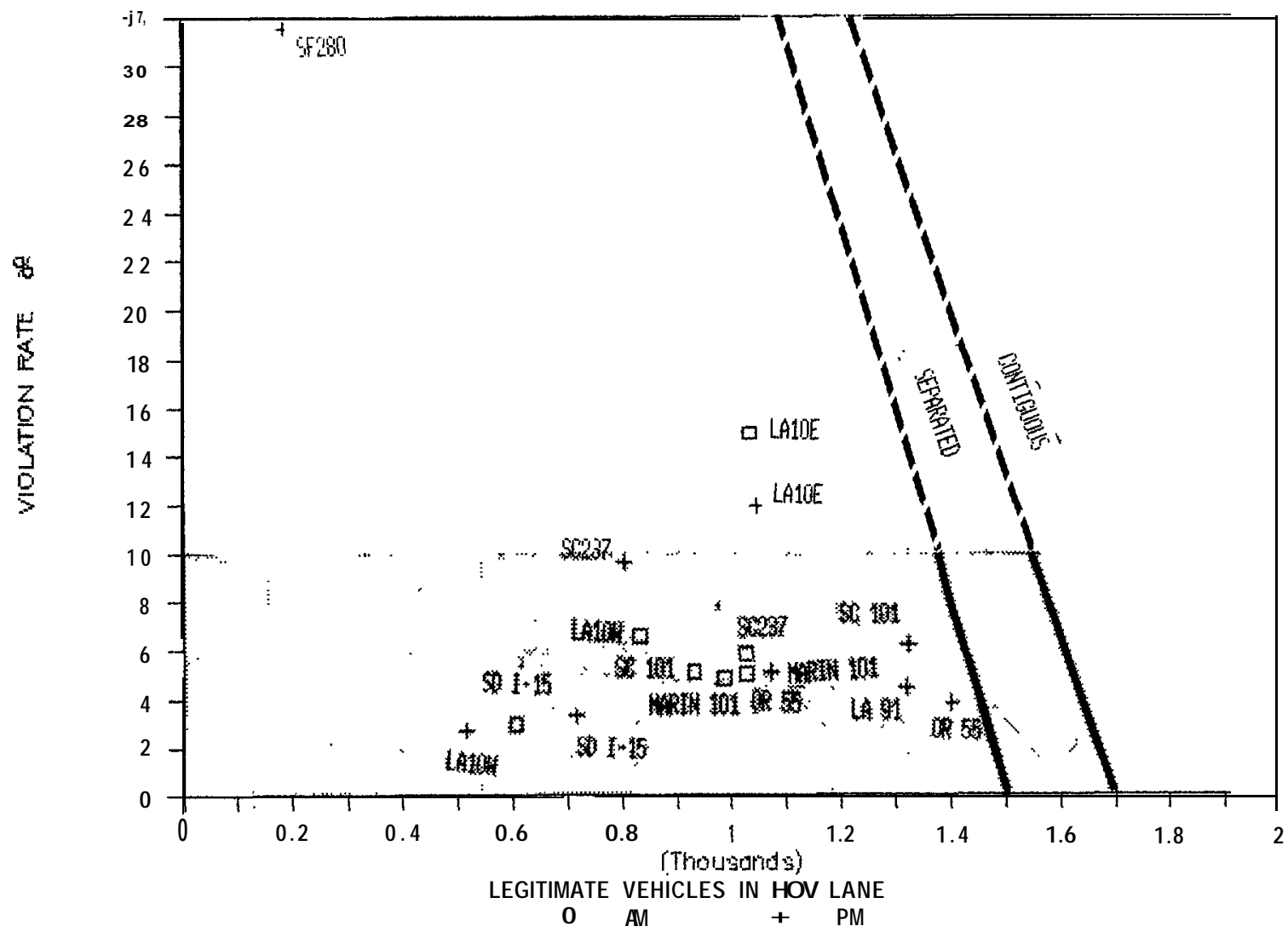

TOLERABLE REGION 


\subsection{GENERAL PLANNING GUIDANCE}

\subsubsection{Overview}

In general, the shorter an HOV facility is, the less routine enforcement it will receive. Consequently, the greater the amount of special enforcement that will be needed to maintain an acceptable level of violations. The HOV facilities receiving the lowest levels of routine enforcement are ramp meter bypass lanes. Violators are exposed to capture for relatively short periods of time, and officers typically cannot spot ramp violators while patrolling the freeway itself. HOV bridge lanes such as the toll-free lane on the San Francisco-Oakland Bay Bridge receive only slightly more routine enforcement than a heavily violated ramp meter bypass lane. In the case of mainline HOV lanes, short lanes with no refuge area (i.e. Marin 101) receive relatively little routine enforcement. Longer lanes and lanes having a refuge area (i.e. the enforcement area on LA 91 or the median shoulder on Santa Clara 101 receive relatively high levels of routine enforcement). Barrier-separated lanes such as San Diego l-15 must receive substantial amounts of dedicated special enforcement because the lanes cannot be enforced from adjacent lanes and must be patrolled on a daily basis by assigned officers. As a result of these daily assignments, however, relatively little additional enforcement is needed to keep violation rates within acceptable bounds.

\subsubsection{Monitoring}

CALTRANS should monitor violation rates on all mainline HOV lanes at least twice yearly. Lane violation rates should be calculated and supplied directly to the captain of the local CHP Area responsible for enforcement. In addition, mainline lanes should be observed if complaints about violators rise markedly at any time or if the CHP plans to change enforcement levels or policies.

\subsubsection{Violation/Enforcement Relationships}

In order to plan for special enforcement on a mainline HOV lane, then, it is necessary to consider the amount of routine enforcement the lane is likely to receive. In the case of existing lanes, routine citations are a matter of record. In the case of planned lanes or newly opened lanes, it may be possible to estimate the likely number of routine citations from a knowledge of the projected number of lane violators. Based on existing experience with California's mainline HOV 
lanes, a multiple regression analysis suggests that the following relationship exists between routine citations, violations, and lane length:

(Equation 1) Routine Citations/Day $=-2.8+.017$ (Violations/Day) +0.55 (Lane Length)

Thus the number of citations issued is directly proportional to both violation levels and lane length. Given an estimate of HOV lane usage and a target violation rate, Equation 1 can be used to estimate the number of routine citations likely to be issued on a lane with no operating history.

\subsubsection{Planning Nomograph}

Underlying Assumptions. Given an estimate of the number of routine citations likely to be issued on a particular mainline HOV lane, it is possible to compute the level of special enforcement needed to attain a pre-selected apprehension rate. The total of routine citations and special citations must equal the desired apprehension rate. That is

\section{Routine Citations + Special Citations $=$ Apprehension Rate}

Using the formula for routine citations (Equation 1), the following number of special citations would be necessary to achieve an apprehension rate of $2.5 \%$. That is, to ticket $2.5 \%$ of a lane's violators:

(Equation 2) Special Citations/Day $=2.8-.008$ (Violations/Day) -0.55 (Lane Length)

Exhibit 7.2 plots the annual levels of special enforcement needed to achieve an apprehension rate of $2.5 \%$, assuming that officers able to use an enforcement area can issue twice the number of citations per overtime hour as officers enforcing lanes with no refuge areas. The level of $2.5 \%$ has been selected rather arbitrarily, but it approximates the apprehension rate in existence on California's mainline lanes during the current study, when mainline violation rates were under control.

It is also assumed that a minimum level of special enforcement will be required for all mainline HOV lanes. This level has been set at 64 overtime hours per year (i.e. one officer, two days per week, for four weeks twice a year), roughly the same level established for the average ramp meter bypass lane. 


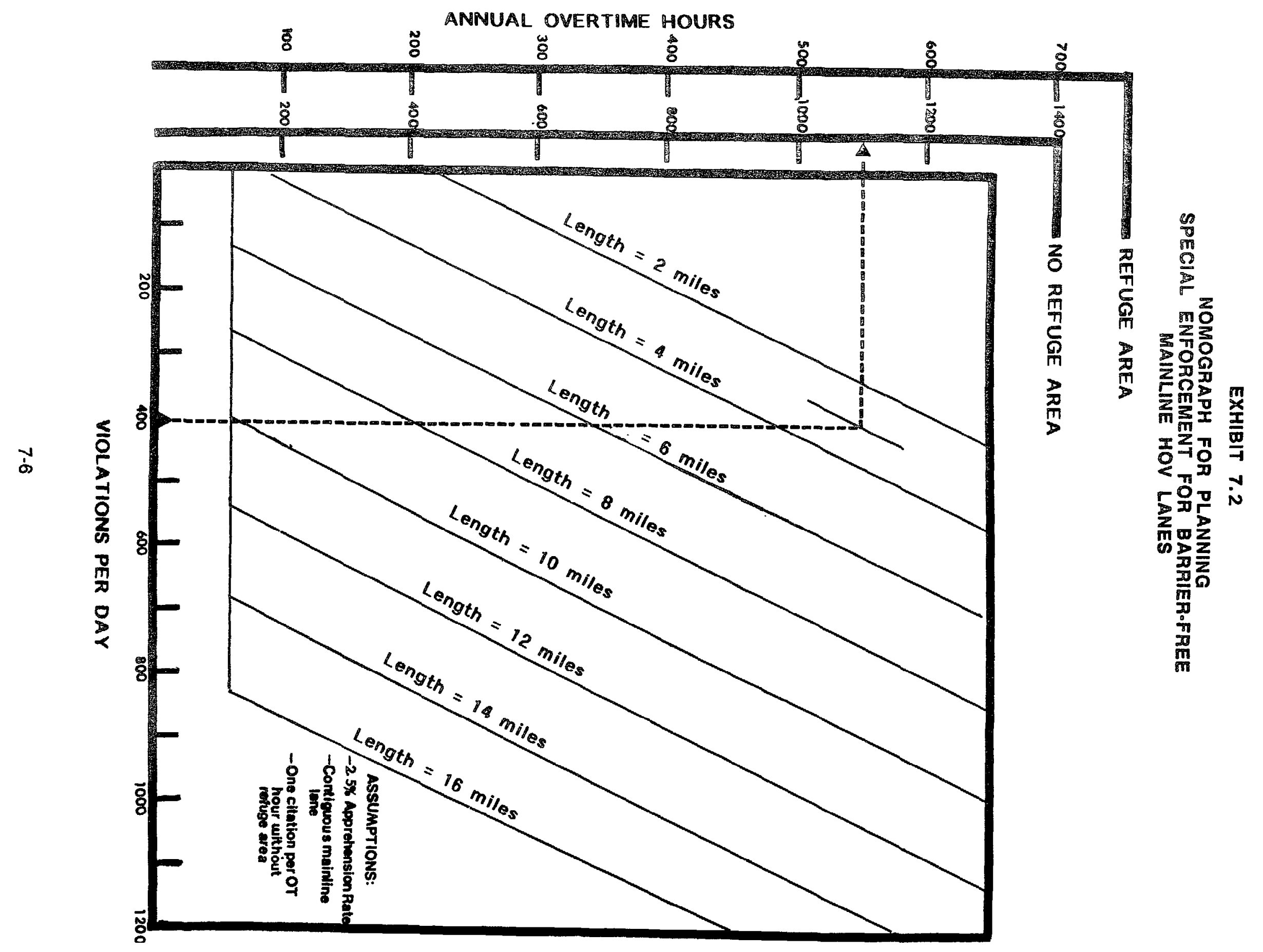


Sample Use. To use Exhibit 7.2, it is necessary to obtain a count of the total number of violators using the lane in question over both peak operating periods. This number may come from CALTRANS counts, or, in the case of a newly opened lane, from projections of total lane usage, along with an assumed violation rate (an assumed rate of $10 \%$ represents a conservative estimate of current conditions on California's mainline HOV lanes). Taking Marin 101 as an example, approximately 400 violations per day occur on the 3 mile stretch of HOV lane north of San Rafael. A vertical line drawn from the $\mathbf{4 0 0}$ violation point on the horizontal axis intersects the 3-mile diagonal at the point corresponding to $\mathbf{1 1 0 0}$ overtime hours (for a lane with no refuge area). This suggests that 1100 overtime hours per year will be needed in order for the combination of routine and special enforcement to result in tickets for $2.5 \%$ of all occupancy violators. This estimate reflects the broad assumption that special enforcement officers on Marin 101 will issue one 21655.5 citation per overtime hour (roughly the rate achieved during the first enforcement wave). The graph also reflects the underlying assumption that officers able to use a refuge area to enforce mainline lanes can issue two citations per overtime hour (including set-up and reporting time...roughly the special enforcement experience on Santa Clara 101). The indicated number of hours should be spread throughout the year in special enforcement bursts lasting no more than a month. To avoid disrupting freeway flow, no more than one or two special enforcement officers should be assigned per peak period.

The nomograph reflects the counter-intuitive finding that longer mainline HOV lanes actually require less special enforcement than shorter lanes. This is because the longer lanes receive heavier doses of routine enforcement from officers working adjacent lanes, so that officers assigned to special enforcement have fewer citations to issue in reaching the $2.5 \%$ target.

In instances in which an HOV lane covers more than one CHP area (as, for instance Santa Clara 101, which is enforced by the CHP's San Jose and Redwood City offices), the annual overtime hours should be prorated among field offices on the basis of lane mileage.

Application Guidance. The planning nomograph was constructed from a relatively limited set of data from four mainline HOV lanes. Two of the lanes were relatively short (three miles in length), while two were over eight miles long. In developing the nomograph, it was assumed that a single count at a single location gave representative violation data along the length of the freeway, and, implicitly, that all violators passed that location. This is clearly not the case. However, it is more nearly true for short lanes than for long lanes. 
As longer HOV lanes are constructed in California, violation rates should attempt to determine violation patterns and update the information gathered in this study. If different populations of drivers use a longer HOV lane, it might be appropriate to consider a longer lane to be composed of lengths of shorter lanes for the purposes of enforcement planning. For example, a twelve-mile HOV lane might be considered to be composed of two six mile lanes if the average trip length made by drivers using the lane is six miles.

The accompanying planning aid will provide relatively low levels of special enforcement for longer mainline lanes. So long as routine enforcement levels are sufficient to keep violation rates below $10 \%$ this is entirely appropriate. Should violation rates increase, the nomograph will automatically prescribe higher levels of enforcement. In the face of increasing violations, planners may wish to increase special enforcement levels beyond those indicated to bring violation rates under control.

\subsection{PROPOSED PROGRAM}

\subsubsection{Overview}

In developing a program of enforcement for mainline HOV lanes in California, it is important to recognize several facts:

- $\quad$ Routine enforcement is relatively high on most mainline HOV lanes.

- The dispersion of a small number of mainline HOV lanes throughout the state reduces the burden of enforcement felt by any one CHP area to manageable levels.

- Violation rates are currently considered to be at a manageable level on all major mainline HOV lanes. Lane violation rates are typically below $10 \%$ and violators represent less than $2 \%$ of all the vehicles traveling on all freeway lanes.

Thus the proposed program is designed to maintain violation rates at existing levels or lower, and to ensure that violators never cause the HOV lanes to operate under congested conditions.

Exhibit 7.3 presents a proposed enforcement program for California's mainline HOV lanes. Levels of special enforcement were calculated using the planning nomograph derived in Section 7.2. Levels of routine enforcement reflect the number of 21655.5 citations issued by beat officers in each project during 1988. 
EXHIBIT 7.3

PROPOSED ENFORCEMENT PROGRAM

\begin{tabular}{|c|c|c|c|c|c|c|c|c|c|c|c|}
\hline & $\mathrm{i}$ AM & PM & $\begin{array}{l}\text { DAYS/ } \\
\text { WEEK }\end{array}$ & WEEKS & $\begin{array}{l}\text { TIMES/ } \\
\text { YEAR }\end{array}$ & $\begin{array}{r}\text { OVERTIME } \\
\text { HOURS }\end{array}$ & $\begin{array}{c}\text { ROUTINE } \\
\text { HOURS }\end{array}$ & $\%$ MOTOR & $\begin{array}{l}\text { OVERTIME } \\
\text { COST }\end{array}$ & $\begin{array}{l}\text { ROUTINE } \\
\text { COST }\end{array}$ & $\begin{array}{r}\text { TOTAL } \\
\text { COST }\end{array}$ \\
\hline MARIN 101 (San Ralael) & 3 & 3 & 3 & 4! & 4 & 1152 & 210 & 0.6 & $\$ 58137$ & $\$ 5074$ & $\$ 63210$ \\
\hline MARIN 101 (Corte Madera) & $3^{\prime}$ & 3 & 3 & 4 & 4 & 1152 & 52.5 & 0.6 & $\$ 58137$ & $\$ 1268$ & $\$ 59405$ \\
\hline SANTA CLARA 101 & 1) & $1 \vdots$ & 2 & 4 & 2 & 128 & 706 & 0.2 & $\$ 5719$ & $\$ 17057$ & $\$ 22776$ \\
\hline SANTA CLARA 237 & $1 !$ & 1 & $4^{\prime}$ & 4 & 2 & 256 & 6625 & 0.2 & $\$ 11439$ & $\$ 16006$ & $\$ 27445$ \\
\hline ORANGE 55 & 1 & $\begin{array}{r}2 ! \\
i\end{array}$ & 2 & 4. & 2 & 192 & 737 & 067 & $\$ 9884$ & $\$ 17806$ & $\$ 27690$ \\
\hline LOS ANGELES 91 & 0 & $1^{i}$ & 2 & 4 & 2 & 64 & 150 & 0.2 & $\$ 2860$ & $\$ 3624$ & $\$ 6484$ \\
\hline SAN DIEGO I-15 (Daily) & 1 & $1 i$ & 5 & 50 & 1 & 2000 & 0 & 1 & $\$ 112500$ & $\$ 0$ & $\$ 112500$ \\
\hline SAN DIEGO I-15 (Special) & $1 !$ & 1 & 2 & 2. & 2 & 64 & 0 & 0.2 & $\$ 2860$ & $\$ 0$ & $\$ 2860$ \\
\hline SAN FRANCISCO t-280 & 0 & 1 & 5 & 4 & 4 & 320 & 74 & 1 & $\$ 18000$ & $\$ 1788$ & $\$ 19788$ \\
\hline ORANGE I-405 & 1 & 1 & 2 & 4: & 4 & 256 & 69 & 0.2 & $\$ 11439$ & $\$ 1667$ & $\$ 13106$ \\
\hline EL MONTE BUSWAY (Buffer) & $4 !$ & $3 !$ & 2 & 4 & 4 & 896 & 731 & 0.2 & $\$ 40035$ & $\$ 17661$ & $\$ 57696$ \\
\hline EL MONTE BUSWAY (Barrier) & 1 & 0 & 2. & 4. & 2 & $\begin{array}{r}64 \\
\mid\end{array}$ & & 0.6 & $\$ 3230$ & $\$ 0$ & $\$ 3230$ \\
\hline TOTAL & & & & & & 6544 & 3392 & & $\$ 334238$ & $\$ 81951$ & $\$ 416189$ \\
\hline
\end{tabular}




\subsubsection{Special Enforcement}

The recommended special enforcement program for existing mainline HOV lanes is outlined in Exhibit 7.3. The program and rationale are described below for each of the HOV lane projects.

Marin 101. The current level of enforcement on Marin 101 assigns two officers during the morning peak and two or three officers during the evening peak to enforce the Marin HOV lanes. With violation rates currently below $10 \%$ it is recommended that this level be cut back somewhat. The current level should be cut back on the San Rafael HOV segment to month-long applications of three officers during each commute peak. This should be repeated once each quarter. During different month-long periods, the Corte Madera HOV segment should be covered by a similar level of enforcement. To the extent possible, officers assigned during the evening peak on the San Rafael segment should follow the visible enforcement strategy tested during those of the current study, with one motor officer always visible in the median shoulder.

CALTRANS should examine both segments of Marin 101 to identify locations where the freeway could be widened to accommodate suitable enforcement areas. CALTRANS should also monitor violation rates on both segments more closely (at least quarterly) during the first six months of the proposed enforcement program to make sure that violation rates do not increase with the proposed cutback in special enforcement activity.

Santa Clara 101. Routine enforcement levels on Santa Clara 101 have been quite high, averaging over ten citations per day. At the same time, officers have been assigned to special overtime enforcement two or three times per week. It is recommended that special enforcement activities be cut back to twice yearly applications of a single officer enforcing two days per week, morning and evening, for a period of one month. The visible presence of routine enforcement on the median shoulder should be sufficient to keep violation rates at an acceptable level throughout the year. Overtime allocations beyond these levels should be focused on the ramp meter bypass lanes in the San Jose area.

Santa Clara 237. In recent years, Santa Clara 237 has been enforced almost exclusively by beat officers in the course of their routine duties. It is recommended that special enforcement officers be explicitly assigned to the freeway at twice the level recommended for Santa Clara 101: One officer per peak period, four days per week for a month, twice yearly. 
Orange 55. In recent years, the CHP' s Santa Ana office has reportedly assigned one or two units per shift to special enforcement along OR 55. At the same time, routine enforcement has produced over ten citations per day on the freeway. It is recommended that special enforcement activities on OR 55 be cut back to three officers covering both AM and PM peaks two days per week for two one-month periods each year. The three officers should follow the program of visible enforcement tested during the second wave of the current study, with one motor officer continuously present in the enforcement area just below Katella Avenue. Two motor officers may share this duty, with one pursing violators while the other maintains a presence in the enforcement area, radioing violator descriptions to local patrol units. If a spotter and chaser system is employed, no more than one chase unit should be detailed to respond to violator sightings. Limiting the amount of overtime enforcement to three officers will minimize the flow disruption caused by the enforcement process.

Los Angeles 91. Relatively low levels of special enforcement, combined with routine enforcement, have kept average violation rates on LA 91 below $5 \%$ for the past year. During the first wave of special enforcement, officers working in the enforcement area complained that there were too few violators to keep them busy during the last two weeks of the four week period. Accordingly, special enforcement activities were dropped altogether during the second enforcement wave, with no measurable increase in violation rates.

In view of the low violation rates on LA 91 a minimum level of special enforcement is recommended. The proposed special enforcement levels would assign one officer to work the enforcement area twice a week for a period of four weeks. This level of enforcement should be repeated twice per year. CALTRANS should monitor violation rates to make sure that this reduction in special enforcement activity does not lead to an increase in violation rates.

San Diego l-15. The single motor officer assigned daily to the separate right of way on San Diego I-15 appears to be able to keep violation rates low enough (currently below $5 \%$ ) so that relatively little additional enforcement is needed. It is recommended that the CHP continue to assign a single motor officer to patrol I-15 on a daily basis. One additional officer should be assigned to assist the motor officer on two days per week for two different months each year. Alternatively, officers assigned to enforce the mixed flow lanes on I-15 could provide this additional enforcement by making a pass through the barrier-separated HOV lanes at this suggested frequency. 
San Francisco 1-280. The two-mile stretch of HOV lane on I-280 south of San Francisco has the highest violation rate of any of California's mainline HOV lanes. A low utilization rate by $3+$ carpoolers helps to contribute to the high violation rate. The lane presents a difficult enforcement problem and has historically received relatively light levels of routine enforcement (slightly over one citation per day). It is recommended that a single motor officer be assigned to enforce I-280 every weekday for four weeks on a quarterly basis in an attempt to reduce the violation rates.

Orange County 1-405. In January, 1989, a mainline HOV lane was opened in the northbound direction on 1-405 in Orange County between Westminster Avenue and the Los Angeles County line. The segment contains an enforcement area and is part of a longer stretch of HOV lanes to be opened later in the year. After four months of operation, the northbound lanes on I-405 experienced violation rates of $2.8 \%$ or lower during both morning and evening peaks. During the four month period, an average of 2.6 citations per day were issued to occupancy violators. Of these, 1.5 were given by special enforcement officers, and 11 were given by officers assigned to routine enforcement of the adjacent freeway.

It is recommended that an ongoing program of special enforcement be established with one officer using the enforcement area during the morning peak twice a week for four weeks. This level of enforcement should be repeated four times per year. In addition, a single officer should be deployed twice a week during the evening peak over similar four week periods, four times per year. This level of special enforcement, combined with routine enforcement, should be sufficient to maintain violation rates at these current low levels.

El Monte Busway. Violation rates above $10 \%$ were recorded on the buffer-separated segment of the El Monte Busway during 1988. In an attempt to reduce these levels, special enforcement units should be assigned four times each year to special enforcement. On two days each week for a month, a total of four officers in the morning and three in the evening should cover the buffer-separated segment of the busway. Violations in the physically separated section are negligible and can be enforced by having one of the officers from the East Los Angeles Area drive through the busway once in the morning. Enforcement in the morning is more crucial since extreme peaks of HOV traffic occur between 7:00 and 8:00 a.m. For short periods during this peak hour, violators could conceivably cause slow-downs in the Carpool lane. If the next CALTRANS violation count is below $10 \%$ for both of the peak periods, the number of special enforcement applications can be reduced to two per year. 


\subsubsection{Routine Enforcement.}

Routine enforcement efforts by officers on their normal beats are also documented in Exhibit 7.3. The estimate of routine enforcement levels appearing in this exhibit are based on the number of 21655.5 citations issued by beat officers on each project during $1988 .{ }^{*}$ If the proposed program of special enforcement is to succeed, it is essential that historical levels of routine enforcement be maintained on all mainline HOV lanes contiguous with mixed flow lanes.

Barrier-Separated Lanes. Routine enforcement by officers assigned to mixed-flow lanes is not possible in the case of physically separate facilities such as San Diego I-15 and the western end of the El Monte Busway. Since officers passing in mixed flow lanes do not have ready access to separate HOV lanes, any enforcement of these lanes must be accomplished by special assignments.

Contiguous Lanes. Routine enforcement efforts have historically been quite high on most of California's mainline HOV lanes (see Section 4.1.2). Over ten citations per day were issued by beat officers on Orange 55, Santa Clara 101, and the El Monte Busway. On Santa Clara 237, which received no special enforcement at all, routine enforcement levels of 7.5 citations per day kept violation rates below the target level of $10 \%$.

Contiguous lanes receiving lower levels of routine enforcement were Marin 101 (4.2 citations per day during 1988), Los Angeles Route 91 (2.4 citations per day during evening operating hours), and I-280 south of San Francisco (1.2 citations per day during evening operating hours). On Marin 101, special enforcement assignments have historically been so high and enforcement of the mainline HOV lanes by normal beat officers in patrol cars is so difficult that enforcement is left to the special patrol officers. On LA 91, the low level of routine citations reflects the low number of violators and the low violation rate experienced during the evening commute period.

\footnotetext{
* In the case of I-405 in Orange County, the first four months of 1989 were used as a basis for estimating routine enforcement levels.
} 
Four factors account for the low level of routine citations on San Francisco I-280:

(1) Low Violation Levels The total number of violators is lower than that on any other mainline lane. Because relatively few legitimate 3-person Carpools use the lane, however, the violation rate is quite high.

(2) Short Length. The 2-mile length of the lane makes it the shortest in the state. Hence, beat officers pass it quickly and it behaves more like a ramp meter bypass lane, requiring special enforcement.

(3) Limited Enforcement Area. Although the lane has a median shoulder over its first mile of length, the shoulder disappears before the lane ends, making it difficult to enforce.

(4) Low General Surveillance. The relatively low levels of traffic on I-280 do not attract as much general CHP surveillance as other Bay Area freeways (Newman, et al., 1987).

\subsection{ENFORCEMENT COSTS}

The costs of the proposed enforcement program have been estimated in Exhibit 7.2. This subsection describes the assumptions underlying these estimates.

\subsubsection{Special Enforcement}

The CHP has at least two options in assigning officers to special enforcement of mainline HOV lanes:

(1) Officers can be assigned on an overtime basis to special enforcement activities during the commute peak; and

(2) Additional officers can be assigned to the freeway beat adjacent to the mainline HOV lane during the morning and evening shifts;

Overtime Assignment. Most current special HOV enforcement activities follow Option 1 and use overtime officers. As of June 1, 1989, the overtime salary rates for traffic officers and motorcycle officers were set at $\$ 36.04$ per hour and $\$ 50.00$ per hour respectively. Vehicle costs of 23 cents per mile for patrol cars and 258 per mile for a motorcycle must be added to these base hourly costs. Assuming enforcing officers travel 100 miles during a four-hour shift, the cost of overtime enforcement during a single peak commute period would be $\$ 167.16$ for a traffic officer and $\$ 225.00$ for a motorcycle officer. 
Routine Assignment. If additional officers were to be assigned to cover the beat adjacent to mainline HOV lanes routinely on a day-to-day basis, it would be necessary to pay for a full eight hours of service in order to cover a single peak period. Effective June 1, 1989, the base salaries of traffic officers and motorcycle officers were set at $\$ 18.40$ per hour and $\$ 19.16$ per hour respectively. Allowing for vehicle expenses, then, the cost of assigning a beat officer to provide mainline HOV enforcement would be $\$ 193.20$ per peak period for a traffic officer and $\$ 203.28$ for a motorcycle officer.

Overtime vs. Routine Assignments. In the case of traffic officers, the cost of using overtime assignments to provide mainline HOV enforcement is lower than the cost of assigning additional personnel to the full eight-hour morning and evening shifts. The opposite is true in the case of motorcycle officers, who command a higher overtime rate. Because the issues of overtime assignments vs. an increase in day-to-day personnel has significant management and policy implications as well as cost consequences, CHP personnel at all levels were interviewed to determine their views regarding the relative merits of each approach. In general, CHP headquarters personnel, area commanders and beat officers all preferred overtime assignments to increased personnel levels. The responses of participating CHP personnel to this issue are summarized below.

(1) Headquarters Personnel. Headquarters personnel noted that it is easier to obtain budget allocations for directed overtime tasks than for additional beat officers.

(2) Area Commanders. In general, area commanders and their staff expressed a preference for periodic overtime assignments over a permanent assignment of a routine beat officer. They felt that beat officers would be subject to reassignment, and appreciated the management control and clarity associated with specific overtime duty. ("The overtime officer on special assignment knows exactly what he is supposed to do and how his activity will be judged.")

One lieutenant argued that the knowledge that special enforcement units are available took some psychological pressure of the beat officer, who did not feel that he had to chase every HOV violator (since special enforcement would see to the HOV lane) and could concentrate on higher priority tasks. Area commanders felt a permanent assignment would be necessary in the case of barrier-separated lanes such as I-15 in San Diego. In this instance, regular beat officers in mixed flow lanes do not have access to the HOV lane, so that the day-to-day assignment of at least one beat officer is necessary.

(3) Officers. Beat officers and their sergeants appreciated the opportunity to earn overtime hours on special HOV assignments.

In view of the overwhelming preference for overtime assignments as a vehicle for providing special enforcement, the option was followed in computing the cost of the special 
enforcement activity recommended in the proposed program. At current overtime rates, the annual cost of special enforcement activity recommended on all of California's existing mainline HOV lanes totals $\$ 337,543$. This represents a total of 6,224 hours (see Exhibit 7.2 for a projectby-project breakdown). By way of comparison, a total of 32,033 overtime hours were allocated for the enforcement of mainline HOV lanes and ramp meter bypass lanes during the 1988/89 fiscal year. At current hourly rates, using the same mix of motor officers and patrol officers established in Exhibit 7.2, this would represent an annual expenditure of $\$ 1.6$ million. There is no easy way of tracking the actual allocation of these overtime hours between mainline HOV lanes and ramp meter bypass lanes during the past year, but the current analysis makes it clear that the bulk of the statewide special enforcement effort should be directed to ramp meter bypass lanes, which receive very little routine enforcement.

\subsubsection{Routine Enforcements}

The high level of routine enforcement currently experienced on California's mainline HOV lanes does not come for free. At a minimum, it represents an opportunity cost for the patrol officers who might have been attending other duties if they weren't pursuing HOV violators. As routine enforcement is currently conducted on California's mainline HOV lanes, the cost of this enforcement can be estimated to be the marginal cost of the ten-to-fifteen minutes spent by beat officers in apprehending and citing specific HOV violators. Using the June, 1989 rates for traffic officers, and allowing for vehicle expenses, the cost of a routine 15-minute traffic stop is estimated to be $\$ 6.04$. The estimated daily costs of routine enforcement on those mainline lanes operating in 1988 are listed below.

\section{Cane}

Orange 55

Los Angeles 91

Santa Clara 101

Marin 101

Santa Clara 237

S.F. I-280

Los Angeles 10

\begin{tabular}{cr}
$\begin{array}{c}\text { Daily } \\
\text { Routine Citations }\end{array}$ & $\begin{array}{c}\text { Daily } \\
\text { costs }\end{array}$ \\
\hline & \\
11.8 & $\$ 71.27$ \\
2.4 & 14.50 \\
11.3 & 68.25 \\
4.2 & 25.37 \\
7.5 & 45.30 \\
1.2 & 7.25 \\
11.7 & $\underline{70.67}$ \\
\hline
\end{tabular}

50.1
$\$ 302.61$ 
Thus the marginal cost of routine enforcement on California's mainline HOV lanes ranges from \$7.25 per day on 1-280 in San Francisco (where enforcement is concentrated during the evening peak) to over $\$ 70.00$ per day on OR 55 and the El Monte Busway (LA 10).

\subsubsection{Total Costs}

Adding the marginal cost of routine enforcement to the estimated cost of the proposed special enforcement brings the annual cost of enforcing California mainline HOV lanes to $\$ 400,000$. Lane-by-lane contributions to this cost are detailed in Exhibit 7.2. The least expensive lanes to enforce are LA 91, which has a well-designed enforcement area and low violation rates, and San Francisco's I-280, which has few users, a low number of violators, and relatively little routine enforcement. The total annual enforcement cost for each of these lanes is estimated to be under $\$ 10,000$.

At the other end of the spectrum, the most costly enforcement projects are those on Marin 101 and San Diego I-15. Each of these projects incurs over $\$ 100,000$ annually in overtime enforcement costs. Marin 101 has two short lengths of HOV lane with no median shoulder, no enforcement areas, and a skimpy right shoulder. These factors combine to make Marin 101 a relatively difficult enforcement job. Although the HOV lanes on San Diego I-15 have one of the lowest violation rates in California, the barrier separating these lanes from mixed flow traffic makes it necessary to assign a separate officer to patrol the lanes on a daily basis. 
APPENDIX A

FOCUS GROUP PROTOCOL 
FOCUS GROUP PROTOCOL

HOV VIOLATION STUDY

\begin{tabular}{|c|c|c|c|c|}
\hline \multicolumn{4}{|c|}{ SCHEDULE } & COMMENTS \\
\hline Date & Location & Freeway & $\begin{array}{c}\begin{array}{c}\text { Total } \\
\text { Invitees }\end{array} \\
\end{array}$ & $\begin{array}{l}\text { Participants chosen at } \\
\text { random from freeway }\end{array}$ \\
\hline Sept. 29 & Corte Madera & Marin 101 & 14 & city in which discussion \\
\hline October 5 & Anaheim & LA 91 & 14 & is held. Freeway drivers \\
\hline October 6 & Anaheim & OR 55 & 14 & will be selected from list \\
\hline October 11 & Anaheim & LA 91 & 14 & of license plate observa- \\
\hline October 12 & Anaheim & OR 55 & 14 & tions, and an attempt will \\
\hline October 13 & Sunnyvale & SC 101 & 14 & $\begin{array}{l}\text { be made to balance the } \\
\text { attendance of carpoolers, } \\
\text { violators, and non- } \\
\text { carpoolers. Ail partici- } \\
\text { pants will be paid } \$ 40.00\end{array}$ \\
\hline
\end{tabular}

\begin{tabular}{|c|c|}
\hline DISCUSSION CONTENT & COMMENTS \\
\hline $\begin{array}{l}\text { A INTRODUCTION (20 minutes) } \\
\begin{array}{l}\text { 1. Identify CALTRANS and CHP as Sponsors. Emphasize } \\
\text { independence of moderator. } \\
\text { 2. Hand out one-page questionnaire documenting: } \\
\text {. Demographic information } \\
\text { - Use of Study Freeway } \\
\text { - Frequency } \\
\text { - Length of Trip } \\
\text { - Mode (drive alone, Carpool) } \\
\text { - Number of cars in household } \\
\text { 3. Each person introduces themselves and describes } \\
\text { their use of the study freeway in their own words. }\end{array}\end{array}$ & \\
\hline
\end{tabular}




\begin{tabular}{|c|c|}
\hline DISCUSSION CONTENT (Continued) & COMMENTS \\
\hline $\begin{array}{l}\text { B. CARPOOL LANE PERCEPTIONS ( } 30 \text { minutes) } \\
\text { 1. What is purpose of the lane? } \\
\text { 2. What words would you use to describe the lane? } \\
\text { 3. How has the lane changed your commute trip? } \\
\text { - Have you changed your trip patterns as a result? } \\
\text { 4. How much times does the lane save? } \\
\text { 5. How well do you think the lane does its job? } \\
\text { - Effective? } \\
\text { - Safe? } \\
\text { - Fair? }\end{array}$ & $\begin{array}{l}\text { List purposes } \\
\text { List adjectives }\end{array}$ \\
\hline $\begin{array}{l}\text { C. VIOLATION PERCEPTIONS (30 minutes) } \\
\begin{array}{l}\text { 1. Do you see many people using the lane illegally? } \\
\text { - What percentage don't have enough riders? } \\
\text { - What percentage cross buffer illegally? } \\
\text { - Evidence of repeat violations? (Same people } \\
\text { - } \text { or different?) } \\
\text { 2. Whave you ever used lane. illegally? } \\
\text { 3. How serious is HOV lane violation? } \\
\text { - Occupancy } \\
\text { - Buffer }\end{array}\end{array}$ & $\begin{array}{l}\text { Document estimated } \\
\text { percentage } \\
\text { Have participants rank } \\
\text { HOV violations in spectrum } \\
\text { of driving violations that } \\
\text { include overtime parking, } \\
\text { speeding (freeway), } \\
\text { tailgating, parking in a } \\
\text { handicapped space, run- } \\
\text { ning a stop sign, running } \\
\text { a red light, speeding } \\
\text { (residential street) } \\
\text { Rate seriousness on a } \\
\text { scale of } 1 \text { (not serious) } \\
\text { to } 10 \text { (extremely serious) }\end{array}$ \\
\hline
\end{tabular}




\begin{tabular}{|c|c|}
\hline DISCUSSION CONTENT (Continued) & COMMENTS \\
\hline 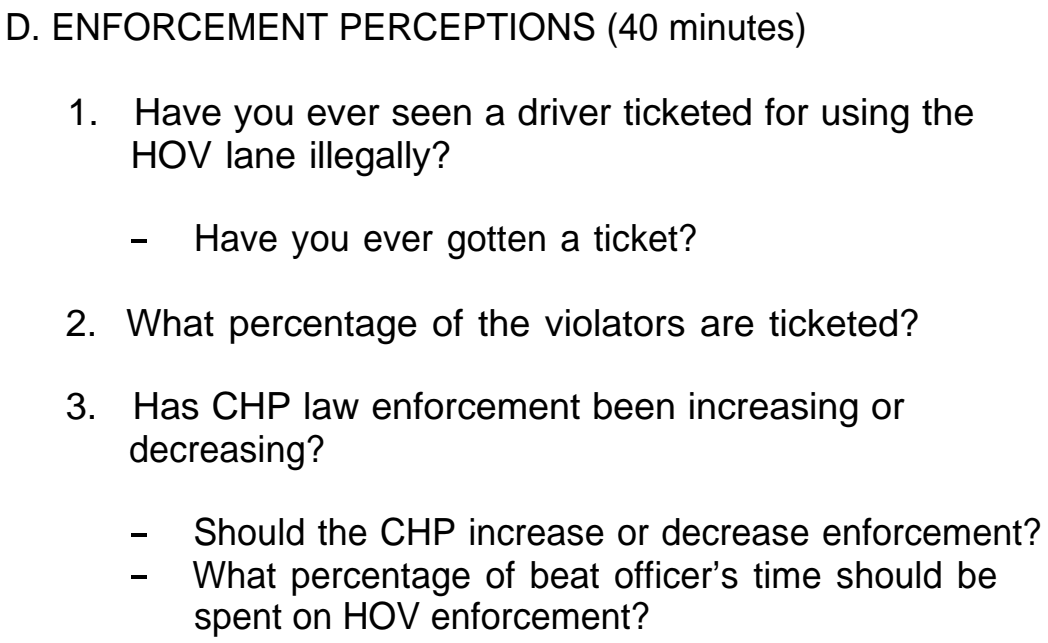 & $\begin{array}{l}\text { Record percentage } \\
\text { response }\end{array}$ \\
\hline & \\
\hline
\end{tabular}




\section{APPENDIX B}

\section{MAIL-OUT SURVEY}




\section{ARTESIA FREEWAY \\ (LOS ANGELES ROUTE 91) \\ CORRIDOR DRIVER SURVEY}

\section{Dear Motorist:}

SYSTAN COMMUTER SURVEYS has been hired to undertake an objective study of freeway operations and special Carpool lanes in your Metropolitan area.

If you or anyone in your household uses the ARTESIA FREEWAY (Los Angeles Route 91), it would be appreciated if the driver would answer the questions below. The information will be used to improve services on future transportation projects in your area as well as elsewhere in California. All information is anonymous and will be kept confidential.

Thank you for your cooperation.

\section{SYSTAN COMMUTER SURVEYS \\ P.O. Box U \\ Los Altos, CA 94023}

FIRST, SOME QUESTIONS ABOUT YOUR TRAVEL ON ARTESIA FREEWAY (Los Angeles Rt. 91)

1. How often do you use the Freeway?

[ ] Once a month_or less

[ ] 2-5 times a month

[ ] 2 or 3 times a week

[ ] 4 times a week or more

2. How long does your complete trip usually take in the morning? Your return trip in the afternoon? $\min$.

3. How long is your total one-way trip? miles

4. How do you usually make the trip?
[ ] Drive alone
( ) Carpool with
( ) Other

(no.) people (include driver)

5. Did you use the Artesia Freeway regularly before the bus/carpool lanes were added?
( ) Yes
() No

If yes, how has your total travel time changed since the bus/carpool lanes were added?

Morning trip time has [ ] increased by Evening trip time has [ ] increased by minutes; [ ] Decreased by minutes; [ ] Decreased by minutes; [ ] Not changed minutes; [ ] Not changed

6. Have the Artesia Freeway bus/carpool lanes caused you to change your travel patterns in any way? (Check as many as apply)

Yes, I

Changed routes to use the bus/carpool lanes

Changed routes to avoid the bus/carpool lanes

] Joined or formed a Carpool

Increased the size of a Carpool

Other (specify) 


\section{NEXT, SOME QUESTIONS ABOUT THE BUS/CARPOOL LANES ON THE ARTESIA FREEWAY}

1. How much time do you think you can save by using the bus/carpool lanes? minutes in the morning minutes in the evening don't know

2. Have you ever used the bus/carpool lanes?

[ ] Yes

[ ] No

3. Have you ever seen the Highway Patrol stopping a driver for using the bus/carpool lane illegally?
[] Yes
[] No

4. Have you ever received a ticket or verbal warning from the

Highway Patrol for using the bus/carpoal lane illegally?

[ ] Yes [ ] No

5. What percentage of the drivers in the bus/carpool lane would you estimate use the lane illegally? $\%$

6. Do you think that drivers using the bus/carpool lane illegally are ticketed by the Highway Patrol
[ ] Always
[ ] Frequently
[ ] Sometimes
[ ] Infrequently
[ ] Never?

7. Do you feel that the use of the bus/carpool lane by non-carpoolers is a
[ ] Serious problem
[ ] Minor problem
[ ] No problem
[ ] Other

8. During the past 3 months, do you feel that Highway Patrol enforcement of the special bus and carpool lanes has
[ ] Increased
[ ] Decreased
[ ] Stayed about the same?

9. How strongly do you agree or disagree with the following statements regarding the bus/carpool lanes?

The bus/carpool lanes:

Save time for carpoolers Contribute to better freeway flow Increase accident potential Motivate people to join carpools Reduce gasoline consumption Reduce air pollution

Are unfair to noncarpooling drivers Should be opened to all traffic Should be enforced more heavily

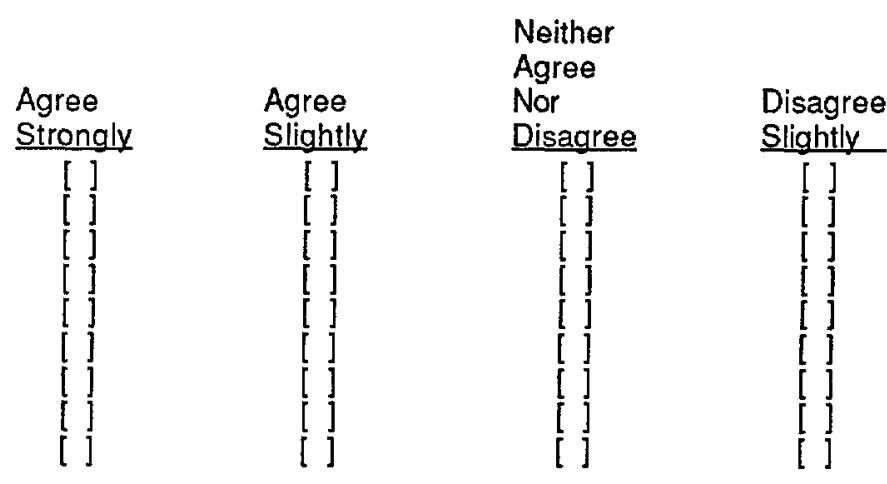

FINALLY, SOME QUESTIONS ABOUT YOU:

1. How many cars are there in your household? (No.)

Licensed drivers? (No.)

2. Sex: [] Female [] Male

3. Age Group: [] Under 20 [] $20-29$ [ [ 30-44 [ ] $45-64 \quad$ [ ] 65 and over WE WOULD APPRECIATE YOUR ADDITIONAL COMMENTS:

THANK YOU FOR YOUR COOPERATION

PLEASE FOLD \& MAIL IN THE ENCLOSED POSTAGE-PAID ENVELOPE Date 19 


\section{APPENDIX C}

\section{GLOSSARY}

Apprehension Rate

Area Characteristics

Citation Rate

Duration of Enforcement

Enforcement History

Enforcement Visibility

Expected Sightings

Follow-through Violation

Frequency of Coverage

Geometries

HOV

HOVL

Historical Citation Rate
Citations issued per day/violators per day.

Socioeconomic, demographic, and geographic statistics related to the area in which HOV project is located.

Number of citations issued over period of time on HOV project.

Period (days) over which a special enforcement program is carried out.

History of previous enforcement programs on HOV projects, including their duration, frequency of coverage, and resulting violation rates.

Applied to metered ramps. Ability to see a CHP officer, if present (or determine that no unit is present). Metered ramps with or without bypass lanes can be categorized into three groups of enforcement visibility: those where an enforcement unit's presence is always determinable; those where it is never known; and those where it is visible only at a certain point on the ramp (thus termed, queue-dependent).

Average number of violators a non-violator in the metered queue or general traffic lanes is likely to see pass by. For mainline HOV lanes this is an empirical observation; for ramps, an attempt will be made to develop a formula relating queue lengths and violation rates to empirical data.

For metered ramps without bypasses:

= \# of cars following another car through meter lights total \# cars using ramp

Number of times a CHP unit patrols a HOV project (days/month).

Physical characteristics of project, such as shape of ramp (e.g., diamond, hook, loop) placement of meter, placement of HOV lane, existence of shoulder/median strip, separation of HOV lane.

High-occupancy vehicle.

High-occupancy vehicle lane.

Number (and trends) of citations given over projects history (a series of data points). 
APPENDIX C

GLOSSARY 
Historical Deployment

Historical Ramp
Violation Rate

Lane Violation Rate

Length of Stay

Meter Violation Rates

$\%$ Regular Users

$\%$ Repeat Violators

Project Life

Queue Delay

RM

RMB

Ramp Violation Rate

Red Violation Rate

Residual Enforcement Impact

Shoulder Violation Rate
Historical manpower level assigned to ramp during special enforcement projects.

Rate (and trends) of ramp violations over time (a series of data points).

For metered ramps with bypasses:

$=$ \# single occupancy cars in carpool lane total \# cars in Carpool lane

For mainline HOVL's:

$=$ \# cars carrying less than 3 people in HOVL

total \# cars in HOV lane

In general:

$=$ \# of vehicles in special lane not meeting lane total \# cars in special lane

Amount of time (minutes) CHP unit is enforcing a HOV project during day of enforcement period.

Red violation rate + shoulder violation rate + followthrough violation rate.

Percentage of vehicles using HOV project regularly.

Percentage of drivers repeatedly violating HOV restrictions.

Time since project's initiation (months).

Average queue lengths and delay in metered lane of ramp.

Ramp metering.

Ramp meter bypass lanes.

For metered ramps with bypasses:

= \# single occupancy cars in carpool lane total \# cars on ramp

For metered ramps without bypasses:

= \# cars running red meter light

Total \# cars using ramp

Length of time after employment activity until average HOVL violation rate equals or exceeds pre-enforcement level.

For metered ramps without bypasses:

= \# cars bypassing meter queue on shoulder total \# cars using ramp 
Start-Up Strategies

Traffic Volume

TSM

Vantage Point

Violation Rate

Visibility Distance
Refers to enforcement strategy employed at initiation of HOV project. Types include a grace period of handing out no citations to violators, and either giving or not giving warnings, a regular enforcemenl scheme, or an intensive enforcement scheme. Start-up strategies may or may not be advertised.

Number of cars on HOVL; on lanes adjacent to HOVL.

Transportation Systems Management.

Enforcement units' view of violators from refuge area.

Term used interchangeably with HOV Lane Violation Rate on projects other than ramps.

Distance from ramp meter at which presence or absence of enforcement unit can be detected. 
APPENDIX D

BIBLIOGRAPHICAL REFERENCES 
BIBLIOGRAPHICAL REFERENCES

Billheimer, John W., Juliet McNally and Robert Trexler, ISM Project Violation Rates, Final_Report prepared for the California Department of Transportation and the California Highway Patrol by SYSTAN, Inc., Los Altos, California, 1981.

Billheimer, John W., and Gail Fondahl, TSM Project Violation Rates: Study Design Prepared for the California Department of Transportation and the California Highway Patrol by SYSTAN, Inc., Los Altos, California, June, 1979.

Billheimer, John W., DMV Marketplace Survey prepared for the California Department of Motor Vehicles by Crain \& Associates and SYSTAN, Inc., Menlo Park, California, February, 1988.

Billheimer, John W., Evalu of the 19o Driving Under the Influence prepared for the California Highway Patrol by SYSTAN, Inc., Los Altos, California, September, 1987.

Billheimer, John W., and Douglas S. Solomon, H Public Information Campaign 5 Evaluatiorn Final Report prepared for the California Highway Patrol by SYSTAN, Inc., Los Altos, California, September, 1987.

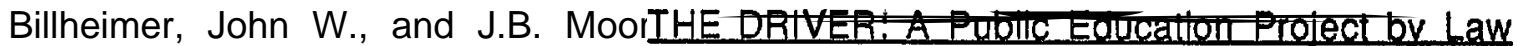
Enforcement, Vol. I: Technical Report and Vol. II: Planning, Implementation and Evaluation Guidelines, prepared for the California Department of Transportation, National Highway Traffic Safety Administration by SYSTAN, Inc., Los Altos, California, January, 1987.

Billheimer, John W., and Robert Trexler, Evaluation Handbook for Transportation Impact Assessment Report No. UMTA-IT-06-0203-81-1, prepared for the Urban Mass Transportation Administration, Washington, D.C., December, 1980.

Billheimer, John W., Robert Bullemer and Carolyn Fratessa, The Santa Monica Freeway Diamond Lanes: An Evaluation. SYSTAN, Inc., Los Altos, California, April, 1977.

Billheimer, John W. San Tomas Expressway Data Review and Requirements prepared for the Santa Clara County Transportation Agency by SYSTAN, Inc., Los Altos, CA, April, 1982.

California Department of Transportation, Guidelines: Bus and Carpool Lanes. Park and Ride, Draft, Sacramento, California, February, 1981.

California Department of Transportation, Caltrans District 04, Bus/Carpool Lanes Route 101 Marin County: Evaluation Report, San Francisco, California, March, 1977.

California Department of Transportation, Caltrans District 04, "San Francisco Route 280 Bus/Carpool Lane Six Month Report," April, 1976.

California Department of Transportation, Caltrans District 04, SCL-101 Commuter Lane Preliminary Evaluation Report, San Francisco, June, 1988. 
California Department of Transportation, Caltrans District 07, Route 55 Newport Costa Mesa Freeway Commuter Lane 18 Month Report, Los Angeles, July. 1987.

California Department of Transportation, Caltrans District 07, Route 55 Newport Costa Mesa Freeway One Year Report of Commuter Lane Use, Los Angeles, December, 1986.

California Department of Transportation, Caltrans District 07, Route 91 Artesia Freeway Operational Report Based on 18 Months of Commuter Lane Use Los Angeles, December, 1986.

California Department of Transportation, Caltrans District 07, "Evaluation of Implemented HOV Strategies," Draft, December, 1977.

California Department of Transportation, Caltrans District 07, Evaluation of High Occupancy Vehicle (HOV) Strategies, Unreleased Report, Los Angeles, April, 1978.

California Department of Transportation, Caltrans District 11, Interstate Route 15 Reversible Roadway for High Occupancy Vehicles Operational Plan, San Diego, July, 1984.

California Highway Patrol, "Golden Gate Division Motorcycle Assignment CalTrans Committee Report," San Francisco, March, 1978.

California Highway Patrol, Freeway Enforcement, HPG 70.18, Sacramento, California, March, 1971.

Cechini, Frank, Operational Considerations in HOV Facility Implementation prepared for Transportation Research Board Task Force ASTS1 (HOV System;) Federal Highway Administration, Sacramento, CA, October, 1988.

DKS Associates, Route 101 in Santa Clara County. Corridor Study and Operations Analysis. Final Report, prepared for Santa Clara County Traffic Authority and the California Department of Transportation, Oakland, CA, July, 1987.

DKS Associates, Montague Expressway Commuter Lane Traffic Analysis prepared for Santa Clara County Transportation Agency, Oakland, CA, November, 1987.

Glazer, Lawrence J., San Bernadino Freeway Express Busway Evaluation of Mixed-Mode Operations, prepared for Southern California Association of Governments, Crain \& Associates, Menlo Park, California, July 1978.

Institute of Transportation Studies, University of California, Irvine, Results of Preliminary Study of Accidents on the SR-55 Freeway, prepared for Orange County Transportation Commission by ITS. Irvine, California, November, 1986.

Kollo, Hanna P.H. and Charles L. Purvis. Regional Travel Forecasting Model System for the San Francisco Bay Area Metropolitan Transportation Commission, presented at the annual meeting of the Transportation Research Board, Oakland, CA, January, 1989. 
May, Adolf D., Demand-Supply Modeling for Transportation System Management Institute for Transportation Studies, University of California, Berkeley: California, July, 1980.

Miller, Craig and Robert Deuser, Enforcement Requirements for High-Occupancy Vehicle Facilities, Beiswenger, Hoch and Associates, Inc., Final Report, December, 1978.

Newman, Leonard, Cornelius Nurworsoo, and Adolf D. May, Operational and Safety Experience with Freeway HOV Facilities in California, Submitted to Transportation Research Board for Publication, January, 1988.

Newman, Leonard, Cornelius K. Nurworsoo, and Adolf D. May, Design of Bus and Carpool Facilities: A Technical Investigation Research Report UCB-ITS-RR-87-15. Institute of Transportation Studies, University of California, Berkeley, November, 1987.

Orange County Transit District, Planning Department, Commuter Market Study, September, 1985.

Orange County Transit District, Memorandum for Debra Irizarry to Gary Edson on "NonTraditional Approaches to Enforcement on HOV Facilities," May 29, 1987.

Orange County Transportation Commission, Commuter Attitudes Toward Proposed High Occupancy Vehicle Lanes in Orange County, August, 1985.

Raub, R.A., Summary and Critique of the Literature Pertaining to the Effects of Increased Enforcement of Traffic on Improving Traffic Safety (Reducing Accidents) Illinois Department of Law Enforcement, Springfield, Illinois, December, 1979.

Shu, Jarvia and L.J. Glazer,Commuter Computer Carpool Program Evaluation Commuter Transportation Services, Inc., Los Angeles, May, 1979.

SYSTAN, Inc., Santa Clara County Commuter Lane Performance Evaluation, prepared for Santa Clara County Transportation Agency, Los Altos, CA, March, 1989.

SYSTAN, Inc., HOV Lane Violation Study: Study Plan, prepared for the State of California Department of Transportation, Los Altos, CA, October, 1988. 


\section{APPENDIX E}

\section{DESIGN AND ENFORCEMENT \\ NOTES}

The following pages summarize key study findings of primary interest to agencies charged with the design and enforcement of HOV projects. 


\section{DESIGN NOTES}
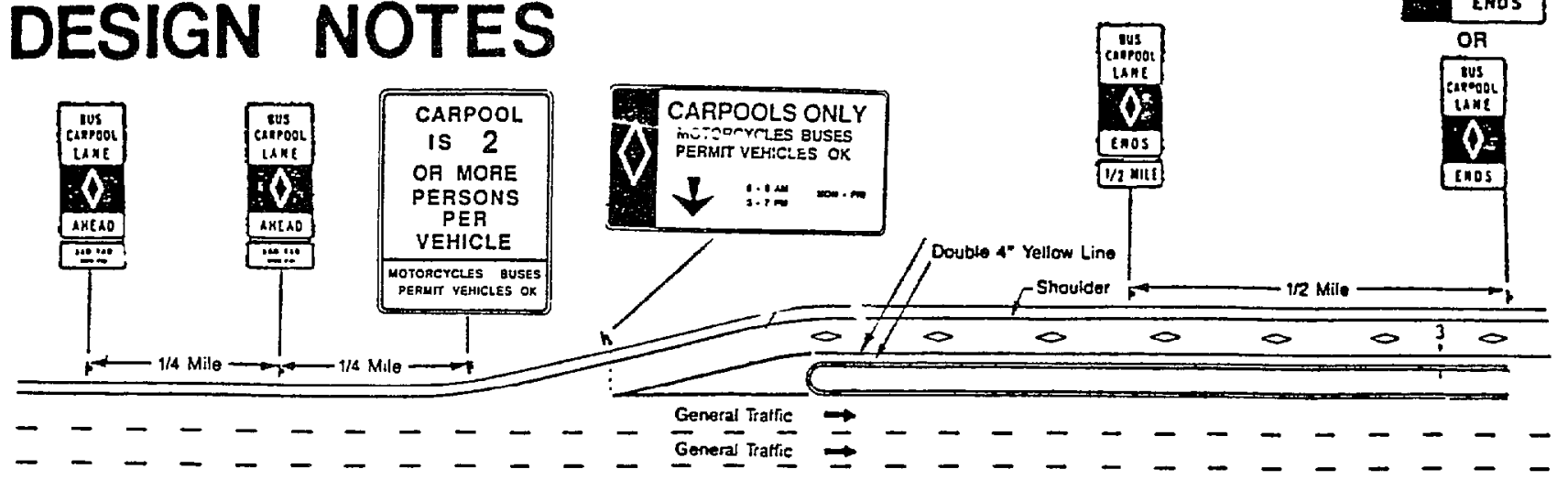

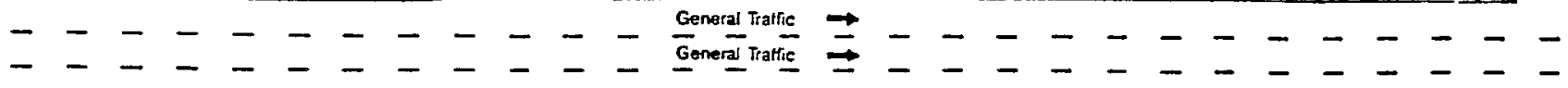

\section{GENERAL OBSERVATIONS}

- Collaboration between design and enforcement agencies is necessary from project inception.

- Adequate refuge areas are essential for the safe and efficient enforcement of all HOV projects.

- $\quad$ Proper signing and striping is necessary to give drivers a clear understanding of HOV lane use and comply with legal requirements. Most drivers appear to be familiar with current signing and striping practices and understand the use of HOV lanes.

- Advance Publicity must advertise all aspects of a project at appropriate levels.

\section{RAMP METER BYPASS LANES}

- Ramp Selection. So long as major structural modifications are not required, even a modest degree of success in encouraging new carpools will generate enough benefits to offset both the cost of enforcement and the average initial investment in a bypass lane. However, bypass lanes should be avoided where

- $\quad$ Ramp storage problems exist;

- Significant numbers of turning vehicles can be trapped in the carpool lane;

- Relatively low levels of violations can threaten the metering system; or

- Major structural modifications cause bypass lane costs to outweigh potential benefits.

- $\quad$ Metering Strategy.

- Design rates should accommodate a $5 \%$ ramp violation rate;

- Faster metering rates lead to somewhat lower violation levels;

- Since drivers will overestimate delays, even short waits provide some carpooling incentive. 
Ramp Layout.

Enforcing officers must have a safe and suitable vantage point and an adequate shoulder area beyond the meter.

If possible, the refuge area should be out of the line of sight of potential violators and shielded from the view of motorists on the freeway itself. Unlike the refuge area itself, however, neither of these characteristics is essential to effective enforcement.

\section{Signing and Striping.}

Bold striping is initially effective in discouraging violations, but its impact diminishes with time.

Delineators separating the bypass lane from general traffic are costly and ineffective.

\section{MAINLINE HOV LANES}

\section{Lane Separation.}

Physically separate mainline lanes are desirable from the standpoint of both safety and enforcement. When buffer zones or stripes are used to separate mixed flow traffic from HOV lanes, the buffers should be as wide as possible, but no wider than four feet. Wider zones can invite use as a breakdown lane, creating a potentially hazardous situation with high-speed traffic on both sides of a stranded vehicle.

Refuge Areas.

Refuge areas are essential to the safe and effective enforcement of mainline HOV lanes. In the absence of a median shoulder, enforcement area consisting of a flared median barrier must be provided as a minimum enforcement measure for the protection of officers observing and enforcing the HOV lanes adjacent to mixed flow lanes. The protected enforcement area should be no narrower than 10 feet at the mouth and be set in a 14-foot median which extends for at least 1300 feet to provide adequate space for acceleration and deceleration.

Where space and funds are available, a continuous 14-foot median shoulder should be provided along the full length of the HOV lane for both safety and enforcement purposes. The median shoulder may be enhanced through the addition of protected enforcement areas. In the absence of adequate refuge areas, violators must be escorted across several lanes of traffic, making enforcement more hazardous, more time consuming, less noticeable to Carpools and violators, and less effective. 


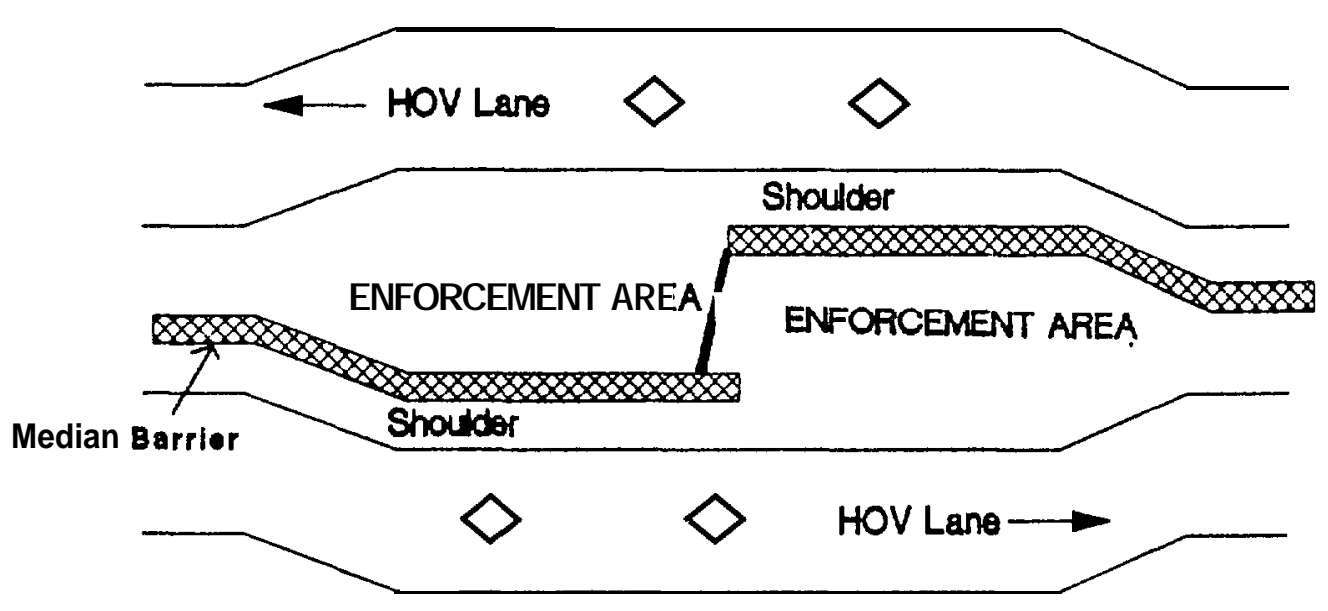

- Hours of Operation.

Proper hours of operation must be determined individually for each mainline HOV project. Twenty-four hour operation simplifies signing problems and eliminates confusion and increased violations at changeover times without increasing enforcement requirements appreciably. However, it is impossible to enforce occupancy restrictions after dark, and operation during off-peak hours when there is no time advantage to be gained from lane use is not likely to encourage many additional Carpools.

- Carpool Definition.

The difference between a 3+ Carpool requirement and a 2+ Carpool requirement has a minimal impact on enforcement requirements. Violators are somewhat easier to recognize when the definition is $3+$, but a $2+$ requirement will lower the total number of violators slightly (while lowering the violation rate significantly, since there will be more legitimate carpoolers in the lane).

- $\quad$ Access/Egress Limitations.

Limiting HOV lane access and egress to prescribed areas through signing and striping appears to have a minimal impact on enforcement requirements. Buffer violations account for only $16 \%$ of the citations issued by officers assigned to special HOV enforcement in areas having access/egress restrictions. To the extent that such restrictions discourage unsafe lane changes, thev should be implemented. 
Signing and Striping.

- The creation of HOV lanes through part-time shoulder conversion is not recommended, since confusion regarding shoulder use can create serious hazards for disabled vehicles.

- Where a continuous 14' median shoulder is available for enforcement activities, it should be designated by placing diagonal Botts Dots at intervals to warn drivers that the widened shoulder is not a traveled way and alert officers using the median to the presence of oncoming vehicles.

\section{SAFETY CONCERNS}

Although accident rates on ramps increased significantly with the introduction of ramp meters and bypass lanes, the total number of ramp accidents remained relatively small, and did not offset the decline in freeway accidents associated with ramp control. In general, short segments of barrierfree HOV lane operation - as on toll plazas, ramps, and freeway interchanges - are not likely to generate accident increases high enough to offset the benefits of the Carpool lane itself. Long stretches of barrier-free mainline HOV lanes operating next to stop-and-go traffic, however, can easily cause major increases in accident rates. The increases in accident rates accompanying barrier-free mainline HOV lanes raise serious questions regarding the suitability of this design in certain settings. These questions appear to exist whether the lanes are created by reserving an existing lane, as was done on the Santa Monica Freeway, or by creating an entirely new lane, as was done in Marin County. The access restrictions on mainline HOV lanes in Southern California represent a compromise attempt to create contiguous HOV lanes without increasing accident rates. 


\section{ENFORCEMENT NOTES}

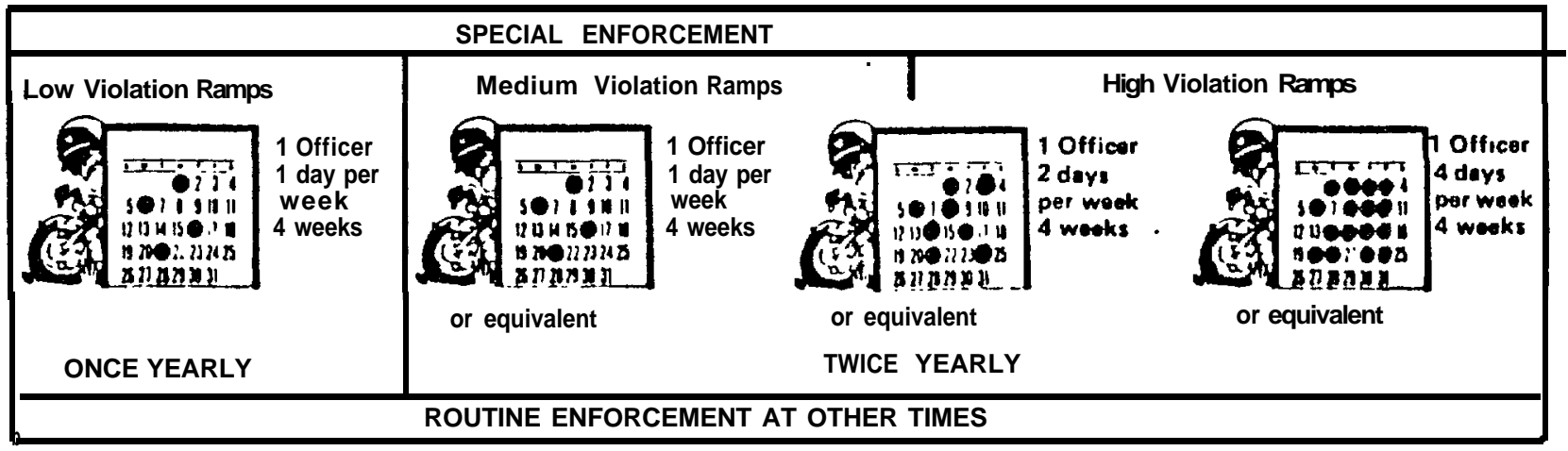

\section{GENERAL OBSERVATIONS}

Enforcement is essential to the success of HOV strategies.

A combination of routine and special enforcement will generally be required for the effective control of violations.

Cooperation between enforcement and operating agencies is necessary both for smooth operations and for effective enforcement.

Court officials should be thoroughly briefed prior to project opening.

\section{RAMP METER BYPASS LANES}

Need for Selective Enforcement.

Routine enforcement alone proved ineffective in controlling ramp violation rates, even when levels were increased by requiring officers to spend ten minutes of each day on ramp enforcement.

Special enforcement efforts nearly always reduce violations, particularly on ramps with high violation rates.

- Special enforcement on selected ramps improved the effectiveness of routine enforcement on nearby ramps.

\section{Proposed Program.}

A program of selective ramp enforcement is proposed which combines the annual monitoring of violations with scheduled applications of special enforcement interspersed with long stretches of routine enforcement.

- $\quad$ Ramps wifh medium and high violation rates receive twice-yearly applications of four-week periods of special enforcement.

- $\quad$ Ramps wifh low violation rates (6.5\% or lower) will receive relatively low levels of special enforcement for four successive weeks each year. 
Newly-opened bypass lanes will receive four weeks of intense special enforcement during the first month of operation.

Program Aims.

The proposed enforcement levels proved effective in the current study and have been designed to

Reduce violations dramatically on ramps with violation rates over $12 \%$ particularly on ramps with violation rates in excess of $20 \%$.

- Control violation rates and achieve further reductions on ramps with violation rates between 6.5 and $12 \%$.

Maintain violation levels on low-violation ramps through routine enforcement and a minimum amount of special enforcement.

The out-of-pocket costs of the proposed program are roughly commensurate with costs incurred in increased congestion and freeway accidents if violations are not controlled.

Enforcement Tactics.

- Special enforcement officers should park their vehicles beyond the ramp meter and assume a stationary position to wave violators over to a safe refuge area.

- $\quad$ Although officers standing out of the view of potential violators issued more citations than officers who assumed more visible positions, they had roughly the same impact in reducing violations.

Enforcement tactics requiring vehicle pursuit were much less efficient than stationary enforcement in generation citations, reducing violations, and providing a cautionary example to other ramp users.

- Where possible, ramps should be enforced out of the view of mainline traffic to avoid disrupting flow on the freeway itself.

\section{Enforcement Priorities.}

Because violations of the ramp meter itself (by running the red signal) occur much less frequently than occupancy violations and pose less of a threat to freeway performance, officers assigned to special ramp enforcement should concentrate on apprehending occupancy violators.

- Officers should focus especially on the $20 \%$ of occupancy violators who, by weaving, sudden stops, and other evasive actions pose an immediate safety threat.

\section{Experimental Findings.}

Four waves of special enforcement over 18 months caused the average ramp violation rates on sample ramps to drop from $11.9 \%$ to $6.5 \%$. 
- Twelve-week periods of special enforcement were not significantly more effective than four-week periods.

- Assigning two officers to a specific ramp for a number of days was nearly as effective as assigning a single officer for twice as many days.

- The immediate decline in violation rates, and the duration of the decline, diminished with repeated applications of special enforcement. The median span of time before violation rates returned at least once to pre-enforcement levels dropped from eight weeks following the first enforcement wave to two weeks following the fourth wave.

\section{MAINLINE HOV LANES}

\section{Special and Routine Enforcement.}

Barrier-Separated Lanes. Physically separate lanes require dedicated doses of special enforcement, with one officer assigned to patrol the separate facility during each peak commute period. Relatively low levels of special enforcement need to be added to the daily assignment to keep violation rates within acceptable bounds.

Contiguous Lanes. Mainline HOV lanes adjacent to mixed flow lanes receive relatively high levels of routine enforcement from officers assigned to the adjacent lanes. An average of five citations per peak period were issued on mainline HOV lanes in 1988 by officers routinely enforcing mixed flow lanes. Routine apprehension rates are roughly ten times as high on mainline HOV lanes as on ramp meter bypass lanes. That is, violators on mainline HOV lanes are roughly ten times as likely to receive a ticket from an officer assigned to routine enforcement duties as violators on bypass lanes. Longer mainline lanes tend to receive more routine enforcement than shorter lanes.

Proposed Program.

A program of selective enforcement, with two to four weeks of special enforcement undertaken two to four times a year, is capable of controlling violation rates on California's mainline HOV lanes, so long as routine enforcement is not neglected during the intervening periods.

Marin 101 Absence of a median makes enforcement difficult on the San Rafael and Corte Madera segments of Marin 101 so that both segments require relatively heavy levels of special enforcement. The San Rafael segment should receive quarterly special enforcement assignments of two officers during the morning peak and three officers during the evening peak. During different months, the Corte Madera segment should be covered by quarterly assignments of one special enforcement officer during the morning peak and two during the evening peak. To the extent possible, one motor officer should be continuously visible on the median shoulder during the evening periods of special enforcement.

Santa Clara 101 and Santa Clara 237. Both of the Santa Clara HOV lanes have adequate shoulders adjacent to the HOV lane. Special enforcement activities can be limited to twice-yearly assignments of a single officer enforcing four days per week, morning and evening, for a period of one month. 
Orange 55. Three special enforcement officers should cover both AM and PM peaks two days per week for two one-month periods each year. One motor officer should be continuously visible in the enforcement area near Katella Avenue. No more than one chase unit should be detailed to respond to violation sightings.

Los Angeles 97. Two officers from the CHP's Westminster area should be assigned to work the LA 91 enforcement area twice a week for a period of two weeks, four times per year.

San Diego $\mathrm{l}-15$ It is recommended that the CHP continue to assign a single motor officer to patrol the separate I-15 lanes on a daily basis. One additional officer should be assigned to assist the motor officer on two days per week for two different months each year.

San Francisco I-280. A single motor officer should be assigned to enforce I-280 two days per week for four days on a quarterly basis in an attempt to reduce the relatively high violation rates on this lightly used and lightly enforced HOV lane.

Orange County 1-405. An ongoing program of special enforcement should be established with two officers using the enforcement area during the morning peak twice a week for four weeks four times per year. A single officer should be deployed for similar periods during the morning peak.

El Monte Busway. Three officers should cover the buffer-separated segment of the busway two days each week for a month four times each year. This level of special enforcement can be reduced to two officers during the evening peak. Violations in the barrier-separated section are negligible and can be enforced by having one of the officers from the East Los Angeles Area drive through the busway at random times once in the morning.

Program Aims.

The proposed program is aimed at ticketing $2.5 \%$ of all mainline HOV violators. This apprehension level appears to be capable of maintaining lane violation rates below $10 \%$.

\section{General Planning Guidance.}

In general, the shorter an HOV facility is, the less routine enforcement it will receive. Consequently, the greater the amount of special enforcement that will be needed to maintain an acceptable level of violations. Given an estimate of routine enforcement levels, it is possible to compute the accompanying level of special enforcement needed to attain a preselected apprehension rate. The accompanying nomograph plots the annual level of special enforcement needed to ticket $2.5 \%$ of the violators on a contiguous mainline lane having a known level of violations. 
EXHIBIT 7.2

NOMOGRAPH FOR PLANNING

SPECIAL ENFORCEMENT FOR BARRIER-FREE

MAINLINE HOV LANES

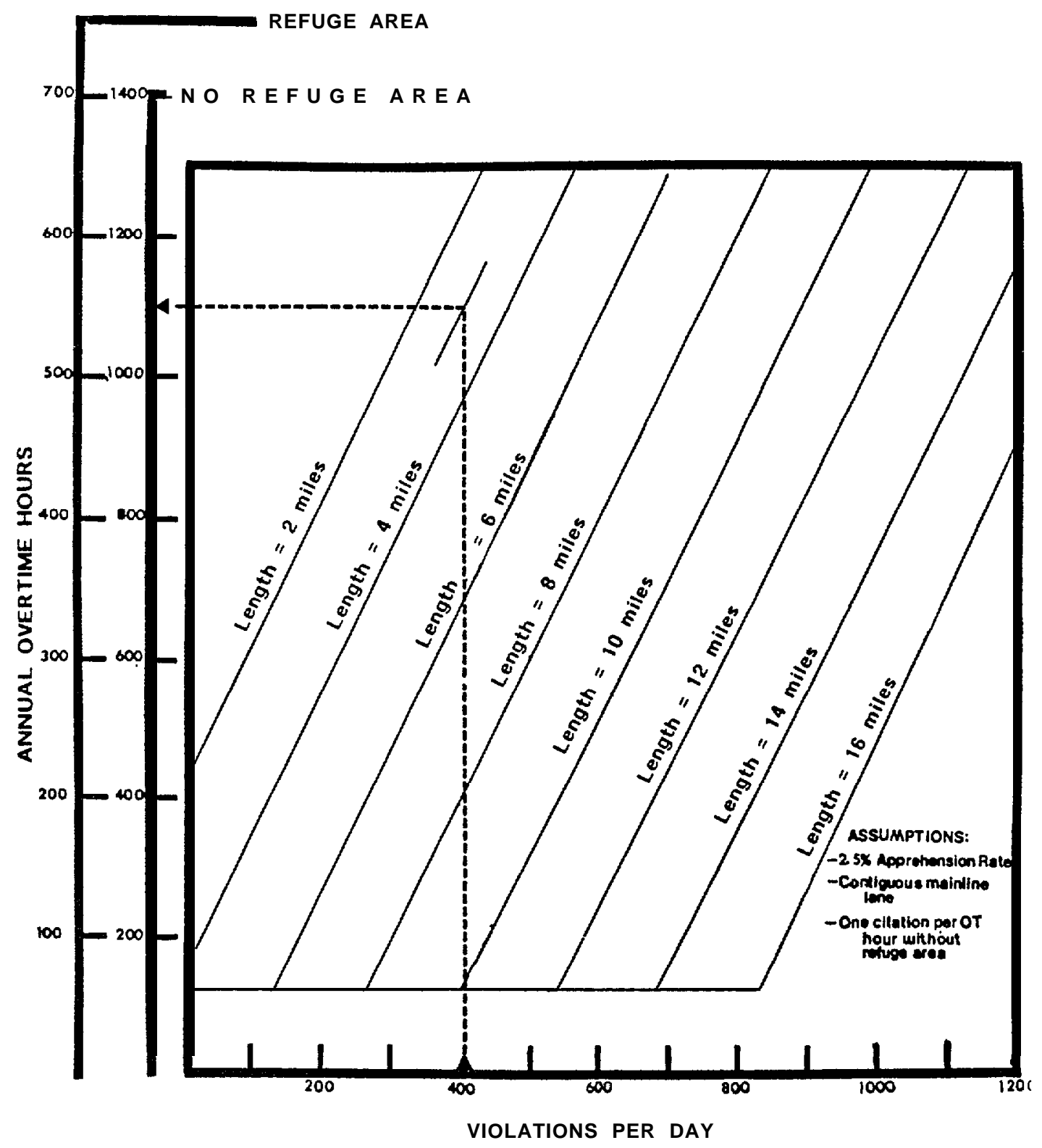

Notes-9 


\section{Enforcement Strategies and Tactics.}

In the absence of a median shoulder or enforcement area, routine and special enforcement units should patrol the lane adjacent to the HOV lane, watching for violators in passing vehicles. Enforcement areas and median shoulders provide the opportunity to assume a more visible, stationary observation post from which to pursue violators, as well as a convenient location for ticketing apprehended violators. If freeways lack enforcement areas and median shoulders have any sort of protected observation posts adjacent to the HOV lanes, these should be used to provide visible evidence of enforcement, with a single officer acting as a spotter for downstream enforcement.

- To minimize impacts of enforcement on freeway flow,

Assign one special enforcement unit at a time;

Avoid bunching of officers;

Stop one violator at a time;

Release cited drivers into the HOV lane;

Avoid pursuit across several lanes;

- Special enforcement during any month can be concentrated in a single peak period, so long as neither peak is neglected in the long run.

\section{TOLERABLE VIOLATION RATES}

Ramp Meter Bypass Lanes. Although less than $20 \%$ of all violators represent a direct safety hazard, all violators threaten the time savings and accident relief available through metered ramp control. Impacts will vary from ramp to ramp, but ramp violation rates in excess of $12 \%$ are likely to have a disproportionately adverse impact on freeway flow and accident levels.

Mainline HOV Lanes. Violators who create immediate safety hazards through unsafe lane changes should be accorded top enforcement priority. In theory, occupancy violators pose no immediate safety hazard and will not cause Carpool flow to deteriorate until flow rates in the HOV lane approach 1500-1700 vehicles per hour. For the most part, California's mainline HOV lanes operate under free-flow conditions below these limits. Severe peaking may cause Carpool traffic to slow on OR 55 or Santa Clara 101, those lanes which are closest to capacity. Under free flow conditions, violation rates on mainline lanes should not exceed a $10 \%$ target level. If violations cause HOV flow levels to approach 1500 vehicles per hour on separated lanes or 1700 vehicles per hour on concurrent-flow lanes, target levels lower than $10 \%$ may be necessary. 


\section{FINE LEVELS}

- $\quad$ Earlier studies, found little evidence to suggest that $\$ 50$ fines were any more effective than $\$ 35$ fines in controlling ramp bypass lane violations.

- In January, 1989 the cost of a first conviction for an HOV occupancy citation in California was raised to $\$ 100$. The minimum cost of second and third convictions ranged from $\$ 150$ to $\$ 250$. There was little evidence that the increase in fines affected violation rates on mainline lanes, which were already at historically low levels. However, surveys suggest that the driving public was not generally aware of the increase in fines. 


\section{NOTICE}

This document is disseminated under the sponsorship of the U.S. Department of Transportation in the interest of information exchange. The United States Government assumes no liability for its contents or use thereof.

The United States Government does not endorse manufacturers or products. Trade names appear in the document only because they are essential to the content of the report.

This report is being distributed through the U.S. Department of Transportation's Technology Sharing Program.

DOT-T-90-22 
DOT-T-90-22 